\section{Consejo de Editores (Editors Board)}

Editora Jefe (Editor-in-Chief):

Dra. Rosa García-Ruiz, Universidad de Cantabria, España

Editores Adjuntos (Assistant Editors):

- Mgt. Jaime Padilla, Universidad Politécnica Salesiana, Ecuador

- Dr. Napoleón Esquivel, Universidad Politécnica Salesiana, Ecuador

\section{Comité Científico (Advisory Board)}

- Dr. Antonio Bautista, Universidad Complutense de Madrid, España

- Dr. Carlos Paladines, PUCE, Ecuador

- Dra. Carmen Martínez, Universidad de Kentucky, USA

- Dra. Cristina Allemann, Universidad de Colonia, Alemania

- Dr. Daniel Mato, Universidad Nacional Tres de Febrero, Argentina

- Dr. Geraldo Caliman, Universidade Católica de Brasília, Brasil

- Dr. Javier Loredo Enríquez, Universidad Iberoamericana, México

- Dr. Ignacio Aguaded, Universidad de Huelva, España

- Dr. José Joaquín Brunner, Universidad Diego Portales, Chile

- Dr. Mario Óscar Llanos, Università Pontificia Salesiana, Italia

- Dr. Ronaldo Zacharias, UNISAL, São Paulo, Brasil

\section{Consejo Internacional de Revisores (International Reviewers Board)}

- Dra. Adelina Novaes, Universidade Cidade de São Paulo, Brasil - Dr. Alexandre Dotta, Centro Universitário Autônomo do Brasil

- Dra. Alexia Cachazo Vasallo, Universidad de Valladolid, España

- Dra. Alicia Villa, Universidad Nacional de La Plata, Argentina

- Dra. Alma Hernández Mondragón, Universidad La Salle, México

- Dr. Amauris Leyva, Universidad de La Habana, Cuba

- Dra. Amelia Gort Almeida, Universidad de La Habana, Cuba

- Dra. Ana Lupita Chaves, Universidad de Costa Rica, Costa Rica

- MSc. Ana Castellanos Guzmán, Universidad La Salle, México

- Dra. Ana Eyng, Pontificia Universidad Católica de Paraná, Brasil

- Dra. Anita Gramigna, Università degli Studi di Ferrara, Italia

- Dra. Annachiara Del Prete, Universidad Autónoma de Chile

- Dra. Antonella Cagnolati, Università degli Studi di Foggia, Italia

- Dr. Aristeo Santos, UAEM, México

- Dra. Azucena Ochoa, Universidad Autónoma de Querétaro, México

- Dra. Beatriz Celada, Universidad Nacional de Comahue, Argentina

- Dra. Bianca Thoilliez, Universidad Autónoma de Madrid, España

- Dra. Carla Förster, Pontificia Universidad Católica de Chile

- MSc. Carlos Crespo, UASB, Ecuador

- Dra. Carmen Villora Sánchez, CES Don Bosco, España

- Dra. Caterina Benelli, Università degli Studi di Messina, Italia

- Dra. Cecilia Correa, Universidad Simón Bolívar, Colombia

- MSc. Claudia Cayulef, UCSH, Chile

- Dra. Claudia Vélez, USB Cali, Colombia

- Dr. Cristian Desbouts, Università Pontificia Salesiana, Italia

- Dr. Daniel Suárez, UMET, Argentina

- MSc. Daniel Llanos, UPS, Ecuador

- Dra. Dora Marín Méndez, UNAM, México

- Dr. Eduardo Fabara, UASB, Ecuador

- Dr. Eduardo Mercado Cruz, ISCEEM, México

- MSc. Elena Rodríguez-Roa, Universidad La Salle, México

- Dra. Emiko Saldivar, University of California, Santa Barbara, USA

- Dr. Enrique Arturo Parra Marín, Universidad de Chile, Chile

- Dr. Enrique Sánchez Rivas, Universidad de Málaga, España

- Dr. Felipe Perales, UPN - Unidad Torreón, México
- MSc. Fernando Paladines, UPS, Ecuador

- Dr. Francisco Merchán Iglesias, Universidad de Sevilla, España

- Dr. Gabriel Suárez, Pontificia Universidad Javeriana, Colombia

- Dra. Gema Sáez, Universidad Complutense de Madrid, España

- Dr. Gersem Dos Santos, UFAM, Brasil

- Dra. Gina Benavides, UASB, Ecuador

- MSc. Giovanna Barroca, Universidade Estadual dal Paraíba, Brasil

- Dr. Greby Rioja, Universidad Mayor de San Simón, Bolivia

- Dr. Gunther Dietz, Universidad Veracruzana, México

- MSc. Hamlet González, Universidad Distrital, Colombia

- Dra. Herminia Hernández, Universidad de La Habana, Cuba

- Dr. Jaime Brito, Universidad Católica Silva Henríquez, Chile

- Dr. Jean Carlos García, PUCE, Ecuador

- Dra. Jennie Brand Barajas, ANUIES, México

- Dr. José García, ENAH, México

- Dr. José Fernández, Universidad Camilo José Cela, España

- Dr. José Alvarado, Universidad Iberoamericana, México

- Dr. José Luis Guzón, Universidad Pontificia de Salamanca, España

- Dr. José Luis Moral, Università Pontificia Salesiana, Italia

- Dr. José Alfonso, Universidad Pontificia de Salamanca, España

- Dr. José Jiménez Ibáñez, Universidad de La Salle, Colombia

- Dr. Juan Ortiz, Fundación Universitaria Los Libertadores, Colombia

- Dr. Julio Cabero, Universidad de Sevilla, España

- Dra. Laura Sánchez, Universidad Pontificia de Salamanca, España

- Dra. Leonor Buendía Eisman, Universidad de Granada, España

- Dra. Lisset Coba, FLACSO, Ecuador

- Dr. Lorenzo Cantoni, Universidad de Lugano, Suiza

- Dr. Luis Reyes Ochoa, UCSH, Chile

- Dr. Luis Sime Poma, Pontificia Universidad Católica del Perú

- Dr. Luis Cuji Llugna, UNTREF, Argentina

- Dr. Manuel Riesco, Universidad Complutense de Madrid, España

- Dra. Marcela Salazar Ibáñez, Universidad La Salle, México

- Dra. Maria Lopes Moreira, Universidade do Minho, Portugal

- MSc. María Augusta Santillán, UPS, Ecuador

- Dra. María Fortoul Ollivier, Universidad La Salle, México

- Dra. María Rinaudo, UNRC, Argentina

- Dra. Maria de Fátima Pereira, U. Porto, Portugal

- Dra. María Domingo, UIC, España

- Dra. María Elena Ortiz, UPS, Ecuador

- Dra. María Copello, Universidad de la República, Uruguay

- Dra. María José Arenal, CES Don Bosco, España

- Dra. María Batista, UFMG, Brasil

- Dra. María José Bermeo, Columbia University, USA

- MSc. María Marhx Bracho, Universidad La Salle, México

- Dra. María Sol Villagómez, UPS, Ecuador

- Dra. María Teresa Prieto, Universidad de Guadalajara, México

- Dra. Mariana Carmo, Universidade Estadual de Campinas, Brasil

- Dra. Maribel Miranda Pinto, IPV, Portugal

- Dra. Maribel Alegre Jara, Universidad Nacional del Santa, Perú

- Dr. Marlécio Maknamara, UFRN, Brasil

- Dra. Mirtes Lira, Universidade de Pernambuco, Brasil

- Dra. Mónica Sáenz, UPS, Ecuador

- MSc. Nelson Martínez, Universidad Don Bosco, El Salvador

- Dra. Olga Espinoza, Pontificia Universidad Católica de Chile

- Dra. Patricia Correia, Universidade do Estado da Bahia, Brasil

- MSc. Raimundo França, Universidade Federal de Alagoas, Brasil

- Dr. Ramon Alcântara, Universidade Federal do Maranhão, Brasil

- Dra. Regina Barra, Universidade Federal de Juiz de Fora, Brasil

- Dra. Renata Vasconcelos, Universidade Federal de Alfenas, Brasil

- Dra. Romilda Ens, PUCPR, Brasil

- Dra. Ruth Aguilar, UTPL, Ecuador

- Dra. Ruth Amanda Cortes Salcedo, IDEP, Colombia 
- Dra. Salomé Sola-Morales, Universidad de Santiago de Chile

- Dra. Sandra Santiago, Universidade Federal da Paraíba, Brasil

- Dr.(c), Sebastián Granda, UPS, Ecuador

- Dra. Shirlei Rezende, Universidad Federal de UFMG, Brasil

- Dra. Sílvia Ester Orrú, Universidade de Brasília, Brasil

- Dra. Sonia Sampaio, Universidad Federal de Bahía, Brasil

- MSc. Susana Barco, Universidad Nacional de Comahue, Argentina

- Dra. Suzana Gomes, Universidade Federal de UFMG, Brasil

- Dra. Sylvia Schmelkes, Universidad Iberoamericana, México

- Dra. Tânia Dantas, Universidade do Estado da Bahia, Brasil

- Dra. Tania Azevedo, UFOPA, Brasil

- Dra. Vanessa Neumann, UFMS, Brasil

- Dra. Vania Biavatti, Universidade Regional de Blumenau, Brasil

- Dra. Wedja Oliveira, PUC-SP, Brasil

- Dr. Wellington De Oliveira, UFVJM, Brasil

- Dra. Yamirlis Gallar, UISEK, Ecuador

\section{Consejo Técnico (Board of Managment)}

MSc. Tania X. Barrezueta

Dr. Ángel Torres-Toukoumidis
Edita (Published by)

Universidad Politécnica Salesiana

www.ups.edu.ec

\section{Consejo Editorial Institucional \\ (Publishers Council UPS)}

\section{Consejo de Publicaciones \\ (Board of Publication)}

Dr. Javier Herrán Gómez, sdb

Dr. Juan Bottasso Boetti, sdb

MSc. Juan Pablo Salgado Guerrero

MSc. José Juncosa Blasco

MSc. Jaime Padilla Verdugo

Dra. Floralba Aguilar Gordón

MSc. Sheila Serrano Vincenti

MSc. Fabricio Freire Morán

MSc. John Calle Sigüecia

MSc. René Unda Lara

MSc. Betty Rodas Soto

MSc. Andrea De Santis

MSc. Mónica Ruiz Vásquez

\section{Editor General UPS (General Editor UPS)}

Dr. Luis Álvarez-Rodas

\section{Servicio de Publicaciones \\ (Publication Service)}

Hernán Hermosa (Coordinación General)

Marco Gutiérrez (Soporte OJS)

Paulina Torres (Edición)

Raysa Andrade (Maquetación)

Martha Vinueza (Maquetación)

Traductor (Translator)

Joaquín Crespo

\section{Editorial}

Editorial Universitaria Abya-Yala (Quito, Ecuador) Av. 12 de Octubre N23-116 y Wilson, Bloque A, UPS Casilla 17-12-7-19

Teléfono: (593-2)3962-800 ext. 2638

E-mail: editorial@ayayala.org

Portal electrónico: http://www.abyayala.org 


\section{Índice}

Editorial

SECCIÓN MONOGRÁFICA (Monographic Section)

FAMILIA Y EDUCACIÓN EN EL SIGLO XXI: FORMACIÓN PARENTAL PARA LOS NUEVOS RETOS SOCIALES

NIDIA MILENA MORENO, ANGIE CAROLINA GONZÁLEZ, ANA CAROLINA TORRES Y

JULISSA ARAYA HERNÁNDEZ.

Alfabetización digital a padres de familia en el uso de las redes sociales

Digital Literacy to parents in the use of social networks

MIRIAM MARIANA GALLEGOS

Las familias de estudiantes con discapacidad en la escuela, sus necesidades y demandas. Caso Ecuador

The student's families with disabilities in school, their needs and demands. Ecuador case

ANDRÉS JOSÉ SALAZAR

El currículum familiar: herramienta pedagógica alternativa para la educación

Family curriculum: an alternative pedagogical tool for education

JOSÉ MIGUEL OLAVE Y CLAUDIA VÉLEZ DE LA CALLE.

Las familias entre fines educativos y económicos. El caso de Chile

Families between educational and economic ends. The case of Chile

MARISA CLAUDIA JACOMETO Y ADRIANA ROSSATO.

Relaciones familiares versus aprendizaje: un análisis con niños de 5 y 6 años

Family relationships versus learning: an analysis with children aged 5 and 6 years

\section{SECCIÓN MISCELÁNEA (Miscellaneous Section)}

LUIS JAVIER PENTÓN Y ÁNGEL ANTONIO TOLEDO

Alfabetizando al alfabetizador: Mujeres hispanas en un nuevo contexto social

Educating the Educator: Hispanic women in a new social context

ELIZABETH MENDOZA CÁRDENAS Y MARÍA ZÚÑIGA CORONADO

Factores intra y extra escolares asociados al rezago educativo en comunidades vulnerables

Intra and extra school factors associated with educational backwardness in vulnerable communities

ALICIA RIVERA MORALES

Aspectos psicosociales y gestión de la evaluación en secundarias de alto y bajo logro

Psychosocial aspects and management of evaluation in secondary high and low achievement

JUAN ILLICACHI GUZÑAY

Del castigo corporal al buen encauzamiento de las conductas en la educación

From the body punishment to the good setting of behaviors in education

DIANA SOFÍA ZEVALLOS, NELLY PATRICIA ARCOS Y JUAN CRUZ RIPOLL

La concepción simple de la lectura en alumnos de $4^{\circ}$ de primaria de una escuela fiscal de Quito

The simple view of reading in $4^{\text {th }}$ grade grade students from a public school in Quito

Normas de Publicación en «Alteridad» 


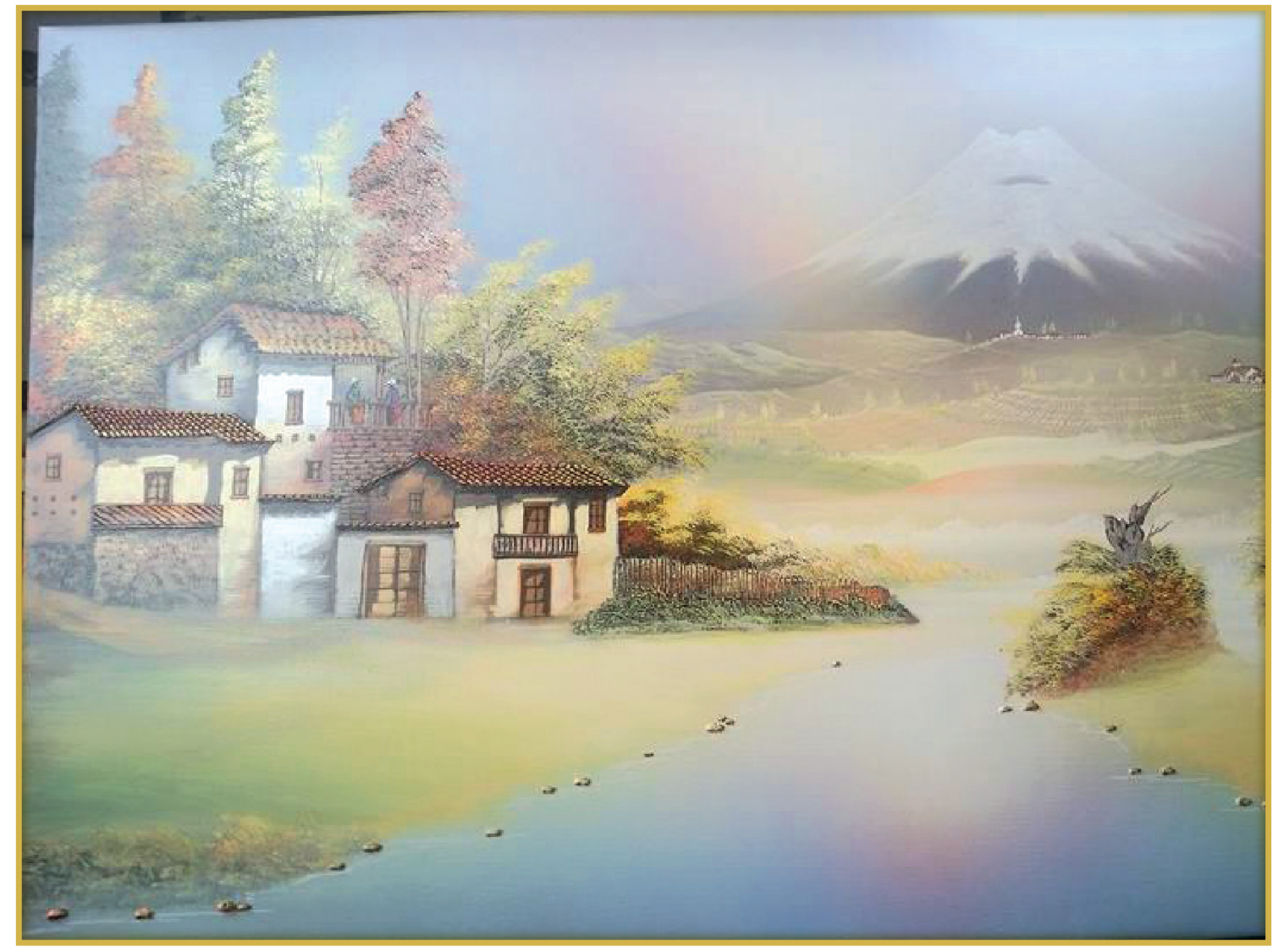

Familia andina Óleo sobre lienzo

\section{JULIO REINOSO}

Artista ecuatoriano que por medio de sus obras exterioriza el "paisaje exterior" fruto de diez años de haber vivido junto al río, a pájaros, al lodo, al cielo, a los tejados, al aire y al agua. Sus obras también expresan el "ambiente familiar" que forma el "paisaje interior del hombre" hecho de retazos de amor, heroísmo, esfuerzo, ternura y fe. Ha expuesto y recibido premios y reconocimientos a nivel nacional e internacional. 


\section{Editorial}

La familia como célula original de la vida social está llamada a la educación de sus miembros en todos los ámbitos en donde estos se desarrollan. Por ello, resulta relevante que los padres, como cabezas de familia, se encuentren preparados ante los nuevos retos que nuestra sociedad actual nos plantea. Con el desarrollo de las nuevas tecnologías y medios de comunicación, la formación en estrategias pedagógicas adaptadas a los ritmos y estilos de aprendizaje actuales representan un tema emergente. Sabiendo que esta es una urgencia es necesario estudiar aquellos factores que ayudan a los niños, jóvenes, y en general, a las familias, a alcanzar su propia realización personal, social, educativa y espiritual. De ahí que en la Sección Monográfica de esta edición, un conjunto de especialistas, desde distintos enfoques de las ciencias, muestren un panorama sobre la situación actual de las familias y su formación, compaginándolo con la educación escolar, así como una serie de consejos, técnicas y estrategias para impulsar el desarrollo de los mismos.

La investigación Alfabetización digital a padres de familia en el uso de las redes sociales de Nidia Moreno, Angie González, Ana Torres y Julissa Araya describe la alfabetización digital de los padres de familia del centro educativo Coopteboy O.C de la ciudad de Tunja, Colombia. La alfabetización de los padres la realizaron los adolescentes de secundaria de la institución. Los resultados permitieron evidenciar el desconocimiento de los progenitores sobre el uso, riesgos y beneficios de las redes sociales. Se concluye que los padres no tienen estrategias de control y vigilancia en cuanto al uso de redes sociales, evidenciando la importancia de alfabetizarlos.

El trabajo investigativo Las familias de estudiantes con discapacidad en la escuela, sus necesidades y demandas. Caso Ecuador de Miriam
Gallegos evidencia las necesidades de las familias con hijos discapacitados, analiza cómo los discapacitados influyen en los proyectos de vida de los padres, resalta las fortalezas de la familia para apoyar la inclusión social y educativa. De las encuestas a las familias de los estudiantes de diversas escuelas de educación especial, emerge que un alto porcentaje de padres abandonan y/o postergan sus proyectos de vida, también las instituciones educativas no toman en cuenta algunas necesidades, cuando es ésta quien tiene la función de brindar el apoyo pertinente.

Andrés Salazar en el manuscrito El currículum familiar: herramienta pedagógica alternativa para la educación expone el proceso de generación de conocimientos por medio del currículum familiar, visto como herramienta pedagógica útil para valorizar lo vivido. En la investigación se tomaron como muestras a tres familias del Estado Sucre-Venezuela. El currículum favoreció el conocimiento de la historia familiar, la observación del comportamiento cotidiano, la preservación de valores, costumbres, creencias y tradiciones. El trabajo evidencia las percepciones de la familia sobre el desarrollo de los hijos, la formación, la educación y el trabajo cotidiano.

Las familias entre fines educativos y económicos. El caso de Chile es un estudio de José Olave y Claudia Vélez. Ellos aseguran que a mediados del siglo XX la educación latinoamericana se privatiza, que los Estados por medio del crecimiento del sistema educativo y la productividad promueven la idea del capital humano. Los autores al analizar las normas del sistema educativo chileno en el periodo 1860 a 2008 observan que la evaluación sirve para gobernar, regular los flujos sociales y traspasar a las familias la responsabilidad de escoger entre fines formativos y metas económicas. Esta elección demuestra el dominio del gobierno sobre 
la familia, que sostiene el sistema neoliberal, por medio de las evaluaciones.

El trabajo Relaciones familiares versus aprendisajes: un análisis con niños de 5 a 6 años, de Marisa Claudia Jacometo y Adriana Rossato identifica los conflictos en las relaciones familiares y verifica si comprometen la educación de los niños. En su estudio participaron 219 familias con hijos de 5 y 6 años. Los resultados indican que existe distanciamiento de los padres en relación a la vida escolar de los hijos, y las relaciones familiares son una mezcla de afecto y conflicto. Además, el aprendizaje de los niños se ve comprometido por los conflictos familiares visto que depende, en primer lugar, de la interelación familiar; y, en segundo lugar, de la relación professor-estudiante.

La Sección Miscelánea comienza con la indagación Alfabetizando al alfabetizador: Mujeres hispanas en un nuevo contexto social de Ángel Toledo y Luis Pentón, la cual sostiene que la población hispana en Estados Unidos continúa aumentando y de forma rápida. El incremento de hispanos ha cambiado el contexto social del país y los expone a realidades sociales, lingüísticas y educativas inéditas. Los estudiantes aprendices del inglés se enfrentan a un reto lingüístico que necesitan superar para tener éxito en sus escuelas. A su vez, los padres inmigrantes atraviesan otros desafíos similares en sus ambientes laborales donde el idioma y otros componentes les dificultan ejercer su trabajo y participar de manera activa en las escuelas de sus hijos.

La investigación Factores intra y extra escolares asociados al rezago educativo en comunidades vulnerables cuyas autoras son Elizabeth Mendoza y María Zúñiga, quienes afirman que uno de los seis Objetivos de Desarrollo del Milenio de la ONU es asegurar para el 2015 que todos los niños terminen la enseñanza primaria. En esta lógica, las expertas muestran los resultados de un estudio sobre la percepción que tienen directivos, profesores y habitantes de nueve agebs del Polígono San Bernabé, del municipio de Monterrey, sobre los factores que causan el rezago educativo. De entre las diversas causas, la pobreza y el género, mantienen a los niños fuera de la escuela.
El artículo de investigación Aspectos psicosociales y gestión de la evaluación en secundarias de alto y bajo logro de Alicia Rivera es el resultado de entrevistas a 80 directivos de escuelas secundarias de alto y bajo logro educativo de Sonora, Durango, DF y Oaxaca. Por un lado, los directivos de las escuelas de bajo logro aspiran cambiar la actitud de los docentes ante la evaluación, desean que los supervisores controlen a los profesores y quieren el apoyo de especialistas en evaluación. Por otra parte, en las escuelas con alto logro, los directores favorecen la participación, tienen altas expectativas de alumnos y docentes, alcanzan los objetivos y evalúan buscando mejorías.

El documento Del castigo corporal al buen encauzamiento de las conductas en la educación de Juan Illicachi considera que el campo educativo es un ámbito privilegiado para estudiar el ejercicio del poder, de ahí que analiza la manera cómo opera el poder disciplinar sobre la población, cómo se alimenta de sus saberes, cómo estas formas de poder en el campo educativo monocultural fue cuestionada por la educación intercultural bilingüe. Sobre todo porque la educación intercultural emerge en oposición a la educación hegemónica, como bandera de lucha política e insurrección, y retorno del saber sometido. Aunque la educación intercultural bilingüe, continúa reproduciendo algunas prácticas de saber-poder.

La investigación La concepción simple de la lectura en alumnos de $4^{\circ}$ de primaria de una escuela fiscal de Quito de Diana Zevallos, Nelly Arcos y Juan Ripoll explica la comprensión lectora a partir de la habilidad para la descodificación y la comprensión del lenguaje oral. Con este objetivo, los investigadores recogen datos sobre la aplicabilidad de la concepción simple de la lectura en inglés a la lectura del español. Para ello, con la batería PROLEC-R y con el test CLP a 87 evaluaron a alumnos de una escuela pública de Quito. Los resultados indican que incorporar la velocidad de lectura al modelo puede ayudar a la comprensión lectora del español.

Napoleón Esquivel 


\section{Sección Monográfica}

Familia y Educación en el siglo XXI: Formación parental para los nuevos retos sociales

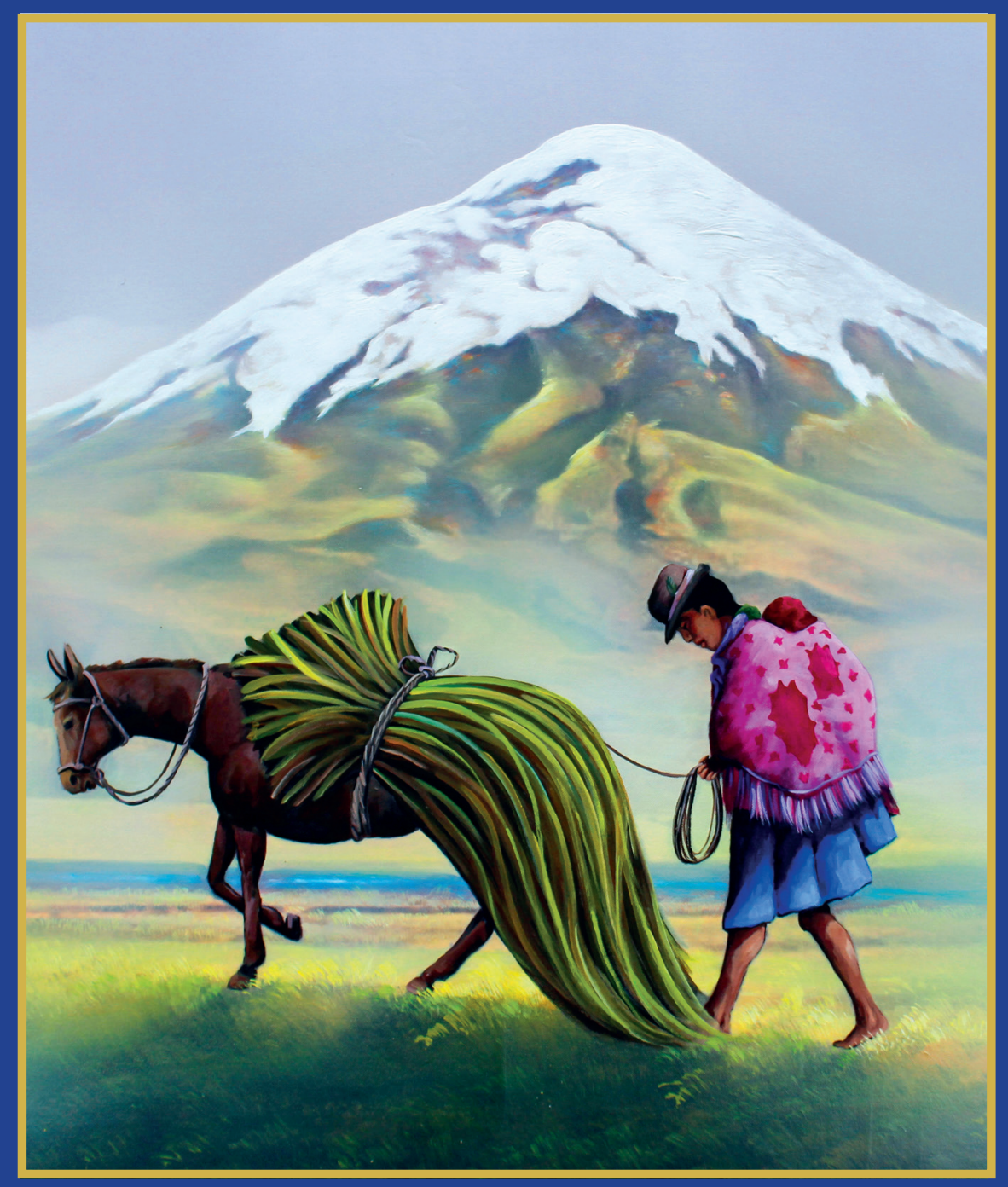

Mujer andina trabajando Acrílico sobre lienzo 


\title{
Alfabetización digital a padres de familia en el uso de las redes sociales
}

\author{
Digital Literacy to parents in the \\ use of social networks
}

Investigación

\author{
Nidia Milena Moreno López \\ Universidad Nacional Abierta y a Distancia - Colombia \\ nidia.moreno@unad.edu.co \\ Angie Carolina González Robles \\ Universidad Nacional Abierta y a Distancia - Colombia \\ angie.gonzalez@unad.edu.co \\ Ana Carolina Torres Gómez \\ Universidad Nacional Abierta y a Distancia - Colombia \\ ana.torres@unad.edu.co \\ Julissa Araya Hernández \\ Universidad Estatal a Distancia - Costa Rica \\ jarayah@uned.ac.cr
}

Recibido: 31 de octubre de 2016 / Aceptado: 05 de enero de 2017

\section{Resumen}

El presente artículo tiene como objetivo describir el proceso de alfabetización digital dirigido a padres de familia en el reconocimiento y uso de las redes sociales, en la institución educativa Coopteboy O.C de la ciudad de Tunja, Colombia. El estudio fue de enfoque cualitativo, tipo investigación acción apoyada en el modelo ecológico de Urie Bronfenbrenner (1987), la recolección de la información se realizó mediante grupos focales, la observación participante descrita en los respectivos registros y el relato como técnica de indagación y reflexión. El proceso de intervención se basó en el enfoque psicosocial de Empowerment (Banda y Morales, 20I5), utilizando como estrategia innovadora, la prestación del servicio social de los adolescentes de secundaria de la institución educativa, quienes alfabetiza- ron digitalmente a sus padres, bajo el acompañamiento de los investigadores. Los resultados preliminares permitieron evidenciar el desconocimiento que tienen los padres de familia con respecto al uso, riesgos y beneficios de las redes sociales que utilizan los adolescentes, por tanto, los padres no tienen estrategias de control y vigilancia en cuanto al uso de estas, validando la importancia de alfabetizar a los padres en el uso de las redes sociales más utilizadas en la actualidad. El proyecto logra la adquisición de competencias digitales en el uso de las redes sociales y el reconocimiento de los riesgos a los que se exponen tanto padres como jóvenes en la red.

Descriptores: Alfabetización digital, dinámica familiar, comunicación interpersonal, redes sociales, adolescentes.

Forma sugerida de citar: Moreno López, Nidia, González Robles, Angie, Torres Gómez, Ana, \& Araya Hernández, Julissa (2017). Alfabetización digital a padres de familia en el uso de las redes sociales. Alteridad, 12(1), pp. 8-19. 


\begin{abstract}
The present article has as objective to describe the process of digital literacy directed at the parents of family in the recognition and use of social networks, in the educational institution Coopteboy O.C of the city of Tunja, Colombia. The study was a qualitative approach, type supported action research in the ecological model of Urie Bronfenbrenner (1987), the collection of information was carried out through the use of focus groups, participant observation described in the respective records and the stories as a technique of inquiry and reflection. The intervention process was based on the psychosocial approach of empowerment (Banda y Morales, 20l5), using as an innovative strategy, the provision of the social service of teenagers of
\end{abstract}

\section{Introducción 1}

En la actualidad la llegada de la tecnología, ha permeabilizado los entornos familiares, generando cambios en sus dinámicas y las formas tradicionales de relacionarse, surgen diversos medios de comunicación mediados por las tecnologías de la información y la comunicación TIC, generando innovación en los procesos de educación, el trabajo y las relaciones interpersonales. En la transición a la sociedad digital, las generaciones fueron trazando un rezago en el manejo y uso de estas herramientas, los adolescentes por su parte se convirtieron en la generación de nativos digitales y surgió una brecha generacional con sus padres y el analfabetismo digital (Andrade, 2004). En los jóvenes se evidencia un uso frecuente de internet especialmente de redes sociales, las cuales se hacen

1 Se extienden agradecimientos a la comunidad educativa de la Institución Coopteboy O.C de la ciudad de Tunja, y especialmente a los estudiantes del Servicio Social Obligatorio y padres de familia, quienes de manera voluntaria participaron en esta investigación. Así mismo, los aportes conceptuales y la amplia experiencia de los colaboradores pertenecientes a la Universidad a Distancia de Costa Rica UNED, con el proyecto sobre alfabetización digital para adultos. Finalmente se resalta la labor de los estudiantes pertenecientes al programa de Psicología de la UNAD, quienes desde el componente práctico disciplinar apoyaron el desarrollo metodológico del proyecto. secondary of the educational institution, who digitally literate to their parents, under the accompaniment of the researchers. The preliminary results allowed to evidence the lack of awareness among the parents with respect to the use, risks and benefits of social networks that use teenagers, therefore the parents have no control and surveillance strategies in regard to the use of these, validating the importance of literacy for parents in the use of social networks most used at present. The project achieves the acquisition of digital competences in the use of social networks and the recognition of the risks to which they are exposed both parents and young people in the network.

Keywords: Digital literacy, family dynamic, Interpersonal communication, social networks, teenagers.

fundamentales para su interacción social (Díaz y Bújez, 2011), les permiten relacionarse con muchas personas de diferentes partes del mundo en tiempo real, intercambiar información, imágenes, música, videos, así como crear perfiles y comunidades en la red, existen diversas redes sociales organizadas por intereses y gustos, por ejemplo: de tipo educativo, empresarial o social (Gómez y Lara, 2010).

Las redes sociales en la actualidad son quizás uno de los principales medios de comunicación e interacción entre las sociedades, de aquí radica la importancia de esta temática, debido a su influencia en la dinámica y las relaciones familiares (Galindo, 2009). La forma de relacionarse en las redes sociales, está cambiando el modo de comunicación e integración de los hijos y padres, y nace una preocupación de los alcances de las redes sociales en el diario vivir de los adolescentes, quienes hacen uso de estas con poco control $\mathrm{y}$ vigilancia, dado que los padres desconocen su uso, funcionalidad y los inminentes riesgos a los que se están expuestos en la red. Es así como el presente estudio buscó alfabetizar a los padres de familia en el reconocimiento y uso de las redes sociales que utilizan los adolescentes con mayor frecuencia, a través de la prestación del servicio social de sus hijos, quienes los alfabetizaron y acompañaron durante el proceso. La 
investigación acción permitió el cambio social y educativo a partir de la interacción con expertos y la reflexión del rol paterno filial en la actual sociedad de las TIC, la intervención psicosocial basada en el enfoque de Empowerment consintió en la potenciación de los recursos de las familias y el liderazgo de estas en sus propios procesos de formación, la síntesis del proceso se describe en líneas posteriores.

\section{Fundamentación teórica y metodológica}

\section{Las redes sociales}

Las redes sociales son comunidades virtuales o plataformas de internet que congregan a personas que se relacionan entre sí compartiendo y difundiendo información de interés común (Bedoya y Londoño, 2014). El principal objetivo, es entablar contactos con gente para re encontrarse con antiguos vínculos o para crear nuevas amistades, pertenecer a una red social le da la posibilidad al usuario de construir un grupo de contacto que puede exhibir como su lista de amigos, estos amigos pueden ser amigos personales o amigos de amigos, a veces también son contactos que se conocieron por internet, por sugerencias que hace la misma red social (Morduchowicz et al., 2010).

Hacia el año 1995 un ex estudiante universitario de los Estados Unidos diseño una red social en internet a la que llamó classmates.com (compañeros de clase.com) que tenía como objetivo mantener contacto con los amigos de estudio (Morduchowicz et al., 2010). En 1997 aparece Sigx Degrees. Com (seis grados.com) se genera el primer sitio de redes sociales, tal y como lo conocemos hoy, permitiendo crear perfiles de usuarios y contar con una lista de amigos. A comienzos del año 2000 entre 2001 y 2002, aparecen los primeros sitios web que tiene como base las redes sociales con círculos de amigos en línea. Estos círculos se extendieron con el desarrollo de redes sociales determinadas, que tenían como fin ya no solo re encontrarse con amigos o conseguir nuevas amistades sino como espacios de intereses afines (Morduchowicz et al., 2010). Las redes sociales comenzaron a ser utilizadas desde 1997 y se ha convertido en un lugar predilecto para la conversación de personas en donde se dan a conocer diferentes puntos de vista (Pazmiño, 2011).

Las redes más visitadas por los adolescentes de acuerdo a Morduchowicz et al., (2010) son Facebook, WhatsApp y Twitter:

Facebook fue creada en el año 2004, por estudiantes de la Universidad de Harvard, en Estados Unidos, en la actualidad es una red social conocida en todo el mundo para hacer nuevos amigos o re encontrase con antiguos, los usuarios tienen la opción de publicar información personal, subir fotos, compartir música o videos, chatear e incluso crear grupos según intereses a fines (Morduchowicz et al., 2010).

WhatsApp: para el año 2009 nace esta red social cuyo nombre original "What's up" (¿Qué pasa?) y "app" (aplicación) creada por Jan Koum, quien fue el director del equipo de operaciones de plataforma de Yahoo, solo necesita conexión a Internet y en tiempo real estarás conectado con tus amigos. Entre los jóvenes causo furor, al poco tiempo la aplicación ya tenía más de 250000 usuarios y buscaron inversores, 10 millones de dólares por parte de la empresa Sequoia Capital para ampliar servidores (Cascón, 2016).

Twitter: Nació en el 2006, permite que sus usuarios envíen mini textos, mensajes muy breves denominados tweets, de no más de 140 caracteres. Otras redes utilizadas entre los adolescentes son: Sónico, Orkut, Flickr, Yahoo 360, DevianART, (artística) y Linkedin (profesional). Al año 2009 más de 850 millones de personas en todo el mundo estaban en alguna red social (Morduchowicz et al., 2010).

\section{Los adolescentes y las redes sociales}

La adolescencia es una etapa de la vida del ser humano que se caracteriza por una serie de cambios a nivel psicológico, biológico y social. Erikson (1987) postula que el ser humano se 
desarrolla en ocho etapas o estadios durante el ciclo vital, el interés de éste estudio se centra en la etapa número cinco del ciclo vital, correspondiente a la adolescencia, comprendida entre los 12 y los 20 años, es "el período de la pubertad $y$ de la adolescencia que inicia con la combinación del crecimiento rápido del cuerpo y de la madurez psicosexual, intereses por la sexualidad y formación de la identidad sexual" (citado por Bordignon, 2005). Esta es una etapa caracterizada por la búsqueda constante de la identidad e independencia, en la cual se prefiriere pasar el mayor tiempo posible con el grupo de pares, buscando el espacio de intercambio de experiencias que les permiten la construcción de su yo, en la actualidad el adolescente se ve permeado por la era de la tecnología representada en las redes sociales, a las cuales la mayoría de ellos tiene acceso y la tradicional forma de relacionarse ha cambiado y se ve mediada por la internet generando una revolución en la forma de acompañamiento de los padres quienes aún no tienen el conocimiento necesario sobre el manejo y uso de la red social (Bordignon, 2005).

Marc Prensky (2001), desarrolló el término de "nativos digitales" y como lo señalan varios autores como García, Portillo, Romo y Benito (2001):

Los nativos digitales forman parte de una generación que ha crecido inmersa en las nuevas tecnologías, desarrollándose entre equipos informativos, videoconsolas y todo tipo de artilugios digitales, convirtiendo el teléfono, el email, la mensajería instantánea en parte integral de sus vidas y en su realidad tecnológica (citados por Sánchez y Martínez, 2011).

En la búsqueda de la identidad y de su rol en la sociedad; la popularidad y aceptación en el grupo social es uno de los aspectos que más valoran los adolescentes de sí mismos. Para ser popular se necesita de amigos, humor, espontaneidad, entre otros, herramientas con las que no siempre cuenta el adolescente, lo que mediado por el internet y las redes sociales puede solucionar. Sin embargo, en su afán de popularidad como medio de aceptación e inclusión social, el adolescente no vislumbra su exposición al riesgo de ser víctima de los múltiples delitos que por las redes sociales se presentan a diario.

En este sentido Internet y las redes sociales son una fuente inmensa que ofrece importantes oportunidades para los adolescentes en áreas como entretenimiento, educación, comunicación y participación, de igual forma el uso online permite el desarrollo de habilidades que resultan fundamentales para lograr una integración y ajuste social satisfactorio en la sociedad actual, sin embargo con el sin número de beneficios, Internet trae consigo riesgos a los que los adolescentes se ven expuestos, algunos pueden ser: uso compulsivo o adicción a Internet, contactos con extraños, acceso a contenidos considerados inapropiados, cyberbullying o acoso sexual, exposición de la privacidad, entre otros (García y Cruz, 2013), a los cuales sus padres y familiares deben conocer y estar a la vanguardia para poder hacer seguimiento y acompañamiento y prevenir la exposición de sus hijos a estas problemáticas.

\section{La familia, medidas de control y vigi- lancia en las redes sociales}

Existen muchas definiciones de familia, desde la perspectiva religiosa, política, sociológica y psicológica. La familia es la una unión de personas que comparten y desarrollan un proyecto de vida común que se supone es duradero, dentro de este se generan fuertes sentimientos de pertenencia a dicho grupo, existe un compromiso personal entre sus miembros, y se establecen diversas relaciones de intimidad, reciprocidad y dependencia (Oliva y Villa, 2013). Como se ha venido mencionando las TIC han permeabilizado cada uno de los lugares en los que el ser humano socializa y tiene un campo de acción, siendo los jóvenes los más sumergidos en una cibercultura que ha crecido a la par de ellos, razones como el sentirse populares y estar a la vanguardia en el uso de redes sociales permite que el uso de estas abra espacios de beneficios y de riesgos en el que 
los padres necesitan del conocimiento en todo lo relacionado al ¿Qué? ¿Cómo? y de qué forma influye el uso de las redes sociales en sus hijos, para brindar acompañamiento efectivo en el control y vigilancia de estos (López, 2007)

Los padres cuentan con una gama diversificada de estrategias para llevar a cabo esta labor que la sociedad les ha encomendado, las tácticas de regulación parental son diversas según el tipo de familia, aspectos sociales y culturales, entre otros, estas pueden ir desde el control temporal del uso de las redes sociales orientado a evitar repercusiones negativas en la vida cotidiana como las calificaciones escolares, hasta la restricción de la exposición y contacto con la Internet. Las medidas de control y vigilancia se pueden implementar de forma implícita o explícita, pero esto dependerá del conocimiento de los padres sobre las redes sociales su necesidad, uso y peligros. En este orden de ideas el acompañamiento debe ir más allá de la restricción y seguimiento de los contenidos a los que acceden y debe estar centrado en el diálogo, la concienciación y autocontrol que deben desarrollar los adolescentes con el uso de la Internet y las redes sociales (Livingstone y Bovill 2001).

A pesar de las diversas estrategias que pueden implementar los padres para supervisar y regular el uso que sus hijos hacen de las redes sociales algunos estudios han indicado la baja implicación de los padres en el acompañamiento a sus hijos en Internet. Según datos del Euro barómetro, sólo el 15\% de los padres españoles había establecido alguna norma para la utilización de Internet en 2006 y el $48 \%$ de los padres de chicos de 6-17 años afirmaron en 2008, no imponer reglas a sus hijos cuando navegan. Estos datos indican que la falta de control ejercido puede presentarse entre otros por la carencia de habilidades y conocimientos tecnológicos de los padres y la dificultad para ejercer esa labor de vigilancia y supervisión cuando los menores se recluyen en sus dormitorios asociados al desconocimiento de los riesgos de las redes sobre los propios hijos (García y Cruz, 2013).
En este orden de ideas, es fundamental determinar el tipo de medidas y dinámicas familiares que favorecen el empoderamiento de los padres y adolescentes para que estos logren hacer un uso responsable de las redes sociales, minimizando los posibles efectos negativos sobre la integridad física y psicológica de los jóvenes. Es así como se valora positivamente la regulación orientada a promover, facilitar o requerir ciertas actividades de los adolescentes en la red, mediante el uso del diálogo y una dinámica positiva de la relación paterno-filial, y negativamente toda actividad orientada a desincentivar, impedir o prohibir mediante normas o medidas técnicas de seguimiento y filtrado (Livingstone y Bober, 2006 citados por García y Cruz, 2013).

\section{Alfabetización digital}

La alfabetización es la capacidad humana de usar un conjunto de técnicas para descodificar y producir material escrito o impreso. El concepto de alfabetización va más allá de la pura capacidad de leer y escribir; la alfabetización es esa competencia demostrada, dentro de las destrezas comunicativas, que permite al individuo funcionar, según su edad, de manera independiente en la sociedad y con un potencial para moverse dentro de ella, es decir, la alfabetización es el proceso acorde a las etapas de la vida y al entorno, mediante el cual se aprende a interpretar signos y símbolos, a unificarlos e interpretarlos, para estar conectados con la realidad, para establecer junto con otros componentes, mejores relaciones sociales, para estar a la vanguardia de los cambios y la dinámica social, para mejorar el desempeño en sociedad (Bawden, 2002).

Dicho lo anterior, y tras los grandes avances y el surgimiento de las nuevas tecnologías e Internet, se añade el término digital a la alfabetización, de acuerdo a su uso, entendiendo la palabra digital, asociada a las tecnologías y a la informática. La alfabetización digital es la capacidad de acceder a las fuentes de redes informáticas y de utilizarlas. La capacidad para comprender y utilizar las fuentes de información cuando se 
presentan a través del ordenador o cualquier dispositivo tecnológico. La alfabetización digital es el proceso de aprender a interpretar y manejar los dispositivos y herramientas que ofrece las nuevas tecnologías de la información y la comunicación, como los computadores, teléfonos inteligentes, tablets y demás dispositivos digitales, y sus diversas aplicaciones, y la navegación en la red, es saber buscar y hacer buen uso de la información que se muestra en pantalla (Bawden, 2002).

\section{El modelo ecológico}

El modelo ecológico es desarrollado por el profesor Urie Bronfenbrenner quien nació en Moscú en 1917 y murió en 2005 en Nueva York, se propuso para entender el desarrollo de la conducta humana, que concibe al ambiente ecológico desde el conjunto de estructuras concéntricas y estruc- turadas en diferentes niveles, en donde cada nivel contiene al otro, se enfoca principalmente en los diferentes contextos sociales que influyen en el desarrollo del individuo durante todo el ciclo vital (Chalá, 2009).

El proyecto de alfabetización digital se soporta conceptualmente en el modelo ecológico indicando como los sistemas concéntricos en los que se encuentra inmerso el ser humano, desde las relaciones más cercanas como la familia en el microsistema, hasta los aspectos socioculturales e históricos que se encuentran en el macro y el crono sistema, influyen en la conducta de este. Este modelo permite mostrar en la actualidad como las TIC son transversales a todos los sistemas, modificando la tradicional forma de relacionarse, interactuar y generando cambios en los roles establecidos socialmente. En la tabla 1 se describen los cinco sistemas propuestos por el modelo.

\section{Tabla 1. Sistemas ambientales propuestos en el Modelo Ecológico de Bronfenbrenner (1990)}

\begin{tabular}{|c|c|c|}
\hline $\begin{array}{c}\text { Sistema } \\
\text { Ambiental }\end{array}$ & Descripción & Personas o escenarios influyentes \\
\hline Microsistema & $\begin{array}{l}\text { Constituye el nivel más inmediato en el que se } \\
\text { desarrolla el individuo es el sistema relacional pri- } \\
\text { mario en el que el individuo pasa la mayor parte } \\
\text { del tiempo. }\end{array}$ & $\begin{array}{l}\text { Familia } \\
\text { Pares } \\
\text { Escuela } \\
\text { Vecindario o barrio }\end{array}$ \\
\hline Mesosistema & $\begin{array}{l}\text { Comprende las interrelaciones de dos o más } \\
\text { sistemas concéntricos, es decir vínculos entre } \\
\text { microsistemas. }\end{array}$ & $\begin{array}{l}\text { Relación entre la familia y la escuela. } \\
\text { Relación entre la familia y el barrio. }\end{array}$ \\
\hline Exosistema & $\begin{array}{l}\text { Está compuesto por los contextos más amplios } \\
\text { que no incluyen a la persona como sujeto activo, } \\
\text { pero que sus decisiones o acciones influyen en él. }\end{array}$ & $\begin{array}{l}\text { El consejo superior de la escuela } \\
\text { La Junta de Acción Comunal del barrio. } \\
\text { Las leyes y ramas del poder público. }\end{array}$ \\
\hline Macrosistema & $\begin{array}{l}\text { Lo configuran la cultura y la subcultura en la que } \\
\text { se desenvuelve la persona y todos los individuos } \\
\text { de su sociedad. Es el valor comunitario, las tradi- } \\
\text { ciones, creencias, la cosmovisión social. }\end{array}$ & $\begin{array}{l}\text { Valores } \\
\text { Costumbres } \\
\text { Creencias religiosas }\end{array}$ \\
\hline Cronosistema & $\begin{array}{l}\text { El sistema más amplio aborda los otros cuatro y } \\
\text { comprende las condiciones socio-históricas que } \\
\text { influyen en el desarrollo del individuo. }\end{array}$ & $\begin{array}{l}\text { En la actualidad las tecnologías de la informa- } \\
\text { ción y la comunicación TIC han modificado la } \\
\text { tradicional forma de vivir y relacionarse, influ- } \\
\text { yendo en el desarrollo de los individuos con } \\
\text { cada uno de los sistemas contenidos. }\end{array}$ \\
\hline
\end{tabular}

Fuente: Chalá (2009). 


\section{Intervención psicosocial por Empowerment}

La intervención se basó en el enfoque del Empowerment el cual tiene como objetivo meto- dológico, el empoderamiento, considerado como el proceso mediante el cual las personas, organizaciones y comunidades logran control sobre sus problemáticas o situaciones que a partir del diagnóstico y la reflexión ameritan un cambio (Banda y Morales, 2015). Ver figura 1.

Figura 1. Enfoque de Empowerment

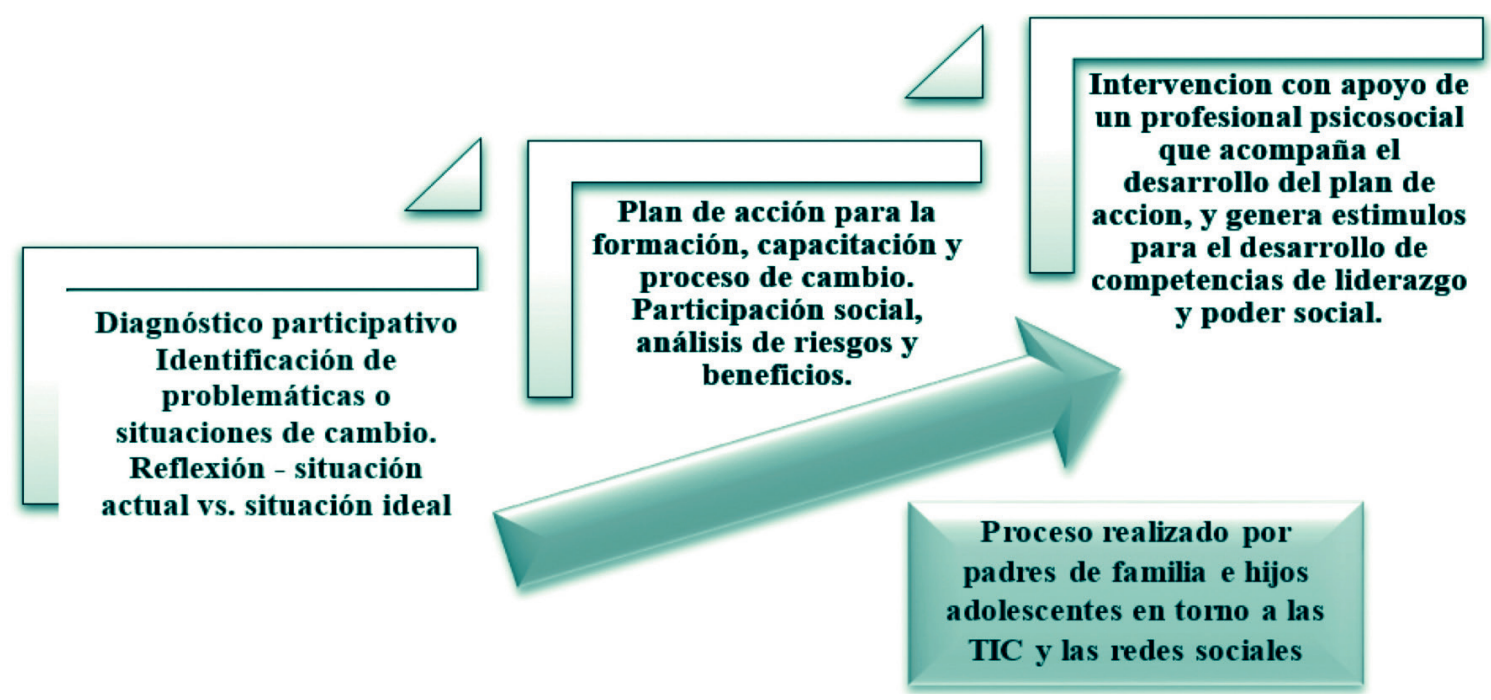

Fuente: Banda y Morales (2015).

\section{Enfoque y tipo de investigación}

El estudio se realizó bajo el enfoque cualitativo, de tipo Investigación Acción IA, por cuanto se inició con el análisis de la realidad donde se identificaron diversos fenómenos asociados a la brecha digital y la infopobreza a causa del analfabetismo digital, el enfoque cualitativo permitió hacer un análisis de las causas y consecuencias de la invasión de las TIC en la vida cotidiana y a partir de estas el desarrollo de alternativas de solución, condensadas en un plan de intervención para transformar la realidad del contexto digital y tecnológico de las familias participantes, en ese orden de ideas la IA desde su precepto básico de conducir y propiciar el cambio incorporando en el propio proceso de investigación al objetivo de indagación, permitió investigar al mismo tiempo que se realizó la intervención (Hernández,
Fernández y Baptista, 2014), integrando en el proceso a los padres de familia y sus hijos adolescentes como investigadores activos, a partir de un diálogo reflexivo que llevo al análisis de cada uno de los factores internos y externos causados por las redes sociales, que afectan la relación y comunicación paterno filial, con el fin de generar conciencia de cambio y formación en cada uno de sus miembros.

\section{Población y muestra}

Se contó con una población de 29 Padres de familia de la Institución Educativa Coopteboy de la ciudad de Tunja y sus hijos adolescentes de 14 a 17 años, pertenecientes al grado décimo de secundaria. La Muestra se seleccionó mediante un muestreo no probabilístico de tipo intencional, teniendo en cuenta la participación voluntaria de 
la población y los objetivos de los investigadores, la cual estuvo compuesta por 6 padres de familia en un rango de edad de los 38 a los 60 años y sus hijos adolescentes, en edades de 15 y 17 años.

\section{Técnicas e instrumentos}

La recolección de la información se realizó mediante el grupo focal, la observación participante descrita en los respectivos registros y los relatos como estrategia de indagación y reflexión, para el análisis de la información se desarrollaron matrices descriptivas y comparativas acorde a las fases de la investigación, esto permitió condensar los resultados y hallazgos más relevantes.

\section{Procedimiento}

El proyecto se desarrolló en tres fases comprendidas así:

\section{Fase 1. Diagnóstico}

Recolección de información por grupos focales, conformados por padres y adolescentes, para identificar las redes sociales que utilizaban con mayor frecuencia los jóvenes, el conocimiento y manejo que tenían los padres de familia sobre estas redes y la percepción inicial sobre el proyecto.

\section{Fase 2. Plan de Acción}

En Colombia con la ley 115 de 1994 se establece el servicio social obligatorio para los estudiantes de los grados $10^{\circ}$ y $11^{\circ}$ de educación bachiller media, el cual busca que los estudiantes generen un aporte a sus entornos durante 80 horas de trabajo comunitario que se convierten en un requisito para su graduación. Desde la estrategia de prestación del servicio social, se desarrolló la capacitación a padres de familia en el conocimiento y uso de las redes sociales más usadas por sus hijos, se formuló un plan de intervención participativo sobre el proceso de alfabetización, el cual se desarrolló mediante la directriz de un profesional en Ingeniería de Sistemas quien guio a los adolescentes en el proceso y el acompañamiento de los investigadores.

\section{Fase 3. Intervención Empowerment}

Se hizo el registro de observación participante, durante el proceso de alfabetización digital en redes sociales liderada por los adolescentes, se fortaleció en el ámbito psicosocial a los padres, generando una potenciación de sus recursos y capacidades comunicativas, identificando los riesgos a los que están expuestos en las redes sociales los jóvenes, y las estrategias de control y vigilancia que se deben implementar, esto a través del empoderamiento en un ambiente que favoreciera las relaciones con sus hijos y la oportunidad para re estructurar el rol paternal en la sociedad de las TIC a partir del liderazgo, y la transformación de sus entornos.

\section{Fase 4. Evaluación}

A partir de los relatos se desarrolló la evaluación de la intervención, los padres relataron su experiencia, el antes, el después y lo que les espera ahora con los conocimientos adquiridos y las herramientas de empoderamiento.

\section{Análisis y resultados}

Teniendo en cuenta que el microsistema constituye el nivel inmediato en el que se desarrolla el individuo (Frías, López y Díaz, 2003) y está determinado por el patrón de actividades, roles y relaciones interpersonales, de formación continua que constituyen la familia desde la interacción paterno filial, la primera fase de diagnóstico desde los grupos focales, logró identificar que los padres de familia tienen un bajo nivel en el manejo de las TIC; específicamente en el desconocimiento y uso de las redes sociales que utilizan los adolescentes, como facebook, whatsapp y twitter. Este hallazgo evidencia la brecha digital existente entre padres e hijos en el uso de las redes sociales, afectando la interacción del microsistema, representada en 
distanciamiento y resistencia, abriendo paso a relaciones paterno filiales conflictivas.

La fase 2, permite la planificación del ejercicio de alfabetización digital de los adolescentes a sus padres en el uso de las redes sociales que ellos más utilizan. Acompañados por un ingeniero de sistemas y los investigadores, los adolescentes y los padres de familia formularon el plan de acción correspondiente para el cumplimiento de las ochenta horas de servicio social exigidas por el ministerio de educación nacional para la graduación de la media secundaria.

La fase 3 eje central del proyecto correspondiente a la intervención fue liderada por los adolescentes, quienes en el proceso de 80 horas desarrollaron el ejercicio de alfabetización digital a los padres de familia. Lo anterior permitió evidenciar el mejoramiento de las competencias comunicativas en la relación paterno filial, en donde los padres de familia comprendieron la importancia de las TIC y el uso de las redes sociales en la actualidad, así mismo los riesgos de estas.

Los adolescentes formadores se centraron en las redes de Facebook, Twitter y WhatsApp, los padres adelantaron ejercicios prácticos de manejo e interactividad social mediante el uso de las redes. Por ejemplo, la creación de un grupo en Facebook, en la búsqueda de información relacionada con las redes sociales para compartir el producto de dicha indagación a través del grupo/perfil abierto en la red social "Alfabetización digital a padres Psicología UNAD" "Comunidad virtual" Alfabetización Digital a padres COOPTEBOY-UNAD, y en el grupo de comunicación WhatsApp. Finalmente, mediante el Cine foro: "Riesgos de las Redes Sociales" se desarrolló un proceso de socialización y dialéctica con el fin de conocer la percepción de los padres y sus hijos acerca de los riesgos a los que están expuestos cuando se hace un uso inadecuado.

La fase 4 orientada en la evaluación del proceso de alfabetización y apoyados en el análisis de las tres fases anteriores, además de los relatos de los padres y los adolescentes se evidenció un alcance del proceso, en cuanto al mejoramiento de las relaciones paterno - filiales a partir del mejoramiento de competencias comunicativas.

Se considera que el proyecto ha favorecido la comunicación y el vínculo familiar que se veía afectado por la brecha existente en razón del uso de dispositivos tecnológicos constantes por parte de los adolescentes y la imposibilidad de comprender su uso o ejercer algún tipo de control en la regulación de tiempo del uso de las redes o acompañamiento por parte de los padres. Se logra que los adolescentes compartan con sus padres las redes sociales en que tienen un perfil. Los padres resaltan la importancia de capacitarse en el uso de las TIC y en otras temáticas que manejan sus hijos para estar a la vanguardia y poder hacer un acompañamiento más efectivo y eficiente a sus hijos. Los jóvenes comprenden la importancia de hacer un buen uso de las redes sociales y de permitir el acompañamiento de un adulto.

\section{Discusión y conclusiones}

Es indudable como en la actualidad las Tecnologías de la Información y la Comunicación, están modificando las dinámicas relacionales del ser humano, lo cual obliga a las familias a desarrollar estrategias que les permitan ejercer su función socializadora, lamentablemente no siempre se está haciendo de la manera adecuada, teniendo en cuenta la brecha de analfabetismo digital que ocasiona que padres e hijos se perciban en dos mundos diferentes, aumentado así mismo la angustia de los padres frente al acompañamiento y manejo de la autoridad, que en su rol paterno pueden realizar con sus hijos y de los jóvenes, frente a no saber cómo hacer entender a sus padres de las exigencias que el contexto actual les obliga a asumir un rol digital.

Es preocupante cómo la inmersión de las redes sociales ha ocasionado un desafortunado distanciamiento intrafamiliar, alimentado por diversas creencias y mitos, como los encontrados en el presente estudio; en donde para padres de familia consideran inicialmente que el uso de las redes sociales "son para desocupados", "para la distracción”, "para perder tiempo", ocasionando 
que los jóvenes al sentirse rechazados excluyan de manera radical a sus padres y manifiesten comportamientos inadecuados frente a ellos. Se evidencia con el estudio lo encontrado por Carrizo (2012), donde se destacó la falta de control y conocimiento que tienen los padres con respecto a los contenidos que sus hijos manejan en las redes sociales como en Facebook.

Lo anterior permite comprender que efectivamente el bajo nivel en el conocimiento del uso de las TIC y las redes sociales por parte de los padres de familia y generaciones superiores como tíos y abuelos, afecta las dinámicas familiares, lo que evidencia la importancia de implementar estrategias que puedan fortalecer las relaciones intrafamiliares en las que se vea disminuida la brecha en cuanto al analfabetismo digital. Con el presente estudio se concluye, que efectivamente los padres de familia tienen un bajo conocimiento en el uso de Internet y redes sociales.

De igual manera sobresale en el comienzo del proceso, apatía de los adolescentes por el temor de sentirse vigilados y controlados por sus padres teniendo presente los pensamientos que sus padres tenían con respecto al internet y su uso. Además, si se tiene en cuenta que, en la adolescencia, el grupo de pares adquiere gran importancia y mantener su privacidad es fundamental, las medidas de control que intentan implementar los padres, no son siempre bien recibidas e incluso son el desencadenante de conflictos intrafamiliares. Sumado a lo anterior, la contemporaneidad trae consigo un nuevo factor, las redes sociales, en las que ya sin salir de casa el adolescente permanece ausente de la dinámica familiar, ocasionando que los padres de familia refuercen sus creencias frente al uso del internet, relacionándolas con pérdida de tiempo y promotor del ocio de sus hijos (Livingstone y Bober, 2006).

Sin embargo, es también evidente que al generar encuentros entre padres e hijos, alrededor de las redes sociales como el factor que los distancia, posibilita que las dos partes reconozcan ventajas y desventajas frente al uso adecuado e inadecuado de Internet. Convirtiendo el factor de riesgo en un factor de protección, en la medida en que tanto padres como hijos, reconocen que el internet hace parte de la vida cotidiana, en la era de la globalización, replanteando la importancia de asumir esta inclusión tecnológica con ética y responsabilidad.

El presente estudio evidenció la posibilidad del aprovechamiento de los conocimientos que tienen los adolescentes como nativos digitales para la implementación de planes de alfabetización digital en donde ellos incluyan a sus padres en la nueva era de desarrollo tecnológico. Estas estrategias educativas, permiten generar escenarios de interacción entre padres e hijos favoreciendo el reconocimiento de los riesgos a los que se exponen unos y otros cuando se manejan de manera inadecuada las redes sociales (Carrizo, 2012). De igual forma, padres e hijos identificaron las ventajas que tiene el uso adecuado de la red, validando nuevos ciberespacios de encuentro familiar, como la apertura de grupos familiares y el compartir de experiencias intrafamiliares en la red, en donde se reafirmó el rol de autoridad de los padres y el fortalecimiento de la relación paterno filial.

Es evidente el valor de la educación en el fortalecimiento del desarrollo del ser humano, por lo que es primordial acoger este recurso para enfrentar de manera óptima las exigencias de un nuevo mundo, de nuevas generaciones "nativas digitales". En este sentido, validar estrategias como la alfabetización digital, en familias invadidas por las TIC, hace parte de la responsabilidad social de la ciencia, en pro de salvaguardar a la familia como la célula de la sociedad e inclusive de la cibersociedad.

Con el desarrollo de este proceso de alfabetización digital, se fortaleció la relación paternofilial mediante la formación en el uso adecuado de las redes sociales, previniendo sus riesgos y rescatando sus ventajas en la dinámica familiar.

El generar espacios educativos de reencuentro entre padres e hijos alrededor del manejo de las redes sociales, permite restablecer la confianza y el respeto de los adolescentes hacia sus 
padres y el manejo de la comunicación y autoridad de los padres hacia los adolescentes.

Es fundamental implementar estrategias psicosociales que permitan a los miembros de las familias construirse desde la ética y la responsabilidad en un mundo con nuevas exigencias, como las que demanda la era de las tecnologías de la Información y la comunicación, de tal manera que sean familias competentes para enfrentar las nuevas dinámicas familiares y sociales.

Desde la formación en el uso de las redes sociales se hace evidente la importancia de replicar este proyecto encausándolo como forma de interacción más activa dentro de las estrategias de fortalecimiento de las dinámicas familiares, como por ejemplo, en las "Escuelas de padres".

La alfabetización digital en el uso adecuado de las redes sociales dirigida a padres e hijos logra minimizar riesgos y contribuye en el mejoramiento de la dinámica familiar, desde el fortalecimiento de las competencias comunicativas, que a su vez generan escenarios de participación y acompañamiento mutuo, optimizando la calidad del tiempo que brindan los padres a sus hijos como los primeros responsables en el cuidado y la educación.

\section{Referencias bibliográficas}

Andrade, L. (2004). Analfabetismo Tecnológico: Efecto de las Tecnologías de Información. Actualidad Contable Faces, (7) Recuperado de http://www.redalyc.org/articulo. oa?id=25700804 $>$ ISSN 1316-853

Banda, A. \& Morales, Z. (2015). Empoderamiento psicológico: un modelo sistémico con componentes individuales y comunitarios Revista de Psicología, 33(1), 3-20 Pontificia Universidad Católica del Perú Lima, Perú.

Bawden, D. (2002). Revisión de los conceptos de alfabetización informacional y alfabetización digital. Revistas Científicas de la Universidad de Murcia. Anales de documentación, 1 (5), 361-408. Recuperado de http://revistas. um.es/analesdoc/article/viewFile/2261/2251

Bedoya, M. \& Londoño, J. (2014). Taller: Acoso en las Redes Sociales. Facultad de Psicología,
Universidad de Ces: Medellín. Recuperado de http://bdigital.ces.edu.co:8080/repositorio/ bitstream/10946/3596/1/TALLER_ACOSO_ REDES_SOCIALES.pdf

Bordignon, N. (2005). El desarrollo psicosocial de Eric Erikson. El diagrama epigenético del adulto. Antioquia, Colombia. Revista Lasallista de Investigación. 2 (2) 50-63. Recuperado de http://www.redalyc.org/pdf/695/69520210. pdf

Carrizo, M. (2012). Las redes sociales como factor determinante de transgresión en la comunicación entre adolescentes El fenómeno de Facebook y su influencia (Tesis Pregrado). Facultad de Ciencias de la Educación y de la Comunicación Social. Universidad del Salvador. Buenos Aires. Recuperado de http://www.usal.edu.ar/archivos/di/carrizo_ mercedes.pdf

Cascón, J. (2016). La historia de WhatsApp. Frikipandi. Recuperado de http://www.frikipandi.com/ public/post/historia-whatsapp/

Chalá, M. (2009). Módulo de comunidad, sociedad y cultura; lección 7: teoría ecológica de Bronfenbrenner. Escuela de Ciencias Sociales Artes y Humanidades, UNAD. Recuperado de http://datateca.unad.edu.co/contenidos/434202/2013_2/Contenido_en_Linea/ leccin_7_teora_ecolgica_de_bronfenbrenner.html

Díaz, M. \& Bújez, A. (2011). Los jóvenes como consumidores en la era digital. Revista Electrónica Interuniversitaria de Formación del Profesorado (14) (Sin mes) Recuperado de http://www.redalyc.org/articulo. oa? id=217019031011> ISSN

Frías, M., López, A. \& Díaz, S. (2003). Predictores de la conducta antisocial juvenil: un modelo ecológico. Estudios de Psicologia, 8(1), 15-24. Universidad de Sonora: México. Recuperado de http://www.scielo.br/pdf/ epsic/v8n1/17231.pdf

Galindo, J. (2009). Ciudadanía Digital. Signo y Pensamiento, 26(54), 164-173. Bogotá, Colombia: Pontificia Universidad Javeriana.

García, B. \& Cruz, M. (2013). Los padres ante el uso de Internet $y$ redes sociales por menores. Control y protección. (V Congreso Internacional Latina de Comunicación Social) Universidad de la 
Laguna. Recuperado de http://www.revistalatinacs.org/13SLCS/2013_actas/077_Catalina.pdf

Gómez, E. \& Lara, T. (2011). Cultura digital. Razón y Palabra, 15, 73. Estado de México, México: Instituto Tecnológico y de Estudios Superiores de Monterrey.

Hernández, R., Fernández, C., \& Baptista, P. (2014). Metodología de la Investigación. México, D. F.: McGraw-Hill Interamericana.

Livingstone S. \& Bovill, M. (2001). Families and the Internet: an observational study of children and young people's internet use. Final Report of BT, London, Media@LSE. Recuperado de http://eprints.lse.ac.uk/21164/1/Families_ and_the_internet_n_observational_study_ of_children_and_young_people's_internet_ use.pdf.

Livingstone, S. \& Bober, M. (2006). Regulating the Internet at home: contrasting the perspectives of children and parents. En VV.AA. (D. Buckingham y R. Willett Eds.), Digital generations children, young people and new media. Mahwah: Lawrence Erlbaum Associate.

López, M. (2007). Tecnologías de la Información y Comunicación en la Familia (Tesis Inédita). Universidad Rey Juan Carlos. Recuperado de http://dialnet.unirioja.es/servlet/ tesis? codigo $=2268$
Morduchowicz, R., Marcon, A., Sylvestre, V. \& Ballestrini, F. (2010). Los adolescentes y las Redes Sociales. Ministerio de Educación Presidencial de la Nación. Recuperado de http://www.me.gov.ar/ escuelaymedios/material/redes.pdf

Oliva, E. \& Villa, V. (2013). Hacia un concepto interdisciplinario de la familia en la globalización. Scielo. 10 (1). Recuperado de http://www. scielo.org.co/scielo.php?script=sci_arttext\&p id $=$ S1692-85712014000100002

Pazmiño, P. (2011).Cómo aprovechar las redes sociales en la educación superior (Institutos Tecnológicos Fiscales). Universidad Tecnológica Israel. Recuperado de http://docplayer.es/4702428Universidad-tecnologica-israel.html

Sánchez, L. \& Martínez, E. (2011). Adolescentes y redes sociales: Contenidos educativos y efectos del uso de las TIC. Eje 1: La educación mediática y la competencia digital. Marco teórico y legislación educativa. Facultad de Comunicación y Documentación, Universidad de Granada: España. Recuperado de http://www.educacionmediatica.es/comunicaciones/ Eje\%201/Lourdes\%20S\%C3\%A1nchez\%20 Mart\%C3\%ADn\%20,\%20Estrella\%20 Mart\%C3\%ADnez\%20Rodrigo.pdf 


\title{
Las familias de estudiantes con
}

\section{discapacidad en la escuela, sus}

necesidades y demandas. Caso Ecuador

\section{The student's families with disabilities in school, their needs and demands. Ecuador case}

Investigación

\author{
Miriam Mariana Gallegos \\ Universidad Politécnica Salesiana - Ecuador \\ mgallegos@ups.edu.ec
}

Recibido: 1 de noviembre de 2016 / Aceptado: 3 de diciembre de 2016

\section{Resumen}

El presente trabajo identifica las necesidades de las familias con hijos con discapacidad y analiza cómo los requerimientos de la familia influyen en la continuidad de los proyectos de vida de los padres, así como las fortalezas de la familia para apoyar el proceso de inclusión social y educativa de sus hijos e hijas con discapacidad.

En el análisis de la información recabada a partir de la aplicación de la encuesta y grupos focales a las familias de los estudiantes que asisten a diversas escuelas de educación especial, se encuentra que un alto porcentaje de padres de familia abandonan y/o postergan sus proyectos de vida personal a causa del nacimiento de un hijo con discapacidad, de igual manera se identificó un listado de necesidades que las instituciones educativas no toman en cuenta o no consideran se debe satisfacer, cuando es la escuela quien tiene la función de brindar los apoyos pertinentes al estudiante y su familia con el objetivo de brindar una educación de calidad que desarrolle los máximos niveles de autonomía de sus estudiantes.

Descriptores: familia, discapacidad, inclusión, derechos, educación, proyecto de vida, necesidades.

\begin{abstract}
This paper identifies the needs of families with children with disabilities, strengths to support educational processes and analyzes how family requirements affect the continuity of parents' life projects. This research aimed to know the emotional status of parents, commitment to the education of their children, the dreams of the family to ensure their inclusion in life.

In the analysis of the information gathered, from the implementation of the survey and focal groups, to the families of students who attend different special education schools was obtained as a finding that a high percentage of parents leave and/or delay their personal life projects because of the birth of a child with disabilities, just as a list of needs that educational institutions do not take into account or do not believe that must be satisfied. When the school has a role in providing the relevant supports to the student and his family with the aim of providing quality education to develop the highest levels of autonomy of their students.
\end{abstract}

Keywords: family, disability, inclusion, rights, education, life project, needs.

Forma sugerida de citar: Gallegos, Miriam (2017). Las familias de estudiantes con discapacidad en la escuela, sus necesidades y demandas. Caso Ecuador. Alteridad, 12(1), pp. 20-31. 


\section{Introducción ${ }^{1}$}

En el marco del curso de formación continua de Diseño Curricular desde la perspectiva Ecológica Funcional, desarrollado por la Universidad Politécnica Salesiana en el año 2015-2016, evento en el que participaron treinta docentes de educación especial de trece instituciones de todo el Ecuador, surgió el proyecto de investigación denominado "Estudio de la aplicabilidad del enfoque ecológico funcional en instituciones de Educación Especial del Ecuador", estudio liderado por el grupo de investigación de Educación Inclusiva (GEI). Parte de la temática abordada en el curso se refirió a la situación de la familia de la persona con discapacidad ya que su participación es relevante para alcanzar los objetivos de aprendizaje de los estudiantes que asisten a las instituciones de educación especial.

Los actuales paradigmas con los que se define a la discapacidad permiten también redefinir el rol de la familia en la vida de una persona con discapacidad, la Convención de los derechos de las personas con discapacidad en su artículo 1 señala que:

Las personas con discapacidad incluyen a aquellas que tengan deficiencias físicas, mentales, intelectuales o sensoriales a largo plazo que, al interactuar con diversas barreras, puedan impedir su participación plena y efectiva en la sociedad, en igualdad de condiciones con las demás.

Este concepto obliga a la familia a desterrar ideas que consideran a la discapacidad como castigo divino o enfermedad que impide a la población valerse por sí misma. La evolución histórica de la noción de discapacidad enfatiza que las limitaciones se encuentran en el entorno donde se desenvuelve la persona. En función de este concepto, una familia que no se apropie de esta nueva concepción sobre la discapacidad se puede convertir en la primera barrera para el crecimiento de su hijo o hija, y de esta manera,

Esta investigación se realizó gracias al apoyo económico de CBM Internacional y la Universidad Politécnica Salesiana. también limitar su propio crecimiento personal (Díaz, 2011, p. 125).

Conocer las necesidades, estilos de crianza de los padres, limitaciones y potencialidades de las familias de los estudiantes con discapacidad es un paso importante para que éstas se constituyan en el principal apoyo del crecimiento personal de sus hijos y alcancen un proyecto de vida propio, así como un proyecto de vida en común con la familia.

El soporte que desde los servicios de educación especializada reciben las familias, debe centrarse en que éstas acepten la condición de discapacidad de su hijo y cumplan con las disposiciones escolares. En las instituciones no se analiza la situación de los padres desde su esfera personal, cómo se sienten, qué sueños tienen, cómo influye en su desarrollo personal la presencia de un hijo con discapacidad, en qué estado se encuentran sus planes de vida personales; no se observan procesos donde se apoye a los padres a reencontrarse con ellos, a retomar sus vidas y sus proyectos.

Los docentes de las instituciones de educación especial manifiestan la casi nula colaboración de los padres en las actividades escolares, nos preguntamos si los padres no encuentran en la escuela la suficiente motivación y confianza sobre la propuesta educativa para sus hijos. Puede ser que el diseño educativo esté descontextualizado o no atienda las demandas reales de las familias. Muy pocos docentes visitan los hogares de los estudiantes con discapacidad, la relación escuela-familia transcurre y se enfoca en atenuar las dificultades del estudiante, más no las de la familia, sin embargo, en la literatura consultada se manifiesta que, si bien la familia que tiene un miembro con discapacidad tiene mayores desafíos que las otras familias, esto no debería marcar o ser obstáculo para que esas familias abandonen su propia vida.

Dada la importancia que tiene la participación de la familia en la educación, surgen las siguientes preguntas ¿Qué situaciones enfrentan y cuáles son las necesidades de apoyo que tienen las familias de los estudiantes con discapacidad en la escuela? ¿Cuál es el índice de cancelación o postergación de los proyectos de vida de 
los miembros de las familias con personas con discapacidad?

La presente investigación se planteó como objetivo general que los docentes identifiquen las demandas y potencialidades que tienen las familias de los estudiantes que asisten a las instituciones de educación especial para que puedan brindar los apoyos que la familia y el estudiante requieren.

\section{Fundamentación teórica}

Actualmente en la sociedad coexisten diferentes formas de familias, situación que vuelve inconveniente establecer una definición general de familia, sin embargo, para fines de esta investigación, se define a la familia como:

"la unión de personas que comparten un proyecto vital de existencia en común que se quiere duradero, en el que se generan fuertes sentimientos de pertenencia a dichos grupos, existe un compromiso personal entre sus miembros (...)" (Palacios y Rodrigo, 1998, p. 53).

Esta definición permite profundizar en el hecho de que la familia es el espacio donde se da respuesta a las necesidades de sus miembros y al mismo tiempo se genera a través de un proyecto de vida familiar la consecución de los sueños presentes y futuros de cada uno de sus integrantes y su proyección social (Palacios, 2008, p. 97).

Por esta razón la familia es un espacio a ser protegido por la sociedad como lo manifiesta la Declaración Universal de los Derechos Humanos en el artículo 16, numeral 3 y la Constitución Política de la República del Ecuador del año 2008: "La familia es el elemento natural y fundamental de la sociedad y tiene derecho a la protección de la sociedad y del Estado" en consonancia con la carta magna el Código de la Niñez y la Adolescencia en sus artículos 22 y 33 manifiesta que:

Los niños, niñas y adolescentes tienen derecho a vivir y desarrollarse en su familia biológica. El Estado, la sociedad y la familia deben adoptar prioritariamente medidas apropiadas que permitan su permanencia en dicha familia. En todos los casos, la familia debe proporcionarles un clima de afecto y comprensión que permita el respeto de sus derechos y su desarrollo integral (Código de La Niñez y Adolescencia, 2003).

Las familias que cuentan con uno o varios miembros con discapacidad cumplen las mismas funciones que una familia sin esta condición, sin embargo, el nacimiento de un hijo con discapacidad constituye para la misma un acontecimiento inesperado, ninguna familia está preparada para esa eventualidad. La aceptación de la condición de discapacidad de un miembro de la familia requiere de un proceso en el cual ésta afronte de manera exitosa esa situación imprevista.

Es conocido también que muchas familias no logran asumir este proceso de aceptación y viven sumergidos en un sentimiento de culpa e inconformidad. "Algunos se bloquean y no saben cómo reaccionar, otros entran en un estado de shock y desencadenan emociones que los acompañarán el resto de sus vidas" (Buscaglia, 1983, p. 27). Independientemente del tiempo que los padres tarden en aceptar la condición de discapacidad de su hijo o hija.

La mayor parte de las necesidades de las familias con personas con discapacidad, son las mismas que las de todas las familias, sin embargo, la presencia de un miembro con discapacidad puede generar requerimientos diferentes en las diversas etapas de la vida familiar, necesidades mediadas por factores sociales, económicos y culturales.

Muchos autores consideran que el proceso de vida de una familia con un miembro con discapacidad:

Debe ser en conjunto lo más parecido posible al proceso de cualquier otra familia. $Y$ creemos que también se ha de preparar para la posible independización de la persona con discapacidad. Muchas veces más que aceptar e integrar a la persona con discapacidad cuesta a las familias el dejarlas volar en la medida de sus posibilidades y también en su caso el posibilitar su independencia (Fantova, 2000, p. 40).

Ya que el tiempo no se detiene para la persona con discapacidad, en cada etapa de su ciclo vital 
demanda diferentes tipos de apoyo por parte de la familia, por lo tanto, es imperioso atender las necesidades de las familias desde tempranas edades.

Se espera que la familia no solo acepte la condición de discapacidad de su hijo, sino que se convierta en un espacio que potencialice las capacidades de la persona para lograr los mayores niveles de autonomía.

Para que la familia sea un entorno positivo para la persona con discapacidad no hace falta nada que vaya contra la espontaneidad de la relación, aunque en ocasiones vendrá bien el consejo de otros padres o especialistas para hacer las cosas mejor (Fantova, 2000, p. 42).

Las familias deben conocer que sus hijos con discapacidad tienen los mismos derechos que los demás "a caerse, a fracasar, a sufrir, a censurar, maldecir, a desesperarse. Si los protegemos de estas experiencias, les impedimos de vivir su propia vida" (Buscaglia 1983, p. 95).

Es importante reflexionar que "actualmente todas las familias atraviesan tensiones propias de este tiempo" (FEAPS, 2000), es decir, todas las familias enfrentan tensiones debido a varias causas, las más comunes, y que tienen incidencia directa en el proceso de aprendizaje en la escuela son: tensiones debido al limitado tiempo que los padres dedican a la familia e influencia de los medios de comunicación; según Minuchin (1998, p.125), la familia está conformada por tres subsistemas, el parental, el conyugal y el filial, esto significa que la:

Comparecencia de la persona con discapacidad puede desequilibrar o agudizar el desequilibrio en la relación entre los subsistemas... Por ejemplo, hay riesgos de que se pueda dejar de lado a los hermanos, ante el requerimiento mayor de atención de la persona con discapacidad; o de que se pueda ver resentido el sistema conyugal... (Minuchin,1998, p.126).

Según (Núñez, 2007) en la etapa de la adolescencia y la juventud, las familias incrementan sus inquietudes acerca del futuro de sus hijos con discapacidad: “¿Qué será de él cuándo ya no estemos? ¿podrá arreglárselas solo? ¿podrá hacer una vida independiente?" (p. 24) preguntas que pueden aumentar en los padres el sentimiento de sobreprotección limitando las posibilidades de autorrealización y autodeterminación de la persona con discapacidad, es aquí donde se hace impostergable el apoyo a los padres para que sus hijos asuman y definan su proyecto de vida con sus nuevas proyecciones y sueños personales, como puede ser trabajar, vivir solos entre otros, (Valdés y Ángel, 2010).

En esta misma etapa los jóvenes con discapacidad desean una relación de camaradería con los padres que tome en cuenta las necesidades propias de la edad y los desafíos que esta etapa representa en sus vidas y los orienten en las cuestiones importantes de la vida. Si los padres asumen una actitud de sobreprotección pueden influir en la consolidación de un proyecto de vida personal desconectado de los intereses de su hijo y por otro lado considerar que la persona con discapacidad no puede tener un proyecto de vida propio.

Estas tensiones que aparecen en las familias con personas con discapacidad, pueden influir en los planes y estilos de vida de la familia, pueden alentar a los padres y madres a cambiar o postergar sus proyectos personales planteados antes del nacimiento de su hijo o hija con discapacidad, esto también puede ocurrir con los hermanos, por lo que, las familias necesitan apoyos adicionales tanto para mejorar su propia calidad de vida y retomar o sostener sus proyectos personales y familiares (FEAPS, 2000) y así convertirse en apoyo eficaz para su hijo. Desde el punto de vista educativo, se considera a la familia como el primer y más vigoroso recurso natural y sostén para los hijos, por lo tanto, trabajar colaborativamente con la familia es una garantía para potenciar el proyecto de vida de cada una de las personas con discapacidad; de lo contrario la familia puede convertirse en un obstáculo para su desarrollo. Según Durán (2014), son muchos los padres sobreprotectores que no creen en las posibilidades de sus hijos, miran a sus hijos como eternos niños, impiden su vivencia en actividades de la vida diaria, de ocio, recreación y 
uso del tiempo libre, en consecuencia, cualquier aporte para atender las necesidades de la familia, va a definir el estilo de vida de la persona con discapacidad y su familia.

En consecuencia los estilos que adoptan los padres en la educación de sus hijos tienen influencia directa en la socialización de los mismos, estos modelos o estilos educativos no son modelos fijos o estables, son referentes que varían de acuerdo a diversos factores como la edad, el sexo, lugar que ocupa entre los hermanos. Como resultado de variadas investigaciones realizadas por Baumrind (1967) cuando se habla de estilos de prácticas educativas parentales, se refiere a tendencias globales de comportamiento, de igual manera este autor identifica los siguientes estilos que los padres adoptan en la educación y crianza de los hijos, el democrático, autoritario, permisivo e indiferente.

Es importante analizar que cada familia tiene su estilo de vida y circunstancias que la condicionan, independientemente de la presencia de un miembro con discapacidad, de ahí que se hace necesario que en el hogar se establezca una forma de vida donde existan reglas o normas que tornen atractiva la convivencia de todos. Es importante recalcar que el estilo de vida contribuye a la conformación de la identidad familiar, de ahí que el modo de vida de las personas esté determinado por el estilo de vida de su familia:

Desde una perspectiva integral, es necesario considerar los estilos de vida como parte de una dimensión colectiva y social, que comprende tres aspectos interrelacionados: el material, el social y el ideológico" (Bibeau, Pedersen y Fuentes, 1985, p. 23).

Desde esta perspectiva integral, los estilos de vida no pueden ser aislados del contexto social, económico, político y cultural al cual pertenecen y deben ser acordes a los objetivos del proceso de desarrollo, orientado a enaltecer la persona en la sociedad a través de mejores situaciones de vida y de bienestar biológico, social y espiritual, en armonía con el proyecto personal y familiar, es decir, los proyectos de vida deben ser proyectos que permitan la realización plena el individuo.
Cuando nos referimos a proyectos de vida, autorrealizadores, estamos ubicando al individuo en el contexto de sus relaciones sociales cotidianas como entes transformadores $y$, por tanto, críticos, reflexivos, problematizadores y proactivos, capaces de dar nueva forma y encontrar nuevo sentido a las situaciones interactivas de su entorno, actividad profesional y vida personal (D’Angelo, 2003, p. 14).

Este concepto de proyecto de vida está dado desde una visión holística del ser humano, que toma en cuenta las complejas articulaciones de la persona y su entorno social. En concordancia con D'Angelo, Maslow en su pirámide de necesidades coloca en la cúspide, a la autorrealización como la meta de la vida de la persona.

La autorrealización es la utilización y el desarrollo plenos de nuestros talentos y capacidades, es por eso que la autorrealización ocupa la parte más elevada en la jerarquía de necesidades (Chapman, 2007, p. 8).

Las necesidades humanas se desarrollan generalmente en una secuencia, en primer lugar, está la satisfacción de las necesidades fisiológicas, siguen las de seguridad y luego vienen las sociales que involucran la autoestima y obtención de logros y habilidades que sean reconocidas por su entorno y permitan la aceptación en la sociedad y la consecución del proyecto de vida.

Los proyectos de vida no se limitan únicamente al plano individual, los proyectos de vida familiares, también juegan un papel decisivo en la vida de sus miembros, el proyecto de vida familiar se cristaliza en acciones y actitudes que se convierten en los pilares sobre los que se construye la vida en familia. Hablar de proyectos de vida familiar es hablar de proyectos de vida en común que contemplen los objetivos que se quieren obtener como pareja, el modelo de familia que se busca vivir, lo que se espera de los hijos en función de los ideales y las estrategias que se pueden emplear en el proceso educativo. Los proyectos de vida familiares permiten hacer frente a adversidades naturales de la vida y del matrimo- 
nio, de la vida en pareja o del tipo de familia que se ha configurado.

Cabe mencionar que la construcción del proyecto de vida familiar no es incompatible con la construcción de proyectos personales. La construcción de proyectos de vida tanto a nivel familiar como individual está directamente relacionada con los estilos de vida, que responden a las condiciones de vida de las personas y de sus posibilidades y potencialidades.

\section{Fundamentación metodológica}

El presente estudio es de tipo descriptivo, se pretende decir cómo es y se manifiesta determinado fenómeno, haciendo el esfuerzo de especificar propiedades importantes del asunto sometido a análisis, buscando medir diversos aspectos, dimensiones o componentes de la cuestión sujeto a examen. Medir desde el enfoque de las ciencias sociales es tratar de vincular conceptos abstractos con indicadores empíricos. Un instrumento de medición adecuado es aquel que registra los datos observados y que representan las variables que el investigador tiene en mente. Para acercarnos a la realidad de las personas con discapacidad y sus familias, con el fin de describir diversos aspectos de la vida familiar que influyen en el proceso educativo escolar de los estudiantes con discapacidad y poder cuantificar lo observado, hemos hecho uso de la técnica cualitativa.

El enfoque cualitativo a través de grupos focales dio amplio margen de expresión a las familias y nos permitió observar y por lo tanto registrar, las potencialidades y debilidades de los padres y las familias de los estudiantes con discapacidad. Toda buena medición debe reunir dos requisitos esenciales: confiabilidad y validez, así la técnica del grupo focal, muy empleada en las ciencias sociales, aplicada correctamente con una selección de muestra apropiada para el estudio, consigue cumplir las exigencias que procura toda investigación.

La muestra seleccionada fue de 554 padres y madres de familia de estudiantes con discapacidad de 13 escuelas de educación especial del país de Costa, Sierra y Oriente. La recolección de datos lo realizaron los docentes de las instituciones de educación especial antes mencionadas que fueron estudiantes del curso de formación continua de Diseño Curricular desde una perspectiva ecológica funcional, una respuesta a las personas con discapacidad en el año 2015.

\section{Tabla 1. Muestra}

\begin{tabular}{|c|c|c|}
\hline Región & Provincia & N. Escuela \\
\hline \multirow{5}{*}{ Costa } & Los Ríos & 4 \\
\hline & Esmeraldas & 1 \\
\hline & El Oro & 1 \\
\hline & Guayas & 1 \\
\hline & Santo Domingo de los Tsáchilas & 1 \\
\hline \multirow{2}{*}{ Sierra } & Pichincha & 2 \\
\hline & Azuay & 1 \\
\hline \multirow[t]{2}{*}{ Oriente } & Napo & 2 \\
\hline & Total & 13 \\
\hline
\end{tabular}

Fuente: Grupo de investigación GEl año 2016

Elaboración propia 


\section{Análisis y resultados}

Gráfico 1. Necesidades de las familias de personas con discapacidad que asisten a las instituciones de educación especial

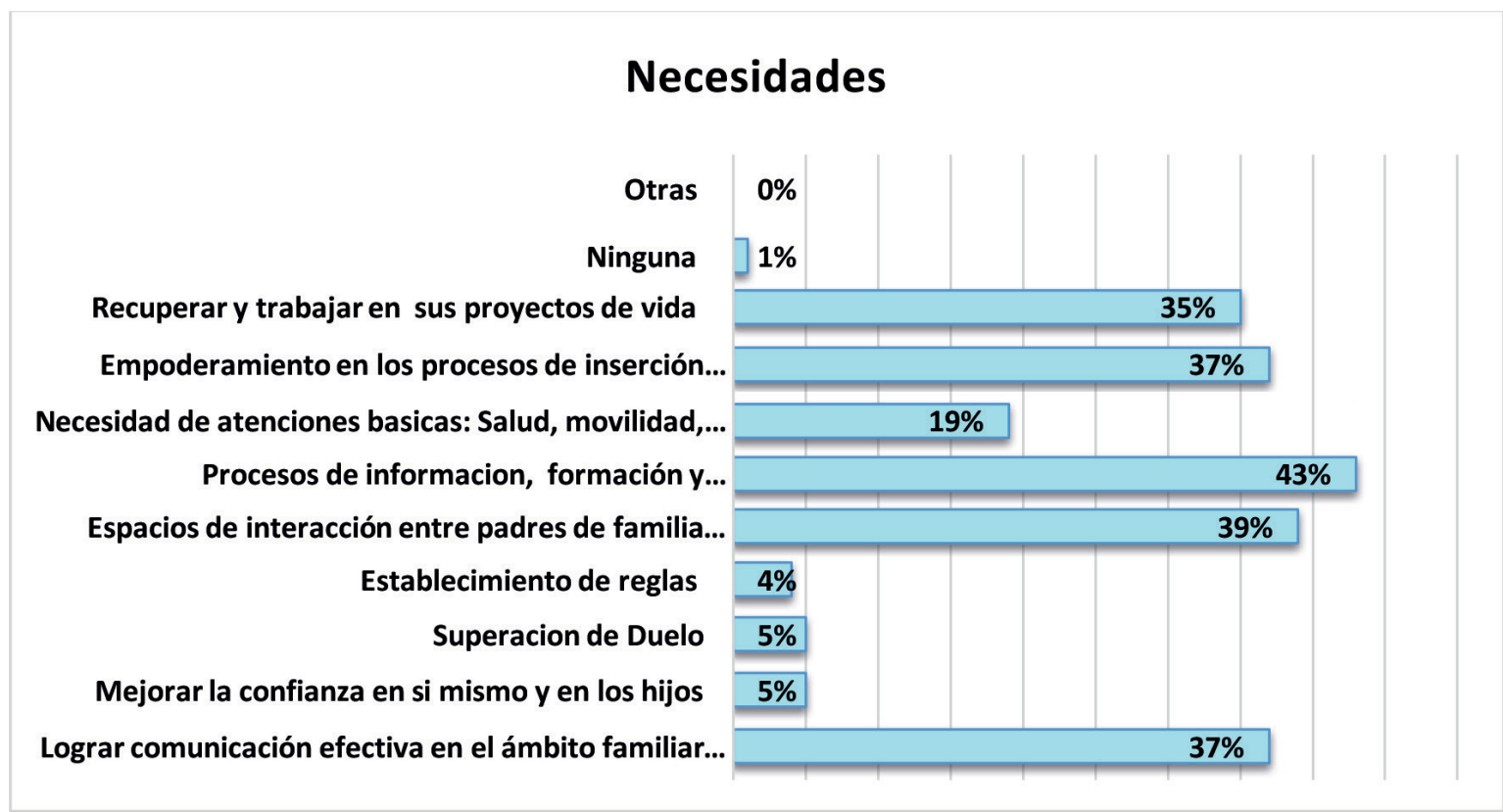

Fuente:. Grupo de investigación GEl año 2016

Elaboración propia

Las necesidades más relevantes que manifiestan los padres de familia encuestados, como se observa en el cuadro, ubica en primer lugar la demanda de recibir información, formación y acompañamiento para comprender y aceptar los límites y alcances de la condición de discapacidad de sus hijos y su influencia en el aprendizaje y la vida futura, este requerimiento alcanza el $43 \%$. La segunda exigencia con un $39 \%$ es contar con espacios de interacción entre padres de familia, formación de redes de apoyo y programas de respiro familiar, entendiéndose este último como "un apoyo de carácter no permanente dirigido a los familiares que conviven con personas con discapacidad intelectual con el fin de facilitar la conciliación de su vida personal, familiar y laboral, prestando una atención temporal y a corto plazo a su familiar con discapacidad" (FEAPS 2000, p.
18). En tercer término con un $37 \%$ se encuentra la cuestión de contar con apoyo para trabajar por el futuro de sus hijos, sobre todo despejar dudas sobre la inclusión laboral.

El 37\% busca alcanzar una comunicación efectiva en el ámbito familiar y escolar. El 35\% de los padres y madres manifiesta la necesidad de recuperar y trabajar en sus proyectos de vida personales. El 19\% anhela recibir apoyos en áreas básicas como: salud, movilidad, nutrición y apoyo económico. Un 5\% expresa el deseo de mejorar la confianza en sí mismo y en los hijos, un 5\% también necesita establecer reglas en el hogar para la mejor convivencia entre los miembros de la familia. Únicamente el $4 \%$ revela la aspiración de superar el duelo que genera la perdida de las expectativas de vida que tenían los padres acerca de su hijo. 
Gráfico 2. Fortalezas de las familias

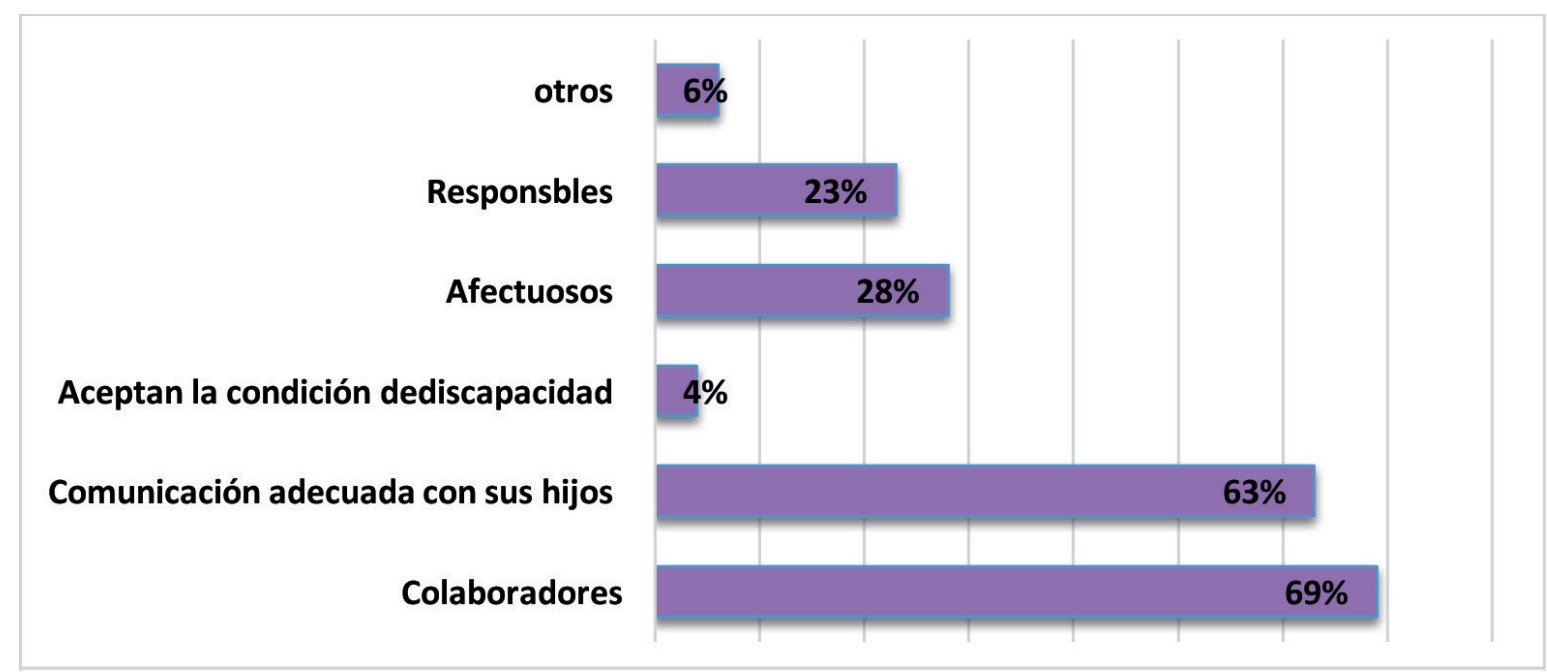

Fuente: Grupo de investigación GEI año 2016

Elaboración propia

Entre las fortalezas que los padres identifican poseer para apoyar a sus hijos, tenemos en primer lugar la actitud colaborativa con un $69 \%$; seguido de un $63 \%$ que opina que tienen como un elemento a su favor, una comunicación adecuada con sus hijos, estos puntos fuertes de la familia constituyen la piedra angular de apoyo para empujar las áreas en que los padres encuentran limitaciones.
El 4\% afirma aceptar la condición de discapacidad de su hijo frente a un $96 \%$ que no acepta aún o que está en proceso de aceptarla, esta respuesta se contradice con la respuesta emitida en el cuadro anterior que solo el $4 \%$ no ha superado la etapa de duelo que viven los padres frente al nacimiento de un hijo con discapacidad, este dato puede relacionarse al desconocimiento que tienen los padres y docentes sobre este proceso o este término.

Gráfico 3. Influencia de la discapacidad en los proyectos de vida de los padres y madres

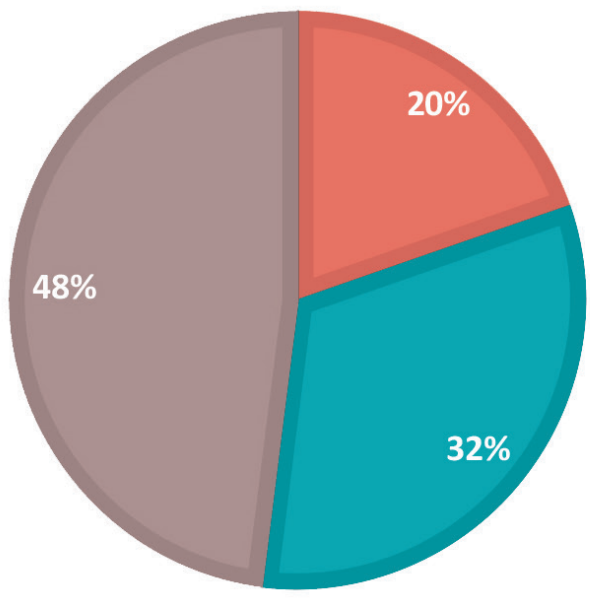

Mantienen su proyecto de vida

- Cambiaron su proyecto de vida

- Postergaron su proyecto de vida

Fuente: Grupo de investigación GEI año 2016

Elaboración propia 
Un dato relevante de esta investigación es el porcentaje de padres que cambiaron el proyecto de vida personal y/o lo postergaron para un futuro cercano, la cifra alcanza el $68 \%$, es un porcentaje elevado, lo que nos ratifica la influencia que tiene la presencia de un hijo con discapacidad en la vida personal de los padres y la familia.

Gráfico 4. Tipos de relación que establecen los padres con sus hijos

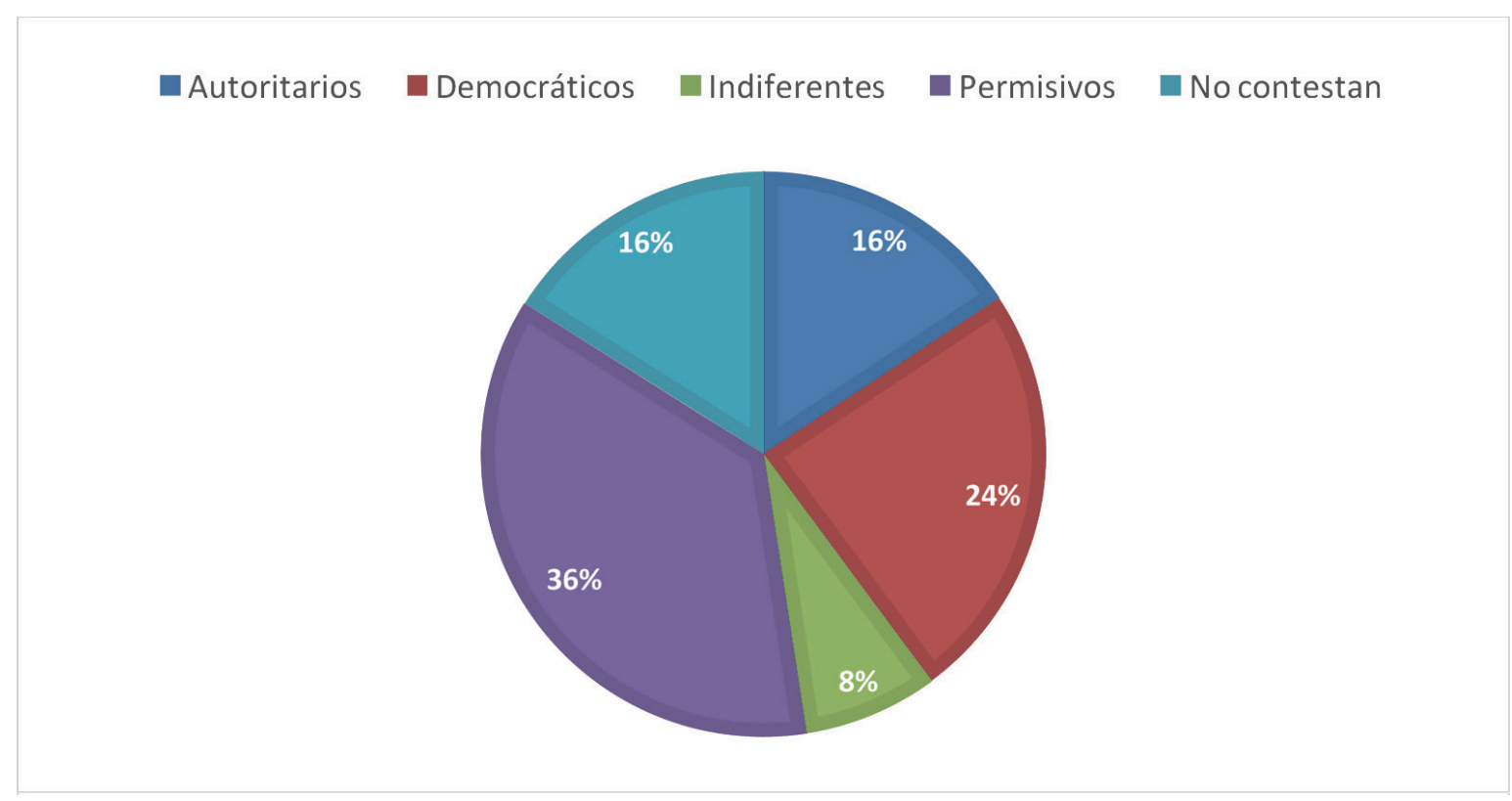

Fuente: Grupo de investigación GEl año 2016

Elaboración propia

El estilo que adoptan los padres determina el tipo de relación que mantienen con sus hijos, los padres marcan una tendencia que establece los comportamientos de la familia. De todos los modos de ser del padre o madre, el estilo democrático es el que ha demostrado aportar más beneficios para el desarrollo de los hijos. Los padres y madres que manifiestan este estilo, además de mostrarse afectuosos, establecen normas claras y coherentes en el hogar, guían el comportamiento de sus hijos y promueven su autonomía, como apreciamos en el cuadro anterior, el $24 \%$ de padres manifiestan ser democráticos, frente al $36 \%$ que se reconoce como permisivos, este dato se relaciona con las debilidades que pueden generar en los padres la presencia de un miembro con discapacidad, el estilo de padres permisivos se caracteriza por mostrarse afectuoso y comunicativo pero no pone límites al comportamiento de su hijo, dificultando el control de su conducta. El 16\% de los padres manifiestan mantener un estilo de relación autoritario, demuestran poca afectividad y comunicación, controlan de forma rígida el comportamiento de su hijo. El 8\% se reconoce como indiferente y poco afectuoso. El 16\% no contesta, no tiene definida su tendencia predominante en el estilo de relación con su hijo. 
Gráfico 5. Compromisos de los padres y madres con la institución educativa a la que pertenecen

Accesibilidad y participación en redes sociales y de apoyo

\section{Participación y colaboración en toda actividad institucional}

Sentido de pertenencia con la institución

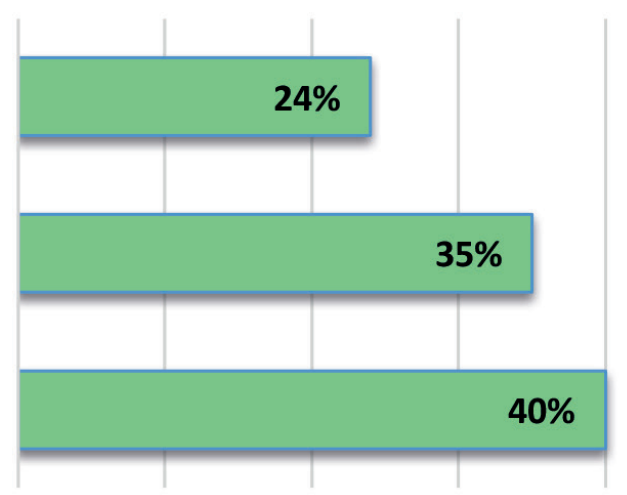

Fuente:, Grupo de investigación GEl año 2016 Elaboración propia

Se indagó el compromiso que los padres asumen con la escuela; del $100 \%$ de padres, el 40\% mantiene sentido de pertenencia con la institución, es decir, se identifica con ella; el $60 \%$ manifiesta que en la escuela no encuentra respuesta integral a sus necesidades. El 35\% participa en todas las actividades de la institución, el $65 \%$ lo hace a veces o nunca. Con relación a la participación de los padres en redes de apoyo, accesibilidad a redes sociales, únicamente el 24\% manifiesta tener esta posibilidad.

\section{Discusión y conclusiones}

Los hallazgos de esta investigación permitirán a los docentes y directivos de las Instituciones de Educación Especial del Ecuador, establecer estrategias para atender las demandas de la familia, implantando un modelo educativo centrado en el involucramiento de la familia como el principal apoyo del estudiante con discapacidad, y así lograr potenciar sus capacidades. Es necesario cubrir las demandas que manifiestan las familias: recibir información, apoyo y acompañamiento. De esta manera se estaría cumpliendo con lo que señala el artículo 23 inciso 3 de la Convención de los Derechos de las Personas con Discapacidad:

Los Estados Partes asegurarán que los niños y las niñas con discapacidad tengan los mismos derechos con respecto a la vida en familia. Para hacer efectivos estos derechos, $y$ a fin de prevenir la ocultación, el abandono, la negligencia y la segregación de los niños y las niñas con discapacidad, los Estados Partes velarán por que se proporcione con anticipación información, servicios y apoyo generales a los menores con discapacidad y a sus familias (Convención de los Derechos de las Personas con Discapacidad, 2006).

La falta de información que recibe la familia de como asumir las situaciones propias que se originan de la condición de discapacidad de su hijo, le limita a asumir deberes y responsabilidades, y colaborar en los procesos educativos de un hijo, afectando la armoniosa relación entre los miembros de la familia.

Frente a un acontecimiento inesperado como es el nacimiento de un hijo con discapacidad, un porcentaje elevado de familias encuentran obstáculos y limitaciones para desarrollar sus metas personales y sueños, estos pasan a segundo plano, los programas educativos no establecen acciones que permitan a la familia retomar y/o concluir sus proyectos de vida, desconociendo que el apoyo que reciban los padres en esta área es vital para el desarrollo de la autonomía de los estudiantes e influye directamente en el aumento de la confianza y capacidades de los hijos. 
Visibilizar las fortalezas de los padres se constituye en una palanca para superar las debilidades, tanto de ellos como de sus hijos con y sin discapacidad, fomentando una vida en familia más armoniosa.

En las instituciones de educación especializada no se generan espacios para apoyar a la familia en su crecimiento personal, se enfatiza en la responsabilidad y en los problemas que el hijo con discapacidad genera, pero se olvida que los padres también tienen sueños y metas que cumplir. Según la Ley Orgánica de Discapacidades (LOD) en su artículo 31 sobre capacitación y formación a la comunidad educativa, declara que la autoridad educativa nacional propondrá y ejecutará programas de capacitación y formación relacionados con las discapacidades en todos los niveles y modalidades del sistema educativo, por otro lado, en los artículos 35 y 37 sobre la educación co-participativa y la demanda a las instituciones educativas especiales de involucrar como parte de la comunidad educativa a la familia, se establece la participación de los procesos educativos y formativos desarrollados para favorecer la transición de la persona en sus diferentes ciclos vitales.

Artículo 37.- Formación de transición.- La autoridad educativa nacional, desarrollará programas de acuerdo a las etapas etarias de la vida para las personas con discapacidad que se formen en los centros de educación especial y regular; y, ejecutarán programas orientados a favorecer la transición de una persona que adquiera una discapacidad en cualquier etapa de su vida.

En las instituciones antes mencionadas, es importante motivar a los padres a optar por un estilo democrático de relación con sus hijos debido a que este estilo fomenta la autonomía e incentiva la construcción de su proyecto de vida personal, lo que contribuye a que la transición a la vida adulta sea compatible con los sueños de la persona con discapacidad, y mitiga la preocupación de la familia por el futuro del hijo con discapacidad, ya que el contar con un proyecto de vida permite ir eliminando las barreras que impiden su plena realización.

\section{Referencias bibliográficas}

Asamblea Nacional (2012). Ley Orgánica de Discapacidades. Quito: Suplemento - Registro Oficial $N^{\circ} 796$.

(2012).Ley Orgánica de Educación Intercultural Bilingüe. Quito: Registro Oficial No 417.

Baumrind, D. (1967). Child care practices anteceding three patterns of preschool behavior. Genetic psychology monographs, 75(1), pp 43-88. Recuperado de: http://scholar.google.com. ec/scholar?q=Baumrind,+D.(1967)+Child + care+practices+anteceding+three\&hl=es \&as_sdt=0\&as_vis $=1 \&$ oi $=$ scholart $\&$ sa $=\mathrm{X} \&$ ved=0ahUKEwjuo-Pdkd3QAhXHbiYKHXG0AicQgQMIFjAA

Bibeau, G., Pedersen, D., y Fuentes, G. (1985). Estilos de vida y sistemas de trabajo. Santiago de Chile: Editorial Universitaria.

Buscaglia, L. (1983). Los discapacitados y sus padres. Buenos Aires: Editorial: Emece.

Chapman A. (2007). Maslow's Hierarchy of Needs. Recuperado de: www.businessballs.com/ maslow.htm

Código de la Niñez y Adolescencia, publicado por Ley No. 100. En Registro Oficial 737 de 3 de enero del 2003.Ultima modificación 7 julio 2014. Recuperado de http://www.igualdad.gob.ec/ docman/biblioteca-lotaip/1252--44/file.html

Constitución Política de la República del Ecuador del año 2008. Recuperado de http://www. asambleanacional.gov.ec/documentos/constitucion_de_bolsillo.pdf

D’Angelo, O. (2003). Proyecto de vida y desarrollo integral humano. CIPS: Recuperado de: http://biblioteca.clacso.edu.ar/Cuba/ cips/20150429033758/07D050.pdf

Díaz, M. (2011). La planificación centrada en la persona (PCP): una vía para la construcción de proyectos personalizados con personas con discapacidad intelectual. Recuperado de: www.oei.es/historico/noticias/spip. php?article9576

Durán, M. (2014). Familia y discapacidad: Vivencias de madres y padres que tienen un hijo/a ciego/a o sordo/a. Recuperado de: http://repositoriocdpd.net:8080/handle/123456789/379

Fantova, F. (2000). Trabajando con las familias de las personas con discapacidad. Revista Española 
sobre Discapacidad Intelectual, 31, (192), 2000, pp. 33-50.

FEAPS (2000). Familias y Discapacidad Intelectual. Recuperado de: http://www.feaps.org/biblioteca/libros/coleccion_tex6.htm (2008). Cuadernos de Buenas Prácticas N.14. Recuperado de: http://www.feaps.org/biblioteca/libros/cuadernos.htm

Minuchin, S. (1998). El arte de la terapia familiar. Barcelona: Editorial Paidós.

Organización de las Naciones Unidas (2006). Convención de la ONU sobre los derechos de las personas con discapacidad.
Palacios, J., y Rodrigo, M. (1998). La familia como contexto de desarrollo humano. Madrid: Editorial Síntesis.

Palacios, A. (2008). El Modelo social de discapacidad origen, caracterización y plasmación en la convención internacional de Derechos de las personas con discapacidad. Madrid: Editorial Cimca.

Núñez, B. (2007). Familia y discapacidad de la vida cotidiana a la teoría. Buenos Aires: Editorial Lugar.

Valdés C. Ângel, A. (2010). Familia y crisis. México: Editorial Arson. 


\section{El currículum familiar: herramienta pedagógica alternativa para la educación Family curriculum: an alternative pedagogical
tool for education}

Investigación

Andrés José Salazar

Universidad de Oriente-Venezuela anjosafron@hotmail.com

Recibido: 24 de noviembre de 2016 / Aceptado: 13 de diciembre de 2016

\section{Resumen}

La investigación que aquí se presenta está centrada en el proceso de generación de conocimientos y verdades a través del currículum familiar, como herramienta pedagógica alternativa para la tejer encuentros con lo vivido. En el trabajo se tomaron como muestras representativas a tres grupos familiares del Estado Sucre, específicamente de la península de Araya: El Rincón, familia Ortiz; Manicuare, familia Pereda; Araya, familia Salazar. A través de este currículum se logra conocer su historia y se observa su comportamiento en varios aspectos de su vivir cotidiano; entre los que se pueden señalar: la preservación de los valores, costumbres, creencias y tradiciones propias de su lar nativo. De igual manera, se toma en cuenta el papel de la educación familiar más allá de los espacios escolarizados y, se logra conocer de estos testimonios vivientes sus sabidurías, calidez y autenticidad; legados dejados, durante el transcurrir de su existencia, como aporte de vivir o haber vivido. Estos aspectos personales, de cada familia en particular, fueron importantes para que el investigador fijara su postura sobre la conceptualización del "currículum familiar". El estudio es netamente empírico y se enmarca dentro del enfoque cualitativo aplicando dos variantes metodológicas: La fenomenología y las historias de vida; en un estudio etnográfico que combina observación participante y entrevista en profundidad de tipo biográfico. En el trabajo se pone de manifiesto cómo se desarrollan las percepciones de la crianza, la formación, la educación, el trabajo y otras categorías de análisis de mucha importancia de las familias inmersas en el estudio, ligadas con las condiciones y las experiencias de su transitar por la vida.

Descriptores: Currículum familiar, herramienta pedagógica, historias de vida.

\begin{abstract}
The research that here is presented is centered in the process of generation of knowledge and truths through the curriculum family, as tool pedagogical alternative for weaving encounters with it lived. In the work is taken as samples representative to three groups family of the State Sucre, specifically of the peninsula of Araya: the corner, family Ortiz; Manicuare, Pereda family; Araya, Salazar family. Through this curriculum is achieved to know its history and shows its behavior in various aspects of his live daily; among those who can point out: the preservation of the values, customs, beliefs and traditions of his native lar. Similarly, the role of the family education beyond school spaces are taken into account, and get know these living testimonies of their wisdom, warmth and authenticity; legacies left during the course of its existence, as a contribution of live or have lived. These personal aspects, each family in particular, were important for the researcher to set its position on the conceptualization of the "family resume". The study is purely empirical and is part of the qualitative approach by applying two method-
\end{abstract}

Forma sugerida de citar: Salazar, Andrés (2017). El currículum familiar: herramienta pedagógica alternativa para la educación. Alteridad, 12(1), pp. 32-42. 
ological variants: Phenomenology and the life stories; in an ethnographic study that combines observation participant and interview in depth biographical type. At work is made clear how develop perceptions of breeding, training, education, work and other categories

\section{Introducción}

Esta investigación es una experiencia que forma parte de la vida cotidiana de tres grupos familiares, hombres y mujeres: pescadores, ceramistas y salineros; que habitan en espacios sociales diferentes en la península de Araya. Estos grupos a través del transcurrir de su existencia han mantenido una dinámica constante en la formación de la familia como proceso de enseñanzaaprendizaje, que no es otra cosa que su educación, desarrollada e impartida desde el hogar; técnicamente hablando, una educación que constituye o representa una configuración socioeducativa que se reflejó en el aprendizaje del grupo familiar al margen de la escolaridad o ajeno al formalismo curricular de la escuela. La investigación presenta una motivación especial, a la vez que puede resultar oportuna. En primer lugar, porque en ella se recogen las experiencias vividas por la familia Ortiz; la familia Pereda y la familia Salazar, como testimonio de una realidad que le ha tocado vivir entre satisfacciones y vicisitudes. $Y$ en segundo lugar, se presenta la gran oportunidad del estudio al encontrarnos ante la inminente comprensión de una nueva temática: el currículum familiar.

La concepción del currículum familiar como proceso sistemático, comprensivo y continuo, que tiene el cometido de valorar y de reorientar el accionar de los agentes que operan en el marco de una realidad vivida y convivida, constituyen la razón fundamental del presente trabajo; de allí, que se tomaron como señales de identificación la realidad vivida por estas familias, representantes genuinos de la región peninsular. A la luz de sus reflexiones, se abordaron algunos desafíos de carácter epistemológicos y ontológicos presentes en los tres grupos familiares, con el of analysis of importance of families involved in the study, linked with the conditions and experiences of its transit through life.

life stories.

Keywords: Family curriculum, pedagogical tool,

firme propósito de que mediante la interpretación de sus relatos, buscar consolidar el conocimiento a través de los valores que aún persisten en ellas. La investigación se llevó a cabo bajo el enfoque de las historias de vida, y hemos creído conveniente presentarlo aquí con el título de: el currículum familiar: herramienta pedagógica alternativa para la educación.

El currículum familiar que nos hemos propuesto estructurar lleva implícito los valores ganados en la familias. debe mirarse como un proceso por el cual han transitado estos grupos familiares; identificando en ellos un conjunto de competencias claras y significativas de lo que son sus valores y su modo de vida. claro está, dichas competencias están enmarcadas dentro de lo que les ha tocado vivir; es decir, desde su propia realidad. igualmente, el currículum familiar es un ámbito socializador de la membrecía familiar que toma en cuenta al sujeto y su realidad, que se nutre de la experiencia presente en su entorno $y$, toma en consideración, dentro de su contexto social, sus necesidades y restricciones; dando por sentado los significados en los que se sustenta su identidad; logrando hacer de ese ámbito un espacio para expresar sus ideas, un espacio para compartir y debatir, en la medida de lo posible, aspectos que tienen que ver con la vida familiar.

Podría decirse que el currículum familiar constituye un importante instrumento social, cultural e histórico para el individuo en particular y para la sociedad en general, porque a través de él se va a permitir detectar las más diversas problemáticas presente tanto en los grupos familiares como en las localidades donde estos hacen vida. El haber convivido desde muy cerca con estos grupos familiares, nos llevó a conocer que en cada comunidad, en cada pueblo, existen personajes 
que de alguna manera vienen a formar parte de la identificación plena de su tierra y hasta le dan un punto de individualidad, transcendiendo la historia, porque poseen algo excepcional en sus aptitudes, que los convierten en expresión genuina de sus valores sociales y humanos. Las familias Ortiz, Pereda y Salazar, quienes son los testimonios vivientes de esta investigación, representan uno de esos tantos baluartes que han sublimado el gentilicio peninsular. Representan la esencia pura, identificable e insustituible de las manifestaciones culturales populares e históricas, que no son otra cosa sino la naturaleza misma de nuestras raíces y la sabiduría y dignidad de nuestros pueblos. En la investigación se trata de conocer, desentrañar e interpretar "los tesoros ocultos" de estas tres familias. Se busca en estos personajes las revelaciones y reflexiones narrativas de su vivencia y convivencia $y$, a través de sus relatos, basados en sus experiencias, construir la teoría que el autor abordó desde una perspectiva de las ciencias sociales, haciendo aportes y destacando algunas ideas propias del proceso evolutivo de cada familias.

Un día, bastante lejano ya, buscando en el remolino de los recuerdos, tuvimos la idea de emprender un trabajo de investigación donde se recogiera la vida cotidiana de algunos grupos familiares nacidos en la Península de Araya. Y, una vez, abierto el abanico narrativo de nuestras experiencias pasadas sobre esos grupos familiares, se desempolvó el baúl de remembranzas retenidas en la cabeza, logrando de esta manera darle rienda suelta a la investigación que aquí se describe. Para ello tomamos como referente histórico la película "Araya", de la cineasta venezolana Margot Benacerraf, ganadora de dos grandes premios en el Festival de Cannes, en Francia, el 13 de Mayo de 1959; porque en ella recogió la señorita Benacerraf la vida de las tres familias y de los tres pueblos que representan los protagonistas centrales o testimonios vivientes de este trabajo investigativo. Siempre habíamos soñado hacer una investigación sobre la identidad de este grupo de hombres y mujeres (pescadores, ceramistas y salineros), para conocer esas características que dentro del entorno familiar se guardan con mucho celo y, que a la vez nos definen como pueblo; estos personajes con su experiencia narrativa, con sus relatos, brindaron esa oportunidad. Nos permitieron "buscar sus almas" y, extraer de ellas las más diversas expresiones de su vivir cotidiano; contando las anécdotas que no siempre los cronistas estampan en sus escritos. De la misma manera consideramos importante hacer un bosquejo general, tanto de los pueblos, como de las familias inmersas en el estudio, ya que de esta manera se podría conocer mejor la temática tratada, y percibir el currículum familiar como método de estudios y como herramienta pedagógica alternativa en las prácticas docentes para tejer encuentros con lo vivido.

Muchas veces lo casual ha sido determinante en el acontecer educativo y el currículum familiar no es la excepción. la fácil maestría con que se puede admitir en las intervenciones pedagógicas, fue lo que hizo que surgiera esta conceptualización, en el preciso instante, cuando ninguna de las instituciones que planifican y programan los distintos tipos de currículum existente dentro del ámbito educativo, había pensado en él como instrumento de enseñanza-aprendizaje. De allí, que es de suma importancia que se describan las características de los pueblos de la península, como también los rasgos personales de sus habitantes. Todo ello con la sana intención de comprender mejor los fundamentos epistemológicos planteados por el investigador $y$, de esta manera conocer el beneficioso aporte que el currículum familiar ha de brindar en todo lo que concierne al proceso educativo.

\section{De los pueblos y las familias clave en la investigación}

Siempre se ha dicho que la gran mayoría de los pueblos que conforman la península de Araya son comunidades sin partida de nacimiento firme, porque no existen evidencias ciertas de cuando fue su fundación. Eso hace suponer que su desarrollo como comunidad organizada, aparte de ser incidental y espontaneo, fue un proceso lento, en el cual intervinieron como factores determinantes, 
su estratégica ubicación dentro de la Geografía peninsular y la topografía del terreno donde sus primeros pobladores fijaron su asiento; espacios idóneos, donde pudieron desarrollar libremente el arte de la pesca y otras actividades propias de cada lugar. Visto desde esta perspectiva, es lógico considerar a la península, como una larga extensión de costa marina, vigilada por un cinturón de cerros de vegetación xerófila, que proporcionaron materiales para la edificación de las primeras viviendas, leña para los menesteres de la vida doméstica y otros elementos indispensables para la subsistencia. La antología recopilada en cada uno de los pueblos, es una muestra fehaciente de todo ese acontecer que se desarrolla y se transmite de generación en generación. Aquí, los informantes clave narran los hechos, los sucesos, con la naturalidad que solamente puede lograrse dejando que ellos hablen por si solos, con su propia voz y estilo, sin afeites ni enmendaduras; lo cual hace que cada quien desnude, a través de sus palabras, el terruño donde han visto pasar silentemente su vida.

El Rincón-Pueblo de los Ortiz: El Rincón tiene desde sus orígenes una vegetación xerófila, la misma que predomina en toda la península. Es una región que por la aridez de su clima y lo reseco de sus tierras, no es posible sustentar en ella una actividad agrícola suficiente para el autoconsumo. Por ello, tradicionalmente, su modo de vida ha estado unido, por siempre, a la pesca artesanal. Los pescadores artesanales, fundamentalmente, han ido transmitiendo sus experiencias de pesquería de generación en generación, cómo una enseñanza silenciosa y elocuente que emana de este prístino paisaje. Sus habitantes recuerdan que del proceso de emparentarse varias familias, surge la unión conyugal entre Antonio Narváez y Benita Ortiz, padre y madre de Adolfo Ortiz, representante genuino de este pueblo de pescadores. La actividad económica de Los Ortiz, ha girado, desde siempre, en la pesca artesanal. Hicieron en un pasado y aún hacen uso de las herramientas de trabajo propiedad de uno de ellos para la manutención de todos; a este respecto, Ysabel, la mujer de Adolfo, dice: "esos mandingas eran propiedad de mi padre", Esto es corroborado por un nativo del pueblo al decir: "esos trenes de pesca eran propiedad de Cruz Vásquez, el suegro de Adolfo, el padre de Ysabel". Es importante resaltar que Los Ortiz con la venta del pescado lograron mantener a toda la familia. Comenta Ysabel: "la venta del pescao por las calles era mi modo de vida" y, hasta hubo el sacrificio de los mayores para que los hijos menores fueran a estudiar; razón por la cual dice: "...que estudiaran algo pa'que no jueran como yo...que no conozco ni la "o" por lo redondo...tengo un hijo que es Contador Público...y otra que es maestra de manualidades...eso es bueno que haigan echao pa'lante a pesar de mi pobreza y brutalidad”. En la narrativa se pudo observar el deseo de querer tener una educación proveniente de una institución escolarizada... "Yo no jui a la escuela, porque un día como no sabía la "plana" me castigaron. Lloré mucho por no saber leer ni escribir, yo quería aprender". A pesar de la experiencia vivida y del cúmulo de conocimientos adquiridos en su trajinar por la vida, hacían uso del término "brutalidad" por no saber leer ni escribir. El grupo estaba integrado por familias extensas; entendida ésta, como aquella estructura familiar que puede incluir parientes políticos, abuelos, tíos, sobrinos, primos, hijos, etcétera; lo cual es propio de patrones rurales de conducta. Los Ortiz, resguardan con celo un modo de vida singular: la pesca artesanal; cultura y corazón, tanto de ellos, como del pueblo de El Rincón; ya que no pudiendo vivir en una tierra sedienta, se dirigieron a un mar que era, y es, pródigo en recursos. (Al momento de realizada la investigación, ya Adolfo Ortiz, había fallecido).

Manicuare-Tierra de los Pereda: De todos los pueblos y caseríos que conforman la geografía peninsular, es Manicuare, quien ha mantenido desde épocas inmemoriales la alfarería como actividad económica y cultural. De esto da razón el barón Alejandro de Humboldt, quien escribiera: "Las ollerías de Manicuare, célebres desde tiempo inmemorial, forman un ramo de industria que se halla exclusivamente en manos de las mujeres indias. La alfarería se hace todavía según 
el método empleado antes de la conquista”. Bajo este contexto, podríamos decir que el trabajo de alfarería ha continuado, sin interrupción, trasmitiéndose de generación en generación hasta el presente. Con respecto al grupo familiar, hay testimonios de personas del pueblo, quienes indican y dan fe del cruce de los apellidos Gamardo y Pereda. Este cruce se dio entre Juan Gamardo y Catalina Pereda; padres de Beltrán Pereda, Esta familia, tuvo que salir a trabajar desde muy temprana edad para llevar el sustento a su hogar. Dice Fortunato Pereda: "tuve una infancia muy pobre. Apenas abrí los ojos al mundo me atrapó el trabajo....yo empecé a trabajar con mi tío Beltrán desde muy chiquito". Trabajaron bajo la protección del más viejo de la familia..."Trabajábamos con Beltrán el mayor de la familia...sacando sal de noche y de día ayudando a las mujeres a hacer la loza”. Este grupo familiar, al igual que Los Ortiz, en sus primeros años no "gozaron" de una educación escolarizada.... "Aprendí a leer en una escuelita del pueblo, aquí habían varias mujeres que se dedicaban a enseñar...en mi época de niño...no había escuela del gobierno". Sin embargo, se sacrificaron para que sus descendientes estudiaran.... "Tuve ocho hijo: tres mujeres y cinco hombres, las hembras son maestras...estudiaron con mucho sacrificio...los varones no tienen profesión, se dedicaron a trabajar con pico y pala, como dice uno por aquí". Era una familia mono parental y, al mismo tiempo numerosa; es decir, que estaba estructurada sobre la base de la existencia de una sola figura parental, quien funge en ese momento de protector familiar.... "Yo me crié con Beltrán, él era mi tío, hermano de mi mamá....con su trabajo mantenía a toda su familia, tanto a sus padres, hermanos y sobrinos....no nos dejaba pasar necesidad". Su herencia histórica, aparte de salineros nocturnos, es reconocible en el trabajo cultural de la cerámica, .... "Luisa Pereda, la alfarera, era mi mamá...."Junto a Daría, la mujer de Beltrán estaba su hermana Luisa, la alfarera, la mejor según dicen...ella conocía cual era la arcilla y la tierra buena para fabricar las múcuras, los aripos, los tinajones y tantas otras cosas que sabía hacer con el barro; lo que no conoció nunca fue el torno, tampoco el horno"... "aquí es con las manos todavía, con el puño como se moldean las múcuras" (Para el momento de la investigación, ya Beltrán Pereda había fallecido).

Araya-Refugio de los Salazar: De todos los pueblos que conforman la península, Araya es el más poblado y el de mayor actividad económica. Es tierra árida, seca y muy caliente. Es una población que combina los trabajos de su salina, que existe desde hace varios miles de años, con la pesca artesanal. En el contexto histórico, hablar de Araya como pueblo es hacerlo también de su salina y su castillo. Cada uno de ellos guarda una historia conocida desde la colonia hasta nuestros días. Recuerda esta familia que fue Silvestra Salazar, madre de Dámaso Salazar, quien tuvo que salir de la isla de Coche, estado Nueva Esparta con sus cinco hijos a cuestas hacia la península de Araya. La familia tuvo que realizar un difícil proceso migratorio; fue la familia entera que se vino con sus animales domésticos y hasta con los humildes implementos de trabajo y enseres del hogar. En su seno siempre predominó el tipo de familia nuclear. El hogar en todo momento estuvo representado por la pareja (padre y madre), más todos los hijos (varones y hembras) viviendo bajo un mismo techo. Una de las cualidades que más busca y exige este grupo familiar de las personas, es su honestidad, porque a ellos sus semejantes siempre se la han reconocido. Dice el Cronista del pueblo: "Dámaso fue...un hombre honesto $y$, esa honestidad se la impartió a sus hijos para que fueran hombres de bien....Los Salazar eran gente muy pobres, pero honestos". Trabajaban todos para proveer los gastos que conlleva el hogar. A este respecto dice Benito Salazar, hijo de Dámaso y Petra...."Era la manera de mantener a la familia... a mis hermanos menores, que todavía estaban chiquitos...había que mantener a la familia...mi "pai" y mi hermano Nemesio sacaban la sal y yo la llevaba en la cabeza, en una mara hasta la cima del pillote". Los mayores fueron apoyo y ejemplo para los más pequeños. Vuelve a referir el Cronista..."Dámaso...envió a sus hijos a estudiar...para que una vez graduado 
uno de ellos ayudara a sus otros hermanos... a los menores.. En el nivel educativo de Los Salazar, hay que resaltar que muy a pesar de que los padres nunca aprendieron a leer ni a escribir, sus hijos, menos los dos mayores, se formaron en una escuela institucionalizada. Comenta uno de los vecinos del pueblo..."Dámaso fue un hombre sin estudio... no sabía leer ni escribir...Petra, su mujer, la madre de sus hijos, al igual que él, tampoco sabía leer ni escribir.... el legado dejado por Dámaso Salazar a su familia fue haberlos puesto a estudiar...él siempre inculcó a sus hijos buenas costumbres" (Cuando se llevó a cabo la investigación, ya Dámaso y Petra habían fallecido).

Como se puede observar en las entrevistas, las tres familias con la educación que lograron darles a sus hijos, rompieron con un mito existente por muchos años en los pueblos de la península de Araya y que la señorita Benacerraf recogió en su película: "De todas maneras no hay escogencia posible. Bajo este sol se puede pensar en escoger?; aquí de padre a hijo se es pescador o se es salinero, y así desde siempre". Esto hoy día, no es una realidad. Cada una de las familias tiene dentro de sí una gran cantidad de profesionales en diferentes áreas del saber. También cabe decir, que más allá de las vicisitudes con que se han tropezado y a las cuales han tenido que hacerle frente durante años, la gran mayoría de estos pobladores se sienten aferrados a su lar nativo. Aquí la vida le ofrece un sinnúmero e inmejorables placeres para su deleite. Pese a sus limitados modos de lograr las cosas, manifiestan sus querencias pueblerinas; donde están inmersos sus tristezas, sus alegrías, sus emociones, sus amores, sus anhelos, sus sueños y, porque no decirlo, muestran también su rebeldía $\mathrm{y}$ un rechazo fuerte a determinadas acciones que dañen su modo de vivir.

En innumerables ocasiones, durante el desarrollo de la investigación, se presentaron interrogantes respecto a la forma de vida de estos grupos familiares en el pasado: ¿Cómo fue su modo de vida?: ¿Cómo fue la crianza familiar?; ¿Cuál era su formación a través de la escuela?; ¿Cómo llegaron bajo tanta pobreza a educar en la escuela, cada quien por separado, a algunos de sus miembros; ¿Cómo podían vivir con tantos miembros familiares en casas de una sola habitación?; ¿Cómo pudieron trabajar, durante años, la extracción de la sal de manera primitiva: con las manos. En fin, interrogantes respecto a la sociedad en que vivían. Todas y cada una de estas interrogantes, en su desarrollo, representan contribuciones para comprender el currículum de cada familia en particular y, de todas en general. Por la compenetración que tuvimos con estas familias, nos gustaría rechazar la tendencia de algunos estudios sociológicos a identificar a la clase humilde casi exclusivamente con el vicio, el crimen y la delincuencia juvenil, como si la mayoría de los pobres fueran ladrones, méndigos, rufianes, asesinos o prostitutas. Por supuesto, en nuestras propias experiencias en los tres pueblos y con las tres familias, la mayoría nos parecen seres humanos decentes, justos, valerosos y susceptibles de despertar afectos. El novelista Fielding fue quien escribió: "Los sufrimientos de los pobres son en realidad menos advertidos que sus malas acciones". Bajo los contextos señaladas, nos empeñamos en llevar a cabo la investigación, para extraer de estos grupos familiares sus experiencias vividas y poder plasmarlas como categorías de análisis que nos condujeran hacia la conceptualización del currículum familiar. Así fue como pudimos decir que, el currículum familiar: representa un proceso educativo de orden implícito presente en el escenario en el cual transcurre el quehacer cotidiano de las familias dentro y fuera del hogar. Este proceso educativo del currículum familiar no está escrito, sino que se afianza sobre características propias de la familia, las cuales deben ser tomadas en cuenta por todos y cada uno de los miembros; dando mucha importancia a los valores, actitudes y expectativas de su entorno familiar.

El diseño de un currículum familiar debería llamar la atención no sólo de pedagogos, sino de toda la sociedad y, afianzarse grandemente en la búsqueda de respuestas o líneas de acción, que permitan mejorar la educación con fundamentos epistémicos que vengan de los espacios familiares, a través del dialogo de saberes para tejer encuentros con lo vivido. El mejoramiento de la calidad 
de la educación se ha convertido en un reto que debemos asumir como un deber y un compromiso, comprometiéndonos todos por igual: maestros, familia y sociedad en general.

\section{Antecedentes de la investigación}

En la búsqueda de trabajos previos que tengan coherencia con la temática aquí planteada, no se encontró alguna que hablara del currículum familiar. Sin embargo, se logró encontrar en la publicación "familia y centros escolares", de la Oficina Internacional de Educación de la UNESCO, del profesor Sam Redding (2000), de la Universidad de Philadelphia, una guía donde recopila una síntesis de las investigaciones realizadas sobre la colaboración entre comunidad, familia y los centros escolares. En la introducción expone la importancia del "currículum del hogar" como una esperanza de intervención entre el ámbito familiar y la escuela. Redding identifica una serie de patrones específicos de la vida familiar que contribuyen a la formación del sujeto. Finalmente, argumenta que ese ambiente está relacionado con una serie de normas, actitudes y valores familiares que pueden ser reconstruidos social y culturalmente, y que constituyen lo que se denomina "el currículum del hogar". Rodrigo y Acuña (2001), al señalar que el término hogar deriva del latín "focus"-"hogar" dicen que "es el lugar geográfico donde las personas además de residir, desarrolla, generalmente, sus actividades familiares, sociales y económicas (....) y que luego viene extendido a referirse a la casa misma o a la familia que habita en ella”. De allí se desprende, según mi criterio, que el hogar es la estructura estática, mientras que la familia es una institución en constante accionar de cambio.

\section{Fundamentación teórica}

Dentro del contexto de la investigación y debido a su alcance, consideramos necesario trabajar con cinco (5) componentes teóricos, los cuales nos ayudaron a reforzar los fundamentos epistemológicos del estudio; estos fueron:

- Currículum-Educación-Familia

- Experiencia Narrativa

- Construcción Sociohistórica

- La escuela como continuidad del hogar en la educación en valores

- La familia en su etapa de formación y transición

Estas teorías fueron estudiadas, analizadas y desarrolladas bajo enriquecidos argumentos epistemológicos, ontológicos y axiológicos de diversos y reconocidos autores, entre los cuales se pueden citar:

1.- Currículum: (Grundy, 1994; De Alba,1991; Lundgren, 1992); Educación: (Perera, 1999; Berger \& Luckman, 2006; Leontiev,1978); Familia: (Albornoz, 1995; Santamaría, 2009; Elzo, 2003).

Currículum: Es bien conocido que conceptuar el currículum, en términos generales, es una tarea compleja. Pues, puede dificultarse su construcción por la diversidad de definiciones que al respecto puedan surgir, influenciadas además por la cosmovisión de quienes lo construyen. El currículum, según Shirley Grundy, "se construye en interacción dinámica entre los miembros del grupo-comunidad crítica". Así, el currículum es entendido como una construcción social, donde se consideran las prácticas curriculares como elementos que surgen de circunstancias históricas en determinados medios sociales. Es decir, pensar en el currículum sería pensar en la forma en que interactúan un grupo de personas en determinadas circunstancias. Uno de los aspectos importantes que toma en cuenta Grundy en su praxis curricular es "el entorno social del individuo", ya que este no es igual en todos los casos, todos somos distintos.

El currículum es una construcción social. Es más, la forma y objetivo de esta construcción estarán determinados por intereses humanos fundamentales que suponen conceptos de personas y de su mundo (Grundy, 1994, pp. 19-39). 
Educación: Resulta de interés aclarar que dada la temática tratada en la investigación, es necesario hacer la salvedad de que el concepto sobre educación, en el caso que nos ocupa, se concibe como el proceso multidireccional mediante el cual se adquieren conocimientos, valores, costumbres y formas de actuar. Partiendo de la idea de que la educación no se da siempre en el aula; sino que por su carácter de informal, fundamentalmente se recibe en los ámbitos sociales; es decir, se obtiene progresivamente a lo largo de la vida. Durkheim, 1895/1976 (Citado por Perera, 1999); haciendo mención al aspecto educativo y al aspecto social, dice que:

Educación es la acción ejercida por las generaciones adultas sobre las que no están maduras todavía para la vida social. Tiene por objeto suscitar y desarrollar en el niño un cierto número de estados físicos, intelectuales y morales que reclaman de él, tanto la sociedad política en su conjunto, como el medio social al cual está particularmente destinado (p. 16).

Familia: Como distintos estudios lo han abordado, "cada contexto sociohistórico define un recorte específico de las problemáticas y los actores sociales que son incluidos y estructuran las distintas dimensiones de la vida social, entre ellas la educativa" (Santillán, 2006). De acuerdo con este criterio, la vida social o también llamada, en este caso, socialización, ocurre en el marco de diferentes grupos sociales, entre los que se encuentran la familia, el grupo de amigos y la escuela, ente otros. En el caso de la familia se puede decir que ésta se ubica en el centro de este proceso. La socialización en la familia adquiere valor a través de las acciones que ponen en una relación situacional al núcleo familiar, en este sentido el sujeto va recibiendo un conjunto de signos sociales a partir de las representaciones de su ámbito familiar, y va registrando o adquiriendo una serie de símbolos que le permiten adquirir su propia identidad. Albornoz (1995) señala que:

Es en la familia donde realmente ocurren los más variados aconteceres de la conducta humana.
Amor, violencia, ternura, odio, verdades, mentiras, honestidad, trampa. Es una institución donde ocurre el drama y la tragedia, lo sublime y lo alegre de la existencia (pp. 121-122).

2.- Experiencia Narrativa (Piglia, 2007; Ricoeur, 1987; Mélich, 2002; Folguera, 1994).

Experiencia Narrativa: Dentro de las ciencias sociales, la enseñanza de la historia oral ha ocupado un papel protagónico en la vida de sus narradores. Los hombres a partir de hechos, procesos y fenómenos históricos narran su experiencia en la vida; en la narración de su experiencia se pone de manifiesto su forma de pensar y de vivir. Sus experiencias de vida son una fuente de recursos inagotables para la apropiación de valores. La historia oral (utilización de testimonios directos de aquellos que participaron en la gestión de un proceso histórico) es, en palabras de Paul Thompson, "la más nueva y la más antigua forma de hacer historia". Bajo la experiencia narrativa, se llega a la utilización de testimonios directos de los informantes claves que participan en uno que otro proceso histórico, social y cultural, entre otros. Es lo que podríamos dar en llamar, como dicen algunos autores (Folguera, 1994; Marinas, 1993), "la historia oral". Esa que no está escrita. Aquella que permite profundizar en el análisis de grupos sociales, de esas "gente sin historia"; quienes mediante sus testimonios hacen una reconstrucción narrativa de su pasado.

3.- Construcción sociohistórica (Berger \& Luckman, 1966 y 1991).

Construcción sociohistórica: Se realizó un análisis de la construcción social de las figuras centrales del estudio; a efectos de precisar como incide en la construcción simbólica la vida de estos personajes. Para su desarrollo, la investigación se apoyó en las reflexiones teóricas del construccionismo social o el socio construccionismo.

4.- La escuela como continuidad del hogar en la educación en valores (Odreman, 2008; Jiménez y Valale, 1999; Capella, 1988).

La escuela como continuidad del hogar en la educación en valores: Para iniciar este componente teórico se tiene que reconocer que la familia es el 
primer grupo social que enseña y educa, que transmite a sus integrantes las reglas, normas y conductas. Mediante la interacción del grupo familiar, se da inicio a la formación en valores desde una edad muy temprana. La escuela, bien podríamos decir, viene a servir de complemento a la formación en valores que recibe el sujeto desde su hogar. La formación en valores está determinada por todas y cada una de aquellas acciones que el sujeto aprende, y que son inculcadas por las familias a cada uno de sus integrantes, quienes aprenden a reconocer sus valores y se ajustan a ellos.

5.- La familia en su etapa de formación y transición (Aurenque, 2010).

La familia en su etapa de formación y transición: Para analizar la temática del proceso de formación y transición de cada una de las familias, se realizó un estudio descriptivo, donde se puso de manifiesto cómo ha sido la formación de ellas durante el transcurrir de su existencia. En su etapa de formación, las familias fueron transmitiendo en su proceso formativo sus experiencias de vida, actitudes, valores, formas de trabajo, etcétera, con sinceridad y simplicidad natural, propias de su comunidad. Heidegger traduce Paideia como Bildung (formación). "La Paideia es un Bildung (formación), que atañe a la esencia misma del alma, al fundamento de la condición humana. El término Bildung es un acto formador". Para los fines de formación, Platón utilizaba el término Paideia. De allí, que fue de gran utilidad articular, en este trabajo, la Paideia platoniana con el Bildung heideggeriano.

\section{Fundamentación metodológica}

Trabajamos dentro de los lineamientos del enfoque cualitativo, por cuanto el objeto de estudio tiene la particularidad de estar estrechamente ligado a manifestaciones históricas del quehacer cotidiano de tres familias, a su proceso social, cultural e histórico y a la reflexión de sus valores. En vista de las características que presenta el tema planteado, por estar vinculado al hombre, a la sociedad, a procesos sociales, culturales e históri- cos, fue pertinente utilizar como variantes metodológicas la fenomenología y el enfoque biográfico o historias de vida. Ello con el propósito de tener una mayor cobertura y poder atender mejor los requerimientos que el trabajo exige. ¿Por qué Fenomenología? Se hizo uso de la fenomenología, porque su actuación como variante metodológica de investigación, trata de buscar la forma como nos aparecen las cosas directamente y no de una forma mediatizada. ¿Por qué Historias de Vida? En este caso se utilizó historias de vida, ya que esta herramienta metodológica permitió reconstruir de donde vienen y la formación paulatina de cada una de las familias (Ortiz, Pereda y Salazar) dentro de su contexto social, cultural, histórico y económico que les ha tocado vivir, además de otros hechos que los han marcado.

\section{Análisis y resultados}

La investigación realizada dentro de un espíritu crítico del currículum familiar, consustanciado con los valores, creencias, costumbres, actitudes y otros elementos inmersos en el estudio, condujeron a presentar algunas concepciones y resultados de acuerdo a nuestras propias reflexiones. Para esta comprensión, es menester llevar adelante una descripción articulada de cómo debería ser el recorrido a tomarse en cuenta en su proceso de desarrollo. A continuación, se abordan reflexiones desde la perspectiva del currículum familiar, donde se señalan algunos presupuestos conceptuales: el currículum familiar es confeccionado o parte del entorno familiar, por tanto tiene incidencia sobre sus miembros. Se sirve de la realidad cotidiana vivida en la familia. Se desarrollan prácticas educativas que están implícitas en la dinámica de una comunidad de familia, las cuales se dan universalmente entre adultos, niños y jóvenes, que promueven y participan en espacios interactivos generando procesos de enseñanzas y aprendizaje. Se realizan actividades que están definidas por los valores, creencias y actitudes culturales de los grupos familiares. Imparte conocimientos. Tiene directrices. Generalmente es implícito y en 
ciertas ocasiones oculto. Contribuye a configurar el entorno educativo de los hijos. Se elabora comprendiendo la idiosincrasia de la propia familia, para que no haya discrepancia entre los miembros en su proceso evolutivo. (El currículum familiar evoluciona). Busca integrar a toda la familia. Todos pertenecen al mismo "equipo" (la familia). Todos tienen oportunidades (nivel de inclusión).

El currículum familiar, como fenómeno social al servicio de la sociedad, y por ende de sus integrantes, debe orientar su desarrollo a través de un proceso que guie el comportamiento de cada uno de sus miembros. Igualmente, éste currículum visto como un subsistema del sistema educativo, en su forma más simple, debería desarrollarse dentro del siguiente proceso: Planificación curricular, implementación curricular y evaluación curricular.

Planificación curricular: La planificación de las actividades instruccionales del currículum familiar deben enmarcarse en un contexto de participación, para que cada familia sea protagonista de los hechos con responsabilidades individuales y compartidas, donde se contrasten y contrapongan tipos de interés entre ellas, lo cual permite converger hacia una permanente y mutua realización personal, para bien propio y para la sociedad.

Implementación curricular: Esta es la etapa diseñada para que cada familia ponga en condiciones de funcionamiento los elementos de valor o las experiencias que a ellas le ha tocado vivir y que desean transmitir a sus generaciones futuras.

Evaluación curricular: Para este caso, la evaluación curricular tendría por finalidad constatar los niveles de logros, valores y decidir la conveniencia de mantenerlos o mejorarlos; asumiendo la posición de que hay que valorar la eficiencia e impacto que el currículum ha tenido sobre el grupo familiar. Evaluar un currículum en términos generales, un programa o un proyecto implica un proceso de obtención de información sobre los efectos y valores del mismo.

Es importante tener presente, en primer lugar, que en el proceso de desarrollo del currículum familiar, la fase de planificación abre el horizonte para el diseño curricular que se espera.
A través de dicho diseño, se ubicará anticipadamente en el tiempo las acciones para que los grupos familiares logren sus competencias previstas. En segundo lugar, en la etapa de implementación poner en condiciones de óptimo funcionamiento todo aquello que se necesita para pasar del diseño a la ejecución: normas de conductas, vida cotidiana, experiencias vividas etcétera, e ir generando el desarrollo de las competencias de cada miembro del grupo familiar. Y en tercer lugar, la existencia de un monitoreo y evaluación del quehacer de las familias, con la idea de ejercer sobre ese accionar un control y retroalimentación de las actividades realizadas, con el propósito de asegurar la óptima calidad de la forma de proceder del grupo.

\section{Discusión y conclusiones}

Como idea importante desarrollada en la investigación, debe resaltarse que en la agrupación y descripción de las categorías, que surgieron de las entrevistas y conversatorios, el investigador consideró conveniente integrarlas en tres grandes grupos:

Categorías sociales: Valores Familiares (la cortesía, el respeto, el orden, el aprecio, la responsabilidad, la solidaridad, la honradez, la obediencia, la amistad, el compadrazgo, el parentesco, etcétera); Condiciones Sociales; Oficio/Trabajo; Protección Familiar; Vida Sacrificada; Fidelidad; Socialización; Familia Unida; Tipo de Familia; Entorno Familiar; Felicidad; Condiciones de Trabajo; Ingreso Familiar.

Categorías de desarrollo personal: Autoestima; Experiencia; Precaución; Valoración Personal; Alteridad; Actitud; Formación de la Personalidad; Esperanza; Disciplina; Analfabeta; La Escuela como Ideal.

Categorías idiosincrásicas: Sentido de Arraigo; Querencias Pueblerina; Condición Humana; Saberes de Comunidad; Cultor Popular; Vida Cotidiana; Cultura Popular.

En términos generales nos encontramos con un enfoque de comprensión social sobre la vida de cada una de las familias estudiadas. Cada 
familia llegó a presentar un esquema biográficonarrativo de su vivir cotidiano. La oralidad hecha por cada grupo familiar tuvo su asiento dentro de un giro hermenéutico (participante-investigador). De las reflexiones de cada familia se realizó una perspectiva interpretativa, llegándose a conocer aspectos de su modo de vivir y convivir.

\section{Referencias bibliográficas}

Albornoz, O. (1995). Familia y educación. Manual de autogestión educativa. Caracas: Fundación educación y desarrollo.

Araya. Benacerraf, Margot y Pierre, Seghers (Director). (1958).[Motion Picture] Caracas.

Aurenque, Diana (2010). Heidegger y el "enredo" de la filosofía con la política: Sobre su origen romántico-platónico. Revista De Filosofía, 66, 195-213.

Berger, P. y Luckmann, Thomas (1966 y 1991). La construcción social de la realidad. Buenos Aires: Amorrortu, 15.

Capella, Juan (1988). Formación de valores en la familia (la crisis de los valores). Disponible [on line] en: http://www.waece.org/enciclope$\mathrm{dia} /$ resultado2.php?id=80090 [Consultado: Septiembre 05 - 2009].

De Alba, Alicia (1991). Evaluación curricular. Conformación conceptual del campo. México: UNAM -Universidad Nacional Autónoma de México-.

De Humboldt, A. (1941). Viaje a las regiones equinocciales. Caracas: Biblioteca Venezolana de Cultura.

Elzo, Javier (2003). Texto de la conferencia II conversas pedagógicas. Universidad de Vigo, Campus de Ourense. [on line]. 13/08/2012.

Folguera, P. (1994). Cómo se hace historia oral. Madrid: Eudema.
Grundy, S. (1994). Producto o praxis del curriculum (3 ed.). Madrid: Morata.

Jiménez O, Regina \& Valale M., Lucina (1999). Sociología de la educación. México: Trillas, 13.

Leontiev, A. N. (1978). Actividad, conciencia y personalidad. Argentina: Ciencias del hombre.

Lundgren, Ulf P. (1992). Teoría del currículum y escolarización. Traducción Caridad Clemente Aparicio. Madrid: Edición Morata.

Marinas, J. (1993). La historia oral: Métodos y experiencias. Madrid: Debate.

Mélich, Joan-Carles (2002). Filosofía de la finitud. Barcelona: Herder.

Odreman, N. (2008). Diseño curricular del sistema educativo bolivariano. Diario Últimas Noticias.

Perera, M. (1999). A propósito de las representaciones sociales. Apuntes teóricos, trayectoria y actualidad. La Habana, Cuba: CIPS.

Piglia, R. (2007). El arte de narrar. Universum (Talca), 22(1), 343-348.

Ricoeur, P. (1987). Tiempo y narración. Madrid: Cristiandad.

Rodrigo, M. y Acuña, Marciano (2001). El escenario y el currículo educativo familiar. En: Rodrigo M. J. y Palacios J. (Ed.), Familia y desarrollo humano (pp. 261-276). Madrid: Alianza Editorial.

Redding, Sam (2000). Familia y centros escolares. Compromisos educativos del currículum del hogar. En: UNESCO (Ed.). México: Series prácticas educativas- 2 .

Santamaría, Sandy (2009) Disponible [on line] en: http:/www. monografías.com/trabajos 12/ social. Consultado el 13/08/2012.

Santillán, L. (2006). La construcción social del problema de la educación: Un estudio antropológico desde la perspectiva y los modos de vida de los grupos familiares. Intersecciones en Antropología, 7, 375-386. 


\title{
Las familias entre fines educativos y económicos. El caso de Chile
}

\section{Families between educational and economic ends. The case of Chile}

Propuesta

\author{
José Miguel Olave \\ Universidad de Chile - Chile \\ jose.olave@uchile.cl \\ Claudia Vélez de La Calle \\ Universidad San Buenaventura - Colombia \\ cvelez02@yahoo.es
}

Recibido: 7 de noviembre de 2016 / Aceptado: 15 de diciembre de 2016

\section{Resumen}

Este artículo problematiza la privatización de la educación en el contexto latinoamericano de mediados del siglo $X X$, cuando los Estados promueven la idea del capital humano por medio del crecimiento de sus sistemas educativos y la productividad como una razón de Estado. Las familias del continente creen en la promesa que les asegura que por medio del acceso a la educación se encontrarán la ansiada movilidad social. Confirmamos que para el inicio del siglo XXl el cumplimiento de esta promesa recae únicamente en los hombros de las familias quedando estas entregadas al mercado.

Sostenemos nuestra argumentación bajo el análisis de las diversas normativas que afectan al sistema educativo chileno en el periodo que va de 1860 a 2008. En ellas observamos particularmente la normativa en Evaluación Educativa, que va marcando este tránsito como un mecanismo de gobierno de la población, regulando los flujos sociales, traspasando, por medio de herramientas del mercado, la responsabilidad a las familias para escoger entre fines formativos y resultados académicos.

Finalmente concluimos con algunos alcances producto de este fenómeno que obliga a las familias a una doble renuncia: la renuncia económica que impone la inversión en educación por sobre otros proyectos alternativos; y la renuncia que implica dejar sus propias formas significativas de relacionarse al interior de las familias, por la adopción de una cultura del éxito escolar. Esta elección reafirma la matriz de gobierno colonial instalada sobre la familia y la vez la convierte en una unidad productiva eficiente sobre una idea de mérito neoliberal transmitido por medio de las evaluaciones.

Descriptores: Sociedad, cultura, familia, Chile, educación, evaluación educativa, decolonial.

\begin{abstract}
This article is part of the process of problematization on the privatization of education in Latin America with a special focus on the Chilean case. It analyzes elements of the Latin American context in the middle of the 20th century when States promote the idea of human capital through the growth of their education systems and productivity as a State reason. The families of the continent grow the promise that through access to education the long-awaited social mobility will be achieved. We confirm that at the beginning of the 2 I st century this promise falls only on the shoulders of families being left to the market.

We hold our argument under the analysis of various regulations affecting the Chilean educational
\end{abstract}

Forma sugerida de citar: Olave, José Miguel \& Vélez de la Calle, Claudia (2017). Las familias entre fines educativos y económicos. El caso de Chile. Alteridad, 12(1), pp. 43-54. 
system in the period between I 860 and 2008. In these we observe in particular the regulations in Educational Evaluation, which is marking this transit as a mechanism of government of the population, regulating social flows, transferring through market tools, responsibility to families to choose between training purposes and academic results.

Finally we conclude with some scope resulting from this phenomenon that forces the families to a double resignation. The economic waiver imposed by investment in education over other alternative projects. And the renunciation of leaving their own significant ways of relating to the interior of families, by adopting a culture of school success. This election reaffirms the matrix of colonial government installed on the family and at the same time makes it an efficient productive unit on an idea of neoliberal merit transmitted through assessment.

Keywords: Society, culture, education, family, Chile, assessment educational, decolonial.

alimentada por un legítimo deseo de crear una buena vida para sus seres queridos.

En el caso de Latinoamérica tal promesa de superación por medio de la educación se vuelve un relato aceptado pero vaciado de realidad, dada la evidente brecha de desigualdad y concentración económica que cubre al mundo globalizado y que, en particular, se muestra con cierta indolencia en la realidad latinoamericana. Según cifras de CEPAL $(2011,2013)$ el nivel de desigualdad de América Latina y El Caribe es bastante alarmante. Se plantea que el ingreso de la quinta parte más rica es 19,7 veces mayor que el ingreso del $20 \%$ más pobre; en este contexto, una de cada tres personas es pobre, con variaciones que van desde países donde los pobres superan el 50\% de la población como Bolivia, Paraguay, Honduras o Guatemala, a otros en los que el porcentaje de pobres es inferior al 20\% como Costa Rica, Uruguay y Chile.

Adelantando el desarrollo del artículo, afirmamos que esta aspiración de superación vía acceso a la educación, solo ha provocado una ampliación del mercado educativo y ha dejado sobre los hombros de las familias los costos de tan preciada promesa. Las familias fueron invitadas a integrarse al deseo de cobertura en educación primaria y secundaria, y en la actualidad también lo hacen como demandantes de educación terciaria; demanda bien recibida por el sistema privado educativo, dado que de esta manera se consolida un creciente mercado a partir de la reinstitucionalización de las Universidades (Bernasconi y 
Fernández, 2012) para cubrir la demanda. Este problema tiene una raíz profunda en la neoliberalización de los sistemas educativos, que aprovechan este envión de la demanda, quedando el grueso de la inversión en manos de las familias, tal cual lo indica el reporte Panorama Educación Indicadores de la OCDE 2014.

En este informe se señala que la inversión en educación es altamente rentable (nótese el lenguaje). Para un hombre su inversión en educación tendría un retorno económico de US 100 000. No sería lo mismo para una mujer ya que su retorno sería de US 60000 , lo cual ya constituye una brecha de desigualdad. Además se afirma que:

El nivel educativo influye en las oportunidades de trabajo y los ingresos, que a su vez afectan al nivel de salud. La educación puede también mejorar los conocimientos sobre cómo vivir una vida más saludable, lo que lleva a mejores elecciones del uso del tiempo y de los bienes que afectan la salud (OCDE, 2014, p. 35).

Lo que no dice el informe es que en países como los de Latinoamérica, los niveles de precarización de los trabajos han aumentado y que los servicios, como educación, vivienda y salud, no son subsidiados por el Estado, es decir, son las personas, individualmente consideradas, las que tienen que pagarlos de sus bolsillos.

Este reporte sitúa a Chile como el país con mayor porcentaje de gasto privado en todos los niveles educativos dentro de los países miembros de esta organización económica: un $40 \%$ del gasto en educación proviene de las familias, cifra que se dispara al $76 \%$ en la educación terciaria (OCDE, 2014b). Asimismo, esta política de desresponsabilización de los Estados cae sobre los sectores más sensibles de la vida social y económica. Esta es parte de una política que tiene como consigna, menos Estado y más mercado, afectando los ámbitos básicos de la vida de la población: salud, vivienda, transporte público, pensiones de vejez, entre otros. En Chile, en el caso de la educación, se genera una mercado educativo multisegmentado, ya que no todos pueden pagar los colegios privados, es decir, quien tiene más puede pagar más, quien tiene poco, accede a poco y quien tiene menos que poco, se va a la educación pública

Se observa en consecuencia un panorama desregulado en el mercado educativo o, más bien, una suerte de aplicación maximizada de la "mano invisible del mercado", que deja a Chile no solo como el país con el mayor gasto privado en educación, sino además como uno de los países con mayor desigualdad social y económica (OCDE, 2013; CEPAL, 2011). Chile, según el último informe de desigualdad emitido por la OCDE (2014a) es el país con mayor índice de desigualdad de los países miembros de esta organización económica internacional con un 0,53 en el coeficiente GINI, donde el valor 0 indica mayor igualdad y 1 es el valor de mayor desigualdad 1 .

Todo lo anterior, no solo genera inequidad en relación a la posibilidad de pago de la educación, sino además genera una suerte de ethos social de la competencia, reafirmando la idea de que solo con virtudes individuales se puede asegurar el anhelado progreso social y económico, confirmando el sentido del mérito neoliberal.

La comprensión de la dimensión de nuestras preocupaciones la trabajaremos en un primer apartado donde situaremos la emergencia de esta promesa de la educación como vía de mejoramiento que marca la vida de las familias en Latinoamérica. En segundo lugar, buscaremos en la relación entre educación y evaluación un camino metodológico para explorar las normativas en el ámbito educativo y, en particular, sus reglamentos de evaluación, que son los que orientan la conducción de las familias hasta el momento actual, en el que se encuentran abandonadas a la suerte del mercado. Finalmente ofreceremos reflexiones sobre las implicancias de este proceso privatizador.

Ver más en http://data.oecd.org/inequality/income-inequality.htm 


\section{Fundamentación: educación latinoamericana, una promesa heredada}

Para comprender mejor la emergencia de este relato sociocultural que hemos llamado "La promesa latinoamericana", se debe mirar a la generación de los sesenta quienes crecen con la América Latina del proyecto desarrollista tardío que impulsa Estados Unidos (1961) en la región, el cual propuso un programa de ayuda económica y social denominado "Alianza para el Progreso", como respuesta a la revolución cubana de corte izquierdista; este consideraba mejorar las condiciones de vida de la población y se basaba en un riguroso sistema de planificación social:

Ya en la década de los sesenta y extendiéndose a lo largo de la siguiente, se crea y se difunde en el contexto de Estados Unidos y Europa, el pensamiento de la teoría del capital humano que, sin duda, marca las prioridades de la época. Para decirlo muy sencillamente, esta teoría intenta vincular la inversión en educación y su rendimiento, definiendo a la educación como un servicio con valor económico (Carlino, 1999, p.51).

Dado este contexto político, económico y social, en la Conferencia de Punta del Este (1961) los delegados de todos los países miembros de la Organización de Estados Americanos (OEA) acuerdan su adhesión a dicho plan (Alianza para el Progreso); excluyéndose Cuba, quien se niega a firmar el pacto vislumbrando el condicionamiento geopolítico que enmarca la situación de Latinoamérica hasta la época actual.

La política económica comienza a copar todos los espacios de la vida cotidiana y se pone en marcha una política de regulación nacional promovida desde un Estado que aplica estrategias de conducción cimentadas en principios regulatorios modernos (De Sousa, 2011, 2013), marcados por la dualidad totalidad/individualidad que se aplican en materia económica. Es la promoción del Estado asistencialista o benefactor (totalidad), quien se asume como motor de inversión creando estrategias de pleno empleo, impulsando la industria nacional, los servicios y la administración estatal, mientras que los ciudadanos (individualidad) que participan como trabajadores en el mercado también ahora lo harán como consumidores. Se produce un régimen de verdad reconocido por los ciudadanos, que aceptan la promesa moderna que su integración al mundo del trabajo les permitirá superar la desigualdad económica, y de que por medio de la educación y las políticas sociales del Estado, podrán integrarse, gracias a sus esfuerzos familiares, a esta pequeña totalidad construida.

La escuela asumirá el desafío de superar la desigualdad y la exclusión, consolidándose como la mayor institución regulatoria del Estado. Esta situación se expresa en la reforma de los años sesenta, bajo el Decreto 27.952 del año 1965, reforma que será frenada por las dictaduras latinoamericanas. Es tiempo de recesión económica, violencia política y dictaduras en el Cono Sur, incluyendo por cierto la dictadura en Chile de Pinochet (1973-1990). Es tiempo del viraje hacia las políticas neoliberales, entonces, la promesa Latinoamericana tendrá un condimento distinto, aunque manteniendo su sello original, la fe en la educación. Lo distintivo será que ahora los Estados latinoamericanos van a asumir un rol de promotores de la oferta educativa, tal como se define en la Constitución Política del Estado de Chile de 1980, ${ }^{2}$ donde el Estado debe garantizar el derecho a la enseñanza, es decir, hacer florecer el mercado educativo. Cambia el papel que asumen los Estados: desde un Estado providencial (Santos, 2003) que asume la dirección del proyecto desarrollista, a un Estado que media entre el mercado y los ciudadanos.

Para fines del siglo XX las orientaciones emanadas por organizaciones de distinta naturaleza tendrán un poderoso ascendiente en el diseño de políticas educativas tanto en Chile como en el conjunto de los países de Latinoamérica.

2 Ver más en http://muw.leychile.cl/Navegar?idNorma $=242302$ 
Un ejemplo de esta política regional es el informe Transformación productiva con equidad (CEPALUNESCO, 1990) y el documento Educación y conocimiento: eje de la transformación productiva con equidad (CEPAL-UNESCO, 1992), que expresan la relación entre sistema educativo y sistema productivo, dejando ver un marcado tono economicista para entender el fenómeno educativo como un proceso que debe maximizar sus resultados al menor costo posible.

Luego de la noche dictatorial de los ochenta (en Argentina, Uruguay, Chile y Brasil), llega un tiempo de grandes acuerdos en los países de la región para consolidar sus sistemas democráticos a través de la inversión en sus sistemas educativos. Es un período de plena influencia neoliberal en la política educativa que deja ver la relación insoslayable entre la economía política de financiamiento educativo y las vinculaciones entre educación y rendición de cuentas. En el caso de Chile, la dictadura de Pinochet termina con un proceso de gran movilización social que provoca que en 1988 se realice un plebiscito que da paso al retorno a la democracia. En marzo de 1990, el Dictador no entrega el poder sin antes promologar la última de las leyes llamadas de "amarre", la Ley Orgánica Constitucional de Educación (LOCE, 1990) promulgada un día antes del traspaso de mando.

Resumiendo este apartado, la promesa latinoamericana tiene su emergencia en las décadas de los cincuenta y sesenta del siglo pasado junto al proyecto desarrollista asociado a la idea del "capital humano", propia de la estrategia hegemónica de los Estados Unidos y Europa, para consolidar su control geopolítico en Latinoamérica. Más adelante, se instala la confianza en que el mercado y su productividad se basan en una racionalidad económica que los Estados recogerán a pie firme, desarrollando una política económica aplicada a la vida de la población, impactando con especial precisión en el campo educativo, asociándolo a la veleidosa idea de la promoción social para quienes participen de esta promesa.

\section{Metodología: la evaluación en una promesa privatizada}

Tal apuesta, en su inicio, es promovida por los Estados latinoamericanos a partir de estrategias de gobierno de la población, asumiendo un papel de corresponsabilidad junto a las familias. Su objeto de gobierno será la productividad de la población. Sin duda, podemos hablar aquí con propiedad de una conducción biopolítica (Foucault 2004, 2005) que a partir de estrategias de control sobre la población se intensifica, visibilizando la productividad como una razón de Estado. El fin de siglo estuvo marcado por el abandono por parte del Estado de su rol promotor de esta estrategia, abriendo espacio a otras estrategias más invisibles para imponer la relación entre el mercado, los sistemas educativos y las familias. En este sentido, se remarcan los costos económicos que esta tozuda oferta implica, aspectos que han sido suficientemente estudiados desde los ámbitos de la reproducción, la segregación y la desigualdad; abordajes que han silenciado otros costos que las familias deben pagar.

Con el fin de analizar el fenómeno de privatización que afecta al sistema educativo chileno, el que incide directamente en las familias, la metodología que utilizaremos revisa las principales normativas desde el inicio de la República de Chile en 1860 hasta el año 2008 (ver Tabla Anexo 1) con objeto de ilustrar cómo estas normativas afectan al sistema educativo chileno. Este análisis documental de primera fuente es combinado con la revisión de literatura de autoras que han avanzado en este camino. En específico, se investiga sobre las disposiciones en evaluación que van agenciando las decisiones de las familias por el acceso a un determinado nivel educativo, gobernando sus vidas por medio del acceso o no, a distintos niveles educativos, ya que entendemos, al igual que la autora Teresa Flórez (2012), que:

Hasta hoy el poder de la evaluación, refleja su capacidad para hacer que todo el sistema educativo se mueva en una dirección específica. Hay 
mucho que perder y que ganar como para ignorarla, por lo que más allá de cualquier principio o ideal pedagógico y, por lo tanto, de cualquier idea de sociedad que se quiera desarrollar, es la evaluación de alto riesgo la que define las reglas para la práctica y la que decide, finalmente, los destinos de nuestra sociedad (p. 84).

En Chile, al igual que en otros países de Latinoamérica, la educación previa a la Independencia fue mayormente una preocupación de las organizaciones religiosas. Con el paso de la Independencia a las repúblicas emergentes, el control de la educación por parte de las nuevas naciones se constituye en un efecto legitimador. El naciente Estado promovió la creación de establecimientos educativos que imprimieran los valores de la nueva Nación, como el Instituto Nacional $(1813)^{3}$ creado por José Miguel Carrera, luego de la primera Junta de Gobierno celebrada en 1810. La idea era crear un sistema educativo que fomentara los idearios de la naciente Nación chilena y alojara a la elite criolla de la época. Este establecimiento es el primer liceo chileno público de varones y, hasta hoy, es quien lidera los rankings de efectividad para entrar a la universidad y, por lo tanto, acceder a él también constituye el principal objetivo para las familias, con vistas a la promoción social. Es uno de los liceos a los que en Chile se les llama coloquialmente "emblemáticos" por su larga tradición pública y republicana.

El control de la educación por parte del Estado se llevó a cabo a través de estas instituciones, quedando las organizaciones educativas religiosas supeditadas a rendir examen de validación ante comisiones evaluadoras representantes del sistema estatal, tarea que le fue encomendada a la naciente Universidad de Chile (1942) ${ }^{4}$. La fundación de la Universidad de Chile en 1842 es, sin duda alguna, uno de los hitos más significativos de la naciente República. Representa en sí uno de los más claros actos de autodeterminación,

\footnotetext{
Ver más en http://institutonacional.cl/el-instituto/

4 Ver más en http://uww.uchile.cl/portal/presentacion/historia/ resena-historica/4727/una-mirada-a-la-historia
}

al situar en el saber y la enseñanza pública el eje articulador del país que comienza a construirse. Existía consenso entre los intelectuales de la época de que un Estado - aun no estando separado de la Iglesia como en ese entonces- debía velar por el progreso y la promoción de valores universales. Desde un comienzo la Universidad de Chile se define a sí misma como garante de la cultura clásica, humanista y secular.

A partir de la Ley Orgánica para la Instrucción Pública de 1860, se comenzó a regular el sistema educativo en dos segmentos, educación primaria y educación secundaria, con este instrumento normativo. Se ordena el flujo educativo que tendría la población chilena, distribuyéndola funcionalmente. A partir de los exámenes, un tipo de estudiante terminaría sus estudios en la primaria para incorporarse a las tareas productivas; los que logran pasar el examen, principalmente los hijos de las elites, podrían seguir estudios para luego optar por una de las profesiones liberales para el servicio del Estado naciente. Se observa que para el nivel primario su énfasis era la educación moral y la alfabetización de la población. El segundo nivel se componía de las escuelas preparatorias, escuelas secundarias e instituciones de la educación superior -dependientes de la recién creada Universidad de Chile- dirigidas a la formación de profesionales y a la elite burocrática. El tono que marca este periodo es la especial preocupación por la educación secundaria, por el contrario, se observa un cierto desprecio por la educación primaria, entendida como la educación de las clases populares. Se imprime en ella el tono civilizatorio ilustrado que identifica esta época en Latinoamérica:

La única autoridad que tienen los docentes es sobre los estudiantes, quienes son descritos frecuentemente como si se tratara de salvajes provenientes de familias incivilizadas, en el contexto de una época en que la disciplina, el silencio y el orden eran considerados parte fundamental de la educación (Flórez, 2012, p. 11).

En síntesis se observa una regulación de orientación centralizada y verticalista, que por 
medio de sus instituciones regula y controla los flujos de la sociedad. Además, este periodo inicial se caracteriza por un marcado afán civilizatorio y de baja consideración pedagógica.

En un primer momento, en la primera mitad del siglo XX, en Chile se percibe la influencia de las ideas educativas representantes de la "escuela nueva", centrada en las experiencias educativas de los niños y niñas, lo que implica mirar la relación entre profesor y estudiantes de otra manera; intención que se observa en la Ley de Obligatoriedad de la Educación Primaria (Ley $3.654,1920$ ), además de la reforma educativa de 1928 y 1929, principalmente promovida por los docentes de la época. En este periodo los reglamentos en evaluación se caracterizan por mantener una suerte de bajo control académico para la educación primaria (Decreto 3060, 1929; Circular No 77, 1934), no así para la educación segundaria (Decreto 6087, 1927; Decreto 2545, 1929; Decreto 2944, 1944; Decreto 1469, 1949 y Decreto 842, $19595)$. En estas normativas se observa un avance al sugerir que los exámenes no solo sean al final de cada periodo escolar para evitar que el juicio evaluativo sea reservado a un solo examen, entrando en vigencia la idea de un promedio de calificaciones. Para regular el acceso a la educación terciaria, se estableció en 1929 un solo examen administrado por la Universidad de Chile, el llamado examen de "Bachillerato", como un requisito de ingreso a todas las universidades. El Estado por medio de los exámenes busca asegurar procesos de socialización, remarcando la responsabilidad individual en el proceso educativo:

Debido a las prácticas de evaluación más objetivas, los resultados se conectaron cada vez más a título personal, las actitudes de los individuos y mérito, y los alumnos eran vistos cada vez más como responsables de su propio éxito o fracaso (Gysling, 2015, p. 6).

5 Para mayor profundidad, revisar el detalle de la normativa en evaluación en el trabajo realizado por Gysling (2015), donde se agrupan normativas y se las ordenadas bajo una estricta mirada crítica.
Un segundo momento en el siglo XX es el ingreso del discurso del capital humano, recogiendo la demanda por mayor cobertura y eficiencia. Se lleva a cabo la reforma educativa (1967) que va a administrar estos intereses agregando dos años de escolaridad obligatoria (de seis se pasa a ocho años de obligatoriedad) y nuevas materias escolares, reforzando un currículo escolar en el área de ciencias naturales y matemáticas. Asimismo, se introducen las técnicas de evaluación por selección múltiple y de esta manera se implementará en Chile una prueba única para seleccionar el ingreso a las universidades. La llamada Prueba de Aptitud Académica (PAA) fue entregada para su aplicación a la Universidad de Chile, la cual evaluaba las aptitudes verbales y matemáticas de los estudiantes siguiendo el modelo internacional SAT (por sus siglas en inglés, Test de Aptitudes Escolares) muy difundido en Estados Unidos e Inglaterra, que se utiliza para predecir resultados en la vida académica futura (Stobart, 2010). Este modelo supone que las aptitudes o capacidades se pueden desarrollar en un ambiente educativo donde el docente resulta un habilitador de estas capacidades, por lo tanto, se aleja del modelo innatista promovido por los test de inteligencia que suponen medir el coeficiente intelectual fijo. Se incorporó la evaluación criterial ${ }^{6}$ focalizada en materias escolares excluyéndose aspectos de conducta y de personalidad.

En materia de evaluación la normativa tendrá algunas innovaciones asociadas a la instalación de la reforma educativa de 1967 y que se expresan en el Decreto 11.207, 1967; Decreto 6.859, 1968; Decreto 7056, 1967 y el Decreto 192, 19727). Entre las principales modificaciones, se encuentra la elaboración de una prueba local, la cual será diseñada por grupos de maestros de distintas escuelas. La promoción estaba ligada solo a

6 La evaluación criterial corresponde a la pedagogía de dominio o mastery learning relacionada con la pedagogía por objetivos y el conductismo. Esta surge vinculada a la difusión de la enseñanza programada y el auge de los objetivos conductuales.

7 Ver mayor detalle en Gysling (2015). 
aspectos académicos siendo excluidos elementos de comportamiento moral.

Estas reformas de índole democratizador son interrumpidas por la irrupción de la dictadura de Pinochet (1973-1990) que se caracterizó por una gran represión a los movimientos y organizaciones sociales populares y de las clases medias. Se favorece el control de los contenidos y se le quita poder a los docentes, organizados antes en Departamentos, para generar sus pruebas locales y estas son reemplazadas por las pruebas globales que ahora son de responsabilidad individual de cada docente (Decreto supremo 164, 1974; 440, $1975 ; 2.038,1978 ; 2.088,19798)$. Específicamente el Decreto 2038, 1978, que aprueba el Reglamento de evaluación y promoción escolar para estudiantes de Educación General Básica (primaria) y Educación Media (segundaria), en su artículo número 1 de disposiciones generales, letra $\mathrm{C}$, establece:

Al término del año escolar, se aplicará una Prueba Global escrita a los estudiantes de $5^{\circ} \mathrm{a}$ $8^{\circ}$ año de Educación General Básica, en cada una de las asignaturas del respectivo Plan de Estudios (...). La prueba Global será elaborada por el respectivo profesor, conforme a los criterios establecidos en los Departamentos de asignaturas, correspondientes (Decreto Ley, 2038, www.Leychile.cl).

De acuerdo a esta normativa, se pierde la posibilidad de generar un juicio compartido en evaluación por parte de distintos maestros, por el contrario, se instala un juicio evaluativo individual, práctica evaluativa que responsabilizaría en mayor medida a estudiantes y profesores de sus éxitos y fracasos. Asimismo en este periodo, se debe mencionar que a la PAA creada en la etapa anterior (1975), se le agregan otras pruebas de conocimientos específicos, volviendo a la postura tradicional del dominio académico por sobre las aptitudes, lo cual ejerce mayor presión en el rendimiento individual para acceder a la universidad.

8 Ver http://www.leychile.cl/Navegar?idNorma $=251386$
En un tercer momento, a fines del siglo XX, se intensificará la política de apertura al mercado de abierta influencia neoliberal (Ruiz, 2010) y la toma de posición de un Estado Evaluador (Elliot, 2002), promotor de las evaluaciones nacionales estandarizadas, y que partir de ellas genera un complejo de incentivos económico, pudiendo comparar a las escuelas por medio de los resultados de este tipo de pruebas. El tiempo del "Estado Evaluador" abre el paso a una administración geopolítica de los resultados académicos, donde Chile y los demás Estados de Latinoamérica participan como condición de entrada a determinados mercados. En esta lógica, como mecanismo adicional, en Chile se fomenta el emprendimiento de escuelas particulares impulsadas por el financiamiento a la demanda o sistema de "voucher", nombre que se le da en Chile al subsidio a la demanda. Este sistema consiste en que a cada estudiante se le asigna un valor, que el Estado pagará a los establecimientos públicos y particulares subvencionados. Este sistema también se ocupa para movilizar el mercado de la salud o de la construcción, subsidiando a las familias que desean comprar su primera vivienda. Los "voucher" serán el mecanismo que moverá la competencia entre escuelas tratando de capturar la matrícula. Los estudiantes se convierten, así, en un valor que se agrega al negocio de la educación. La llamada prueba nacional SIMCE -sistema de medición nacional basado en estándares- será el índice que los padres podrán seguir para invertir en educación. Asimismo las escuelas competirán por capturar a los estudiantes y hacer cobro de los "voucher".

Finalmente, en una última normativa, la Ley Orgánica Constitucional de Enseñanza (LOCE, 1990) se contempla que los resultados de las pruebas nacionales se puedan publicar, impulsando un perverso sistema de competencia entre escuelas.

En un cuarto momento, al inicio del siglo XXI, la intensidad de las pruebas estandarizadas aumenta. En materia de evaluación Chile se integra prontamente a este sistema de control geopo- 
lítico de los resultados, participando en las pruebas Pisa, Timss y en el sistema de evaluaciones regionales promovido por OREALC/UNESCO. Pero, sin lugar a dudas, la característica principal del período es la ampliación en número y niveles de las pruebas nacionales. Este sistema resulta ser de multipropósito, de allí la evidente tensión entre los fines pedagógicos y su marcada funcionalidad como mecanismo para la rendición de cuentas. La ley de Garantía de Calidad (Ley 20.529, 2011) le concede al Estado la capacidad de intervenir e incluso cerrar las escuelas, dado un sistema de clasificación de escuelas basado principalmente en los resultados obtenidos en la prueba SIMCE.

Paralelamente, se aprueba una nueva normativa, la Subvención Escolar Preferencial ${ }^{9}$ (Ley, $\mathrm{N}^{\circ} 20.248,2008$ ), que asigna un nuevo subsidio a cambio de resultados académicos. La Ley de Subvención Especial Preferencia (SEP) se establece como una medida de equidad con el fin de entregar más recursos por medio del sistema, una vez más, del subsidio a la demanda ("voucher"). La mayor asignación se entrega a los estudiantes de sectores con mayor vulnerabilidad llamados estudiantes "prioritarios" una sutileza para categorizar la pobreza. En 2011 se integran cambios a esta ley, subiendo en un $21 \%$ el bono de asignación económica por estudiantes, a cambio de que las escuelas diseñen un plan de acción de mejora de resultados académicos llamado Plan de Mejoramiento Educativo (PME). De esta manera se asocian resultados a un modelo de gestión de recursos. Con esto se amarra el funcionamiento y gestión de las escuelas a los resultados alcanzados en este tipo de pruebas. Todos estos aspectos van quitando autonomía a las escuelas y otorgando mayor poder a las pruebas estandarizadas que asumen el control del sistema educativo.

9 Ver más en http://portales.mineduc.cl/usuarios/convivencia escolar/doc/201 103050058380.Anexo\%201\%20Resumen\%20 Ley\%20SEP.pdf

\section{Análisis y discusión: reflexiones del proceso privatizador}

Hemos descrito hasta aquí el centro de una problemática compleja situando a las familias frente a un problema social que tensiona finalidades educativas versus finalidades económicas. Hemos mostrado como la promesa de movilidad social a través de la educación ha sido incumplida, por medio de una política de privatización educativa donde se combinan estrategias de privatización abierta e interna (Bellei, 2015).

Esta proposición supera la definición binaria entre educación pública y privada, propuesta por UNESCO, la que entiende que "escuela pública" se refiere a las instituciones que son operadas por autoridades del Estado, es decir el control es realizado por autoridades públicas; empero, al interior de las instituciones se adquiere un modo de funcionamiento privado, gracias a la entrada de sistemas de administración y gerenciamiento privado. Formas de planificar la enseñanza y las evaluaciones son realizadas por instituciones privadas. En este ejercicio la escuela pública busca asimilarse a la educación privada, creándose una competencia abiertamente desleal. En definitiva, este es un fenómeno que debe ser estudiado con mayor precisión, dado que:

En rigor no se trata de una privatización del sistema de educación pública, sino de una privatización del sistema educacional, por cuanto incrementa la presencia de la educación privada sin que esto implique necesariamente una transformación de las escuelas públicas existentes (Bellei, 2015, p. 65).

Este silencioso proceso es preocupante no solo porque ha modificado las relaciones entre lo que se entiende como "lo público" y "lo privado" -aquello que tiene su sentido común afianzado en la comunidad, diferente de aquello que responderá en última instancia, a intereses particulares -. Esta relación de privatización silenciosa, tensiona al sistema, favoreciendo a las escuelas privadas ya que además de tener el derecho de seleccionar y 
discriminar a sus estudiantes, su modo de funcionar está orientado a un modelo de negocios que buscar generar lucro, quedando las familias en medio de estas operaciones.

Observamos cómo la normativa en evaluación convertida en un cuchillo que agranda la herida apoya este proceso económico, construyendo por medio de sus prácticas de exclusión y segregación, subjetividades vinculadas al mercado y la competencia. De fondo, las prácticas evaluativas ponen el foco en la producción de una subjetividad de mercado, produciendo modelo de matriz colonial, que utiliza a la familia como objeto de gobierno clave en los procesos de estructuración social:

Podemos concluir entonces que "el huérfano" por excelencia de la pedagogía de la dominación no es solo el niño, sino el niño de la periferia, el huérfano colonial, neocolonial, el mestizo latinoamericano al que le introyectan gato (cultura imperial) por liebre (naturaleza humana) (Dussel, 1980, pp. 38-39).

No solo son los estudiantes, en general, más allá de su condición de niñez y juventud, los que sufren esta deformación de horizontes educativos, son también los docentes que particularmente son instrumentalizados para que este modelo de dominación funcione con mayor encubrimiento. Nuestra cultura latinoamericana es oscurecida, negada por este momento ontológico basado en un relato inventado en la Modernidad, la vieja promesa latinoamericana.

El problema de la evaluación va cruzando todos estos temas casi invisiblemente, coloniza todas las esferas de la vida cotidiana, interiorizando un modo de ser individual que penetra la estructura de las familias, moviéndolas a aceptar este modelo individualizante que los responsabiliza de sus resultados académicos. En un principio se hace parte de nuestros cuerpos dóciles, por medio de las múltiples prácticas evaluativas dispuestas en la escuela; más tarde, en el afuera de la sociedad nos controla como dispositivo biopolítico, ya que es por medio de esta técnica de poder gobierna las decisiones que la familia deberá tomar, ejerciendo un control a distancia sobre la vida.

Este control interno, implicado en nuestra estructuración colonial resulta ser inmanente a la forma en que nos reconocemos, a nuestra forma de habitar, conocer y situarnos frente al mundo y dentro de él, es aquello que los autores del enfoque decolonial refieren como "colonialidad del poder" (Restrepo y Rojas, 2010) que opera en cada uno de los espacios, ámbitos, dimensiones materiales y simbólicas de la sociedad.

Hemos destacado un proceso que, por medio de normativas y reglamentos, ha configurado un fenómeno que ha dejado en la orfandad del mercado a las familias, y que pese a ello aún mantienen la esperanza de promoción social. Sin embargo, esta situación no agota el problema, ya que la entrada a la escuela de un niño o niña implica una renuncia a aquello que ha constituido su soporte cultural. Todo el sistema de pensamiento social que portan los estudiantes producto de su socialización primaria entra en conflicto con los códigos culturales que sustenta la escuela, lo que es evidente al observar lo dificultoso que se hace para los estudiantes avanzar en el entretejido cultural del cual está hecha la escuela. Para un estudiante de origen socioeconómico popular, este proceso de renuncia es aún más radical, ya que posee menos herramientas que un estudiante con mayor capital cultural para enfrentar este proceso de asimilación cultural, entonces su mejor manera de adaptarse es sacarse buenas calificaciones, que lo habiliten en el flujo de los méritos individuales y que lo ayude a igualarse entre los iguales.

Vemos este fenómeno no solo desde el prisma económico, sino que lo reconocemos también como un problema cultural, ya que la escuela es impensable fuera de procesos civilizatorios $y$, a la vez, es impensable sin calificaciones, estas últimas son el mecanismo de agenciamiento social y cultural que despoja a las familias de sus formas culturales, alentados por la idea de progreso, que siempre está delante de sus ojos con los brillos de un neón que no deja de encandilar. Es hora ya de pensar, la escuela fuera de estas elecciones de 
mercado, de manera tal que prometa otros horizontes de justicia.

\section{Referencias bibliográficas}

Bellei, C. (2015). El gran experimento. Santiago: LOM. Carlino, F. R. (1999). La evaluación educacional. Historia, problemas y propuestas. Buenos Aires: Aique editorial.

CEPAL (2011). Informe estadístico 2011. (2013). Informe estadístico 2014.

CEPAL-UNESCO (1990). Transformación productiva con equidad. Santiago: UNESCO.

(1992). Educación y conocimiento: eje de la transformación productiva con equidad. Santiago: UNESCO.

De Sousa Santos, B. (2011). Epistemologías del Sur. Utopía y Praxis Latinoamericana. Revista Internacional de Filosofía Iberoamericana $y$ Teoría Social, 16(54), 17-39.

(2013). Descolonizar el saber, reinventar el poder. Santiago: LOM.

Dussel, E. (1980). La pedagógica latinoamericana. Red de Bibliotecas Virtuales de CLACSO. Recuperado de http://biblioteca.clacso.edu.ar

Elliot, J. (2002). The Paradox of Educational Reform in the Evaluatory State: Implications for Teacher Education. Recuperado de http://www.researchgate.net/publication/225971650.

Fernández, D. E. \& Bernasconi, A. (2012). Elementos conceptuales para el análisis organizacional de universidades en contextos de mercado. Innovar, 22(46), 87-98.

Flórez, T. (2011). La importancia de una perspectiva histórica para el análisis de las políticas educativas (o de cómo llevamos haciendo lo mismo durante mucho tiempo). Revista Historia 2.0, Conocimiento histórico en clave digital (2). Recuperado de http://historiaabierta.org/historia2.0/index.php/revista/article/view/31

Foucault, M. (2004). El nacimiento de la biopolítica. México: Fondo de Cultura Económica.

Foucault, M. (2005). Lecciones sobre la voluntad de saber. Buenos Aires: Siglo XXI.

Gysling, J. (2015). The historical development of educational assessment in Chile:
1810-2014. Assessment in Education: Principles, Policy \& Practice, DOI: 10.1080/0969594X.2015.1046812

OCDE (2014a). Income Inequality. Recuperado de http://data.oecd.org/inequality/incomeinequality.htm

(2014b). Panorama Educación Indicadores de la OCDE 2014. Recuperado de http:// www.mecd.gob.es/dctm/inee/indicadoreseducativos/panorama2014/panorama-dela-educacion-2014informe-espanol-05-sep-. pdf?documentId $=0901 e 72 b 81 a 722 a c$

Restrepo, E. \& Rojas, A. (2010). La inflexión decolonial. Fuentes, conceptos y cuestionamientos. Popayán, Colombia: Editorial Universidad del Cauca.

Ruiz, C. (2010). De la República al mercado. Santiago: LOM.

Stobart, G. (2010). Tiempos de pruebas: Los usos y abusos de la evaluación. Madrid: Editorial Morata.

\section{Webgrafía}

http://www.agenciaeducacion.cl/nosotros/quienessomos/

http://www.agenciaeducacion.cl/nosotros/quienessomos/

http://ciperchile.cl/2014/12/01/por-que-se-elige-particular-subvencionado/

http://www.curriculumenlineamineduc.cl/605/ w3-article-33859.html

http://www.leychile.cl/Navegar?idNorma $=30330$

http://www.leychile.cl/Navegar?idNorma $=1006043$

http://www.memoriachilena.cl/602/w3-article-719. html\#cronologia

http://www.fundacionsol.cl/2015/09/la-violenciaestructural-y-cotidiana-a-42-anos-del-golpe-los-11-pilares-dictatoriales-que-todaviasostienen-el-modelo-economico-social/

http://portales.mineduc.cl/usuarios/convivencia_ escolar/doc/201103050058380.Anexo\%20 1\%20Resumen\%20Ley\%20SEP.pdf

http://www.leychile.cl/Navegar?idNorma $=242302$

http://www.leychile.cl/Navegar?idNorma=70774 


\section{Anexos}

Tabla 1. Normativas consideradas en el estudio

\begin{tabular}{|c|c|c|}
\hline Año & Tipo de Normativa & Principales disposiciones \\
\hline 1860 & $\begin{array}{l}\text { Ley General de } \\
\text { Educación Primaria }\end{array}$ & $\begin{array}{l}\text { Regula el sistema educativo en niveles de educación primaria y segundaria. http://www. } \\
\text { archivonacional.cl/616/w3-article-28319.html }\end{array}$ \\
\hline 1920 & Ley Orgánica 3.654 & $\begin{array}{l}\text { Ley de Instrucción primaria. http://www.memoriachilena.cl/archivos2/pdfs/MC0018131. } \\
\text { pdf }\end{array}$ \\
\hline 1927 & Decreto 6.087 & Estatuto de los exámenes de Educación Secundaria. \\
\hline 1929 & $\begin{array}{l}\text { Decreto de Ley } \\
3.060\end{array}$ & $\begin{array}{l}\text { Disposiciones en favor de regular sistema de evaluación para la educación primaria. } \\
\text { http://www.leychile.cl/Navegar?idNorma }=129136\end{array}$ \\
\hline 1929 & Decreto Ley 2.545 & Disposición sobre los grados de educación secundaria y exámenes. \\
\hline 1937 & Circular No 77 & $\begin{array}{l}\text { Disposición sobre los exámenes y otras actividades finales y sobre la planificación del } \\
\text { próximo año escolar que afecta a la educación primaria. }\end{array}$ \\
\hline 1944 & Decreto Ley 2.944 & Disposición sobre los exámenes y promoción para los alumnos de educación secundaria. \\
\hline 1949 & Decreto Ley 1469 & Disposición sobre los exámenes y promoción para los alumnos de educación secundaria. \\
\hline 1959 & Decreto 842 & $\begin{array}{l}\text { Disposición sobre calificaciones, exámenes y promoción para los alumnos de educación } \\
\text { secundaria. }\end{array}$ \\
\hline 1965 & Decreto 27.952 & Reforma educativa que incluye obligatoriedad escolar por ocho años. \\
\hline 1966 & Decreto 11.207 & $\begin{array}{l}\text { Disposiciones para la evaluación y promoción de séptimo grado para los alumnos de } \\
\text { Educación General Básica. }\end{array}$ \\
\hline 1967 & Decreto 7056 & $\begin{array}{l}\text { Disposiciones para la evaluación y la promoción de alumnos de octavo grado de educa- } \\
\text { ción general y la base para la certificación. }\end{array}$ \\
\hline 1968 & Decreto 6.859 & $\begin{array}{l}\text { Disposiciones para la evaluación y la promoción de octavo grado de educación general } \\
\text { y la base para la certificación. }\end{array}$ \\
\hline 1972 & Decreto 192 & Reglamento para la evaluación y promoción de los alumnos de educación básica. \\
\hline 1974 & $\begin{array}{l}\text { Decreto } \\
\text { Supremo } 164\end{array}$ & $\begin{array}{l}\text { Disposiciones sobre promoción y de la evaluación en sistema educativo. http://www. } \\
\text { leychile.cl/Navegar?idNorma=251386 }\end{array}$ \\
\hline 1975 & Decreto 440 & $\begin{array}{l}\text { Disposiciones sobre promoción y de la evaluación en sistema educativo. http://www. } \\
\text { leychile.cl/Navegar?idNorma=251386 }\end{array}$ \\
\hline 1978 & Decreto 2.038 & $\begin{array}{l}\text { Disposiciones sobre promoción y de la evaluación en sistema educativo. http://www. } \\
\text { leychile.cl/Navegar?idNorma=251386 }\end{array}$ \\
\hline 1979 & Decreto 2.088 & $\begin{array}{l}\text { Disposiciones sobre promoción y de la evaluación en sistema educativo. http://www. } \\
\text { leychile.cl/Navegar?idNorma=251386 }\end{array}$ \\
\hline 1990 & $\begin{array}{l}\text { Ley Orgánica Cons- } \\
\text { titucional } 18.962\end{array}$ & $\begin{array}{l}\text { Ley Orgánica Constitucional de Enseñanza, permite publicación de resultados de prue- } \\
\text { bas nacionales (SIMCE). https://www.leychile.cl/Navegar?idNorma=247551 }\end{array}$ \\
\hline 2011 & Ley 20.529 & $\begin{array}{l}\text { Sistema Nacional de Aseguramiento de la Calidad de la Educación, permite fiscaliza- } \\
\text { ción de las escuelas e intervención según resultados SIMCE. http://www.leychile.cl/ } \\
\text { Navegar?idNorma }=1028635\end{array}$ \\
\hline 2008 & Ley 20.248 & $\begin{array}{l}\text { Ley Subvención Escolar Preferencial, asigna subsidios económicos por resultados obte- } \\
\text { nidos en pruebas nacionales. https://www.leychile.cl/Navegar?idNorma=269001 }\end{array}$ \\
\hline
\end{tabular}




\title{
Relaciones familiares versus aprendizaje: un análisis con niños de 5 y 6 años
}

\section{Family relationships versus learning: an analysis with children aged 5 and 6 years}

Investigación

\author{
Marisa Claudia Jacometo Durante \\ Faculdade la Salle-Brasil \\ marisa@faculdadelasalle.edu.br \\ Adriana Rossato Yanagu \\ Faculdade la Salle-Brasil \\ adriana12@gmail.com
}

Recibido: 02 de diciembre de 2016 / Aceptado: 19 de enero de 2017

\section{Resumen}

Como la primera mediadora entre el hombre y la cultura, la familia constituye la unidad dinámica de las relaciones de naturaleza afectiva, social y cognitiva que están inmersas en las condiciones materiales, históricas y culturales de un grupo social determinado. El objetivo general del estudio fue investigar si las relaciones familiares pueden comprometer el aprendizaje de los niños. Específicamente, se pretende: a) Identificar los conflictos en las relaciones familiares; b)Verificar si los conflictos en las relaciones familiares pueden comprometer las relaciones interpersonales de los niños en fase de alfabetización; c) Analizar si el conflicto en las relaciones familiares afecta el aprendizaje de los niños. En el estudio participaron 219 familias con niños de 5 y 6 años. Los principales resultados indican que existe un distanciamiento de los padres en relación a la vida escolar de los hijos, así como en las relaciones familiares ocurre una mezcla de conflicto y afecto. Se considera que el aprendizaje de los niños puede verse comprometido por los conflictos en las relaciones familiares en virtud de que el aprendizaje y el desempeño escolar dependen, en primer lugar, de la interacción familiar y posteriormente de la relación entre profesor y alumno.

Descriptores: Relaciones familiares, aprendizaje, niños, afecto, conflicto.

\begin{abstract}
As the first mediator between man and culture, the family constitutes the dynamic unity of affective, social and cognitive relations that are immersed in the material, historical and cultural conditions of a given social group. The overall objective of the study was to investigate whether family relationships can compromise children's learning. Specifically, it was intended to: a) Identify conflicts in family relationships; B) To verify if the conflicts in the family relations can compromise the interpersonal relationship of the children in the literacy phase; C) Analyze whether conflicts in family relationships interfere with children's learning. A total of 219 families with children aged 5 and 6 participated in the study. The main results indicate that there is a distancing of the parents in relation to the school life of the children, as well as in the family relationships there is a mixture of conflict and affection. It is considered that the learning of children can be compromised by conflicts in family relationships because learning and school performance depend primarily on family interaction and later on the relationship between teacher-student.

Keywords: Family relationships, learning, children, affectivity, conflicts.
\end{abstract}

Forma sugerida de citar: Jacometo Durante, Marisa \& Rossato Yanagu, Adriana (2017). Relaciones familiares versus aprendizaje: un análisis con niños de 5 y 6 años. Alteridad, 12(1), pp. 55-66. 


\section{Introducción}

La familia como una unidad dinámica, a lo largo de la historia ha sufrido cambios constantes, por lo que es difícil seguir un solo curso. Ribeiro (1999) entiende su concepto como una tarea compleja, principalmente cuando se toma como principal referencia sus valores, sus creencias y experiencias personales. La tendencia, según la autora, es conceptualizar la familia a partir de nuestras propias familias. De esta manera, se vuelve fundamental despojarse de los valores, creencias y experiencias familiares personales. Como señala Mioto (1997), cuando hablamos de "familias" debemos atenernos a su especificidad y su particularidad, puesto que las familias difieren significativamente entre sí en los diversos momentos de la historia humana.

En términos jurídicos, Genofre (1997) explica que la familia, originalmente en el derecho romano, era patriarcal y considerada como todo lo que estuviese bajo el poder paterno: esposa, hijos, esclavos e incluso bienes, como tierras, herramientas y animales de trabajo. La tradición romana se constituye en un fuerte factor de influencia en las legislaciones modernas. Bajo la ley brasileña, en que prevalecen los derechos canónico y portugués, en los cuales la Iglesia representaba el concepto principal de familia. El derecho civil, bajo la influencia de la Iglesia, mantuvo durante mucho tiempo el principio de la indisolubilidad del matrimonio.

Con la Constitución Federal (1988), el matrimonio dejó de ser la piedra angular de la familia. Independientemente de la existencia del matrimonio civil o religioso, se considera como una unidad familiar la unión estable entre un hombre y una mujer. También se considera como una entidad familiar a la comunidad formada por uno de los padres y sus descendientes, encajándose en la definición de familias monoparentales, en las que el hombre o la mujer asume las responsabilidades.

En Brasil, el Código de Derecho Civil (2015) asegura la protección a las familias porque se consideran la base de la sociedad y las conceptúa como un conjunto de personas unidas por un vínculo jurídico de carácter familiar. La constitución de la familia aún se forma a través del matrimonio entre el hombre y la mujer, estableciendo una unión plena de vida, sobre la base de la igualdad de derechos y deberes de los cónyuges.

Las familias se constituyen, de modo general, fundamentadas en sentimientos de amor y solidaridad, con el propósito de preservar los lazos afectivos de atención, afecto, cuidado y protección de la pareja y los hijos, en busca de la realización de proyectos de manera compartida.

En el contexto de la afectividad, se encuentra el proceso de aprendizaje y es en la base de la familia donde se desarrollan los primeros hábitos, que garantizan o no, una base sólida y segura para enfrentar las adversidades.

Por lo tanto, la relevancia del estudio está en dilucidar que los conflictos en las relaciones familiares influyen en la formación de las relaciones interpersonales de los hijos, así como en el proceso de aprendizaje.

Esta investigación se llevó a cabo a través de un estudio de caso, que de acuerdo con Yin (2016), es más que un método y constituye una estrategia de investigación, al ser el estudio profundo y sistemático de un grupo, una situación o persona que sea representativa en su universo de investigación. En este sentido, se estudió un grupo de familias con niños de entre 5 y 6 años que están en etapa de educación infantil. El método de enfoque es inductivo para permitir, de acuerdo al método, que los datos conduzcan a la aparición del concepto, de acuerdo a (Yin, 2016). El análisis fue cualitativo debido a la comprensión de los significados situacionales presentados por los participantes (Richardson, 2010). También se caracteriza por ser descriptivo, como se describe en los fenómenos encontrados en las 219 familias encuestadas, mediante el uso de un cuestionario mixto (Richardson, 2010).

Para la revisión bibliográfica se llevaron a cabo lecturas en libros y revistas especializados en el área de educación, así como consultas en artículos publicados. 
El cuestionario se organizó con el fin de responder a los objetivos específicos. Se utilizaron preguntas objetivas y argumentativas (mixto) que permitan alcanzar los objetivos propuestos por la investigación.

El cuestionario fue aplicado a 219 familias con niños de 5 y 6 años de edad residentes en diferentes barrios de la ciudad de Lucas de Río Verde. Estos niños estudian en escuelas públicas y privadas. La muestra fue intencional, pues se delimitó al rango de edad y el criterio de selección fue la aceptación por parte de la familia para participar en la investigación.

La tabulación de los datos fue organizada de manera que las alternativas fueran tabuladas $\mathrm{y}$ las disertativas agrupadas por similitudes $\mathrm{y}$ diferencias.

Para el análisis de datos buscados se buscó coherencia con la revisión de la literatura, utilizando el método inductivo, es decir, la interpretación.

\section{Revisión de la literatura}

\section{El contexto familiar}

La familia, presente en todas las sociedades, es uno de los primeros entornos de socialización de los individuos, que actúa como mediador principal de los patrones, modelos e influencias culturales (Duarte, 1994). También se la considera la primera institución social que, junto con otras, busca asegurar la continuidad y el bienestar de sus miembros y de la comunidad, incluyendo el bienestar y la protección del niño. Por lo tanto, tiene un impacto significativo y una fuerte influencia en el comportamiento de los individuos, especialmente los niños, que aprenden las diferentes maneras de existir, de ver el mundo y de construir sus relaciones sociales.

Como primera mediadora entre el hombre y la cultura, la familia constituye la unidad dinámica de las relaciones de naturaleza afectiva, social y cognitiva que están inmersas en las condiciones materiales, históricas y culturales de un grupo social determinado. Ella es la matriz del aprendizaje humano, con significados y prácticas culturales propias que generan modelos de relaciones interpersonales y de construcción individual y colectiva. Los acontecimientos y experiencias familiares proporcionan la formación de repertorio conductual, de acciones y resoluciones de problemas con significados universales y particulares.

Estas experiencias integran la experiencia colectiva e individual que organiza, interfiere y la vuelve una unidad dinámica, estructurando las formas de subjetividad e interacción social. Y es a través de las interacciones familiares que se concretan las transformaciones en las sociedades que, a su vez, influirán en las relaciones familiares futuras, que se caracterizan por un proceso de influencias bidireccionales entre los miembros de la familia y los diferentes ambientes que componen los sistemas sociales, entre ellos la escuela, que constituyen un factor importante para el desarrollo de la persona (Duarte, 1994). Por lo tanto, ella es la principal responsable de la incorporación de los cambios sociales e intergeneracionales ocurridos a lo largo del tiempo, con los padres ejerciendo un papel preponderante en la construcción de la persona, su personalidad y su inclusión en el mundo laboral y social (Mioto, 1997).

En el entorno familiar los niños aprenden a gestionar y resolver conflictos, a controlar las emociones, a expresar los diferentes sentimientos que constituyen las relaciones interpersonales, a lidiar con las diversidades y las adversidades de la vida. Estas habilidades sociales y su forma de expresión, desarrolladas inicialmente en el ámbito familiar, tienen repercusiones en otros entornos con los que el niño, adolescente o adulto interactúan, provocando aspectos saludables o causando problemas y alterando la capacidad de aprendizaje (Mioto, 1997).

\section{Estudios sobre el afecto}

Este tema aborda la perspectiva sobre la afectividad, con estudios de Piaget, Wallon y otros autores contemporáneos. 
La tesis de Piaget (1977) sobre las relaciones entre afectividad e inteligencia, es que ambas son indisociables e integradas al desarrollo psicológico, no es posible que se trate de dos psicologías, una de la afectividad y otra de la inteligencia para explicar los comportamientos. Se sostiene que la afectividad no se limita solamente a las emociones y sentimientos, sino que también incluye la forma en que se cumplan las tendencias y la voluntad del niño.

Por afectividad se entiende los sentimientos propiamente dichos y, en particular, las emociones; las diversas tendencias, incluyendo las "tendencias superiores" y, en particular la voluntad (Cavenaghi y Saltini, 2014, p. 39).

Según Piaget (1977, p. 265), es indiscutible que el afecto juega un papel esencial en el funcionamiento de la inteligencia. Sin amor no habría ningún interés, necesidad o motivación. El afecto es una condición necesaria en la constitución de la inteligencia. Para él, "el afecto y la cognición resultan de una adaptación continua e interdependiente, en la que los sentimientos expresan los intereses y los valores de las acciones y de las estructuras inteligentes". "Si bien los esquemas afectivos conducen a la formación del carácter, los esquemas cognitivos conducen a la construcción de la inteligencia".

Las experiencias familiares fomentan la formación del repertorio de comportamientos, de acciones y resoluciones frente a los problemas (Dessen, Polonia, 2007). Es en el ambiente familiar donde también el niño aprende a hacer frente a los conflictos, a controlar sus emociones, a demostrar los diferentes sentimientos que impregnan las relaciones y a lidiar con la vida $y$ sus dificultades.

Para comprender el papel de las emociones en la teoría psicogénica de Piaget (1977), es necesario considerar y reflexionar sobre la asociación que él establece entre la génesis de la moral y la formación de la personalidad. En su obra, él presenta la cuestión de la génesis de la moral relacionada con la construcción de la escala de valores, las ideas y los sentimientos morales.
Para el teórico, toda moral está formada por un sistema de reglas y la moralidad consiste en el respeto que el individuo tiene de esas reglas. Los niños que están en el período pre-operatorio se encuentran todavía en la etapa de la heteronomía moral donde las reglas son externas, sagradas e inmutables, impuestas por los adultos. Se entiende entonces, la seriedad con la que debe llevarse a cabo el proceso de formación de estos individuos.

En este sentido, el psicólogo León Festinger (1957) propuso una teoría de disonancia cognitiva centrada en cómo las personas tratan de lograr la coherencia interna. Él sugirió que las personas tienen una necesidad interior para asegurarse de que sus creencias y comportamientos son consistentes. Creencias inconsistentes o conflictivas conducen a la discordia, que las personas se esfuerzan en evitar.

El afecto se refiere al conjunto de emociones positivas que existen en las relaciones interpersonales (Benetti, 2006). Eso implica una relación de cariño y cuidado que se tiene con alguien. Los lazos afectivos proporcionan apoyo psicológico y social en la familia, ayudando a hacer frente a los problemas cotidianos; el conflicto, sin embargo, se caracteriza por sentimientos negativos que pueden llevar al estrés y la agresividad en el sistema familiar.

Según Piaget (1977) el proceso de desarrollo pasa por la dimensión social, e implica la cognición, afecto y moral. El elemento de gran alcance que es la afectividad influye en nuestras actividades intelectuales y a esta selección de actividades, Piaget (1977) las llama de interés, que no son desarrolladas por lo cognitivo, sino por lo afectivo.

En este sentido, Cavenaghi; Saltini (2014) sugieren que el gran desafío de la educación sería favorecer el desarrollo intelectual en armonía con el desarrollo afectivo moral, de modo que el sujeto pueda alcanzar su autonomía intelectual, afectiva y moral, basado en leyes de reciprocidad construidas en sus interacciones con el entorno físico, social, histórico y cultural. El maestro no debe estar comprometido apenas con la construcción del conocimiento del estudiante, sino un profesio- 
nal involucrado con el desarrollo de la autonomía cognitiva, moral, social y emocional.

Por lo tanto, el enfoque de Henri Wallon privilegia el aspecto afectivo, lo que indica su papel fundamental en el inicio de la vida del niño. Para este autor (1995), la emoción organiza la vida psíquica inicial y precede a las primeras construcciones cognitivas. Define el desarrollo como el paso del yo orgánico al yo psíquico a través de las primeras emociones que son, en esencia, el instrumento para interactuar con el otro, antes de que se construya la cognición. Wallon (1995) presenta lo que él considera como la secuencia del desarrollo en relación a la construcción de la persona a partir de la idea del papel estructurador de las primeras emociones en relación con la cognición, para después describir el desarrollo como un movimiento de alternancia de predominancias, a veces emocional, a veces cognitiva culminando con una preponderancia cognitiva.

Las medidas propuestas por Wallon son: 1) falta de diferenciación entre yo y el otro (en la cual las primeras emociones hacen la comunicación y la expresión de las necesidades orgánicas); 2) diferenciación progresiva entre yo y el otro con el despuntar de la persona (inicialmente más para oponerse al mundo en la fase de oposición, para después afirmar su yo en la fase de personalismo); 3) llegando (aproximadamente en la edad escolar) a la etapa categorial, en la cual, ya están en posesión los instrumentos cognitivos tales como la representación y el pensamiento racional, utilizados para coordinar las emociones y construir conocimientos.

Wallon (1995) afirma que la afectividad constituye un papel fundamental en la formación de la inteligencia, con el fin de determinar los intereses y necesidades individuales de la persona. Se atribuye a las emociones un papel clave en la formación de la vida psíquica, un vínculo entre lo social y lo orgánico. Así se puede entender que, bajo la influencia del medio, las emociones tienden a realizar, a través de manifestaciones intensas, una conexión entre el individuo y el aprendizaje.
Va en contra de la naturaleza tratar al niño de manera fragmentaria. En cada edad, ella constituye un conjunto indisociable y original. En la sucesión de sus edades, ella es un ser único en curso de metamorfosis. Hecha de contrastes y conflictos, su unidad será, por eso aún más susceptible al desarrollo y la innovación (Wallon, 1995, p.198).

\section{Aprendizaje}

Vygotsky (1993) expone la idea de que todos los seres humanos son capaces de aprender, pero es necesario que se adapte a nuestra forma de enseñar. Vale la pena recordar que el aprendizaje implica separarse, crecer, tomar conciencia de la diferencia, entendiendo que esta conciencia humaniza y abre camino a lo subjetivo.

Piaget (1977) afirma que el aprendizaje es necesariamente un proceso de equilibrio, ya que hace que el sistema cognitivo busque nuevas maneras de interpretar y comprender la realidad, dado que se aprende educando.

Según Piaget (1977), el niño es idealizado como un ser activo que en todo momento interactúa con la realidad, actuando activamente con objetos y personas. Esa interacción con el medio hace que construya estructuras mentales $\mathrm{y}$ adquiera maneras de hacer que funcionen. El punto central, por lo tanto, es el intercambio entre el organismo y el medio, y esa correlación se produce a través de dos procesos simultáneos: la organización interna y la adaptación al medio, funciones ejercidas por el organismo durante toda la vida. La adecuación definida por Piaget (1977), como el propio desarrollo de la inteligencia, se llevan a cabo a través de la asimilación y la acomodación. Los esquemas de asimilación se transforman y se configuran conforme avanzan las fases de desarrollo.

Se considera todavía que el proceso de desarrollo está influenciado por factores tales como la maduración (crecimiento biológico de órganos), la ejercitación (funcionamiento de los sistemas y órganos que implican la formación 
de hábitos), el aprendizaje social (adquisición de valores, lenguaje, costumbres y las normas culturales y sociales) y equilibrio (proceso de autorregulación interna del organismo, que se constituye en la búsqueda sucesiva de reequilibrio después de cada desequilibrio sufrido).

Según Piaget (1977), el período preoperatorio comienza a los 02 años y se extiende hasta los 07 años, caracterizado por la aparición de la función simbólica o semiótica, es decir, la manifestación de lenguaje que marca el paso del período sensorio-motor para el preoperatorio.

El niño pre-operacional ve las cosas desde su punto de vista. Él piensa que todas las personas piensan como él y, como considera sus pensamientos correctos, nunca los cuestiona. Asimila todo a sí mismo y a su punto de vista, a servicio de sus necesidades subjetivas y emocionales, independientemente de la verdad. Ese egocentrismo se manifiesta en varios niveles: intelectual, social, moral, lingüístico, etc. El pensamiento egocéntrico es involuntario y no es capaz de adaptarse a la realidad, asimila las acciones de acuerdo con su punto de vista personal. De ahí se entiende el desequilibrio entre asimilación y acomodación.

\section{Presentación y análisis de los resultados}

\section{Identificar los conflictos en las relaciones familiares}

En cuanto a la constitución de la familia, el $62 \%$ de los niños de 5 años y el $76 \%$ de 6 años de la escuela pública viven con sus padres, el $38 \%$ de los niños de 5 años y el 24\% de 6 años viven con uno de los padres o con familiares. En la escuela privada, el $92 \%$ de los niños de 5 años y el $94 \%$ de los niños de 6 años viven con sus padres, apenas el $8 \%$ de los niños de 5 años y el $6 \%$ de los niños de 6 años viven con uno de los padres o con parientes cercanos.

Cuando se preguntó a las familias de los niños de 5 años lo que ellos entendían por conflicto, el 50\% respondió que la divergencia de ideas, es decir, cuando cada individuo tiene su pensamiento o creencia acerca sobre determinado objeto o situación, discordando del pensamiento o creencia de otros. $30 \%$ dice que son palabras ofensivas, $20 \%$ lo identificaron como agresión física y $20 \%$ disputas personales. Las familias de los niños de 6 años mostraron la divergencia de ideas y los insultos personales como la mejor explicación para el conflicto, ambos con un 33\% cada uno. Las agresiones físicas y las disputas personales aparecieron enseguida junto con el $22 \%$.

Viviendo en sociedad, se puede ver que los conflictos son comunes en la vida conyugal. Sin embargo, cuando están bien comprendidos por sus pares, se convierten en fuente de madurez para la vida conyugal y pueden conducir a relaciones más estrechas entre sus miembros. Las divergencias de ideas discutidas con calma, con demostraciones de apoyo y de actitudes que favorezcan la resolución de problemas no generan reacciones negativas en los niños, por el contrario, los pueden llevar a entender que a través del diálogo se pueden superar las dificultades. Por otro lado, las luchas por el poder, las agresiones físicas $o$ verbales presenciadas pueden causar sufrimiento a los niños.

Con relación a los conflictos experimentados, el $60 \%$ de las familias de los niños de 5 años dijeron que los conflictos son frecuentes en sus hogares, mientras que el $40 \%$ dijo que no existían. En las familias de seis años, el 56\% dijo que no existen, mientras que el $44 \%$ lo afirmó.

Los resultados de las investigaciones se direccionan para lo que Dessen; Polonia (2007) afirma ser de gran importancia, identificar los aspectos del funcionamiento del sistema familiar que pueden estar relacionados tanto con el buen funcionamiento emocional y cognitivo como a las psicopatologías. Los padres proporcionan, o deberían proporcionar, todo el apoyo necesario para que el desarrollo saludable ocurra, además de funcionar como mediadores de los asuntos sociales.

El motivo generador de conflictos presentados por las familias de los niños de 5 años más común, el $30 \%$ son causados por problemas 
financieros, el $10 \%$ de las diferencias en el pensamiento, el $10 \%$ por diferencias en los proyectos de vida y el $10 \%$ por traición. $40 \%$ de estas familias no respondieron a la pregunta. En las familias de seis años muestran un 33\% como palabras ofensivas, el $22 \%$ como discusiones y agresiones físicas y el $23 \%$ prefirió no contestar.

La calidad de los vínculos afectivos que se forman entre padres e hijos puede ser considerada como indicadora de un desarrollo sano y, en consecuencia, de interacciones y patrones de ajuste positivo en todos los ambientes en los que participan (Dessen, Polonia, 2007). Sin embargo, estos mismos lazos emocionales pueden obstaculizar el desarrollo del niño y causar problemas en su adaptación social.

La teoría de la disonancia cognitiva de Festinger (1957) puede justificar las contradicciones entre las cuestiones que rodean el tema relacionado con las ideas divergentes. Festinger (1957) afirma que "cogniciones contrarias sirven como estímulos para que la mente obtenga o produzca nuevos pensamientos o creencias, o modifique creencias preexistentes, con el fin de reducir la cantidad de disonancia (conflicto) entre las cogniciones". Cuando ocurre una disonancia, el individuo entra en conflicto mínimo y procura adoptar algunas maneras de salir de la incomodidad.

Sobre la gravedad de los conflictos presentados anteriormente, el $40 \%$ de las familias de cinco años dijo que eran graves, el 20\% lo calificaron como intrascendentes y el $40 \%$ dijeron que estaban dentro de límites normales. Las familias de los niños de 6 años respondieron que el 67\% de los conflictos vividos están dentro del rango normal, el 22\% de ellos son graves y apenas el 11\% dijeron que tenían poca importancia.

Si los problemas familiares (conflictos) no son bien manejados y la falta o escasez de relaciones saludables no están ajustadas, la carencia de papeles maternos y paternos puede debilitar la formación sana de las relaciones cognitivas y afectivas de los niños.

Piaget (1977, p.11) postula que "el pleno desarrollo de la personalidad sobre sus aspectos más intelectuales es indisociable del conjunto de relaciones afectivas, sociales y morales". A primera vista, la maduración de la personalidad parece depender, principalmente, de factores afectivos. Formar personalidades independientes moralmente solamente es posible a través de la educación. Piaget (1977, p.11) afirma que "adquirido el lenguaje, la socialización del pensamiento se manifiesta por el desarrollo y los conceptos y las relaciones y el establecimiento de normas". Así, el medio en el cual el individuo se inserta y la forma en que se desarrollará influirá en gran medida en su formación.

En la investigación aplicada, los conflictos verificados que fueron vivenciados por las familias de los niños de 5 años son causados por problemas financieros, diferencias en el pensamiento, diferencias en los proyectos de vida y por traición. Para las familias de seis años, se observó que las palabras ofensivas, discusiones y agresiones físicas se manifiestan habitualmente.

Benetti (2006) afirma que los conflictos entre la pareja pueden presentarse a través de discusiones y peleas a escondidas, que se manifiestan por el boicot y la indiferencia, entre otros. Teniendo en cuenta que toda relación implica cierto nivel de conflicto, es importante entender qué aspectos del desarrollo del niño se ven afectados por ello.

\section{Verificar si los conflictos en las relaciones familiares pueden poner en peligro las relaciones interpersonales de los niños en fase de alfabetización}

Con respecto al comportamiento en el aula: el $92 \%$ de los niños de 5 años y el $90 \%$ de 6 años, de escuelas públicas demostraron ser afectivos con sus colegas, el $8 \%$ de los niños de 5 años y el 10\% de los niños de 6 años mostraron cierta agresividad. En la escuela privada, el $88 \%$ de los niños de 5 años y el 100\% de los niños de 6 años también demostraron ser afectivos, apenas el $12 \%$ de los niños de 5 años demostraron cierta agresividad. 
En cuanto al afecto demostrado a los profesores, el $93 \%$ de los niños de 5 años y el $80 \%$ de 6 años de las escuelas públicas demostraron ser afectivos con los profesores, el 7\% de los niños de 5 años y el $20 \%$ de 6 años mostró cierta agresividad. En la escuela privada, el 88\% de los niños de 5 años y el 100\% de los niños de 6 años también demostraron ser afectivos, apenas el $12 \%$ de los niños menores de 5 años mostraron baja afectividad.

Teniendo en cuenta la dificultad de concentración presentada en clase, el $24 \%$ de los niños de 5 años y el $46 \%$ de 6 años de la escuela pública no mostraron dificultad para concentrarse, el $76 \%$ de los niños de 5 años y el $54 \%$ de 6 años mostraron dificultades de concentración. En la escuela privada, el $88 \%$ de los niños de 5 años y el $81 \%$ de los niños de 6 mostraron un rango normal, apenas el $12 \%$ de los niños de 5 años y el $19 \%$ de 6 años se mostraron dispersos en el aula.

Sobre las dificultades de aprendizaje observadas, el 19\% de los niños de 5 años y el $60 \%$ de seis años de escuelas públicas no mostraron dificultades aparentes, en el $81 \%$ de los niños de 5 años y el 40\% de 6 años se observaron limitaciones. En la escuela privada, el $88 \%$ de los niños de 5 años y el $84 \%$ de los niños de 6 años no demostraron dificultades, apenas el $12 \%$ de los niños de 5 años y el 16\% de los niños de 6 años presentaron limitaciones.

En cuanto a la presencia de la familia en la vida escolar del niño(a), se observó que el 11\% de los niños de 5 años y el $47 \%$ de 6 años de escuela pública no suelen ir acompañados de la familia, el $89 \%$ de los niños de 5 años y $53 \%$ de 6 años son acompañados por los responsables. En la escuela privada se observó que solamente el $4 \%$ de los niños de 5 años y $6 \%$ de los niños de 6 años no son acompañados por los responsables en las actividades escolares, el $96 \%$ de los niños de 5 años y el $94 \%$ de los niños de 6 años son acompañados por la familia.

En cuanto a la participación de la familia en la escuela, el $76 \%$ de las familias de los niños de 5 años y el $46 \%$ de las familias de niños de 6 años de las escuelas públicas no participan en actividades promovidas por la escuela, el $24 \%$ de las familias de los niños de 5 años y el $44 \%$ de familias de niños de 6 años son participativos. En la escuela privada, apenas el $6 \%$ de las familias de niños de 5 años y $12 \%$ de las familias de niños de 6 años no participan, el 94\% de las familias de niños de 5 años y el $88 \%$ de las familias de niños de 6 años participan en actividades promovidas por la escuela.

Con respecto a la ayuda recibida por parte de las familias para la realización de las tareas en casa, el $62 \%$ de los niños de 5 años y el $39 \%$ de 6 años de las escuelas públicas reciben la ayuda, el 38\% de los niños de 5 años y el $61 \%$ de 6 años hacen las tareas sin ayuda. En la escuela privada, el $94 \%$ de los niños de 5 años y el $83 \%$ de los niños de 6 años reciben ayuda, solamente el $6 \%$ de los niños de 5 años y el 17\% de los niños de 6 años no reciben ayuda.

Se preguntó a las familias de los niños de 5 años sobre la forma de resolución de conflictos presentados, el $30 \%$ no respondió, el $20 \%$ dijo que salir de casa es una solución, el 10\% utiliza la fuerza física y el $40 \%$ busca resolverlos a través del diálogo. Para las familias de los niños de 6 años, el diálogo aparece con un 55\% de opciones de respuesta y el $45 \%$ prefiere no contestar.

Los resultados del estudio corroboran la percepción de Piaget (1977) de que si hay afecto, existe la capacidad de desarrollar el respeto mutuo tan necesario y que a través de él, el aprendizaje fluye con más facilidad.

Los padres deberían ser los principales responsables por el apoyo emocional, formación moral y social de los niños, preparándolos para buscar el éxito en el aprendizaje escolar y en las relaciones que se construirán, guiándolos para hacer frente a las frustraciones y conflictos.

Las palabras tienen un gran significado, la comunicación efectiva disminuye la posibilidad de malentendidos. El diálogo es fundamental en la tarea de educar. Las relaciones que se rigen por el compromiso y el diálogo se fortalecen.

Esta observación está cerca de lo que Piaget (2006) clasificó como relaciones de coacción y 
relaciones de cooperación. El proceso de enseñanza y aprendizaje se asocia con las relaciones interpersonales. La familia, las relaciones sociales e institucionales están estrechamente relacionadas con los resultados finales de los avances o la inercia en los procesos de aprendizaje.

Entre las consecuencias de estos conflictos en el cambio de comportamientos de los niños de 5 años en el ambiente escolar, identificados por las familias, las más notables son el nerviosismo y la agresividad, ambos con un $30 \%$ cada uno, el $20 \%$ de los padres dijeron que no percibieron los hay cambios y el $20 \%$ prefirió no responder. Entre las familias de los niños de 6 años, el 34\% de ellas dijeron que sus hijos son agresivos, el $22 \%$ dijo que hay distracción y el $44 \%$ no percibe diferencias.

El niño pre-operacional necesita seguridad, estabilidad, afecto y comprensión para sentirse seguro frente a los procesos de aprendizaje. Un entorno desfavorable favorece la agresividad, sentimientos de incapacidad y, por tanto, un comportamiento antisocial.

La indiferencia de la familia frente a las carencias afectivas presentadas puede poner a los niños frente a problemas de relaciones y aprendizaje. La desorganización familiar, la falta de límites y afectos, la agresividad en las relaciones, las pérdidas, la falta de interacción con el medio y la pobreza son vistas como posibles causas de estos comportamientos. Al analizar las relaciones cada vez más distantes entre los miembros de la familia, vemos que los niños procuran la atención de los padres. En la sociedad actual, la situación escolar puede ser importante para que los padres constaten que sus hijos no están bien en sus actividades, lo que puede llamarles la atención hacia un cambio de enfoque en el entorno familiar.

La encuesta revela que los conflictos familiares pueden comprometer la relación interpersonal que es construida por los niños en la etapa de alfabetización. Al no entender claramente lo que sucede en la familia, el niño puede llegar a sentirse culpable por los problemas y demostrar intolerancia a las reglas que se presenten en relación con los profesores y compañeros.
Como corolario, corroborando a Piaget (1977), una autonomía intelectual no es posible sin una autonomía moral, pues ambas se sustentan en el respeto mutuo, el cual, a su vez, se basa en el respeto por uno mismo y en el reconocimiento del otro como sí mismo. Trabajar con este tema en una propuesta pedagógica presupone la preocupación por desarrollar acciones en las que escuchar, mirar, sentir y pulsar son fuerzas inmanentes que definen los niveles de las relaciones que se establecen entre los individuos, especialmente en acciones de cooperación.

\section{Analizar si los conflictos en las relaciones familiares interfieren en el aprendizaje de los niños}

Se preguntó a los padres de los niños de 5 años sobre cuáles son los gestos afectivos más practicados en sus hogares, el 34\% respondió que el abrazo, el 21\% afirmó que la sonrisa facilita la convivencia, el $20 \%$ dijo que una mirada cariñosa, la atención disponible y la asistencia proporcionada en las tareas escolares demuestran cariño, el $10 \%$ afirmó que el contacto físico aproxima las relaciones, el $15 \%$ son indiferentes a la necesidad de demostrar afecto. Las familias de los niños de 6 años recalcaron el abrazo y la sonrisa con un $29 \%$ como las principales muestras de afecto practicadas, la atención y la disponibilidad para escuchar lo que el otro tiene que decir aparecieron en segunda opción con un $25 \%$, la mirada cariñosa y la ayuda prestada aparecieron con un $14 \%$ de preferencia, el contacto con $10 \%$ y el $22 \%$ de los encuestados dijeron que no tienen tiempo para ofrecer afecto a los niños.

El resultado de la investigación sugiere que parte de las familias analizadas sufre algún tipo de quebrantamiento. Esto causa preocupación, pues es en la familia donde se absorbe la base emocional que acompañará nuestras acciones para el resto de nuestras vidas y es con ella que aprendemos nociones de lo correcto e incorrecto, de ética y de ciudadanía. Dessen y Polonia (2007) considera al ser humano como un todo, siendo 
las emociones responsables del desarrollo de los seres humanos. A través del medio en el que el niño vive, sentimientos como alegría, tristeza, miedo, odio o amor, pasan a tener mayor o menor relevancia.

El desarrollo del niño se caracteriza por cambios de comportamientos que se consideran importantes para permitir que el niño aprenda nuevas habilidades, y pueden ser caracterizados como deseables o indeseables (Dessen, Polonia, 2007). Deseados o adecuados son los cambios que ocurren como consecuencia de la interacción del organismo con el ambiente, permitiendo al niño el contacto con situaciones importantes de aprendizaje que promueven el desarrollo. Los comportamientos no deseados se refieren a problemas de comportamiento resultantes del exceso o falta de situaciones que facilitan o amplían las posibilidades de aprendizaje, y por lo tanto, de desarrollo. Estos se manifiestan mediante la internalización o externalización de comportamientos (Benetti, 2006).

Como internalización de comportamientos, se destacan la retracción y la ansiedad, preocupación exagerada, tristeza, inseguridad, timidez, miedos, manifestaciones psicosomáticas y rechazo a la escuela, entre otros. Los comportamientos de externalización, sin embargo, están marcados por la impulsividad, la explosividad, agresividad, agitación, características desafiantes y antisociales como mentiras, robos, faltar a clases, falta de respeto, luchas y hostilidad en las relaciones (Benetti, 2006). Estos son comportamientos que dificultan la interacción del niño con el ambiente, generan conflictos y con frecuencia causan la ruptura de las interacciones. En general, en el contexto escolar, el comportamiento de externalización se identifica más fácilmente, probablemente por tener una mayor visibilidad e interferir con la dinámica de la clase.

En este sentido, la familia es esencial para asegurar la supervivencia y la protección integral de los hijos, independientemente de la estructura familiar o la forma en que se ha estructurado. Es en la familia que se propicia la construcción de lazos afectivos y la satisfacción de las necesidades individuales, es en ella que deben ser absorbidos los primeros saberes y profundizados los vínculos humanos.

Por lo tanto, es evidente que si el afecto no estuviera presente dentro de la familia, la motivación que impulsa al ser humano a la búsqueda del conocimiento puede verse comprometida. En la visión de Piaget (2006, p.16) el afecto juega un papel primordial en el funcionamiento de la inteligencia, "no se podría razonar sin experimentar ciertos sentimientos y, por otro lado, no existen afectos sin un mínimo de comprensión".

Es importante tener en cuenta que la familia y la escuela son entornos de desarrollo y aprendizaje humano que pueden actuar como propulsores o inhibidores. El estudio de las relaciones en cada contexto, y entre ellos, constituye una importante fuente de información, en la medida en la que permite identificar aspectos o condiciones que generan conflictos y ruidos en las comunicaciones y, en consecuencia, en los patrones de colaboración entre ellos. En este sentido, es importante tener en cuenta cómo la escuela y, específicamente, los profesores emplean las experiencias que los estudiantes tienen en casa.

Los lazos afectivos estructurados y consolidados, tanto en la escuela como en la familia, permiten que los individuos hagan frente a los conflictos, enfoques y situaciones derivadas de estos vínculos, aprendiendo a resolver problemas de manera conjunta o separada. En este proceso, las diferentes etapas de desarrollo, características de los miembros de la familia y también los diferentes segmentos de la escuela, son factores esenciales en la dirección de lograr cambios en las funciones de desarrollo de la persona, con un impacto directo en su experiencia académica y psicológica.

\section{Consideraciones finales}

Después de la presentación y análisis de los resultados, comparándolos con la literatura, se observó que el aprendizaje de los niños puede verse 
comprometido por los conflictos en las relaciones familiares, debido a que el aprendizaje y el rendimiento escolar dependen, en primer lugar, de la interacción familiar $y$, posteriormente, de la relación entre el profesor y el estudiante. La teoría de Piaget (1977) reconoce a la afectividad como motivación para la actividad cognitiva y enfatiza que la afectividad y la razón son términos que se complementan entre sí. Para Piaget (1977) la afectividad es la energía, lo que mueve la acción, mientras que la razón es lo que permite al sujeto identificar deseos, sentimientos variados y obtener éxito en las acciones. En la teoría de Vygotsky (1993) se tiene un enfoque holístico, donde no hay forma de separar los intereses emocionales de los aspectos intelectuales.

La investigación muestra que las relaciones familiares se componen de una mezcla de conflicto y afecto. Por otra parte, estos conflictos pueden poner en peligro las relaciones interpersonales construidas por los niños en la etapa de alfabetización. Este hecho se establece en las relaciones de coacción y cooperación, señalados por (Piaget, 2006).

Los conflictos en las relaciones familiares interfieren en el aprendizaje de los niños, como se destaca en el estudio. Si el afecto no está presente dentro de la familia, la motivación que impulsa al ser humano en la búsqueda del conocimiento puede verse comprometida. Desde el punto de vista de Piaget (2006) el afecto desempeña un papel fundamental en el funcionamiento de la inteligencia.

Por lo tanto, a partir de la consideración de otros trabajos, como Cavenaghi y Saltini (2014), Dessen y Polonia (1992) y Benetti (2006), es evidente que a partir de Piaget, uno de los grandes desafíos de la educación sería fomentar el desarrollo intelectual en armonía con el desarrollo afectivo y moral, para que el sujeto pueda conquistar poco a poco su autonomía intelectual, emotiva y moral, basado en leyes de reciprocidad construidas en sus interacciones con el entorno físico, social, histórico y cultural. Así, el afecto y la cognición deben ser vistos de manera articulada, también en el campo de la educación. Se entiende que la afectividad y la inteligencia son aspectos indisociables, íntimamente vinculados e influenciados por la socialización, por el "vivir con el otro".

Por lo tanto, se entiende que el desarrollo de la inteligencia es a través del intercambio continuo entre el niño y el medio, ya que son las nuevas experiencias la que permiten la construcción de nuevas estructuras cognitivas a partir de las anteriores, hacia una organización mental cada vez más amplia.

La encuesta reveló un distanciamiento de los padres en relación a la vida escolar de los hijos, así como la presencia positiva de la mayoría de los padres en la formación no se notó presente. Tratar del desarrollo humano es también tratar de las relaciones que se establecen, así como de su estructura familiar. A través del estudio, se encontró que, efectivamente, el afecto y las relaciones construidas a partir de ese ámbito, son imprescindibles para que el niño se desarrolle de forma segura y fiable, a fin de que pueda llegar a vivir de forma independiente. La base proporcionada por la familia, de ser segura, proporciona al niño los instrumentos facilitadores del pensamiento, $y$ por lo tanto, influye en la formación de un aprendizaje saludable. Incluso si las familias no tienen una buena situación económica, social y cultural, las relaciones emocionales y morales pueden ser construidas de forma que puedan ayudar a los niños en su proceso de maduración.

\section{Referencias bibliográficas}

Benetti, S. P. C. (2006). Conflito conjugal: impacto no desenvolvimento psicológico da criança e do adolescente. Psicologia: Reflexão e Crítica, 19(2), 261-268.

Brasil (1988). Constituição da República Federativa do Brasil. Disponível em <http://www.planalto. gov.br/ccivil_03/constituicao/constituicaocompilado.htm >. Acesso em 01/02/2016. 
(2015). Código Civil instituído pela Lei no 13105, de 16 de março de 2015. Disponível em < http://www.planalto.gov.br/ccivil_03/_ ato2015-2018/2015/lei/113105.htm>. Acesso em 19/01/2017.

Cavenaghi, D. B. \& Saltini, C. (2014). Relações entre a afetividade e a inteligência no desenvolvimento mental da criança. Rio de Janeiro: Wak Editora.

Dessen, M. A., \& Polonia, A. C. (2007). Família e escola. Paidéia, 17(36), 21-32.

Duarte, L. F. D. (1994). Horizontes do indivíduo e da ética no crepúsculo da família. In: Ribeiro, I. (Org.), Família e sociedade brasileira: desafios nos processos contemporâneos. Rio de Janeiro: Fundação João XXIII.

Festinger, L. (1957). Teoria da dissonância cognitiva de Leon Festinger. Disponível em <http:// ojs.c3sl.ufpr.br/ojs/index.php/educar/article/ view/36006>. Acesso em 01/02/2016.

Genofre, R. M. (1997). Família: uma história jurídica. In: Carvalho, M. do C. B. de (Org.), A família contemporânea em debate. 2. ed. São Paulo: EDUC.

Mioto, R. C. T. (1998). Família e saúde mental : contribuições para reflexão sobre processos familiares. Revista Katálysis, 2, 20-26, maio. Florianópolis,

Piaget, J. (1977). O julgamento Moral na criança. SP: Mestre Jou.

(2006). Seis estudos de psicologia. RJ: Forense.

Ribeiro, M. S. (1999). A questão da família na atualidade. Florianópolis: JOESC.

Richardson, R. J. (2010). Pesquisa Social: métodos e técnicas. 3 ed. São Paulo: Atlas.

Vygotsky, L.S. (1993). Pensamento e linguagem. São Paulo: Martins Fontes.

Yin, R. K. (2016). Pesquisa Qualitativa: do início ao fim. Porto Alegre: Penso.

Wallon, H. (1995). A evolução psicológica da criança. Lisboa, Edições 70.Illicachi, J. (2007). Discriminación discursiva y dominación étnica en la educación. Reporte de investigación. Quito, Ecuador: FLACSO. 


\section{Sección Miscelánea}

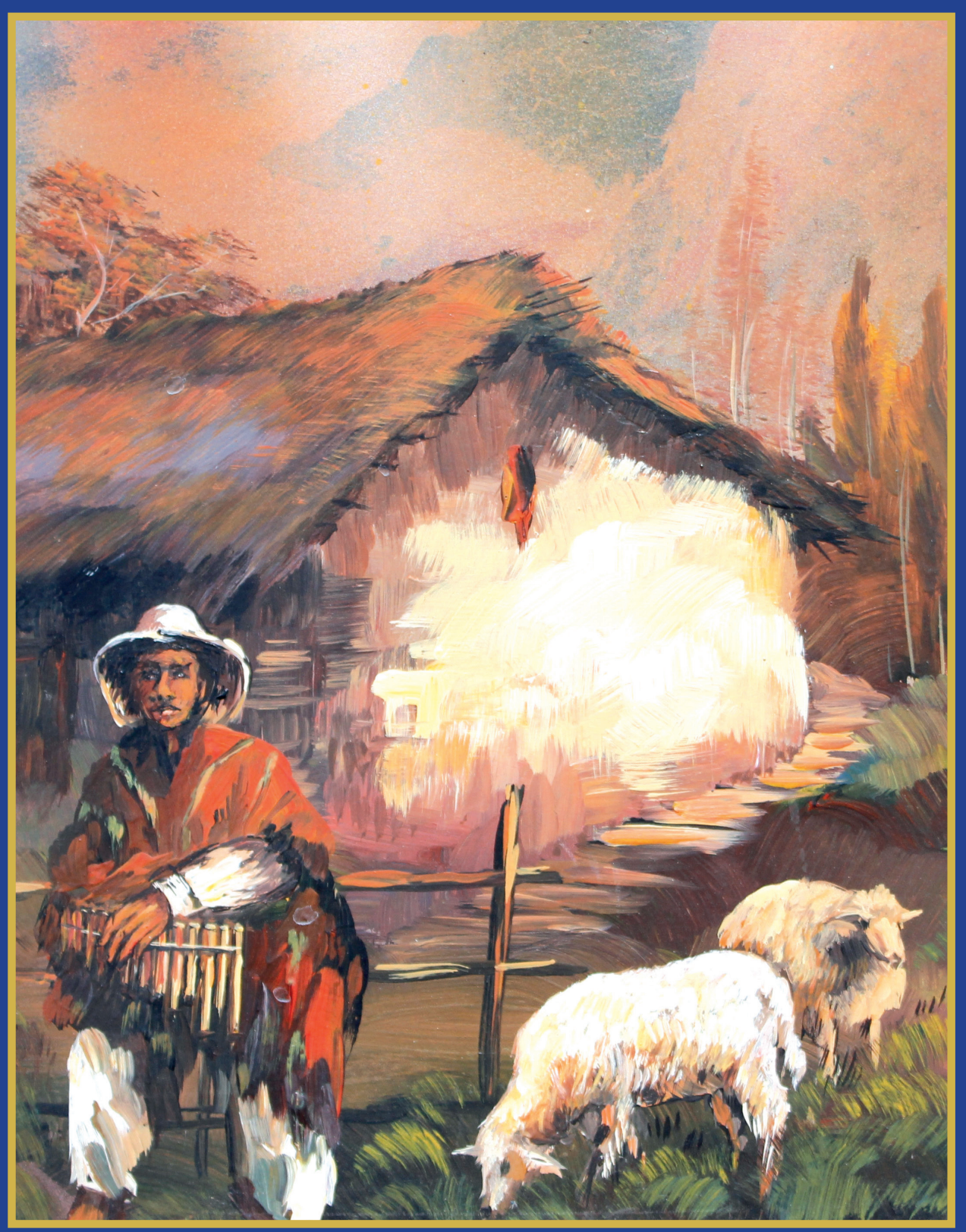

Pastor de los Andes

Acrílico sobre lienzo 


\section{Alfabetizando al alfabetizador: Mujeres hispanas en un nuevo contexto social}

\section{Educating the Educator: Hispanic women in a new social context}

Investigación

Luis Javier Pentón Herrera

Doctorando Concordia University Chicago - USA luis.penton@gmail.com

Ángel A. Toledo López

Sistema Universitario Ana G. Méndez, Universidad del Este - Puerto Rico atoledo@suagm.edu

Recibido: 7 de noviembre de 2016 / Aceptado: 13 de diciembre de 2016

\section{Resumen}

La población hispana en Estados Unidos continúa aumentando establemente y de forma rápida. Este incremento fértil y constante de hispanos ha reorganizado el matiz social del país y expone a los inmigrantes a unas realidades sociales, lingüísticas y educativas no conocidas anteriormente. Estudiantes inmigrantes hispanos aprendices del idioma inglés son inmersos en un sistema educativo completamente desconocido y se enfrentan a un reto lingüístico que necesitan rebasar de forma diligente para tener éxito en sus escuelas. A su vez, los padres inmigrantes atraviesan otros retos similares en sus ambientes laborales en los cuales el idioma y otros componentes sociales les dificultan el éxito profesional y el involucramiento en las escuelas de sus hijos. Este artículo expone las realidades de los estudiantes hispanos y las madres hispanas en Estados Unidos a través de los ojos de cuatro madres hispanas inmigrantes. Mediante la entrevista profunda, este trabajo expone el impacto que tiene la participación parental en el desenvolvimiento escolar y académico de los estudiantes hispanos en Estados Unidos.

Descriptores: ELL, HSS, BLL, consorcio parental, inmigrantes hispanas, estudiantes hispanos.

\section{Abstract}

The Hispanic population in the United States continues growing steadily and rapidly. This fertile and constant growth has reorganized the country's social milieu and exposes immigrants to social, linguistic and educational realities that were previously unknown. Hispanic immigrant English Language Learners are immersed in a completely unfamiliar academic system and face linguistic challenges that must be overcome if they are to be successful in school. In the same way, immigrant parents undergo similar challenges in their work environments in which language and other social barriers impede their professional success and involvement in their children's academic life. This work presents the experiences of Hispanic students and mothers in the United States through the eyes of four Hispanic immigrant women. In depth interviews were used to test for the impact that parental involvement has in the academic development of Hispanic students in the United States.

Keywords: ELL, HSS, BLL, parental involvement, immigrant women, hispanic students.

Forma sugerida de citar: Pentón Herrera, Luis \& Toledo López, Ángel (2017). Alfabetizando al alfabetizador: Mujeres hispanas en un nuevo contexto social. Alteridad, 12(1), pp. 68-78. 


\section{Introducción}

La población hispana se duplicará en cantidad para el año 2060 (Buró del Censo de Estados Unidos, 2014). Es alarmante que el sistema educativo estadounidense no brinda a muchos estudiantes hispanos las herramientas necesarias para aprender inglés (Schneider, Martinez, y Owens, 2006), hacerse biletrados (Pentón Herrera y Duany, 2016) o graduarse (Balfanz et al., 2014). Esto provocará que, para el año 2060, se cree en Estados Unidos una brecha social y educativa aún mayor que dividirá generaciones de familias hispanas iletradas cuyos abuelos, padres e hijos no recibieron la educación necesaria para ser exitosos en sus vidas profesionales (Putman, et al., 2016). Contribuir al desarrollo de las futuras generaciones de estudiantes hispanos en Estados Unidos cobra, entonces, gran importancia.

La población actual de estudiantes hispanos que asiste a las escuelas primarias y secundarias en Estados Unidos se divide en dos grupos principales: (1) estudiantes inmigrantes hispanos aprendices del idioma inglés (ELLs por sus siglas en inglés) y (2) estudiantes hispanos que nacieron y crecieron en Estados Unidos, conocidos como hispanoparlantes por herencia (HSS por sus siglas en inglés). A pesar de que existe una gran diferencia en las realidades sociales y académicas de los ELLs y HSS, estudios demuestran que ambos grupos de estudiantes hispanos tienen un bajo rendimiento académico (Jacobs, 2016; Sparks, 2015). Por su parte, los HSS usan el español limitadamente. Esto, unido a la fuerte influencia que tiene el idioma inglés sobre sus vidas, tiene un impacto en el desarrollo de destrezas de alfabetización académica en ambos idiomas (Viola y Stefan, 2014).

Estudiantes inmigrantes de México, Guatemala, Honduras y El Salvador son actualmente la población de estudiantes ELLs de mayor crecimiento en las escuelas primarias y secundarias en Estados Unidos (Ferris y Raley, 2016). Una reciente publicación de Pentón Herrera y Duany (2016) destaca las necesidades académicas y lingüísticas de esta población estudiantil e introduce el concepto aprendiz binario de lenguajes (binate language learners o BLL por sus siglas en inglés) para describir a una gran proporción de estudiantes inmigrantes de estos países. Los BLLs son estudiantes que, además de ser ELLs, son iletrados, o tienen bajo aprovechamiento en sus destrezas lingüísticas en su lengua materna (L1), en este caso, español. Los BLLs llegan a las aulas estadounidenses con grandes deficiencias en destrezas lingüísticas en español que no fueron satisfechas en sus países natales. El problema es que las escuelas en Estados Unidos no tienen los recursos necesarios para llenar estas brechas. Como consecuencia, los padres se convierten en la fuente de apoyo más poderosa y en el puente que contribuye a crear redes de apoyo entre sus hijos, la escuela, la comunidad y el hogar. Estas redes de apoyo brindan la fortaleza necesaria para que los estudiantes se integren al proceso académico, tomen control de su proceso educativo y salgan airosos en el desarrollo de destrezas académicas y de lenguaje.

Muchos estudios sugieren que la participación de los padres en los asuntos académicos de sus hijos menores es clave en el éxito de estos últimos. Esto es particularmente cierto en el caso de estudiantes hispanos que asisten a escuelas en Estados Unidos (González et al., 2014; Hugo López, 2009; LaBahn, 1995; Panferov, 2010). Por el otro lado, otros estudios demuestran el impacto negativo que tiene la falta de participación parental en nuestra sociedad, nuestras escuelas y el éxito académico de estudiantes hispanos (LaBahn, 1995). Sin embargo, no existen muchos estudios que discutan las diferencias culturales y definan específicamente qué significa la participación parental.

Este estudio se enmarca en teorías sociológicas sobre roles sociales y motivación para auscultar cómo las madres hispanas se convierten en vehículos catalizadores del éxito académico de sus hijos. El estudio evalúa las posturas de madres inmigrantes hispanas que participaron de entrevistas profundas para analizar su sentir acerca de la importancia de educarse como adul- 
tas. Llegadas a la adultez, estas mujeres tenían la opción de trabajar o no y estudiar o no con el fin de lograr sus propósitos. Algunas utilizaron su propia educación como vehículo para promover el éxito estudiantil de sus hijos. Otras, valoraron su rol de madres dentro del núcleo familiar y optaron no seguir sus metas académicas. El estudio proveyó una oportunidad particular para evaluar tres principios esenciales: cómo la educación para adultos promueve el éxito académico de los hijos; cómo la educación para adultos promueve la participación parental en las escuelas de sus hijos; y, qué motivaciones o situaciones viabilizan que las madres inmigrantes hispanas opten por educarse y busquen mejores oportunidades laborales al llegar a Estados Unidos.

\section{Fundamentación teórica}

El impacto del consorcio parental en el éxito académico de los estudiantes es un tema que ocupa a maestros, administradores y generadores de política pública. En el campo de la educación, la participación o consorcio parental se define como la interacción de los padres con las escuelas y con sus hijos para promover el éxito académico de estos últimos (Kim y Hill, 2015). La participación parental se extiende no sólo al ámbito escolar, sino también al hogar. Esto significa que el consorcio parental incluye el compromiso de los padres para proveer, constante y consistentemente, recursos necesarios para que sus hijos alcancen el éxito en el ambiente académico

Varias investigaciones discuten la relación que existe entre el consorcio parental y el éxito académico de los hijos (Goodall y Montgomery, 2014; Harris y Goodall, 2008; Kim y Hill, 2015; Wilder, 2014). Estudios destacan el compromiso laboral como uno de los impedimentos más importantes para lograr que los padres se integren al proceso educativo de sus hijos (Harris y Goodall, 2008). A este se le unen el desconocer el idioma y el analfabetismo que impide que los padres engranen en el proceso académico y se involucren más en las escuelas. Como consecuen- cia, se han diseñado muchos programas para proveer a los padres la oportunidad de involucrase activamente para promover el éxito académico de sus hijos (Harris y Goodall, 2008). Estos programas identifican a los padres como agentes del éxito académico de los menores y cuenta con ellos para garantizar que los estudiantes tengan una oportunidad equitativa y justa de lograr sus metas educativas y profesionales.

El compromiso que los padres asumen en el hogar establece los cimientos para la exitosa ejecutoria académica de los hijos. Wilder (2014) encontró que el involucramiento parental tiene un impacto fuerte y positivo en el desarrollo de hábitos de estudio en los menores y en su posterior éxito académico. Este estudio identificó una correlación existente entre el involucramiento parental en el hogar y el aprovechamiento académico de los hijos. Cuando los padres se involucran en la vida académica de sus hijos desde el hogar, los estudiantes obtienen mejores calificaciones y son más exitosos en la escuela. De igual modo, Harris y Goodall (2008) afirman que el involucramiento parental en el proceso de aprendizaje de los hijos provoca enormes diferencias en el aprovechamiento académico de estos últimos. Esto implica que los padres tienen que involucrarse activamente en establecer normas, y guiar y trabajar con sus hijos estudiantes en la casa. Este compromiso activo por parte de los padres tiene un efecto positivo en el aprendizaje subsiguiente y en el éxito profesional de los menores (Harris y Goodall, 2008).

Cuando los padres se involucran en la escuela, se crea una sinergia padre, hogar y escuela. Goodall y Montgomery (2014) encontraron que el involucramiento parental es instrumental en el proceso de regeneración de ambientes escolares particularmente en escuelas en las que los niños no están ejecutando según esperado. Además, los padres, como coeducadores en las escuelas, contribuyen a mejorar la cultura escolar. El involucramiento parental es un reflejo del interés que tienen los padres en el éxito académico de sus hijos. Por tal razón, los padres que se 
involucran activamente, fortalecen las relaciones familia-escuela y promueven el éxito de los hijos desde el hogar. Tomando esto en consideración, es imperativo considerar qué motivaciones viabilizan que los padres inmigrantes hispanos desarrollen las destrezas necesarias para su mejoramiento y para brindar apoyo a sus hijos.

Este análisis obliga a revisitar el tema de la sociología de la educación e integrar el tema de la cultura y las normas sociales establecidas. Las normas sociales que imperan en los países latinoamericanos se trasladan a Estados Unidos con cada inmigrante y se ponen en práctica entre grupos culturalmente homogéneos. Indudablemente, la cultura que se experimenta en el país de origen, particularmente los países de habla hispana, es diferente a la que se vive en Estados Unidos. Esto implica que, en este proceso de adaptación, se fortalecerán las prácticas sociales y culturales que se traen consigo. Los inmigrantes buscarán identificarse con grupos similares a los suyos de manera que puedan integrarse más eficazmente y acelerar el proceso de adaptación. Ahora bien, mientras más el inmigrante busca asociarse con aquellos grupos con los que se identifica, menos se integra a la cultura del nuevo país y menos necesidad tiene de aprender el nuevo idioma.

Uno de los rasgos que trae consigo el inmigrante y que implementa en el país al que inmigra es el de los roles de género. Lewis (2003) afirma que la diferenciación entre masculinidad y feminidad depende de temas de identidad nacional, clase, raza, religión y etnicidad, entre otros factores. Desde esta perspectiva, la definición de género es socialmente construida a la luz de las diferencias percibidas entre los determinantes biológicos de la mujer y el hombre. Esto implica que los roles de género, o las expectativas sociales que se les imponen a cada persona según su género, se crean culturalmente y se asignan a la luz de la construcción social basada en tradiciones y costumbres. Entonces, para entender algunos comportamientos sociales que adoptan las personas en el ámbito educativo, profesional o familiar, es imperativo conocer las diferencias sociales que imperan entre la masculinidad y la feminidad (Toledo López, 2002). Las expectativas sociales que se les imponen a los hombres y a las mujeres impactan sus comportamientos y las decisiones que toman a lo largo de su vida. El proceso de socialización lleva a los individuos a entender que deben comportarse de cierta manera para llenar las expectativas sociales que le han sido impuestas por razón de su sexo.

Estos patrones de conducta se recrean y se reviven en el extranjero cuando la familia hispana emigra al exterior. La mujer, por su parte, permanece limitada a los confines de la comunidad hispana donde escogió vivir para facilitar su integración, mientras que el hombre rompe las fronteras del barrio o la comunidad, para exponerse a los retos sociales, lingüísticos y económicos con el fin de proveer para su familia. Los roles de género que vivían en sus países de origen se reconstruyen en el nuevo ambiente en el que la mujer permanece bajo el control del hombre -esposo, padre, hermano o hijo- y es más o menos tratada como menor de edad (Bullough, 1979). Según Dávila (2013), la relación hombre-mujer entre los hispanos es una de hombre dominante y mujer sumisa en la que la mujer se deja llevar por normas sociales que las construyen dependientes e incapaces de asumir grandes responsabilidades. Esto explica porqué la mujer hispana, al llegar a Estados Unidos, se encierra dentro de las fronteras de su comunidad y no se expone a aprender el idioma. Se trata de un mecanismo de protección que, eventualmente, tendrá impacto directo en su vida y en la de sus hijos. Foster (1994) atribuye esta costumbre muy hispana a tres factores importantes: la disciplina militar que ha imperado en muchos países de Centro y Sur América; la moral católica que predomina en las sociedades hispanas; y las creencias familiares tradicionales hispanas que hacen que la mujer se circunscriba a unos roles claramente establecidos.

Este fenómeno cultural trae implicaciones serias, particularmente para la mujer hispana, dentro del nuevo contexto social al que se enfrenta. La mujer inmigrante hispana no encuentra razones válidas para educarse ni lingüística ni 
profesionalmente ya que, dentro de los confines de su comunidad, otro idioma además del español resulta innecesario. Trabajar tampoco le es requerido ya que su esposo es quien suple. Sus necesidades se establecen dentro de su nuevo entorno para garantizar la protección que alegadamente necesitan. Dentro del ambiente resguardado y protegido, se comunican en su idioma y cumplen con las labores que sus costumbres y tradiciones les permiten. Mientras el hombre exista, ellas atienden el hogar no solo porque ahí están protegidas, sino también porque ese es su trabajo como mujer. La crianza de los niños les compete a ellas, lo que también representa un reto enorme porque no pueden integrarse al ambiente escolar de estos ni pueden asistirlos en su proceso de aprendizaje e integración social, cultural y lingüística.

La ausencia del hombre en el cuadro familiar y social de la inmigrante hispana provoca que sus estructuras y necesidades se redefinan. Sus necesidades se reorganizan y asumen un nuevo orden jerárquico. Según Maslow (1943), las necesidades humanas se organizan jerárquicamente desde aquellas que plantean la plena subsistencia hasta las que competen la autorrealización. Para alcanzar necesidades de mayor jerarquía, es imperativo satisfacer aquellas que se encuentran en la base y que garantizan la vida y otras necesidades humanas básicas. Alcanzar determinadas metas, afirma Maslow (1943), motiva a los seres humanos a progresar hacia nuevos horizontes y satisfacer otras necesidades. Por ejemplo, una vez que se tiene garantizada la subsistencia, el techo y la cobija, puede darse paso a otras necesidades como el mejoramiento personal, el servicio comunitario y la acción creativa. Esta teoría nos permite comprender porqué, ante la presencia de una figura masculina en el hogar, la mujer hispana inmigrante en Estados Unidos no tiene motivos para educarse, aprender el idioma inglés y buscar integrarse a la cultura general estadounidense. Dentro de los límites comunales y de su hogar se siente protegida. Este sentido de protección no es tal que le permita moverse más allá para satisfacer otras necesidades, sino suficiente para sentir que vive con lo mínimo necesario. Se dedica a su familia y cumple con su rol de género, según su cultura lo establece. El reto comienza cuando el hombre -esposo, hijo, padre- se ausenta bien sea por muerte, mudanza, divorcio o cualquier otra razón. Esto reta los estándares sociales establecidos y obliga a la mujer inmigrante hispana a asumir posturas que antes no le eran requeridas. Esto rompe sus esquemas y les obliga a moverse de su zona de confort en un ambiente que, por mucho tiempo, le era desconocido. La motivación, entonces, surge a causa de un cambio en su situación de vida -la ausencia de la figura masculina- y la mueve a adelantar sus estudios y trabajar, lo que, a su vez, crea las condiciones para su integración en la vida académica de sus hijos. En fin, se presenta como una cadena de eventos que unidos, producen el enlace entre mejoramiento académico y profesional como adulta y el desempeño positivo de sus hijos en el ambiente escolar.

En resumen, este estudio plantea que las situaciones sociales y culturales de la mujer hispana inmigrante establecen el marco dentro del cual ella actúa al llegar a Estados Unidos. Mientras se perpetúan las circunstancias que le permiten mantener y revivir los roles de género que su cultura le impone, ellas se mantendrán ejecutando su rol de mujer cuidadora del hogar. Ahora bien, cuando se altera su entorno y cambian las situaciones, surgen las motivaciones necesarias para que ella rompa esquemas y busque satisfacer otras necesidades que no tenía como prioridad. $\mathrm{Al}$ buscar satisfacer otras necesidades, como las educativas y profesionales, se crean ambientes más propicios para que sus hijos menores también alcancen sus metas académicas en un ambiente saludable y estable. Con conocimiento del inglés, la mujer hispana inmigrante puede insertarse en el mercado del empleo y de la educación en Estados Unidos lo que, a su vez, le permitirá integrarse activamente en el proceso académico de sus hijos. De este modo, la educación adulta se establece como un mecanismo a través del cual se promueven los éxitos académicos de los menores. Gráficamente, se puede resumir esta hipótesis situacional/motivacional de la siguiente manera: 


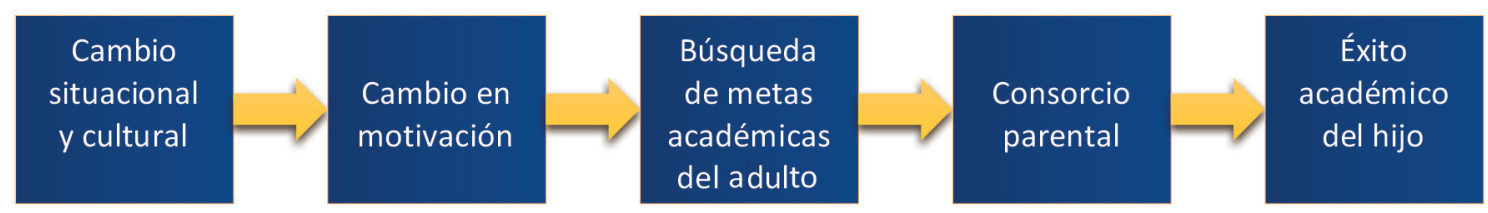

\section{Fundamentación metodológica}

Para corroborar esta hipótesis, se realizaron cuatro entrevistas profundas a cuatro mujeres hispanas que inmigraron a Estados Unidos. Se utilizó la variable de trabajo como factor de clasificación. Dicho de otro modo, sus características son esencialmente similares ya que todas son mujeres, hispanas, inmigrantes y madres, pero dos trabajan fuera del hogar y dos son amas de casa. Las entrevistas son en forma de estudios de caso sobre las experiencias de estas mujeres en el manejo de su entorno familiar. Los cuatro casos nos permiten analizar cómo el involucramiento, o falta de éste, de estas madres en los procesos académicos de sus hijos ha impactado el posterior desenvolvimiento de los jóvenes en el entorno escolar. De igual modo, las entrevistas arrojan luz sobre las motivaciones que tienen las madres participantes para buscar un trabajo, aprender el idioma inglés e involucrarse en los procesos académicos de sus hijos.

El estudio de caso resulta ser la metodología investigativa más apropiada para este análisis. Esta metodología permite explorar el fenómeno bajo estudio desde múltiples ópticas, lo que ayuda a ver el carácter multidimensional del tema (Baxter y Jack, 2008). Además, nos permite analizar el contexto dentro del cual ocurre el fenómeno bajo estudio (Yin, 2003). Ambas de estas fortalezas permiten que el estudio de caso se utilice con eficacia en el presente análisis. Este estudio mira porqué las mujeres hispanas inmigrantes optan por trabajar y aprender inglés como segundo idioma. Se enfoca en las condiciones contextuales de cada una de ellas y mira sus historias de vida para identificar factores que las motivaron o no a explorar alternativas laborales y lingüísti- cas. El análisis de estos casos permite ver cómo las diversas circunstancias impactan de diferentes formas a estas mujeres que participaron del estudio. Naturalmente, el análisis parte de unas variables control que permiten ver el impacto de las variables de estudio sobre las motivaciones y situaciones de las participantes. La decisión que toman estas mujeres de aprender o no un segundo idioma y de trabajar o no nos permite comprender las dinámicas de la educación para adultos y entender cómo la educación de las madres y su involucramiento en el proceso educativo de sus hijos impacta el desarrollo académico de los menores.

De modo que, las participantes de este estudio se ubican en uno de dos grupos: aquellas que trabajan y hablan inglés, y las que no trabajan y no hablan inglés. Provienen estas participantes de cuatro países de habla hispana, dígase, El Salvador, Cuba, Colombia y Honduras. Las preguntas efectuadas giraron en torno a la experiencia migratoria, el momento de entrada a Estados Unidos, el contexto familiar y social bajo el cual entraron y su conocimiento del idioma inglés al momento de entrar. De igual modo, se exploró su actual situación familiar, su conocimiento del inglés en el momento actual, la situación laboral y las motivaciones que tuvieron para cambiar su vida o permanecer bajo situaciones similares a las que existían cuando entraron a Estados Unidos.

\section{Análisis y resultados}

\section{Participantes bilingües que trabajan}

Dos participantes reportaron encontrarse trabajando al momento de la entrevista y capaces 
de comunicarse tanto en inglés como en español. Ambas llegaron a Estados Unidos hace más de dieciséis años, pero una comenzó a aprender inglés antes que la otra. La participante de Colombia, quien inmigró sola con sus hijas, comenzó su proceso de aprendizaje del segundo idioma tan pronto llegó a Estados Unidos. La participante de Honduras, sin embargo, mostró interés en aprender inglés a los nueve años de encontrarse en Estados Unidos. La participante colombiana indicó que el aprendizaje del inglés le resultó indispensable toda vez que tenía que proveer para sus hijas. Entendió que aprender inglés le permitía crecer profesionalmente de manera que pudiera ayudar a sus hijas a desenvolverse apropiadamente en un ambiente que les resultaba extraño. De igual modo, indicó que un factor de gran peso que la movió a aprender inglés de inmediato fue su necesidad de comprender el sistema educativo estadounidense y su funcionamiento. Ella valoró mucho el poder comunicarse con las maestras de sus hijas para identificar maneras en las que podía ayudar a las menores que pasaban por un proceso difícil de ajuste social, académico y lingüístico. Aprender inglés le permitió integrarse más fácilmente a su comunidad y emprender profesionalmente en un campo laboral de difícil manejo. De igual modo, le permitió comunicarse con las maestras de sus hijas, explorar alternativas de estudios para las menores y asistirles en su proceso académico. Le sirvió ella de modelo a ambas de sus hijas quienes hoy día son profesionales altamente capacitadas y con destrezas lingüísticas en ambos idiomas, inglés y español.

A su llegada, la participante colombiana descansaba en sus dos hijas para comunicarse. Las menores adquirieron destrezas en el idioma inglés con relativa facilidad. Se comunicaban son sus compañeros de escuela y con sus maestras, y demostraban tener éxito académico y buen ajuste social. En esa etapa, las dos menores asistían a su madre a ajustarse al nuevo contexto social y económico. Le servían de intérprete y le ayudaban a comunicarse efectivamente. Debido a que había llegado sola a Estados Unidos, la participante colombiana entendió imperativo aprender el idioma y trabajar de manera que pudiera proveer el sustento para sus hijas. Su motivación era clara y, en esencia, la situación a la que se enfrentaba la forzó a asumir roles importantes que, típicamente, nuestras sociedades asignaban a los hombres.

Por su parte, la participante hondureña, abandonó su país de origen en búsqueda de mejores condiciones de vida para su familia. Llegó a Estados Unidos con su entonces esposo y se acomodó en un ambiente social y cultural que le apoyaba sus raíces. Ante su desconocimiento del idioma y de las normas sociales de un nuevo país, la familia optó por buscar bolsillos culturales en los que la participante se sintiera cómoda. Desde ahí, podía cuidar a los hijos, conversar con personas de similar bagaje cultural y mantenerse en un ambiente resguardado y poco intimidante para ella. Su entonces esposo era quien se enfrentaba al diario fuera de la burbuja cultural y fue quien adquirió destrezas lingüísticas en inglés más fácilmente. Él se ocupaba de proveer para la familia y trabajar a diario, mientras que ella cuidaba de la familia y de la casa.

Su poca o ninguna exposición a contextos sociales estadounidenses retrasaron en la participante hondureña el proceso de adquisición de destrezas idiomáticas en inglés. Luego de la ruptura de su matrimonio, aprender inglés y trabajar dejaron de ser opciones. La responsabilidad parental de criar a sus hijos se complicó bastante no solo porque estaba sola, sino también porque no conocía el idioma. Indicó la participante hondureña que en Estados Unidos "quien no habla inglés, no es nadie". Ilustró su sentir explicando que asistir a sus hijos, proveerles apoyo académico, comunicarse con las maestras y socializar en los entornos de sus hijos le resultaba imposible. De igual modo, obtener un trabajo que le remunerara lo suficiente para mantener la familia a flote también era bastante cuesta arriba. Se vio obligada a aprender inglés por las circunstancias que le sobrevinieron luego de su separación. Tuvo que salir de su burbuja social y cultural 
para enfrentarse a un mundo desconocido en el que había vivido por espacio de nueve años. Finalmente, tuvo que visitar las escuelas de sus hijos para ponerse al día de los requisitos importantes, comunicarse con las maestras y ofrecer el apoyo que sus hijos necesitaban. Indica la participante hondureña que su principal motivación era ser un ejemplo para sus hijos. Posteriormente, se matriculó en un programa universitario para obtener una carrera y perfeccionar sus destrezas de comunicación escrita en inglés. Sus hijos, quienes ya se habían adaptado al sistema escolar estadounidense, vieron en el esfuerzo de ella un ejemplo de superación y de éxito. Hoy día continúan sus carreras escolares en búsqueda de un grado académico profesional.

\section{Participantes monolingües que no trabajan}

Dos participantes indicaron que actualmente no trabajan y que no se comunican en el idioma inglés. Ambas han vivido en Estados Unidos por más de diez años y ambas indican que el español es su idioma materno. Ambas indican que la razón primordial para no aventurarse a trabajar ni a aprender el inglés es que prefieren dedicarse a sus familias. Intentaron asistir a escuelas de idiomas para adquirir destrezas lingüísticas en inglés, pero entendieron que esto les quitaba tiempo para estar con sus familias. Irónicamente, la participante salvadoreña indicó que su desconocimiento del inglés le impide asistir a su hija en su proceso académico ahora que se encuentra en la escuela. Sin embargo, ambas admiten que aprender un segundo idioma promueve el crecimiento personal y profesional, y provee una herramienta esencial para alcanzar metas laborales.

Las dos participantes aclararon que se sienten muy incómodas de su incapacidad de comunicarse en inglés, pero que ya es muy poco lo que pueden hacer porque les corresponde atender a sus familias. La participante cubana indicó: "no me siento cómoda con mi conocimiento del lenguaje. Ahora, lo único que me restaría es quitarle tiempo a mi hijo para aprender inglés, y no voy a hacer eso". Para ambas participantes, resulta muy difícil manejarse en un ambiente extraño cuando no conocen el idioma. Se sienten inseguras y, como consecuencia, se han limitado a un ambiente muy cerrado en el que comparten solo con la comunidad y con las personas del hogar. Todavía no ven la necesidad de aprender el idioma, aun cuando esto les impida involucrarse más en las escuelas de sus hijos, establecer lazos con los maestros y contribuir al proceso académico y éxito escolar de los menores. Ambas dependen de sus esposos para moverse, comunicarse y socializar. Sus formas de sustento están supeditadas a la capacidad económica que puedan lograr los esposos y a lo que ellos puedan proveer. Muestran lamento por no poder ayudar más a sus hijos en sus faenas escolares porque ellas mismas no están preparadas académicamente ni conocen el inglés. Esta situación es particularmente más difícil para la participante salvadoreña quien reside en el estado de Maryland, Estados Unidos en donde imperan los sistemas escolares predominantemente anglosajones con algunos bolsillos sociales y culturales que corresponden a la comunidad hispana. El hijo de la participante cubana no muestra tanta dificultad académica como la hija de la participante salvadoreña porque este y su familia residen en Miami, Florida, donde la población y la cultura hispana está entronizada a través de los inmigrantes cubanos. Esto no implica, sin embargo, que el hijo de la participante cubana no muestra dificultades académicas en la escuela, sino que ella, debido a que algunas maestras de su hijo hablan español, puede comunicarse con ellas para conocer sobre los problemas que enfrenta su hijo. Lo que no puede hacer, porque no tiene las destrezas académicas ni lingüísticas suficientes, es apoyar al menor desde el hogar para solidificar las herramientas y el soporte que recibe en la escuela.

\section{Discusión y conclusiones}

La finalidad de este estudio es evaluar cómo los cambios situacionales en la vida de las mujeres inmigrantes hispanas pueden impactar su entor- 
no, romper sus esquemas y motivarlas a perseguir metas académicas y lingüísticas que redundarán en beneficios para ella y su familia. Más específicamente, el estudio busca identificar si la educación de adultos se convierte en vehículo para fomentar la excelencia académica en los hijos y propiciar ambientes de enlace entre el hogar y la escuela. La teoría establece que una mayor participación o consorcio parental con la escuela provoca mayor aprovechamiento académico en los hijos. Los padres que se involucran activamente en las actividades escolares de sus hijos tanto en el hogar como en la escuela, logran que los menores se adapten más rápidamente al ambiente escolar y que muestren mayor aprovechamiento académico que sus contrapartes. Ahora bien, para que se dé el consorcio parental, tienen que existir las condiciones que lo propicien entre aquellos llamados a ocuparse de los menores.

En las culturas hispanas, son las madres las que cargan con la responsabilidad de criar a sus hijos menores. Un enfoque en las teorías de asignación de roles de género permite ver que las sociedades hispanas, debido a las tradiciones entronizadas, la moral religiosa y la cultura militar, promueve que el hombre sea el jefe de la casa y proveedor, mientras que la mujer cuida de los menores y atiende las faenas diarias del hogar. Cuando emigran a Estados Unidos, estas familias traen consigo sus tradiciones culturales y las recrean en un ambiente social que les resulta cómodo y en el que la mujer está protegida. Es el hombre quien se enfrenta al ambiente desconocido, aprende el idioma y se integra lo más rápido posible al ambiente laboral. Esto implica, sin embargo, que la mujer queda rezagada y, quizás, recluida en los confines comunitarios que le resultan conocidos y familiares. El cambio situacional y, como consecuencia, esquemático-social, ocurre cuando desaparece la figura masculina del panorama familiar. Esto puede ocurrir por razón de divorcio, muerte, viaje o cualquier otra razón que separe al asignado proveedor del núcleo familiar al que alimenta y sostiene. Ante este nuevo panorama, la mujer inmigrante hispana se ve en la obligación de adoptar roles que le son extraños en un ambiente que, por su segregación, le resulta también extraño. Consecuencia de esto es que esta mujer ve en su educación adulta un vehículo para alcanzar metas que anteriormente no podía alcanzar. Valora, como resultado, el adaptarse al ambiente social más allá de la comunidad y aprender el idioma de la metrópolis para integrarse a un mundo laboral que le permitirá proveer el sustento para su familia.

Este estudio valida el argumento situacional/motivacional y su conexión con las consecuencias académicas para los estudiantes menores de edad dependientes de las madres participantes. En los hogares en los que se produjeron cambios en el ambiente familiar, las participantes se vieron motivadas a aprender el idioma inglés y obtener una carrera profesional. Ambos recursos, según ellas, se convirtieron en el vehículo para alcanzar mayor estabilidad económica y seguridad en el hogar. Mientras aprendían el idioma, se integraban al mundo laboral de manera que proveyeran para el sustento de sus menores. Ambas vieron que este cambio les permitió crear lazos importantísimos con los maestros de sus hijos que redundaron en beneficios para los menores. Estas madres pudieron dar apoyo académico desde el hogar. Esto facilitó la integración de los menores al ambiente académico que desconocían. De igual manera, las madres se hicieron más participativas en las escuelas de sus hijos, lo que les permitió dar más y mejor seguimiento al progreso académico de estos. Ambas afirmaron que esta integración les sirvió tanto a ellas como a los menores en sus respectivos procesos de integración social, cultural y académica.

Por su parte, las participantes que optaron por mantenerse en el hogar para cumplir con sus roles femeninos hoy día resienten el no haber aprendido inglés. Están felices porque pudieron darles a sus hijos calidad de vida familiar en el hogar, pero reconocen que no pudieron darles soporte académico que facilitara su integración a un ambiente escolar desconocido para ellos. Ambas afirmaron la importancia de aprender el 
idioma como adultas y de educarse independientemente de su edad, pero coincidieron en que se les había hecho demasiado tarde porque su prioridad seguía siendo su familia. Es importante señalar que en ambos de estos casos imperaba la estructura familiar tradicional en la que el hombre ostentaba la posición de cabeza de familia y proveedor de las necesidades del hogar.

Este análisis, preliminar de cierto modo, evidencia el vínculo que existe entre la educación para adultos y el éxito académico de los hijos. Cuando alfabetizamos a la alfabetizadora, le damos las herramientas que necesita para superarse y para viabilizar la superación y el éxito de quienes dependen de ella. La sinergia madre-hogar-escuela permite que los hijos se desarrollen en un ambiente protegido y resguardado que les dé la estabilidad que necesitan para integrarse lingüística y académicamente al ambiente escolar dentro del nuevo contexto. La madre (y el padre también), como modelo y ejemplo, en la medida en que se educa promueve el crecimiento propio y el de sus hijos. Esta madre (y padre) busca integrarse al ambiente escolar para traer la escuela a la casa y hacer al maestro partícipe de las experiencias de sus hijos. Esta combinación promueve el crecimiento y la excelencia académica tan necesaria en un mundo globalizado y competitivo como el de hoy.

\section{Referencias bibliográficas}

Balfanz, R., Bridgeland, J. M., Fox, J. H., DePaoli, J. L., Ingram, E. S., \& Maushard, M. (2014). Building a grad nation: Progress and challenge in ending the high school dropout epidemic. Civic Enterprises. Recuperado de http://files. eric.ed.gov/fulltext/ED556758.pdf

Bullough, V. (1979). Homosexuality: A history. New York, NY: A Meridian Book, New American Library.

Dávila, J. (2013). Sexualidad, género y sociedad en la literatura del Caribe hispanoparlante (19502000) (Doctoral dissertation). Recuperado de ProQuest LLC. (UMI Number 3561667).

Ferris, M. \& Raley, S. (2016). The elephant in the classroom: Mass immigration's impact on public education. Fair Horizon Press. Rescatado de http://www.fairus.org/DocServer/researchpub/FAIR_2016_Education_Report.pdf

Foster, D. (1994). Cultural diversity in Latin American literature. Albuquerque, NM: University of New Mexico Press.

Gonzalez, C., Hutchins, M. C., Hernandez, C., Llama, M., Rossie, M., \& Suarez, S. (2014).

Parents Acquiring Learning Strategies (PALS): How empowering Hispanic parents increases parental involvement and student achievement. Recuperado de http://citeseerx. ist.psu.edu/viewdoc/download?doi=10.1.1.4 $25.6722 \&$ rep $=$ rep $1 \&$ type $=$ pdf

Goodall, J. \& Montgomery, C. (2014). Parental involvement to parental engagement: A Continuum. Educational Review, 66(4), pp. 399-410.

Harris, A. \& Goodall, J. (2008). Do parents know they matter? Engaging all parents in learning. Educational Research, 50(3), pp. 277-289.

Lopez,M.H.(2009).Latinos and education: Explaining the attainment gap. Pew Research Center: Hispanic Trends. Recuperado de http://www. pewhispanic.org/2009/10/07/latinos-andeducation-explaining-the- attainment-gap/

Jacobs, J. (2016). Learning English: Accountability, common core and the college-for-all movement are transforming instruction. Education Next, 16(1), pp. 38-45.

Kim, W. S. \& Hill, N. E. (2015). Including fathers in the picture: A meta-analysis of parental involvement and students' academic achievement. Journal of Educational Psychology, 107(4), pp. 919-934.

LaBahn, J. (1995). Education and parental involvement in secondary schools: Problems, solutions and effects. Educational Psychology Interactive. Recuperado de http://www.edpsycinteractive.org/files/parinvol.html

Lewis, L. (2003). Introduction. En: L. Lewis (Ed.), The culture of gender and sexuality in the Caribbean (pp. 1-21). Gainesville, FL: University Press of Florida.

Maslow, A. (1943). A theory of human motivation. Psychological review, 50(4), 370-396.

Panferov, S. (2010). Increasing ELL parental involvement in our schools: Learning from the parents. Theory into Practice, 49(2), 106-112. 
Pentón Herrera, L. J. \& Duany, M. (2016). Native Spanish speakers as binate language learners. NECTFL Review, 78, pp. 15-30.

Putman, H., Hansen, M., Walsh, K., \& Quintero, D. (2016). High hopes and harsh realities: The real challenges to building a diverse workforce. Brown Center on Education Policy. Recuperado de https://www.brookings.edu/ wp- content/uploads/2016/08/browncenter_20160818_teacherdiversityreportpr_ hansen.pdf

Schneider, B. Martinez, S., \& Owens, A. (2006). Barriers to educational opportunities for Hispanics in the U.S. En: M. Tienda (Ed.), Hispanics and the future of America (pp. 179227). Washington, DC: National Academies Press.

Sparks, S. D. (2015). The building assets-reducing risks program: Replication and expansion of an effective strategy to turn around low- achieving schools. Education Week, 35(11), pp. 5.

Toledo López, A. (2002). Prejudice or proxy: Candidate gender, information, and the vote choice (Doctoral dissertation). Recuperado de ProQuest Information and Learning Company (UMI Number 3077014).

United States Census Bureau (2014). Population Estimates, National Total: Vintage 2014. Rescatado de http://www.census.gov/popest/ data/national/totals/2014/index.html

Viola, G. M. \& Stefan, T. G. (2014). Heritage speakers' Spanish in California: How unbalanced bilingualism affects reverse constructions of the gustar-type. Recuperado de http://citeseerx. ist.psu.edu/viewdoc/download?doi=10.1.1.4 32.7649\&rep=rep $1 \&$ type $=$ pdf

Wilder, S. (2014). Effects of parental involvement on academic achievement: A meta-synthesis. Educational Review, 66(3), pp. 377-397. 


\title{
Factores intra y extra escolares asociados al rezago educativo en comunidades vulnerables
}

\section{Intra and extra school factors associated with educational backwardness in vulnerable communities}

Investigación

\author{
Elizabeth Mendoza Cárdenas \\ Universidad Autónoma de Nuevo León-México \\ bettymendozac@yahoo.es \\ María Zúñiga Coronado \\ Universidad Autónoma de Nuevo León-México \\ maria.zunigacn@uanl.edu.mx
}

Recibido: 16 de agosto de 2015 / Aceptado: 10 de enero de 2017

\section{Resumen}

Ante la situación que presentan los niños y niñas del mundo, sobre todo los de los países en desarrollo, se establecen, con la participación de 189 países miembros de las Naciones Unidas, en el 2000, seis Objetivos de Desarrollo del Milenio dirigidos a la infancia. Uno de ellos pretende asegurar para el 2015 que todos los niños y niñas terminen la enseñanza primaria. Una serie de factores individuales y estructurales impiden el acceso o permanencia de los niños y niñas en la escuela, sin embargo, de acuerdo a una serie de estudios realizados, los factores externos, como la pobreza, y el género resultan ser los factores clave que mantiene a los niñ@s alejad@s de la escuela. El presente trabajo tiene por objetivo mostrar los resultados de un estudio exploratorio realizado desde el enfoque mixto sobre la percepción que tienen directivos, profesores y habitantes de nueve agebs del Polígono San Bernabé, del municipio de Monterrey, sobre los factores que promueven el rezago educativo de los estudiantes que cursan la enseñanza básica. Se dará a conocer, además, las principales estrategias utilizadas en las instituciones educativas para incidir en los factores de riesgo.

Descriptores: Abandono escolar, desigualdad social, educación básica, pobreza, rezago educativo, vulnerabilidad social.

\begin{abstract}
Six Objectives of development of the Millennium focused on childhood were stablished on 2000 with the aid of the 189 countries that form the United Nations, due to the situation presented by children from all around the world. One of the objectives strives to assure that by 2015 all children will complete their primary education. A series of individual and structural factors keep children from staying in school. According to several studies, external factors, such as poverty and gender end up being the key reasons that keep children away from school. This paper has
\end{abstract}

Forma sugerida de citar: Mendoza Cárdenas, Elizabeth \& Zúñiga Coronado, María (2017). Factores intra y extra escolares asociados al rezago educativo en comunidades vulnerables. Alteridad, 12(1), pp. 79-91. 
the objective of showing the result of an exploratory study realized from a mixed focus over the perception that directives, professors, and citizens from Polígono San Bernabé (Monterrey), regarding the factors that promote educational lay back within basic education.

\section{El rezago educativo en México}

Entendemos el rezago educativo como el nivel escolar, de un individuo o un grupo, inferior al nivel académico establecido como mínimo o suficiente. Según Suárez Zozaya (2001), es una condición de desigualdad y falta de justicia en términos de distribución de servicios y oportunidades educativas.

El rezago educativo es uno de los principales problemas que aqueja a México. A nivel nacional, en 2010, el porcentaje de población de 15 años y más que era analfabeta o no terminó la primaria o secundaria fue de $40.7 \%$. El porcentaje de población no terminó la primaria fue $12.9 \%$, lo que equivale a 10082386 personas. En Nuevo León se registra un $28.8 \%$ de rezago educativo, lo que equivale a 958035 individuos que son analfabetas o no terminaron los estudios de primaria o secundaria. Las personas que no terminaron la primaria ascienden a 282141 (8.5\%) (INEGI, 2010).

Los factores asociados al rezago escolar son múltiples, por lo que suelen ser estudiados desde dos enfoques. Un enfoque centra la atención en las variables intra escolares y el otro en las variables extra escolares (Espinoza, Castillo, González y Loyola, 2012). Entre los factores internos a las escuelas que intervienen en los resultados académicos están la asignación y administración de los recursos, la capacitación y las condiciones de trabajo de los docentes, los salarios, los planes de estudio, el modelo de docencia, la percepción y creencias de los profesores sobre los alumnos. El enfoque extraescolar señala que las principales casusas del rezago escolar son la situación socioeconómica, la cultura y el contexto familiar de los y las estudiantes. La pobreza, el desempleo, la
The main strategies used by institutions to avoid this issue will also be presented.

Keywords: Drop-out, social inequality, basic education, poverty, educational backwardness, social vulnerability.

baja escolaridad de los padres, la marginación, el embarazo a temprana edad, el consumo de drogas, la desintegración familiar, así como las bajas expectativas que las familias tienen de la educación son identificados como factores del contexto familiar que pueden desencadenar el rezago educativo (Muñoz Izquierdo, 2009).

A pesar de que los factores asociados a los estudiantes, a la familia y a la escuela han sido identificados en una buena cantidad de estudios como detonantes del rezago escolar, el Programa Sectorial de Educación 2013-2018, atendiendo a la recomendación realizada por la UNESCO, en el 2013, le da prioridad a la construcción y rehabilitación de escuelas a fin de que sean más accesibles y seguras. Con el fin de evidenciar la importancia que tienen las variables culturales, familiares y económicas en el rendimiento escolar se presentan a continuación los resultados de un estudio cualitativo realizado en directivos de escuelas que atienen alumnos de bajo nivel socioeconómico, así como de habitantes de la zona.

\section{Esbozo metodológico}

Se trata de una investigación mixta realizada con la participación de habitantes, docentes y directivos de escuelas primarias y secundarias ubicadas en el polígono San Bernabé del Área Metropolitana de Monterrey caracterizado como pobre. Para el estudio se utilizó la estrategia de procedimientos secuenciales del método de investigación mixta. Lo que significa que el proyecto es primordialmente cualitativo y el análisis cuantitativo se fusionó para proveer introspección en diferentes niveles o unidades de análisis a fin de alcanzar una profunda comprensión del problema. 


\section{Metodología cualitativa}

Se estableció un diálogo con los profesores y representantes de las instituciones educativas por medio de la entrevista a profundidad, así como a adultos que residen en comunidades del polígono. El diálogo estaba dirigido a comprender las perspectivas de cada uno con respecto a los factores que afectan el rendimiento escolar de los estudiantes de nivel básico, así como las propuestas para atenderlo.

El primer contacto con el área que abarca el polígono se realizó a través de una visita exploratoria, lo que permitió identificar las organizaciones sociales y las instituciones ubicadas en las colonias, entre ellas a las educativas. Asimismo, el abordaje con algunos habitantes facilitó la identificación y el contacto con otros pobladores; la bola de nieve fue la estrategia utilizada para este fin.

\section{Perfil de los sujetos entrevistados}

Se estableció diálogo con once personas de distintas colonias ubicadas en ocho agebs del polígono San Bernabé del municipio de Monterrey. Seis de los entrevistados tienen cargos en instituciones educativas de nivel primaria, cuatro de ellas ocupan puestos directivos, una se desempeña como docente y otra como asistente. Además, se conversó con un párroco y los cuatro restantes, son pobladores. En cuanto al sexo, tres son hombres y nueve mujeres. Todas las personas son adultas.

\section{Metodología cuantitativa}

Se utilizó el diseño de investigación transeccional o transversal descriptivo y para seleccionar las viviendas del polígono San Bernabé, se utilizó el método de muestreo probabilístico denominado "aleatorio simple". Una vez seleccionadas las viviendas se acudió a los domicilios elegidos y se aplicó un cuestionario a algún habitante que cubriera el requisito de ser mayor de edad. La muestra de los agebs, objeto del presente estudio, consta de 559 domicilios y se capturó información de 2290 personas residentes de las casas seleccionadas. La muestra permite hacer estimaciones con una confianza del 95\%.

\section{Resultados}

\section{El contexto}

El polígono San Bernabé se ubica en la parte NordPoniente de la Ciudad de Monterrey. Colinda con el municipio de Escobedo y con el Cerro del Topo Chico. De acuerdo a su morfología comprende dos zonas. La zona de San Bernabé que se caracteriza por ser terreno plano y con equipamiento urbano y La Croc, zona ubicada en lomas, con carencia o deterioro de infraestructura urbana.

San Bernabé/ la Croc, surge como asentamiento ilegal urbano a finales de la década de los sesenta y principios de los setenta. Las viviendas eran precarias, se carecía de todo tipo de equipamiento urbano, como servicios básicos al interior de la vivienda y servicios públicos en la colonia, por lo que la obscuridad y lejanía de los predios promovieron que desde los inicios fueran víctimas de asaltos y robos en las viviendas. Actualmente, el polígono se compone de 28 agebs, que comprenden 32 colonias. Se registran avances significativos de desarrollo urbano en la mayoría de la zona. Casi todas las colonias cuentan con servicios básicos, con escuelas de nivel básico, un CONALEP, un Centro de Salud, plazas públicas, canchas deportivas y un macrocentro. La calidad de las viviendas, también han sufrido transformaciones importantes, pues la mayoría están construidas de materiales sólidos, como el concreto, además, de que se ostenta con el título de propiedad. No obstante, los asentamientos ubicados en la zona alta de la Croc son los más marginados por estar situados en territorio federal. Las viviendas se caracterizan por estar construidas en paredes de madera o block apilados u otro material de desperdicio y con techo de lámina galvanizada, no cuentan con la instalación de servicios básicos, por lo que a través de conexiones irregulares tienen acceso a la electricidad y al agua, además de que prácticamente no se cuenta con vías de acceso. 
La carencia o mal funcionamiento de los servicios básicos, la inseguridad, el desempleo, los bajos ingresos, la desintegración familiar, el rezago educativo son las situaciones problema que actualmente enfrentan los habitantes de las comunidades de San Bernabé/La Croc y las principales manifestaciones de esta son: (Ver Figura 1).

Figura 1. Situaciones problema en las comunidades de San Bernabé/La Croc

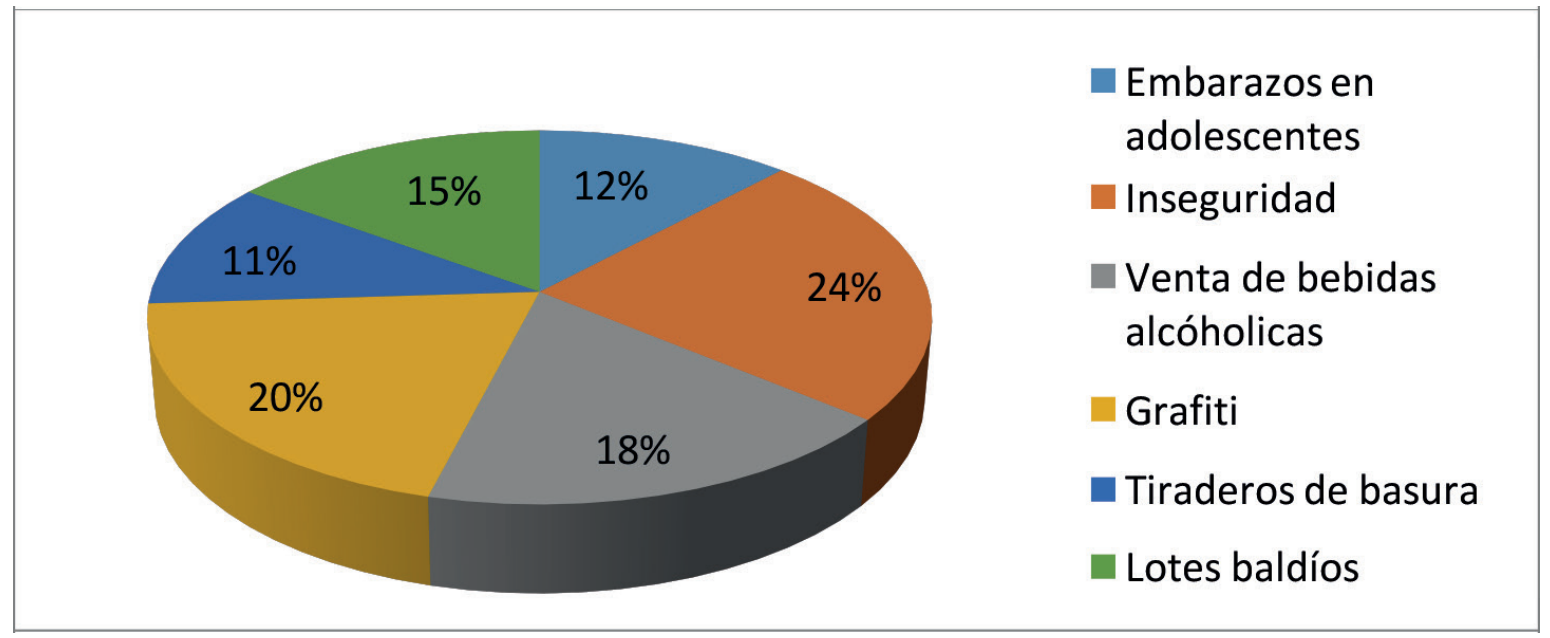

Fuente: Elaboración propia, Ios cálculos presentados se obtuvieron utilizando la información del Cuestionario Línea Base realizado a los hogares, UANL-SEDESOL 2014.

El rezago educativo de estudiantes de la escuela primaria se identifica en nueve agebs de San Bernabé, el 3 (La Croc), 4 y 23 (Ampliación Laderas del Topo Chico), 6 (Gloria Mendiola y (Ver Figura 2).

Figura 2. Mapa del Polígono San Bernabé/ La Croc

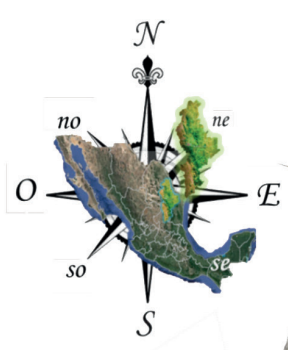

El Porvenir), 12 (Conquistadores/ La Croc), 15 (San Bernabé XIV), 20 (La Croc), 21 (Ampliación Municipal y La Reforma) y 25 (San Bernabé XII). 
La zona de la Croc, es donde se identifica mayor rezago, en comparación con la zona de San Bernabé. La mayoría de los habitantes de estos agebs cuentan con un nivel educativo bajo, y desarrollan trabajos informales. El grueso de la mano de obra masculina se desempeña como albañiles, carpinteros, soldadores o mecánicos. El comercio informal es el segundo sector donde obtienen ingresos para la supervivencia (Ver Figura 3). En el caso de las mujeres, en general, se desempeñan también en el mercado informal, primordialmente como empleadas domésticas en la zona Cumbres. Debido a las características del empleo, los habitantes perciben salarios bajos y carecen de acceso a servicios de salud y prestaciones sociales (Ver Figura 4).

Figura 3. Ingreso mensual familiar en las comunidades de San Bernabé/La Croc

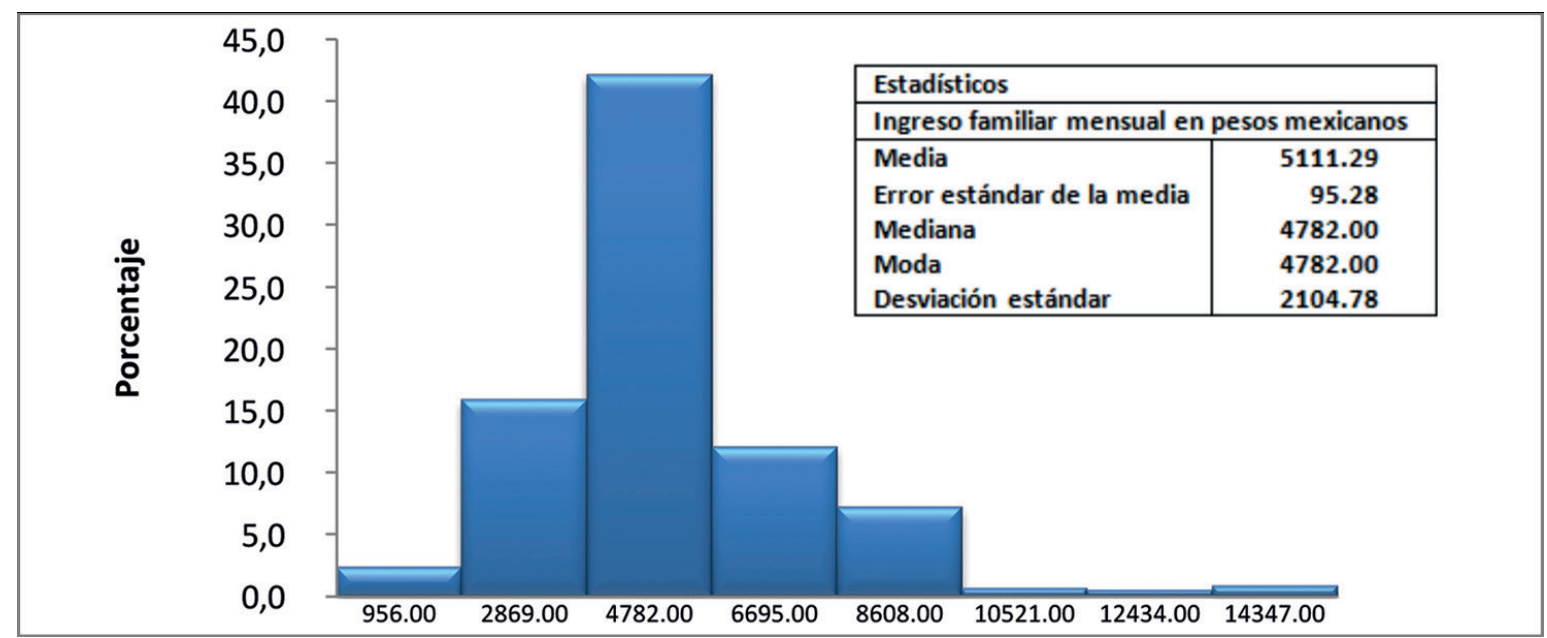

Fuente: Elaboración propia, los cálculos presentados se obtuvieron utilizando la información del Cuestionario Línea Base realizado a los hogares, UANL-SEDESOL 2014.

Las casas son habitadas por cinco personas en promedio $(\bar{X}=5.13, \mathrm{DE}=\$ 2.205)$ y

a finales de 2014, fue de $\$ 5,111.3 \pm \$ 186.75$ el ingreso familiar estimado en la población,

Figura 4. Afiliación a instituciones de salud de los pobladores en las comunidades de San Bernabé/La Croc

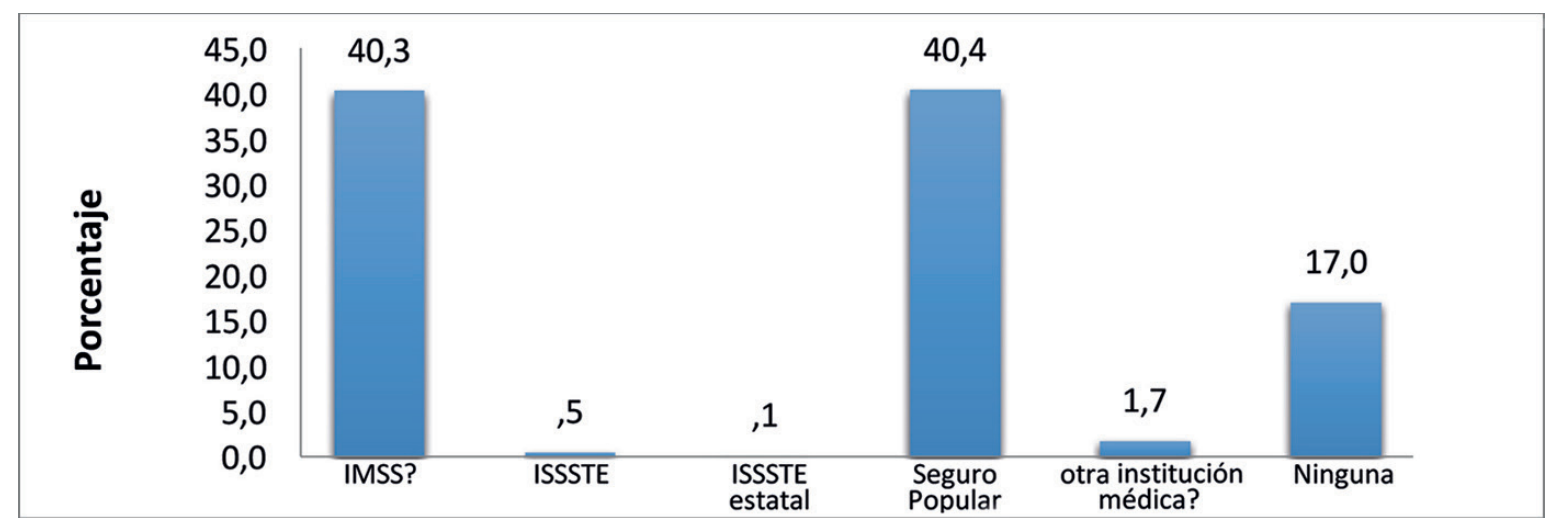

Fuente: Elaboración propia, los cálculos presentados se obtuvieron utilizando la información del Cuestionario Línea Base realizado a los hogares, UANL-SEDESOL 2014. 
El común denominador de estas colonias es la presencia de inseguridad, violencia familiar, desintegración familiar, pandillerismo, drogadicción y desempleo.

\section{Factores asociados al rezago educativo de estudiantes que residen en comunidades vulnerables del municipio de Monterrey}

Múltiples factores intra escolares como extra escolares son asociados por los entrevistados al bajo rendimiento escolar o al rezago educativo de los y las estudiantes de primaria que viven en el Polígono San Bernabé/La CROC, del municipio de Monterrey. No obstante, los factores extra escolares, sobre todo los relacionados al contexto familiar son los que predominan en los discursos de las y los entrevistados. En primer instancia se describen los factores extra aula y posteriormente los factores internos, que desde la percepción de los participantes en el estudio inciden en el rendimiento escolar.

\section{Ámbito extra escolar}

Contexto familiar. En el ámbito familiar, la falta de interés de los padres, el trabajo remunerado del padre y la madre, la desintegración familiar, la violencia doméstica, la pobreza, las adicciones, y la escolaridad de los padres son las principales situaciones identificadas como causantes del rezago escolar de estudiantes de primaria.

Desinterés de los padres. Los padres son los principales actores identificados por los directivos entrevistados de distintas escuelas, como los responsables del bajo rendimiento escolar de los estudiantes.

Este ... el maestro está haciendo su parte como es debido el alumno aquí dentro de la escuela el maestro pues lo motiva a que participe pero el padre de familia que es la otra tercera parte no cumple con lo que le corresponde y por eso la escuela no anda bien académicamente se pudiera decir (Directivo/F/ 4)
La falta de interés y/o apatía de los padres en el proceso educativo se ve reflejado en la inasistencia de los hijos a la escuela y en el incumplimiento de las tareas.

...el padre y los padres que están libres algunos si ayudan pero la mayoría no y cuando citamos, citamos, hemos citado aquí a los papás que te... de alumnos que tiene problema de rezago, aquí nos dejan los niños solos, no vienen, no se presentan, y hay gente como les digo, hacen de cuenta que la escuela es una guardería o un internado, aquí traen el niño en agosto y no vienen por el hasta junio por la calificación, por julio por la calificación, pos nunca los conocemos, tiene mucho problema de ausentismo, de deserción interna que van y vienen, o sea se va, que van a San Luis o que van a otro estado y luego que regresaron... Es desinterés y apatía que tienen, en primer lugar , a que voy si siempre me van a regañar porque mi hijo no trae tareas, porque o sea ya a veces lo recibimos, nosotros no tenemos culpa si le decimos al papá, siempre con negativo, jamás citamos al bueno... (Directivo /M/12).

...el problema que tenemos es la inasistencia, en la inasistencia se batalla mucho, hay mucha irresponsabilidad de los papás, que siempre estamos insistiendo en que nos los envíen diario, pero siempre hay niños que faltan. Es el problema más grande y eso ocasiona el rezago escolar, que los niños se vayan rezagando, este, que viene siendo en su aprendizaje... (Directivo /M/20).

Y en la inasistencia es rotundamente la irresponsabilidad por parte de los padres de familia,..., todos llegando tarde, todos llegando raspando, todos de que, "es que me quede dormida" infinidad de pretextos, así rotundamente, irresponsabilidad de los padres de familia, eso es, en la inasistencia. (Directivo/F/25).

La familia es identificada, por los responsables de las escuelas, como agente importante de socialización en la transmisión de normas y valores para la vida, la escuela y el trabajo, no obs- 
tante, los padres no se desempeñan como agentes transmisores de los valores que son fundamentales en la educación.

Los valores que es, que, los maestros fomen$\tan$, le digo los valores ya los traen de su casa, los maestros nomas los fomentemos, no los hacemos, algunos ya los traen, los valores pues la asistencia del alumno al venir a una escuela...35 años de servicio toda la vida hemos batallado con la puntualidad, pero digo es una cultura mexicana el ser impuntual sí, por eso (Directivo /M/12).

La falta de participación de los padres en el proceso educativo es desalentadora de acuerdo a la percepción de los entrevistados, por la creencia que tienen los padres de que los maestros son los responsables de educar y formar a los estudiantes. El bajo nivel educativo de los padres (Ver Tabla 1), es otro factor que contribuye al fracaso escolar de los hijos.

..., porque quieren que el maestro haga $y$ tengan la varita mágica para que les eduque, aparte de formarlos, que eduquen a sus hijos, error (Directivo/F/25).

...pero como las personas, muchas de aquí de, de esta colonia, desgraciadamente no, no estudiaron más que hasta la secundaria o, o ni la secundaria porque la mamá de estos niños no sabe ni leer, tiene que poner la huella cuando yo le mando a, a que firme un documento ella tiene que poner la huella porque no sabe ni leer (Dependiente/F/3).

Tabla 1.Nivel escolar de personas con 15 o más años de edad que no estudian

\begin{tabular}{|l|l|l|}
\hline \multirow{2}{*}{ Escolaridad } & \multicolumn{2}{c|}{ Sexo } \\
\cline { 2 - 4 } Ninguno & \multicolumn{1}{|c|}{ Hombre } & 50 \\
\hline Primaria & 41 & 272 \\
\hline Secundaria & 201 & 296 \\
\hline Preparatoria & 339 & 88 \\
\hline Normal & 98 & 2 \\
\hline Carrera técnica o comercial & 1 & 37 \\
\hline Profesional & 21 & 20 \\
\hline Total & 23 & 765 \\
\hline
\end{tabular}

Fuente: Elaboración propia, los cálculos presentados se obtuvieron utilizando la información del Cuestionario Línea Base realizado a los hogares, UANL-SEDESOL 2014.

Trabajo remunerado del padre y la madre. El trabajo de ambos padres, particularmente la incorporación de la madre al mercado laboral, es visto como un obstáculo importante del fracaso escolar de los alumnos. Las largas jornadas de trabajo, aunadas al tiempo invertido en el trasla- do, impiden contar con tiempo para apoyar y dar seguimiento a la trayectoria escolar de los hijos.

... la mamá está sola, se va a trabajar, el papá está, puede estar en el penal, porque nos ha tocado casos, a mí me ha tocado muchas situa- 
ciones de esas entonces pues ahí si vemos que le niño está desprotegido... (Directivo/M/12)

Se da por la falta de apoyo por parte del padre de familia, son papás poco responsables en cuanto al apoyo para sus hijos, se dedican a trabajar o hacer otras cosas, y no ponerle atención al hijo, le dan importancia a otras cosas, menos al hijo,... (Directivo/F/25).

las mamás trabaja, pero, trabaja en empresas que les pagan, bien poquito y tienen que trabajar 8 horas y más, con, con, con el traslado del, del camión y todo eso, las señoras están fuera de su casa 12 horas, si, entre ida y vuelta, entonces por eso es que también los niños luego bajan de calificación porque las mamás no, no les ayudan a hacer tarea y, y no se dan cuenta de, de lo que está pasando en...a veces vienen y no saben el nombre del maestro de su hijo (Dependiente /F/3).

...es que a muchas personas como padre de familia, por trabajar, no les ponen atención a sus hijos no saben con quien se juntan ni nada... (Habitante/F/18).

Violencia doméstica. La violencia familiar es identificada como situación que se presenta con frecuencia en las familias.

Pues aquí anda mucho los pleitos en los matrimonios, los golpes, pues si, este casi por lo regular no hay familia que la mujer lo engañó, que el señor golpea a los niños o sea es uno de los problemas yo creo que más se han visto aquí en la colonia (Habitante/F/25).

El maltrato físico y/o psicológico, por parte de algún miembro de la familia, como el padre o el padrastro, provoca consecuencias importantes en la salud psicofísica de los estudiantes.

...se suscitó una problemática con una maestra que tenía al niño que no se podía levantar, y es que no se quiere levantar está llore y llore, y que no puede apoyar los pies, bueno pos que tiene, ve... vengo, le digo al conserje me lo train para acá y yo vi las piernas y estaban todas moretoniadas y lo habían agredido el padrastro con un palo de escoba y a la hermanita que estaba en segundo me la traje también y le empecé a preguntar y dijo es que mi papá no nos... es tu papá el que les pega? (Docente/F/12).

...falta mucho respeto entre el padre de familia y el niño porque parece, digamos el caso, que un padre de familia le llama la atención al niño con palabras muy fuertes, a veces con maltratos (Directivo/M/20).

Sí, si hay maltrato, si hay maltrato porque, eh, quieren que los niños hagan todo, sin ellos poner algo de su parte, y cuando son desobedientes los niños, pues viene el maltrato, de que, si yo soy el papá, si yo soy la mamá, el que obedezcas, y estoy de acuerdo, pero mientras no tengan valores en su casa y no les fundamentan, pues el resultado ahí está, les faltan al respeto, no les gusta y es donde hay maltrato, ...(Directivo/F/25).

Desintegración familiar. El cambio de domicilio o el bloqueo psicológico que sufren los estudiantes cuando los padres se separan o divorcian obstaculiza el avance académicos.

... el famoso, el famosos caso que se fue mi papá, verda, entonces, nos vamos a ir con mi abuelita que vive en otro estado o que se viene el otro esposo para la señora y ya tiene a su señor esposo y luego que viene el papá verdadero y se lleva a los niños, no, problemas, problemas fuertes entre los muchachos, que vemos veda, aquí es muy difícil en cuestión de los problemas psicológico, es muy difícil, si nosotros tenemos un niño o varios niños con problemas obviamente no va a avanzar, va a estar ahí bloqueados entonces yo por eso yo veía oda esa problemática (Directivo/M/12).

...la desintegración familiar de los padres de familia y hay otro problema aquí de que pues hay familias, mínimo verdad pero hay familias donde se consumen droga, entonces es otra cosa que los niños traen, lo ven y 
ellos nos lo platican, pero en minoría, así que principalmente es la desintegración familiar (Directivo/M/20).

En otros casos, el rompimiento del vínculo marital provoca el abandono de los hijos por parte de la madre. Situación que repercute en la estabilidad emocional del niño y en el desempeño académico. Siendo las abuelas las que toman la responsabilidad de la crianza y educación de los nietos.

Muchísimos, muchos casos. No, no lo tengo, pero sí hay, hay madres solteras, divorcios, abuelitas encargadas de los nietos, porque la mamá los dejó, la mamá no se hizo cargo de ellos, se juntó con otra pareja y ya no se los llevó (Directivo /F/25).

Pobreza. El rezago educativo o deserción escolar se desencadena también por razones económicas. Los hijos son utilizados por los padres como instrumento para obtener ingresos para completar el gasto familiar, por lo que en vez de asistir a la escuela, deambulan por las calles o en camiones de transporte público pidiendo dinero o vendiendo algún artículo con el fin de obtener ingresos económicos para completar el gasto familiar.

...alguien que a esos niños los rescate porque cuando esos niños no vienen a la escuela es porque andan pidiendo limosna arriba de un camión, me consta, los han visto, si, venden paletitas venden dulcitos y le ayudan a su papá a, andar vendiendo estampitas de no sé qué para que, para que ellos tengan, los papás, tengan comida, cuando los papás son los que deben de trabajar no ellos y así es,... (Dependiente /F/3).

Petrita (nombre ficticio) que fue la que salió de la secundaria no ha sido atendida y la señora no la está llevando a la secundaria, anda en las calles pidiendo limosna, vendiendo cosas en los camiones, y la otra vez la vi aquí en la cuadra con otra persona de la misma estatura que ella ósea, otro enanito, pero no era su papá, era un jovencito, la niña ya tiene 13 años, verdad, la están descuidando pero ahí no dicen nada en la televisión, no dicen que los papás están fallando como papás (Dependiente /F/3).

De la muestra analizada encontramos 377 jóvenes en el rango de nueve a diecinueve años de edad, de ellos, actualmente 103 no estudian. A partir de este dato podemos estimar que el $27.3 \%$ $\pm 4.5 \%$ de los habitantes en ese rango de edad presentan rezago escolar y expresan como principales motivos para abandonar sus estudios: la falta de dinero, no les gusta estudiar y necesidad de trabajar (Ver Figura 5).

El hambre es también un impedimento en el proceso de aprendizaje de los estudiantes. El hambre y la mala nutrición perturban el progreso escolar porque se reduce drásticamente la capacidad de atención y de concentración.

...aquí con los niños, en mala conducta, en agresión de un niño para otro y en no avance en el rezago por que el niño no se puede concentrar porque tiene hambre, porque está pensando que su papá golpeo a su mamá, está pensando que su mamá llegó tomada o borracha o está pensando en que su papá se durmió... (Dependiente /F/3).

Adicciones. Las adicciones al alcohol y otro tipo de drogas de los padres provocan la falta de apoyo en distintos ámbito, entre ellos el educativo.

Los problemas en los estudiantes son muy marcados, he, hay la tomadera, drogadicción y que los padres no están en casa con ellos, eso es problemático, muy grave aquí en la comunidad. (Directivo/F/25).

La falta de identidad legal, excluye a los niños y niñas de la escuela, puesto que al no contar con el acta de nacimiento no se les permite ser inscritos.

... $\mathrm{mmm}$, siempre o sea bien raros los rostros que sean que las parejas se peleen así, o de los niños o sea hay muchos niños que no están en la escuela o registrados aún; y bueno pss eso también, ss es que necesitan checar así veda familia por familia y si van a encontrar muchas 
que si tú les pides el acta de nacimiento a lo mejor ni la tienen... (Habitante/F/15).

\section{El ámbito intra escolar}

En el ámbito formal, se observa la falta de apoyo de los directivos de las escuelas y de la Secretaría de Educación para que los y las profesoras puedan intervenir en ciertos factores asociados al rezago, como el maltrato infantil y la falta apoyos materiales (libros de texto).

La respuesta de los directivos de las escuelas ante los casos de maltrato es la indiferencia o complicidad, rehusándose a intervenir o tratando de impedir que los profesores intervengan, debido a que tienen que acatar la instrucción de la Secretaría de Educación de no involucrarse en estos casos.

...y claro que me metí en un problemón con la directora porque no quería, dije pero yo tenía que hacer eso, porque no, porque, maestra es que mire van a venir los medios y que, maestra y que quiere que yo haga aquí no van a venir con nosotros porque no fue agredido aquí, pero si yo no lo hubiera hecho, hubieran dicho que maestra tan inconsciente como lo ve golpeado y no actuó, entonces que podía haber hecho maestra? (Docente/F/12).

Y esto no es de,... esto es de la misma Secretaría, de que son como dependencia inconsciente, incongruente, porque lo primero que nos indica, tú no te metas (Directivo/M/12).

La no distribución de los libros de texto por parte de la Secretaría de Educación favorece el rezago educativo de los niños del polígono.

... la falta de apoyo total del padre de familia, falta de apoyos materiales de la Secretaria de Educación como son los libros de texto, que, no sé, por ser, por turno vespertino... (Directivo/M/12)
La impuntualidad e inasistencia de los profesores, así como la falta de planeación y de seguimiento de la trayectoria escolar de los estudiantes promueven también el rezago escolar.

...y he quitado muchos vicios que tenían los maestros por ejemplo que no llevaban una planeación por ejemplo que no registraban los trabajos de los niños en las libretas yo les pedía la libreta cuando yo le...-mándeme la libreta de donde tiene la asistencia donde tienen la calificación- y los maestros-: ¿cuál libreta maestra?-, la libreta que deben de llevar, el registro- me la mandaban no se ya teníamos un mes en la escuela los maestros tenían una o dos calificaciones y yo -que pasa con que califican ustedes tienen que registrar - y empecé y empecé a pedirles y a pedirles y ahorita ya se acostumbraron que tienen que mandarme la planeación ,la libreta de asistencia la libretas de calificaciones y que tienen que promediar con los trabajos diarios si , el examen, entonces hemos ido avanzando y este... falta mucho por hacer todavía, pero, pero ya los maestros, ya no faltan, ya llegan temprano, trabajan en equipo, tenemos proyectos y los llevamos a cabo y tenemos evidencias (Directivo/F/ 4).

[...] Los niños descuidados, muchos no son atendidos en las escuelas, muchos maestros que vienen a clases acá, no quieren venir para acá, entonces vienen a regañadientes, porque requieren una plaza, entonces también repercute en el trato con los niños, entonces nosotros por ejemplo, comenzamos queriendo tener una relación con los maestros, con las escuelas, diciéndoles a ver, en el catecismo nosotros percibimos que estos niños no aprenden, queremos que nos digan cómo están allá en la escuela, a la mejor trae un problema familiar y necesitamos detectar cual es el problema, para darle solución de fondo, juntos, no quisieron, no quisieron, porque mucho problema se genera en la escuela (Párroco/M/21). 


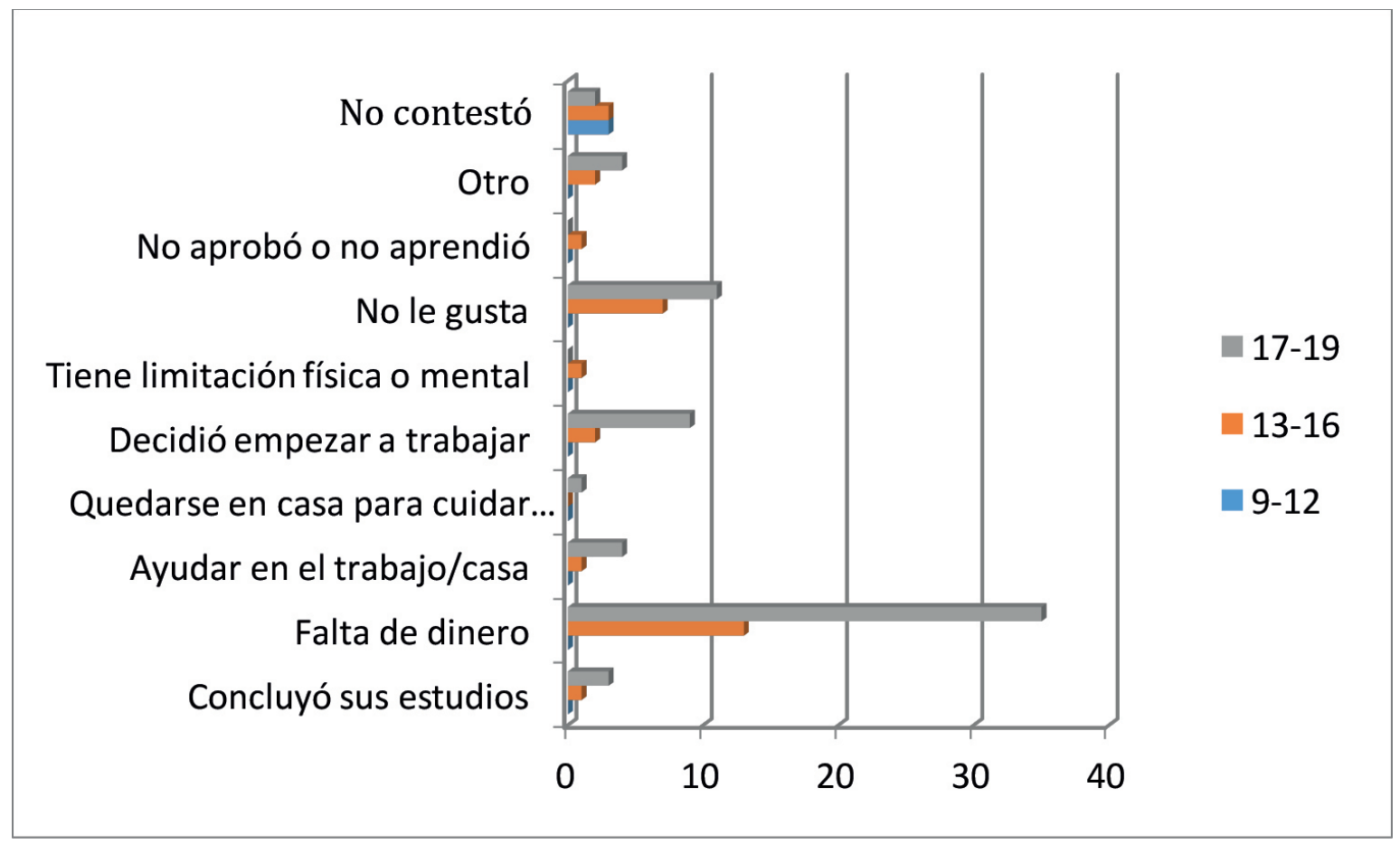

Fuente: Elaboración propia en base a los datos de la Línea Base

\section{Estrategias de afrontamiento}

Entre las principales estrategias que se realizan en las escuelas para incidir en los factores familiares, está la realización de talleres escolares y los talleres de valores dirigidos a padres de familia y a estudiantes, así como los proyectos de apoyo académico.

El objetivo de los talleres escolares es fomentar la participación de los padres en el ámbito académico, promover la comunicación entre padres e hijos y entre padres, profesores y directivos.

Ahorita lo estamos viendo frecuentemente, por ejemplo tenemos fechas marcadas, la semana pasada convivieron 4 grupos, la semana empezó uno ahorita y ósea están las actividades marcadas para cada mes, en las juntas de consejo técnico, marcamos las actividades marcamos todos los grupos y estamos, o sea se están calendarizando para que todos los papás, si tienen por ejemplo, que si tienen hijos en tercero y en quinto, bueno que en este día venga con los de tercero y el día que le toca el quinto, venga con los de quinto. Para que convivan y realicen actividades con sus hijos y cumplen con uno y cumplen con el otro, que los agenda todas esas actividades y con los papás se les envía la invitación (Directivo/F/25).

Del año pasado para acá, yo, se ve una falta grande de valores, me di a la tarea como les digo de estar abierta para los padres de familia en la comunidad, comunicación, y que ellos entiendan, que la responsabilidad dentro de casa fomentando los valores (Directivo/F/25).

Los proyectos de lectura, de escritura y de matemáticas están encaminados a brindar capacitación y asesoría en las áreas donde se presenta mayor rezago. 
...planteamos proyectos para sacar a los niños del rezago educativo como por ejemplo proyectos de lecto-escritura de matemáticas, emm de escritura y de valores, por ejemplo, también eh hacemos los que están en nuestras manos aquí en la escuela... (Directivo/F/ 4).

La ruta de mejora es también implementada para que los estudiantes no se rezagen. [...] bajo rendimiento, bajo rendimiento, por eso estamos ahora implementando muchas estrategias, lo que es la ruta de mejora, buscándoles estrategias adecuadas, para que no se nos queden niños rezagados o en peligro de reprobación, también estamos enfocados mucho en combatir la violencia entre ellos mismos se esté... (Asistente escuela/F/ 6).

\section{Conclusiones}

La etiología del rezago escolar de los y las estudiantes que viven en el Polígono San Bernabé/La Croc se debe tanto a factores extraescolares como escolares. Los factores que no dependen de los esfuerzos de los alumnos, pero que interfieren en el aprovechamiento escolar son principalmente la pobreza y la falta de apoyo familiar.

El factor económico ha sido atendido por el gobierno a través de subsidios en efectivo que las familias reciben a través del programa "Oportunidades", gracias a lo cual se ha logrado la permanencia de algunos niños y niñas en la escuela. Sin embargo, el uso inadecuado que algunos padres de familia hacen de dicho recurso gubernamental, así como las características del empleo y la percepción de ingresos precarios continúan incidiendo en el rezago escolar en estas zonas.

La variable familiar, interviene también en forma significativa en el rezago escolar. La desintegración de la familia, la violencia doméstica y la incursión en el mercado laboral, tanto del padre como de la madre, inciden de manera directa en el estado emocional y por ende en la salud mental de los hijos, afectando su rendimiento escolar.

Los factores internos a las escuelas intervienen también en forma significativa en el rezago escolar, principalmente la indiferencia de parte de las autoridades de las escuelas así como de la Secretaría de Educación ante los efectos que la situación familiar está teniendo en el aprovechamiento escolar. La poca presencia de otros profesionistas, trabajador@s sociales, psicólogos, etc., para atender los aspectos relacionados a la salud mental de los alumnos y alumnas, así como los relacionados al contexto familiar (violencia, desintegración, etc.) es una muestra del olvido o indiferencia de esta problemática.

Para combatir los factores que impiden que los estudiantes puedan concluir el ciclo escolar es necesario implementar diversos programas sustentados en un diagnóstico tanto cualitativo como cuantitativo de cada colonia y familia. Los programas serán más eficaces y eficientes se están basados en las características, intereses y necesidades de los actores involucrados, así como en las de su ambiente. El diálogo entre los distintos actores involucrados debe prevalecer sobre las formas verticales de acercamiento para el trabajo conjunto. Las acciones deben apuntar hacia la re significación que tienen los padres y los y las estudiantes de la importancia de la educación en la calidad de vida, más que en la reeducación de los padres, así como a establecer alternativas para que los niños que no reciban apoyo en su casa para las tareas escolares puedan recibirlo de otros actores de la comunidad, como los estudiantes de preparatoria y universidades, a través de la formación de clubes de tareas.

\section{Referencias bibliográficas}

Espinoza, O., Castillo, D., González, L. E., \& Loyola, J. (enero-marzo de 2012). Factores familiares asociados a la deserción escolar en Chile (Ve). Revista de Ciencias Sociales, XVIII(1), 136-150.

INEGI (2010). Censo de población y vivienda 2010. México. INEGI.

Muñoz Izquierdo, C. (2009). Construcción del conocimiento sobre la etiología del rezago educativo y sus implicaciones para la orientación de las políticas públicas: La experiencia de 
México. REICE. Revista Iberoamericana sobre Calidad, Eficacia y Cambio en Educación, 7(4), 28-45.

ONU México (2000). Objetivos de Desarrollo del Milenio. ONU. http://www.onu.org.mx/ objetivos_de_desarrollo_del_milenio.html. Consultado el 15 abril del 2014.

Secretaría de Educación Pública (2013). Programa Sectorial de Educación 2013-2018. México: SEP.
Suárez Zozaya, M. H. (2001). Rezago educativo y desigualdad social en el estado de Morelos: retos de la gestión social. México, D.F.: Universidad Nacional Autónoma de México.

UNESCO (2013). Compendio Mundial de la Educación 2012. En Oportunidades perdidas: El impacto de la repetición y de la salida prematura de la escuela. Quebec: UNESCO/ Instituto de Estadística. 


\section{Aspectos psicosociales y gestión de la evaluación en secundarias de alto y bajo logro}

\section{Psychosocial aspects and management of evaluation in secondary high and low achievement}

Investigación

Alicia Rivera Morales

Universidad Pedagógica Nacional-México alirimo@hotmail.com

Recibido: 16 de octubre de 2015 / Aceptado: 13 de enero de 2017

\section{Resumen}

En este artículo se presenta un segmento de un estudio de corte mixto más amplio, se recupera una parte del análisis cualitativo en torno a los aspectos psicosociales y la gestión de la evaluación, es resultado de la aplicación de entrevistas semiestructuradas y grupos de enfoque a ochenta directivos de escuelas secundarias de alto y bajo logro educativo ubicadas en cuatro entidades de México: Sonora, Durango, DF y Oaxaca. Los hallazgos se exponen a partir de categorías que consideran el significado, las creencias y expectativas acerca de la evaluación, así como la gestión de la evaluación de los directivos de las escuelas estudiadas. Los casos polarizados permiten, en sus contrastes, identificar procesos y elementos que marcan diferencias o coincidencias entre ellos. De esta manera se encontró que los directivos de las escuelas de bajo logro esperan: cambiar la actitud de los docentes frente a la evaluación, que los supervisores controlen a los docentes y el apoyo externo (especialistas) que les indiquen como evaluar. Por otra parte, se reafirma la idea de que una escuela con alto logro, es una organización en la que el director propicia la participación, tiene altas expectativas de alumnos y docentes, su sistema de gestión y toma de decisiones permite alcanzar los objetivos establecidos y propone acciones de evaluación que buscan la mejora continua.
Descriptores: Aspectos psicosociales, gestión escolar, evaluación, escuelas secundarias, alto y bajo logro educativo.

\section{Abstract}

This article describes a segment of a broader study of mixed cut occurs. In this space only part of the qualitative analysis is recovered around the psychosocial aspects that influence the management of the evaluation results from the application of semi-structured interviews and focus groups with 80 senior secondary schools with high and low achievement located in four states of Mexico: Sonora, Durango, Mexico City and Oaxaca. The findings are presented from categories they consider the meaning, beliefs and expectations about evaluation and how these aspects influence the actions of the directors of the schools studied. Polarized cases allow, in their contrasts, identify processes and factors that mark the differences or similarities between them. Thus it was found that school principals low achievement hope to change the attitude of teachers towards the assessment, expect supervisors to monitor teachers and external support (specialists) that indicate how to evaluate them. Moreover, the idea that a school with high achievement is an organization that promotes the participation director, has high expectations of students and teachers, its management

Forma sugerida de citar: Rivera Morales, Alicia (2017). Aspectos psicosociales y gestión de la evaluación en secundarias de alto y bajo logro. Alteridad, 12(1), pp. 92-103. 
system and decision-making can achieve the objectives set, and reasserts Assessment proposes actions that seek continuous improvement.

\section{Introducción}

La calidad de la educación es una preocupación especial en la agenda de las políticas educativas. En México, se impulsa una vez que se consolida la masificación de la oferta de la educación básica. Esta preocupación ha tenido como uno de sus resultados tangibles la motivación por hacerla visible y medible. De manera que, no sólo se trata de desarrollar sistemas de medición a nivel nacional, comparando por estratos, regiones o niveles de desarrollo. Los procesos de evaluación impuestos desde la política en los últimos años en las escuelas, demandan rediseñar la función directiva, los supervisores y directores, quienes reconstruyen su papel en la escuela, simplificando radicalmente sus tareas administrativas y apoyando su condición de líderes académicos.

En este trabajo, que forma parte de un estudio más amplio, se pretende ilustrar de qué manera influyen algunos aspectos psicosociales, tales como el significado, expectativas y creencias en la gestión de la evaluación de ochenta directivos de escuelas secundarias públicas de los Estados de Sonora, Durango, Oaxaca y Distrito Federal, seleccionando para ello casos polarizados por niveles de logro educativo (20 de alto nivel y 20 de bajo logro). El artículo está constituido por cuatro apartados: 1) fundamento teórico; 2) método; 3) hallazgos y 4) conclusiones.

\section{Fundamento teórico}

Uno de los aspectos que han impulsado el renacimiento de la escuela como foco de atención de investigaciones, lo constituye el movimiento de administración basado en escuelas y de las escuelas efectivas; movimiento que en Latinoamérica coincide con los procesos de descentralización educativa (Slavin, citado en Loera, Cázares,
Keywords: Psychosocial aspects, management, evaluation, secondary, high schools and low educational attainment.

García, González, Hernández, \& G. de Lozano, 2003). La dimensión organizacional de la política educativa considera a sus actores básicos (docentes, directivos, alumnos y padres de familia) en su esfuerzo por constituir, en el espacio institucional de la escuela, una comunidad de aprendizaje efectivo y significativo (Rivera y Rivera, 2006).

Las investigaciones realizadas han sido numerosas, centradas en escuelas eficaces y tienen su origen en el estudio de Coleman (1990) sobre la igualdad de oportunidades en educación. Estudios clásicos en el campo de las escuelas eficaces, se puede citar: el de Rutter et al. (1979) realizado en escuelas del nivel secundaria estableció siete factores vinculados con la eficacia de las escuelas y el de Mortimore (1991) señaló que existen condiciones propias de la escuela tales como el tamaño, el ambiente y a la estabilidad de los profesores que favorecen su mejoramiento. Los factores señalados por Sammons et al. (1995) ofrecen una imagen que perfila las características de las escuelas eficaces, entre otras se encuentran: liderazgo, visión y metas compartidas, expectativas elevadas, entre otras. Similares conclusiones se encuentran en diversas investigaciones en América Latina. Por mencionar, Arancibia (1992), Espinoza y cols. (1995), Zárate (1992), Servat, (1995) y Alvariño y Vizcarra (1999) resaltan como factores claves de las escuelas efectivas, el sentido de misión compartido por directivos y profesores. En tal sentido son relevantes los trabajos de Teddlie \& Stringfield (1993), Reynolds (1996) y Stoll \& Fink, (1999). A la luz de estos estudios aparece con claridad que hay ciertos factores adicionales relevantes para explicar la ineficacia o pérdida de eficacia de las escuelas. Por ejemplo: ausencia de liderazgo (directores con bajas expectativas, poco comprometidos). Dentro de los investigadores que pretenden aproximar ambos paradigmas se encuentran: Hargreaves (1994) Hopkins (1994); 
Ainscow, Hopkins, Soutworth, \& West (1994); Stoll y Fink (1999).

Para la evaluación de las escuelas se han inspirado principalmente en el estudio de Stufflebeam y Shinkfield (1985), Stake (1967), Provus (1971) y en los avances realizados en el campo de la metodología para la medición del valor agregado, específicamente el modelo lineal jerárquico (HLM, por sus siglas en inglés Hierarchical Linear Model), como lo describen Bryk y Raudenbush (1992), Goldstein (1988). La evaluación de las escuelas se concentra en los resultados de los alumnos, medidos por test estandarizados, como si éstos fuesen los únicos resultados válidos de la actividad del estudiante (Gardner, 1995). Loera, Cázares, García, González, Hernández, \& G. de Lozano (2003), incluyen en su estudio: consenso sobre los objetivos de la escuela, liderazgo, oportunidades de aprendizaje, clima escolar y la interacción entre los profesores. Dichos indicadores de resultado proporcionan información sobre definiciones de "buenas escuelas" y "buenas prácticas de gestión" o escuelas de alto nivel de logro.

Por su parte, Horn y Murillo en un estudio multinivel discuten la incidencia de la dirección escolar sobre el compromiso de los docentes (Horn y Murillo, 2016); en otro artículo se cuestionan qué tareas de los directores y directoras escolares son las que más inciden en el aprendizaje de los estudiantes (Murillo, y Hernández-Castilla, 2015); Murillo y Krichesky (2015) ponen énfasis en la mejora de la escuela a partir de las lecciones aprendidas. Estos estudios dieron pie a problematizar sobre la cultura escolar desde una perspectiva psicosocial, se trata de un acercamiento a las representaciones, creencias, expectativas, valores, poder, elementos subjetivos inherentes en toda acción humana cuando se llevan a cabo procesos evaluativos. Para el caso que se ocupa, se pretende responder las siguientes interrogantes ¿De qué manera se representan los directivos la evaluación?, ¿Cuáles son sus expectativas y creencias acerca de la evaluación educativa?, ¿Cómo gestionan dicha evaluación en sus escuelas, qué acciones realizan? ¿Existen diferencias en los elementos y la gestión de la evaluación en escuelas secundarias de alto y bajo logro?

\section{Método}

La investigación amplia es de corte mixto con perspectivas cuanti y cualitativa Hernández, Fernández, \& Baptista (2008). Es de tipo comparativo ya que se han manipulado los escenarios: fueron seleccionadas diez escuelas secundarias en cuatro entidades, cinco de alto y cinco de bajo logro, con base en los resultados de la Evaluación Nacional del Logro Educativo en Centros Escolares (ENLACE). Para el caso de Oaxaca (que no participó en esa prueba) fueron seleccionadas de acuerdo a la perspectiva de las autoridades educativas estatales. En total fueron cuarenta escuelas. Se utilizó un método cualitativo, comparativo, de estudios de casos. La consideración de las escuelas como estudios de caso, tiene como fundamento abordar la manera como los directivos se representan o le dan significado a la evaluación, sus creencias, expectativas y de qué manera la llevan a cabo en la institución escolar que dirigen. En este segmento de la investigación general sólo se consideran los 80 directivos, a quienes se les aplicaron entrevistas semiestructurada y grupo de enfoque con directivos de AL y BL por cada entidad si era posible o de lo contrario se utilizó la entrevista semiestructurada.

\section{Análisis y resultados}

El análisis cuantitativo se llevó a cabo con el programa SPSS, mientras que el cualitativo, que es el que se presenta en este documento, se hizo con base a categorías preestablecidas y subcategorías que emergieron de los hallazgos.

En este caso, se consideran cuatro dimensiones: significado, expectativas, creencias $y$, acciones de los directivos en torno a la evaluación.

Significado.- Incluye el concepto que le otorgan los directores a la evaluación. El significado es un proceso cognoscitivo de atribución a 
experiencias o a conocimientos personales, de un sentido suplementario que se vuelve preponderante en lo vivido por el sujeto (Psycholobiology Glossaire, 2007). Es el resultado del cúmulo de conocimientos del individuo, constituye su mirada de la realidad vivida, como la única lectura verdadera para él y que puede comprenderse por otros inidividuos. Son productos sociales que tienen una historia (Berger y Luckman, 1968).
Los directivos de escuelas de bajo logro, tienen una concepción ortodoxa de la evaluación, así lo manifiestan:

... la evaluación, es un acto en el proceso para revisar qué tanto se están logrando los objetivos planteados $(\mathrm{DB})$.

Por otro lado, los directivos de las escuelas de alto logro, señalan a la evaluación como un proceso continuo: (Ver figura 1):

Figura 1: Significado de la evaluación

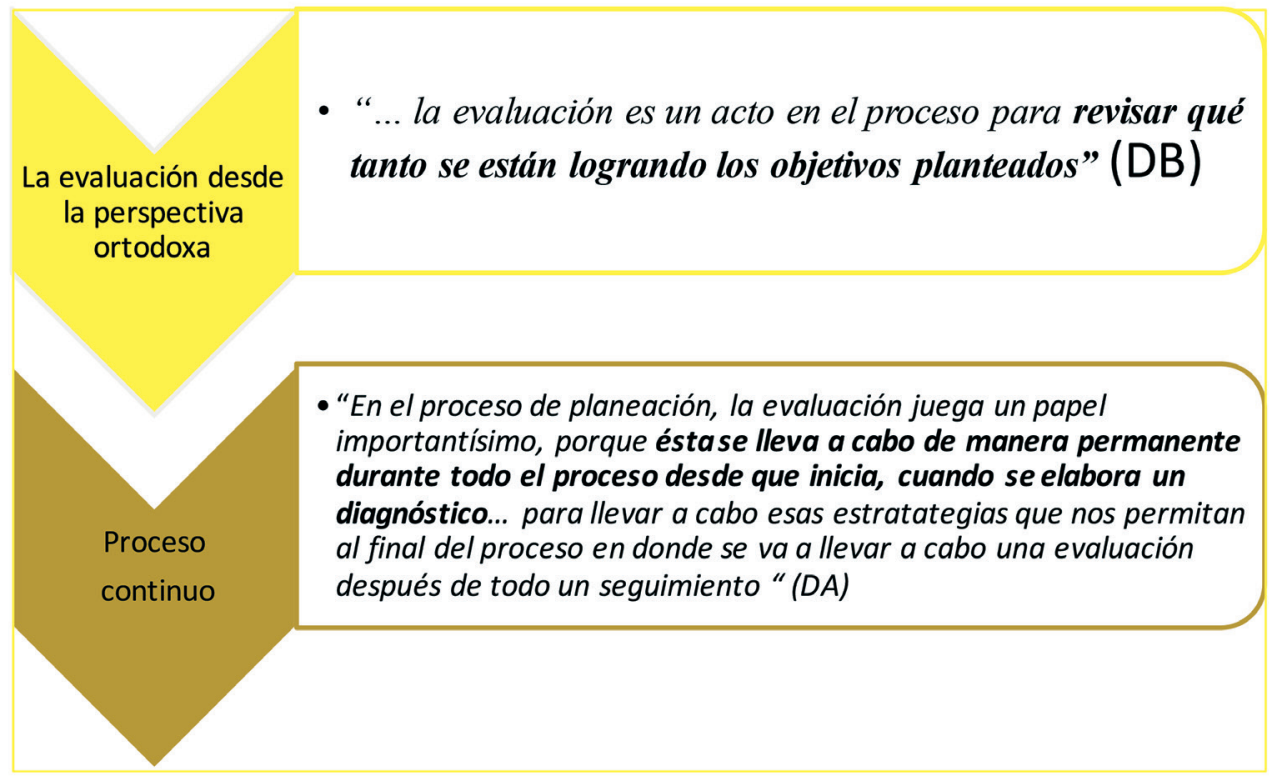

\section{Fuente: Elaboración propia}

Es interesante observar que, tanto en la representación como en el significado de la evaluación, los directivos de las escuelas de $\mathrm{AL}$ y BL existen ciertas coincidencias en cuanto señalan que la evaluación permite revisar los objetivos, rendir cuentas y realizar diagnósticos en sus escuelas. Este estudio, de acuerdo con Berger y Luckman (1968), refrenda que el conocimiento del directivo, su mirada de la práctica evaluativa y lo que hace, le da significado para él y los otros agentes educativos (docentes y estudiantes). Por tanto el significado de la evaluación de los directores de escuelas de AL y BL, es resultado de un proceso social y cultural compartido en la organización escolar. No es el caso de las acciones que desarrollan para llevar a cabo la evaluación, lo que se contrapone con la idea de que la concepción fundamenta la acción.

Expectativas.- incluye lo que se espera lograr a través de la evaluación, a partir de una proposición en la que confían y que los lleva a actuar. Es decir, una profecía que se autocumple, una suposición o predicción que, por la sola razón de haberse hecho, convierte en realidad el suceso supuesto, esperado o profetizado y de esta manera confirma su propia exactitud (Watzlawick, 1993, citado en Santos, 
2001). En este aspecto, directores y directoras de escuelas de AL esperan de y con la evaluación: generar ambientes adecuados para llevarla a cabo, asì como generar una cultura evaluativa individual y colectica. Plantean que es importante recuperar los aciertos y los errores del Sistema Educativo, así como revisar si sus escuelas tienen demanda o si los alumnos no asisten, para aprender y mejorar.

...dentro de los procesos de evaluación nos damos cuenta si la escuela funciona por la demanda que tiene, si los padres siguen mandando a sus hijos ahí,. Si los alumnos ya no van a esa escuela quiere decir que algo anda mal... (DEA)

Estos directivos señalan que la evaluación debe ser real y no maquillada, proponen herramientas que les permiten avanzar en la obtención de mejores resultados con el compromiso de todos porque "el director no lo puede hacer todo" (Ver figura 2).

Figura 2: Expectativa directores alto logro

Genera ambientes adecuados para la evaluación

"... Para que haya una buena evaluación se tiene que estar siempre creando un clima bueno entre el personal docente, intendente, secretarias ..."

DIRECTORES

ALTO

LOGRO

\section{Generar una cultura evaluativa individual y colectiva}

“ ... hacer visitas a los docentes, podemos ir enriqueciendo, ir generando una nueva cultura de la evaluación..."

Reconocer las debilidades para avanzar y cambiar

"Nuestro sistema educativo ... hay situaciones buenas, situaciones malas... se tiene que ver como cambiar lo negativo, las fallas, los errores... de los errores se tiene que aprender y se tiene que mejorar... dentro de los procesos de evaluación nos damos cuenta si la escuela funciona por la demanda que tiene, si los padres siguen mandando a sus hijos ahí. Si los alumnos ya no van a esa escuela quiere decir que algo anda mal..."

\section{La evaluación sea real}

"Cuando las evaluaciones no se maquillen, que realmente sean reales en cuanto al avance del educando, pero que tiene como propósito el reflejarnos una realidad para poder seguir avanzando, seguir creciendo y sobre todo con el compromiso de toda la comunidad, porque el director no lo puede hacer todo..."

\section{Fuente: Elaboración propia}

Por otro lado, los directivos de las escuelas de BL esperan de y con la evaluación que los supervisores monitoreen la evaluación en el aula y de esta manera evitar que el docente improvise sus actividades de planeación, así como que se actualicen a través de cursos, talleres o seminarios en temas relacionados con la evaluación. Esperan, además que el alumno adquiera las habilidades para contestar un examen (Ver figura 3 ). 
Que los supervisores monitoreen la evaluación. "Para que una escuela brinde servicios de calidad tiene que ocurrir un fenómeno el maestro tiene que planear su actividad no puede llegar a improvisar nada más y esa planeación tiene que ser monitoreada por un administrador educativo..."

Que los profesores se preparen en evaluación "...que realmente se llevara a cabo un curso, seminario o taller donde se viera exactamente qué es la evaluación y qué instrumentos puede utilizar el maestro para evaluar..."

Que el alumno desarrolle habilidades para responder el examen. "El alumno tiene que aprender a desarrollar todos esos tipos de habilidades de pensamiento ... también las habilidades que le podrán avudar realmente a contestar un examen"

\section{Fuente: Elaboración propia}

Los directores de las escuelas de BL esperan mayor control por parte de los supervisores a los docentes, que éstos se actualicen en evaluación a fin de mejorar sus prácticas evaluativas y los estudiantes aprendan a responder exámenes.

Tal proposición en la que confían los lleva a actuar a unos y otros directivos. Es decir, la profecía se cumple, una suposición negativa: "el docente no sabe, no planea, requiere de actualización"; o positiva: "un buen clima genera una buena evaluación, de los errores se aprende" son predicciones que, por la sola razón de haberse formulado, se convierten en realidad. La información recabada sostiene que la expectativa, el suceso esperado o profetizado se confirma en la realidad. En este aspecto si se encontraron diferencias significativas entre los directivos de $\mathrm{AL}$ y $\mathrm{BL}$, mientras los primeros tienen altas expectativas, realizan acciones para conseguir lo que se proponen a través del apoyo que brindan a sus maestros y alumnos, trabajan de manera colaborativa, mientras que los segundos tienden a formular profecías negativas de los actores que liderean y esperan que el sistema, los otros, el contexto cambien.

Creencias.- De acuerdo con Villoro (2004) las creencias significa tener algo por verdadero pero sin estar seguro de ello, ni contar con pruebas suficientes. Es un acto de una cualidad específica que ocurre en la mente de un sujeto y sólo podremos conocer el pensamiento de alguien a través de los actos de ese sujeto, en su relación con el mundo que lo rodea (Villoro, 2004). Una creencia es una afirmación que consideramos verdadera consciente o inconscientemente, afecta a la percepción que tenemos de nosotros mismos, de los demás y del mundo en general. Es todo aquello que creemos verdadero e importante para nosotros.

Los directivos de escuelas de AL creen que el reto es saber si el alumno adquirió todos los saberes, conceptual, procedimental y actitudinal, creen que pueden incidir en las prácticas educativas pero no en la realidad que cambia día con día; que para gestionar la evaluación es importante partir de la realidad, determinar las condiciones en las que se encuentran y luego establecer compromisos entre 
la comunidad para crecer de manera eficiente. Añaden que para lograrlo las evaluaciones deben ser reales, de lo contrario queda en un simple informe y todo continúa igual. Para poder cambiar es necesario aceptar que existe un problema y luego establecer compromisos entre compañeros y comunidad para seguir.

Por otra parte señalan que la discriminación y calificación entre maestros es más común

\section{Tabla 1: Creencias de los directivos}

\section{Alto}

El reto es lograr que el maestro pueda registrar los aprendizajes"...ese es el reto, de qué manera el maestro puede registrar que el alumno llegó a adquirir esa habilidad, ese conocimiento, esa actitud...cómo medimos ese aprendizaje, cómo nos damos cuenta que el alumno lo alcanzo..."(DA)

Para gestionar la evaluación es importante partir de la realidad "el problema de la escuela no se ha adaptado a esta nueva realidad..."

Existe discriminación entre los docentes. "La mayoría, sean ,maestros de carrera, sean de potras carreras está discriminando y sancionando - tú si eres bueno, tú eres mediano y tú eres malo... igual es con los maestros, igual es con los directivos-..."

Participación de todos los actores en la evaluación

Creen en la formación de los docentes de lo que se cree, por ser maestros de carrera o de otras especialidades, sin embargo, señalan que cada individuo tiene competencias diferentes y que el número puede o no corresponder a valorar dichas competencias, la inteligencia o el aspecto emocional, esta situación es igual con alumnos, maestros y con los directivos (Ver Tabla 1).
Si se evalúa el desempeño docente mejorarán las cosas

Existe incongruencia entre los niveles evaluativos. "Evaluación no coincide con la forma de evaluar otros niveles...aqui en la evaluación continua, se evalúan una serie de aspectos lo cual dan un resultado final, y cuando el alumno egresa de la secundaria tiene que enfrentarse a un examen de conocimiento totalmente al proceso de evaluación que se lleva en la secundaria y por eso muchas fracasan" $(D B)$

Reproduce formas de evaluación "el profesor tiende a repetir todos los procesos como fue formado, el maestro evalúa como lo evaluaron... estos esquemas los tiene bien establecidos y es difícil modificarlos, hay una resistencia al cambio...",

Carencias de formación pedagógica “...el $80 \%$ de los que componemos la planta docente en secundaria no son normalistas, luego entonces carecen de elementos técnicas pedagógicas-didácticas.

\section{Fuente: Elaboración propia}

Los directores y directoras de las escuelas de AL poseen creencias más positivas e insisten en la necesidad de promover la participación de todos los miembros de la comunidad, incluyendo a los padres de familia.

Mientras que los directivos de las escuelas de BL creen necesario evaluar al maestro, al alumno, al padre de familia, la deserción, eficiencia terminal. Afirman que el docente cree que está bien y cuenta con conocimientos pero en realidad debe actualizarse, prepararse de manera constante. Refieren que existe incongruencia entre los procesos evaluativos que se llevan a cabo en las escuelas secundarias y a los que tienen que sujetarse los estudiantes cuando egresan de las mismas (examen único de ingreso al nivel medio superior), razón por la cual muchos alumnos fracasan. Creen que el responsable de esta situación son los docentes quienes realizan una evaluación de corte cualitativo y no cuantitativo, y éste es el solicita- 
do al estudiante para su ingreso al nivel medio superior. Señalan que el docente evalúa como lo evaluaron. Consideran que por ser la mayoría docentes egresados de la universidad carecen de elementos técnico-pedagógicos-didácticos.

Estos esquemas mentales son difíciles de modificar y existe resistencia al cambio. Los directivos de las escuelas de BL creen que la evaluación es un problema ontológico, que los docentes necesitan ser controlados y para ello aplican una serie de instrumentos para medir la deserción, la eficiencia terminal; creen que el aprendizaje es el principal objeto de evaluación; que existe incongruencia entre los procesos evaluativos de la escuela secundaria y los solicitados externamente; que el docente es el responsable de que sus egresados no se incorporen al nivel medio superior debido a que reproducen procedimientos de evaluación que ellos vivieron como alumnos y carecen de formación en estrategias pedagógicas y de evaluación.

Por otro lado, los directores de escuelas de alto logro creen en la autoevaluación de la gestión, en trabajar con los profesores y aprender con los alumnos, creen que su ámbito de incidencia es acotado; que sólo si se parte de la realidad y con evaluaciones objetivas se puede crecer; evaluar continuamente para que haya éxito en la tarea; que para cambiar de actitudes es necesario evaluar las habilidades, actitudes y aptitudes y, que las reformas curriculares se realizan sin que medie una evaluación de las mismas y creen en la participación de todos los actores en los procesos evaluativos.

Las creencias de los directivos, afirmaciones que consideran verdaderas consciente o inconscientemente, afectan la percepción que tienen de ellos mismo, de los demás y del mundo en general, tal afirmación los lleva a actuar. Sus actos como concreción de su pensamiento los hace diferentes: los de AL emprenden acciones para alcanzar buenos logros; mientras que la creencia de los directivos de BL los paraliza y responsabilizan al entorno social, económico, político de su nivel de logro.

Acciones o gestión de la evaluación.- La acción humana dentro de las organizaciones esco- lares para llevar a cabo la evaluación educativa. O dicho de otra manera, la gestión es la capacidad de articular los recursos de que se disponen de manera de lograr lo que se desea (Casassus, 2000).

Los directivos de escuelas de $\mathrm{AL}$ asumen lo difícil que puede ser, desde su ámbito, el poder cambiar prácticas históricas que propicien la mejora del quehacer educativo. Estos actores educativos, en sus márgenes de acción, llevan a cabo su gestión, poniendo en marcha una serie de estrategias y para ello recuperan su realidad para tomar decisiones..." mi visión es a pesar de todo lo que existe, como existe y como está, atender la problemática de mi institución que es lo que más me preocupa" (DA).

Las sugerencias que plantean los directivos de escuelas de alto logro son variadas y se refieren a lo siguiente: brindan apoyo, los recursos materiales necesarios al profesorado para que desarrolle su labor.

...no le vamos a decir qué haga y cómo le haga es problema de él, pero si brindarle todo ese apoyo, todos los recursos materiales posibles, todos los recursos tecnológicos, el uso de la computadora y apoyar a los compañeros maestros (DA).

También es importante hacer un seguimiento de lo que hace el docente en su aula, en la evaluación.

...si un maestro de matemáticas pasa todos sus alumnos con diez pues hay que irlo a ver, ver que hace en la zona, el sector, hay que darse cuenta como lo está haciendo...y si un maestro saca puro cinco, pues también hay que irlo a ver, que está haciendo, para poder apoyar ese proceso (DA).

Acompañan al docente en su trabajo pedagógico y reiteran la relevancia del trabajo colegiado para establecer un diálogo sobre sus logros y rezagos a fin de comprenderlos y poder mejorar lo que se hace en el terreno de la evaluación. "Como el mecánico que no está actualizado ya no tendrá trabajo y el maestro, ¿qué pasa con él?” 
Señalan que es importante crear un clima que favorezca los procesos de evaluación en la escuela, tienen claro que el estudiante es su prioridad a quien tienen que darle su vida, su trabajo para prepararlo para la vida y garantizar que los padres de familia sigan confiando en la escuela y la recomienden como una buena institución educativa.

...para que haya una buena evaluación se tiene que estar siempre creando un clima bueno entre el personal docente, intendente, secretarias, todo el personal de apoyo para que todos nos centremos ... es el clima que se tiene que crear constantemente si hay fallas inmediatamente corregirlo (DA).

Los directores de AL, insisten en la necesidad de establecer un clima de confianza donde los alumnos puedan externar sus sentimientos y problemas familiares a fin de facilitar un mejor aprendizaje y un ambiente propicio para la evaluación.

...crear el clima, le decíamos a los padres de familia en las primeras reuniones no nos manden a sus hijos todos traumados y temerosos, cansados porque antes de salir de casa tuvieron ustedes un pleito fuerte delante de ellos y el pobre niño no viene aquí aprender porque esta rumiando el problema que vivió en casa, vamos agarrar esos 50 minutos que tenemos en clase ... me da tal maestro que me cae a todo dar y ahí aprendo, pues crear ese clima de tranquilidad un ambiente sano, un ambiente bueno, yo creo que eso nos va a dar la mejor evaluación (DA).

Por otra parte, se manifiesta, en los comentarios que el significado de la evaluación se ha modificado y ha pasado de ser una referencia a la valoración de los aprendizajes a un concepto aplicado a otros objetos del sistema educativo, para ello proponen realizar un ejercicio de autoevaluación de su gestión, considerando el clima organizacional y su liderazgo efectivo (Ver figura 5).

Esto no lo es todo porque también tenemos que valorar, el clima organizacional, que tipo de liderazgo que el director está ejerciendo, qué tipo de comunicación se está dando (DA).

Los directivos en escuelas de bajo logro reflexionan sobre la práctica directiva en relación con la evaluación, un ejercicio que los lleva a proponer procedimientos de evaluación elaborado por su cuerpo docente a fin de mejorar los procesos evaluativos en sus escuelas (Ver figura 5).

Por otra parte, los directivos de las escuelas de BL insisten que el problema está en los maestros, entonces cambiando ellos, de actitud y estén convencidos podrán llevar a cabo la evaluación de manera distinta, pero ello sólo se podrá lograr a través de seminarios, talleres o cursos donde se sensibilice o casi se le obligue a comprometerse a ser un profesional de la evaluación.

...pues buscar sensibilizar al maestro y que evalúe verdaderamente lo que tiene que evaluar lo que establece en los planes y programas de estudio, mientras que el maestro no esté plenamente convencido de qué debe evaluar ... no vamos a lograr ese cambio, que le podrán ayudar realmente a contestar un examen; ¿cómo podemos hacerlo? insisto, diseñando un seminario, taller, curso donde verdaderamente el profesor se le sensibilice, se le, casi, casi se le obligue a que verdaderamente se comprometa a ser un profesional en la evaluación (DB).

Solicitan que la solución sea propuesta por especialistas, del sistema educativo para resolver los procesos evaluativos en sus escuelas o bien les proporcionen instructivos para llevarlos a cabo.

...la propuestas buscar apoyos externos o apoyos de las supervisiones, que sería una de las funciones de la supervisión, apoyar los procesos de la escuela...(DB) "Pues, para mí sería que editaran algún instructivo, libro, folleto, donde si se estableciera la forma de evaluar por un investigador o hacer una compilación de todos los investigadores y que fuera obligatorio en el sistema de secundaria, todas, que llevara un modelo de evaluar (DEB). 
Figura 5: Acciones de los directores

\section{ALTO}

Brindan apoyo y seguimiento al
docente
Acompañan al docente en su trabajo
técnico-pedagógico
Generan nuevos ambientes para la
evaluación

Fuente: Elaboración propia

Los directivos de escuelas de BL centran su propuesta de mejora de los procesos evaluativos en la necesidad de cambiar la actitud de los docentes frente a los procesos evaluativos; de unificar criterios para llevarlos a cabo y consideran que sería importante que se les otorgue un instructivo, folleto donde varios investigadores les digan cómo evaluar.

Los directivos de las escuelas de AL reiteran la relevancia del trabajo colegiado para establecer un diálogo sobre sus logros y rezagos a fin de comprenderlos y poder mejorar lo que se hace en el terreno de la evaluación. Intentan propiciar un ambiente que favorezca los procesos de evaluación en la escuela cuyo beneficiario es el estudiante, insisten en la necesidad de establecer un clima de confianza donde los alumnos puedan externar sus sentimientos y problemas familiares a fin de facilitar un mejor aprendizaje. La gestión de la evaluación en escuelas de AL y BL presenta diferencias importantes (Ver figura 5). Estos hallazgos coinciden con resultados de estudios de prácticas de gestión exitosas de directivos de escuelas de altos niveles de logro educativo.

\section{BAJO}

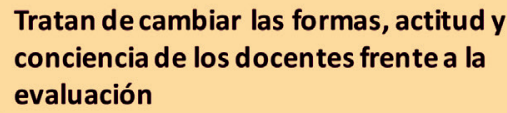

\section{Tratan de unificar criterios en} reuniones colegiadas

Buscan apoyo externo (supervisores,

especialistas

\section{Conclusiones}

La representación y el significado de evaluación de los directivos de las escuelas estudiadas, real o imaginaria, implícitamente coinciden, aunque en la acción los de AL muestran una representación distinta a la concepción ortodoxa de la evaluación. Este estudio refrenda que el conocimiento del directivo, su mirada de la práctica evaluativa y lo que hace, le da significado para él y los otros agentes educativos. Tal significado de la evaluación es resultado de un proceso social y cultural compartido en la organización escolar.

En relación con las expectativas, las de los directivos de escuelas de AL son altas; mientras que las de los de las escuelas de BL tienden a enunciar profecías de autocumplimiento dirigidas a los estudiantes y a ellos mismos, anuncian fracasos de tal manera que el fracaso acaba sucediendo y responsabilizan a los docentes del mismo.

Tal proposición en la que confían los lleva a actuar a unos y otros directivos. Los resultados de este trabajo sostiene que la expectativa, el suceso esperado o profetizado se confirma en la realidad. 
En este aspecto si se encontraron diferencias significativas entre los directivos de AL y BL.

En cuanto a las creencias, se presentan pensamientos dicotómicos: descalificación, etiquetación o lo expresión del deber ser. En este componente se manifiestan diferencias significativas entre los equipos directivos de los dos tipos de escuelas: los de alto logro ven experiencias más positivas mientras que los de bajo se van al otro extremo. Tales afirmaciones, que los directivos consideran verdaderas consciente o inconscientemente, afectan la percepción que tienen de ellos mismo, de los demás y del mundo en general y los lleva a actuar de manera diferente: los de AL emprenden acciones para sostener su nivel de logro; los de BL creen que si el entorno cambia entonces se podrá actuar de otra forma.

Se puede afirmar que, la acción humana dentro de las instituciones marca diferencias entre las escuelas de $\mathrm{AL}$ y $\mathrm{BL}$, en tanto que está generada por las expectativas y creencias de los directivos, en este caso. Al igual que Sammons et al. (1995), quien ofrece una imagen que perfila las características de las escuelas eficaces: liderazgo, visión y metas compartidas, expectativas elevadas, entre otras. Estos hallazgos coinciden con resultados de estudios realizados por Loera (2003) sobre prácticas de gestión exitosas de directivos de escuelas de altos niveles de logro educativo.

Los directores de las escuelas de alto logro reflexionan sobre su práctica de gestión, son más autocríticos y se incluyen dentro de las propuestas de mejora de los procesos evaluativos. Tienen una mirada positiva de sus docentes y son más propositivos. Los directivos de bajo logro responsabilizan el bajo aprovechamiento a los docentes, al sistema educativo, a los contextos, etc. y proponen que los docentes cambien sus procedimientos de evaluación para elevar los estándares solicitados, el riesgo en estas escuelas lo constituye el tener como foco de atención desarrollar mecanismos de evaluación que les permitan elevar su nivel de logro y no los aprendizajes de sus estudiantes.

\section{Referencias bibliográficas}

Ainscow, M., Hopkins, D., Soutworth, G., \& West, M. (1994). Creating the conditions for school improvement. En: A handbook of Staff Development activities. Londres: Roudledge.

Alvariño, C., \& Vizcarra, R. (1999). Gestión para la innovación en educación: desafíos para las escuelas particulares subvencionadas. En: P. Cariola, \& J. Vargas, Educación particular subvencionada. Santiago de Chile: CONACEP.

Arancibia, V. (1992). Efectividad escolar: Un análisis comparado. Estudios Públicos, 47, 101-125.

Berger P. \& Luckmann T. (1968). La construcción social de la realidad. Madrid: Amorrortu Editores.

Bryk, A. S., \& Raudenbush, S. W. (1992). Hierarchical Linear Models: applications and data analysis methods. California: Sage.

Casassus, J. (2000). Problemas de la gestión educativa en América Latina. UNESCO.

Coleman, J. (1990). Equality en Achievement in Education. Boulder, CO: Westview Press.

Espinoza, S., \& cols, y. (1995). Escuelas de calidad y sus procesos organizacionales: un cambio hacia el mejoramiento de la educación. Tesis de Licenciatura no publicada. Santiago de Chile: Pontificia Universidad Católica de Chile.

Gardner, H. (1995). Inteligencias múltiples. España: Paidós.

Goldstein, B. (1988). In Search of Survival: The Education and Integration of Among Refuges Girls. Journal of Ethnic Studies, 16(2), 1-27.

Hargreaves, A. (1994). Changing teachers, changing Times. Teacher' Work and Culture in the Postmodern Age. Londres: Cassell.

Hernández, R., Fenández, C., \& Baptista, P. (2008). Metodología de la Investigación (4ta ed.). México: McGraw Hill.

Hopkins, R. (1994). Narrative schooling: experiential learning and the transformation of American education. New York: Teachers collage.

Horn, A., \& Murillo, F.J. (2016). Incidencia de la dirección escolar sobre el compromiso de los docentes. Un estudio multinivel. Psicoperspectivas, 15(2). 
Loera, A., Cázares, Ó., García, E., González, M. d., Hernández, R., \& G. de Lozano, M. A. (Enero de 2003). El estado inicial de las escuelas primarias de las escuelas de calidad. Informe ejecutivo sobre los indicadores de la Línea de base. Obtenido de Heurística Educativa: http://basica.sep.gob.mx/pec/Documentos/ Evaluaciones\%20de\%20Heuristica/Reporte_ Ejecutivo.pdf

Murillo, F.J., \& Hernández-Castilla, R. (2015). Liderazgo para el aprendizaje: ¿Qué tareas de los directores y directoras escolares son las que más inciden en el aprendizaje de los estudiantes? RELIEVE, 21(1), art. 1.doi: 10.7203/ relieve.21.1.5015 (Scopus)

Murillo, F.J., \& Krichesky, G.J. (2015). Mejora de la Escuela: Medio siglo de lecciones aprendidas. REICE. Revista Iberoamericana sobre Calidad, Eficacia y Cambio en Educación, 13(1), 69-102.

Provus, M. (1971). Discrepancy Evaluation. California: McCutchan Publishing.

Reynolds, D. (1996). The problem of the ineffective school some evidence and some speculations. Londres: Cassel.

Rivera, A., \& Rivera, L. (2006). Organización, gestión y dirección de instituciones educativas. Reflexiones y propuestas. México: Mástextos UPN.
Rutter, M., Maughan, B., Mortimore, P., Ouston, J., \& Smith, A. (1979). Fifteen thousand hours: Secondary schools and their effects on children. Cambridge, MA: Harvard University Press.

Sammons, P., Hillma, J., \& Mortimore, P. (1995). Key Characteristics of Effective Schools: A Review of School Effectiveness Research. London: OFSTED/Institute of Education (University of London.

Santos, M. A. (2001). Teoría y práctica de la evaluación cualitativa de centros docentes. Madrid: Akal.

Servat, B. (1995). Gestión de recursos humanos en el centro escolar. Buenos Aires: Magisterio del Río de la Plata.

Stake, R. (1967). Evaluación comprensiva y evaluación basada en estándares. Barcelona: Graó.

Stoll, L., \& Fink, D. (1999). Para cambiar nuestras escuelas. Refundir la eficacia y la mejora. Barcelona: Octaedro.

Stufflebeam, D., \& Shinkfield, A. (1985). Evaluación sistemática: Guía teoría y práctica. Barcelona: Paidós.

Teddlie, C., \& Stringfield, S. (1993). Schools Make a Difference. New York: Teachers College Press.

Villoro, L., (2004) Creer, saber, conocer. Edit. Siglo XXI. México.

Zárate, G. (1992). Experiencias educacionales exitosas: Un análisis a base de testimonios. Estudios Públicos, 47, 127-158. 


\title{
Del castigo corporal al buen encauzamiento de las conductas en la educación
}

\section{From the body punishment to the good setting of behaviors in education}

Estudio

\author{
Juan Illicachi Guzñay \\ Universidad Nacional de Chimborazo-Ecuador \\ andres1_517@hotmail.com
}

Recibido: 30 de marzo de 2016 / Aceptado: 09 de enero de 2017

\section{Resumen}

Considerando que el campo educativo es un ámbito privilegiado para estudiar el ejercicio del poder, el artículo analiza la manera cómo opera el poder disciplinar-que se ejerce sobre los cuerpos de los individuos y destinados a vigilarlos, controlarlos y adiestrarlos con el objeto de hacerlos dóciles y útiles- y el biopoder que se ejerce en el cuerpo colectivo de la población y se alimenta de los saberes que se engendran a partir de la propia población-.Y, la manera cómo estas formas de poder en el campo educativo monocultural fue cuestionada y sismada por la educación intercultural bilingüe: primero, porque la institucionalidad intercultural emerge en oposición a la educación hegemónica y como una bandera de lucha política, epistémica del movimiento indígena ecuatoriano. Segundo, porque se constituye en la insurrección y retorno de saber sometido. Aunque la educación intercultural bilingüe, en ocasiones también continúa reproduciendo las mismas formas de constitución de sujetos a través de un determinado número de prácticas de saber-poder.

Descriptores: Ritualidad, disciplina, poder, resistencia, episteme.

\begin{abstract}
Whereas Education is a prime area to study the exercise of power, the article analyzes the way power operates discipline which is exercised over the bodies of individuals and intended to watch them, control them and train them in order to make them docile and useful- and biopower which is exercised in the collective body of the people and feeds on the knowledge that are generated from the population itself. And the way how are you forms of power in the monocultural educational field was challenged and sismada for bilingual intercultural education: first, because the intercultural institutions emerges in opposition to the hegemonic education and as a banner of political struggle, epistemic Ecuadorian indigenous movement. Second, because it is in the insurrection and return knowing subject. Although intercultural bilingual education, sometimes also continues to play the same forms of constitution of subjects through a number of practices of knowledge-power.
\end{abstract}

Keywords: Ritualism, discipline, power, endurance, episteme.

Forma sugerida de citar: Illicachi Guzñay, Juan (2017). Del castigo corporal al buen encauzamiento de las conductas en la educación. Alteridad, 12(1), pp. 104-114. 


\section{Introducción}

El trabajo inicia justificando las razones por las cuales se constituye en una caja de herramientas el horizonte teórico del filósofo francés Michel Foucault en el proyecto de investigación más amplio, aún en curso: "El tránsito de una educación disciplinaria a una educación de control en Riobamba"; del cual es parte, el presente artículo: el primero, es de orden teórico y general: resolviéndose incluir la educación por la importancia que ella tiene para las discusiones en el campo de los estudios Foucaultianos y, especialmente en lo que se refiere a la razón política tematizada por el filósofo. Se "arriesga" a decir que este es un componente imprescindible para la operación de la biopolítica, biopoder y los dispositivos de normalización que se extiende sobre los cuerpos sociales. Un tema que no se desconecta de las categorías de vigilar, castigar y disciplinar. El segundo, es de orden práctico. Los procesos educativos -escolares y no escolares-parecen buenos ejemplos y lugares privilegiados para analizar la manera cómo circula el poder disciplinario, la resistencia, la biopolítica y los dispositivos de normalización (Veiga-Neto, 2013), conociendo que Michel Foucault fue uno de los primeros en detectar del despegue de las sociedades disciplinarias hacia las sociedades de control. Aquí resaltamos las reflexiones de Foucault por medio de los autores de Imperio:

El poder disciplinario mantenía a los individuos en instituciones pero no lograba absorberlos completamente en el ritmo de las prácticas productivas y la socialización productiva; no lograba penetrar eternamente en las conciencias y los cuerpos de los individuos, ni llegaba tratarlos a tratarlos y organizarlos en la totalidad de sus actividades. En la sociedad disciplinaria, la relación entre el poder y el individuo continuaba siendo una relación estática: la invasión disciplinaria del poder correspondía a la resistencia del individuo. En cambio, cuando el poder el poder llega a ser completamente biopolítico, la maquinaria del poder invade el conjunto del cuero social que se desarrolla en su virtualidad. Esta relación es abierta, cualita- tiva y afectiva. La sociedad, absorbida dentro de un poder que se extiende hasta los ganglios de la estructura social y sus procesos de desarrollo, reacciona como un solo cuerpo. El poder se expresa pues como un control que se hunde en las profundidades de las conciencias y los cuerpos de la población y, al mismo tiempo, penetra en la totalidad de las relaciones sociales (Negri y Hardt, 2002, p. 186).

El tercero es de tipo vivencial y personal. El ejercicio docente del investigador en los centros educativos de educación básica, bachillerato y superior bilingüe, y monolingüe, avala hacer el entrecruzamiento de la teoría Foucaultiana con la educación en el espacio de Riobamba. Por último, posiblemente sea el más ambicioso y a largo plazo es la creación de un laboratorio de investigaciones en ciencias sociales que, incorporando el método Foucaultiana en la Universidad Nacional de Chimborazo, atienda el estudio de problemas específicos de la realidad educativa ecuatoriana. De allí la importancia de la formación, investigación y difusión de la obra del filósofo francés, y su uso en el estudio de objetos específicos de la realidad social y educativa.

Por otro lado, Ángel Palerm menciona: "Saludo el futuro en que para los científicos sociales será posible hablar de Marx como los biólogos lo hacen de Darwin y los físicos de Einstein" (2008, p. 46). En esta línea de reflexión, se puede decir que si algún científico social no se sumerge en las profundidades de las líneas maestras del pensamiento foucaultiano: el poder, el saber y el sí, es como si algún sacerdote no leyera la biblia.

Es indudable la gran influencia de Michel Foucault en la filosofía, historia, antropología, teoría social y los estudios culturales contemporáneos, sin embargo, en las academias periféricas parece no nacer ni Foucault ni su pensamiento, constituyéndose en una teoría privilegiada solamente de los centros universitarios ubicados en las metrópolis. La ausencia de las obras foucaultianas en las estanterías de las librerías y bibliotecas en los espacios periféricos es visible. Esta crisis en parte puede ser por lo que argumenta Aída Hernández: 
Desafortunadamente la información y las personas no fluyen tan fácilmente de sur a sur, como lo hacen el capital y la fuerza laboral (cuando se le requiere) de norte a sur y de sur a norte, respectivamente. El intercambio político e intelectual entre América Latina, África y Asia se ha visto limitado por barreras lingüísticas y por la precariedad de nuestras industrias editoriales e instituciones científicas y educativas (2014, p. 195).

La estrategia de adoptar y emplear la teoría del filósofo Michel Foucault para estudiar el campo educativo en el contexto de Riobamba no implica ubicar los debates como una simple recepción, como si fuéramos la sucursal latinoamericana o riobambeña de una compañía transnacional llamada "trilogía conceptual: poder, saber y subjetividad", sino mostrar que la especificidad del debate latinoamericano sólo puede apreciar $a$ contraluz de lo que en otros lugares se ha venido discutiendo bajo esta rúbrica (Castro-Gómez, 2005). Es más, Foucault no solo forma parte de los llamados clásicos, sino que sigue siendo parte de la inquietud del pensamiento contemporáneo que no se ubica más en la verdad, sino en la coherencia de los discursos, en las redes de redes que se comunican (Lechuga, 2007). De ninguna manera hay la pretensión de invisibilizar los puntos ciegos o los límites ${ }^{1}$ de la teoría Foucaultiana.

Con estos antecedentes, el texto analiza la manera cómo los castigos en la educación eran ritualizados públicamente. El cuerpo es el lugar donde se ejerce el poder educativo, siendo el cuerpo y la mente escolar el objeto de poder o de la colonialidad: colonialidad del saber, colonialidad del ser, fabricando a su interés; es decir,

\footnotetext{
En una de las críticas, que puede ser aplicable también en la educación, Silvia Federici, en su libro: Calibán y la bruja. Mujeres, cuerpo y acumulación originaria sostiene: "Por su parte, las feministas han acusado al discurso de Foucault sobre la sexualidad de omitir la diferencia sexual, al mismo tiempo que se apropiaba de muchos saberes desarrollados por el Movimiento Feminista. Esta crítica es bastante acertada... Más aún, Foucault está tan intrigado por el carácter productivo de las técnicas del poder de las que el cuerpo ha sido investido que su análisis deja prácticamente fuera cualquier crítica de las relaciones de poder (2016, p. 29).
}

individuos obedientes, sumiso y dóciles. La ritualización del castigo al cuerpo del niño y del joven indígena en los espacios escolares era más radical que en la ciudad. Frente a esta educación punitiva, coercitiva surge la educación intercultural bilingüe como una alternativa y en oposición a la educación monocultural. Son éstos los temas que trata el texto en las siguientes secciones a la luz de la teoría foucaultiana y del trabajo de campo etnográfico. Se esgrimió las entrevistas, las historias de vida, la observación participante. Predominó un enfoque antropológico colaborativo y militante, una investigación emic y no etic, rompiendo con las perspectivas tradicionales de investigación que concebía a los interlocutores como meros "objetos de estudio".

\section{El castigo al cuerpo: ritualidades}

En la educación ecuatoriana, la frase "la letra con sangre entra" operaba con naturalidad y normalidad en las aulas educativas, y con más radicalidad en los espacios rurales e indígenas. De cierta manera la escuela se constituía en una especie de panoptismo $^{2}$ no porque sea un centro carcelario ${ }^{3}$ sino porque se constituía en la casa de inspección, de control del poder. La escuela es una construcción arquitectónica desde donde se dirige y se vigila a las multitudes, en los patios, en los pasillos, en las gradas, en las aulas. Un solo individuo puede controlar y disciplinar a toda una multitud, por ejemplo, el inspector general logra controlar las conductas de un colectivo de mil estudiantes en los patios de la institución. De la misma manera, un docente puede vigilar y castigar, casi, en forma ritualizada a sus discípulos. En este sentido el sujeto-alumno no es abstracto, incorpóreo,

2 La categoría panóptica para Michel Foucault es "una forma en que el poder se materializa en dispositivos arquitectónicos, pero también en un régimen de mirada. Un proyecto de verlo y vigilarlo todo desde un solo punto" (Parrini, 2007, p. 16).

3 Aunque para Miguel Morey: “No sólo los prisioneros son tratados como niños, sino que los niños son tratados como prisioneros. Los niños sufren una infantilización que no es la suya. En este sentido es cierto que las escuelas son un poco prisiones, y las fábricas mucho más" (2008, p. 28). 
vacío, sino que el sujeto se define en el cuerpo a partir de los regímenes del saber y del poder (Lechuga, 2007). El cuerpo es el lugar donde se ejerce el poder educativo. Dicho de otra manera, el cuerpo escolar fue blanco y objeto de poder y saber. El cuerpo escolar siendo un objeto de poder, al entrar en el dominio del poder es fabricado a su interés; o sea, individuos obedientes.

El castigo físico a los y las estudiantes se expresaba de múltiples maneras: con empujones contra el pizarrón; los reglazos en cualquier parte del cuerpo, preferentemente, en las manos o en la cabeza; los pellizcos; los golpes, las sacudidas; las tiradas de las orejas. Estos castigos cumplían el rol de corregir, guiar, mejorar las fallas cometidas (Herrera, 2013). La intención es dominarlos, disminuirlos, sumirlos, hasta el punto de obtener la entrega de sus voluntades y sus espíritus.

Las razones por las cuales violentaban los cuerpos escolares no faltaban, sin embargo citamos algunas con fines ilustrativos: por las malas letras; por ingresar con la comida al salón de clase; por levantarse sin autorización del docente; por ensuciar los cuadernos, por doblar los filos de los libros, etc., sobraban los motivos para los castigos. Los cuerpos se sometían a la docilidad, la obediencia, disciplina y corrección con el fin de hacerlos trabajar y convertirlos en productivos, en fuerza de trabajo físico e intelectual (Lechuga, 2007).

La violencia al cuerpo escolar no se avergonzaba, se expresaba de manera directa e incluso exhibiéndose públicamente, mientras más se presentaba en público más efectivo era el castigo, por ejemplo, uno de los maestros entrevistados revela que el castigo denominado plantón, consistía en hacerle "parar" al estudiante de espaldas en un rincón del aula por mucho tiempo sin que el afectado volteara a mirar a quien ejerce el poder ni a sus espectadores, en este caso sus compañeros del aula. $\mathrm{El}$ individuo individualizado se ubica en un espacio reducido, recortado, vigilado en todos sus puntos, en el que los menores movimientos se hallan controlados, en el que todos los acontecimientos se encuentran registrados (Foucault, 2009). De cierta manera, aquí funciona la fórmula "el observador puede ver al observado y no a la inversa". Al menos en este tipo de castigo el estudiante cercado no puede ver, pero sí, quien ejerce el poder.

Para algunos docentes no era correcto castigar pero admiten que era la mejor forma de educar y hasta expresan su extrañez:

Porque la educación de antes era mejor que la de ahora. Hoy no se puede tocarles, tienen protección del Ministerio de Educación, del Código de la Niñez y de la Adolescencia. No hay miedo a nada, por eso son muy irresponsables (Anónimo, 15 de junio de 2015).

De acuerdo a este testimonio el castigo físico fabricaría el tipo de sujeto responsable, cumplidor y tímido. Esta extrañeza al "pasado", a la forma de educar con castigo también es añorada por algunos estudiantes universitarios, futuros maestros, aunque sugieren "un castigo suave" para formar ciudadanos responsables, respetuosos, a la vez que insinúan aplicar "mano dura" desde la docencia, admitiendo que él es un buen estudiante porque tuvo profesores con "mano dura". Esta narrativa ambigua y contradictoria no solamente circula en los estudiantes y profesores, también son reproducidas por los padres de familia; por un lado cuestionan el castigo al cuerpo de sus hijos, por otro lado ven la necesidad de su presencia y aplicación, incluso en ocasiones sugieren medidas enérgicas para que su hijo sea disciplinado. En este sentido, las "estrategias", "programas" y "tecnologías" de poder se justifican como necesidad y poder moral (Morey, 2008; Gledhill, 2000). “Tengo razón en castigar, puesto que tú sabes que está mal robar, matar, no hacer los deberes, atrasarse,..." (Morey, 2008, p. 28).

Algunos instrumentos empleados para el castigo al cuerpo de los escolares variaban en los escenarios urbano/rural, campo/ciudad. El cuerpo indígena no era el mismo cuerpo del mestizo o del blanco, era el cuerpo del no humano, era el cuerpo del no ser; por lo tanto, el cuerpo animalizado debía ser tratado sin consideración alguna, con acciones represivas. La ritualización del castigo al cuerpo del niño y del joven indígena en el 
campo escolar era más radical que en la ciudad; por ejemplo, se le aplicaba la "fila india", que consistía en formar dos columnas de estudiantes para que por medio de ella pasara el cuerpo indisciplinado recibiendo patadas, puñetes, murmullos, silbidos, gritos. El ritual se solemnizaba aún más, cuando alguien de la fila "por consideración o amistad" no se insertaba en ese juego de poder, corría con la misma suerte de ser castigado.

En este sentido, la tecnología disciplinaria fija, inmoviliza o regula los movimientos; resuelve las confusiones, las aglomeraciones compactas sobre las circulaciones inciertas, las distribuciones calculadas (Foucault, 2009), pero en definitiva quien domina, contrala y direcciona los comportamientos y las fuerzas de los estudiantes son los profesores o cualquier autoridad educativa, sin embargo, no se puede negar de los momentos y formas de resistencias 4 imprevistas e imprevisible de los estudiantes o habrá que explorar los nuevos tipos de luchas de los estudiantes, por ejemplo, las luchas no centralizadas, las luchas transversales (Negri, 2004; Delueze, 2014[1986]), tema que será analizado a profundidad en los posteriores artículos.

Otro instrumento de castigo empleado en el ámbito escolar es la aplicación del ramo de ortiga ${ }^{5}$ negra en el cuello del "afectado", o el hecho de azotar en las manos, produciendo inflamación e irritación en la piel con el picor intenso. El sufrimiento del castigo se debe a que la ortiga, al tener pelos y espinas, liberan una sustancia ácida que produce escozor en la piel.

El instrumento de castigo en las escuelas rurales eran las pepas de eucalipto, los mismos estudiantes solían recoger en un bosque cercano a la institución, sobre esas pepas se ponían de

4 Referente a la resistencia, Gilles Deleuze, citado en Miguel Morey sostiene: "Si los niños llegasen a hacer oír sus protestas en una escuela de párvulos, o incluso simplemente sus preguntas, eso bastaría para provocar una explosión en el conjunto del sistema de enseñanza" (2008, p. 27).

5 La ortiga tiene el tallo de sección de forma de cuadrado, hojas con forma de ovalo, con el borde aserrado. La característica más conocida de esta planta es presencia de pelos urticantes cuyo líquido cáustico produce una irritación con picor intenso en la piel cuando se le toca o roza. rodillas los estudiantes indisciplinados, luego de varios minutos se levantaban con heridas, gotas de sangre rodaban por las rodillas al ritmo de las gotas de lágrimas que rodaban por las mejillas. Dentro o sobre el escritorio del profesor se exhibía un látigo ${ }^{6}$ de cuero de vaca, también denominado "veta" o "azote". Los latigazos provocaban dolores insoportables y sangrados. Tanto los "hortigazos" como los "latigazos", frecuentemente, solían aplicar en los glúteos haciéndoles desvestir sea a mujer o varón, sin ningún pudor. El uso de los latigazos era común y natural en las escuelas, incluso los mismos padres de familia llevaban y les entregaban al profesor, los mismos representantes solicitaban a los profesores que castiguen, como nos relata en una de las entrevistas. Era una de las maneras de normalizar el uso del látigo en los cuerpos de los indisciplinados. Mientras más "bravo", violento era el profesor era considerado como el mejor profesor. La indisciplina de los alumnos era atribuida a la mansedumbre del docente. El látigo era un instrumento que producía fuertes dolores, sin embargo era normal ver a los estudiantes con huellas de los latigazos, era natural ver al docente en los patios, aulas con látigo en mano. El uso de este objeto era sinónimo de corrección y disciplinamiento, hoy es un objeto sinónimo de maltrato y agresión. En ausencia del látigo reemplazaba las denominadas "varas" o ramas de las plantas o de los árboles, señala uno de los entrevistados.

A este tipo de educación punitiva y coercitiva acompañaba los discursos humillantes, discriminantes, machistas, racistas. Por ejemplo, era común escuchar: "Tu no sirves sino para pastorear chivos; en vez de gastar el dinero produce cuidando chanchos; lárgate al páramo y no vuelvas nunca a mi clase". En este sentido la edu-

6 El látigo es un objeto multifuncional esgrimido no solamente por el profesor sino también por los padres de familia para corregir el comportamiento de sus hijos. De acuerdo a las narrativas señalan que el mismo objeto servía para castigar a los indígenas mayores de parte de los hacendados, pero además el indígena besaba el látigo luego de recibir el castigo como signo de humildad y agradecimiento. Este mismo objeto fue empleado para acarrear a los animales, para educar los estudiantes, para disciplinar los indígenas. 
cación se constituye en un instrumento de poder que se impone mediante técnicas, muchas veces sofisticadas e invisibles, de estandarización, de "normalización", que hacen que la escuela, al igual que el cuartel o la fábrica, se parezcan a la cárcel moderna (Foucault, 2009 [1976]). Aunque similar discurso fue expresado por el sociólogo francés Emile Durkheim (1976). Desde su abordaje, la educación moral que se desarrolla en la escuela es clave en la sociedad moderna para someter a los jóvenes a un conjunto de reglas que, a la vez que se imponen como mandatos, generan la regularidad de hábitos necesaria en la sociedad industrial.

\section{Del castigo al cuerpo al control de las almas}

En la actualidad -en el área donde se ejecuta la presente investigación- una de las maneras de controlar, vigilar y castigar no es al cuerpo, sino al alma. La exhibición, la ritualidad del castigo físico, la educación punitiva se diluye, opera de modo más transformada. Porque el castigo físico se considera como una práctica inconveniente, peligrosa e inadecuada para educar a los niños y jóvenes (Herrera, 2013). Los castigos dolorosos, el castigo físico sobre el cuerpo de los niños en la escuela, por considerarlo nocivo y vejatorio han sido cuestionados, denunciados y suprimidos. Se afirma que la fuerza física no asegura ni la autoridad por parte del maestro, ni la obediencia en el discípulo (Herrera, 2013) no obstante, la intromisión de la política y del poder sobre el $b_{i o}{ }^{7}$ de los

7 El biopoder interviene y extiende la vida. La biopolítica dice interesarse por educar y formar físicamente para la vida (Tejeda, 2012, p. 20l. A partir de la década de los 70, con los aportes de Michel Foucault, se introduce en el pensar filosófico las categorías de biopoder y biopolítica para aludir al cambio de paradigma que inaugura el pasaje de las sociedades disciplinarias modernas a las sociedades de control o posmoderna. En realidad, el término biopoder es más amplio que biopolítica, ya que el primero implica el poder que se ejerce sobre la vida de las personas desde cualquier contexto (hospitalario, escolar, empresarial) mientras el segundo refiere específicamente al manejo de la vida de las personas desde la acción del Estado (Lesteime, 2011). individuos y multitudes escolares continúa siendo parte de la educación.

Una de las razones para que los castigos corporales cedan su puesto a los medios espirituales y almas es por los cuestionamientos de la educación intercultural bilingüe (EIB), no por eso se puede decir que las técnicas de control y de la vigilancia a los individuos se han erradicado. En la EIB, también el poder se inmiscuye en la intimidad y penetra cuerpos y mentalidades del mismo modo que en la educación hegemónica y monolingüe. En la EIB, el poder cuida y conserva el cuerpo, ya no reduce o maltrata el cuerpo escolar y colegial, de ahí la relevancia que adquiere el cuerpo escolar indígena como portador de la identidad cultural: vestido, cabello largo. En este sentido, ahora son exaltados los cuerpos indígenas esculpidos y violentados históricamente, ahora son valorados y humanizados los cuerpos indígenas animalizados (Tejeda, 2012).

Evidentemente, en este campo, el funcionamiento del poder positivo no es, en modo alguno, un poder represivo, sino productivo, un poder inventivo y no conservador. El descubrimiento de Foucault del poder positivo radica en que su funcionamiento no se reduce a decir "no", ni a prohibir, impedir, obstaculizar; si el poder no tuviera más funciones que las de excluir y reprimir, "si no se ejerciera más que de una manera negativa, sería muy frágil". Si es fuerte, es debido a que produce efectos positivos a nivel del deseo y también a nivel del saber (Lechuga, 2007, p. 117).

Las relaciones de poder no deben limitarse a la posibilidad de la violencia, pues son un conjunto de mecanismos y tecnologías muy complejas cuya esencia no es prohibir, sino vigilar, controlar conductas, ocuparse del desarrollo de la gente en instituciones como las escolares, y actuar sobre sus gestos, sus maneras de actuar, sus aptitudes (Lechuga, 2007, p. 120).

No obstante del pasaje de una educación punitiva a una educación positiva, del tránsito de una educación prohibitiva a una educación de 
permisiva ${ }^{8}$, ambas formas de educación continua siendo -en la práctica- monolingüe, monocultural, hegemónica. En este sentido:

El sistema educativo recrea y reproduce las jerarquías raciales de la sociedad ecuatoriana. Es más, la mayoría de los educadores reproducen las jerarquías raciales en sus salones de clase. Por lo tanto, el paso por la escuela, el colegio y la universidad son, por lo general, experiencias traumáticas llenas de vejámenes y obstáculos (De la Torre, 1996, p. 34).

En oposición a este tipo de educación y como alternativa emerge la educación intercultural bilingüe ${ }^{9}$ como un proyecto político, epistémico de los pueblos indígenas, que atenúa a la forma de educación prohibitiva/ productiva.

\section{EIB como proyecto político y epistémico}

En este apartado empiezo formulando algunas preguntas de corte epistémico. ¿Qué implica considerar a la EIB como un proyecto epistémico? ¿La irrupción de la EIB al sistema educativo nacional colonial ha contribuido a la toma conciencia del proceso propio de conocimiento y del

8 "Se me ocurrió cantar, inconscientemente, el profesor sin dudar y de buena manera me dijo que cantara para todos. Pero me dio mucha vergüenza". Pues, aquí funciona el poder facultativo, permisivo.

9 La Dirección Nacional de Educación Intercultural Bilingüe, DINEIB, fue creada mediante Decreto Ejecutivo No. 203 del 9 de noviembre de 1988, publicado en el Registro Oficial No. 66 de 15 del mismo mes y año, para atender las necesidades educativas de la población indígena del país. Entre sus funciones, se responsabiliza del desarrollo del currículo apropiado para cada uno de los sistemas y modalidades de educación intercultural bilingüe, así como de la promoción y fortalecimiento de las lenguas indígenas. Mediante Ley No. 150 de 15 de abril de 1992, publicada en el Registro Oficial No. 918 de 20 de abril del mismo año, se eleva a la DINEIB al nivel de un organismo técnico, administrativo y financiero descentralizado; y para su funcionamiento cuenta con su propia estructura orgánica funcional. De la misma manera, en 1992, se oficializa el Sistema de Modelo de Educación Intercultural Bilingüe con fundamentos filosóficos, jurídicos, pedagógicos y psicológicos. Más adelante, en el año 2003, fue rediseñado sobre la base de las diferentes experiencias de EIB en el país (MOSEIB, 1992; García, 2007; Zavala, 2007; Martínez, 2009). saber indígena? La institucionalización de la EIB vehiculiza -en términos foucaultianos- la lucha por la insurrección de los saberes sometidos:

Y por saber sometido entiendo dos cosas. Por una parte, quiero designar, en suma, contenidos históricos que fueron sepultados, enmascarados en coherencias funcionales o sistematizaciones formales...En segundo lugar, por saber sometido creo que hay que entender otra cosa y, en cierto sentido, una cosa muy distinta. Con esa expresión me refiero, igualmente, a toda una serie de saberes que estaban descalificados como saberes no conceptuales, como saberes insuficientemente elaborados: saberes ingenuos, saberes jerárquicamente inferiores, saberes por debajo del nivel del conocimiento o de la cientificidad exigidos (Foucault, 2006 [1976], p. 21).

La recuperación de los saberes sometidos o los intentos por la recuperación por medio de la EIB no se dan en un campo pacífico, sino en un campo de lucha permanente que desafía a un orden institucional históricamente jerárquico, que busca enfrentar los legados coloniales, incluyendo las geopolíticas del conocimiento. Aquí es interesante importante señalar la nueva, o mejor dicho, la renovada atención puesta por grupos indígenas y afros al pensamiento como campo de lucha, intervención y creación, haciendo así evidente un proyecto de la EIB que no es sólo político, sino también epistémico (Walsh, 2007) en el sentido de imaginar también no ya "nuevos paradigmas" inscritos en el proyecto de la modernidad (tanto colonizadores como liberadores), del cual el proyecto del neoliberalismo es parte y consecuencia, sino de "paradigmas otros" (Mignolo, 2000), que afectan y deslegitiman el currículo nacional hegemónico, con la insurgencia de un saber sometido, condensado en el Modelo del Sistema de Educación Intercultural Bilingüe (MOSEIB). La insurgencia de un saber sometido, según Luis Macas (2005) va en contradicción directa con el pensamiento occidental. Para este activista e intelectual indígena existen dos luchas paralelas y de carácter fundamental. La primera hace referencia 
a los desafíos que tienen las comunidades y pueblos indígenas frente a los embates de la globalización. La segunda se refiere a la disputa que existe en el terreno del conocimiento, en la formación de los saberes. En este juego de lucha, la emergencia de la EIB, por lo menos en su discurso, intenta descolonizar la educación oficial hegemónica, punitiva, excluyente; pero no desde fuera de la estructura sino desde dentro; por tanto, la lucha es "legal" y "admitida". El movimiento indígena ecuatoriano no pretende ni nunca ha pretendido actuar y definirse fuera del Estado:

El poder es del pueblo, no del gobernante. Queremos que el gobierno de Rafael Correa termine su mandato pero debe escuchar el clamor popular. No queremos que se caiga el gobierno, queremos que se caiga el sistema corrupto que le rodea... (Discurso del nuevo presidente10 ${ }^{12}$ de Ecuarunari, 21 de diciembre del 2009).

De cierta manera, la aparición de la EIB reconocida por el Estado ecuatoriano, significó una justicia social que implica justicia cognitiva, ontológica e histórica. Es decir, evitar el olvido histórico (de dónde venimos), el olvido epistemológico (qué sabemos) y el olvido ontológico (quiénes somos) (De Sousa Santos, 2010).

Varios indígenas intelectuales se casaron con las mestizas a fin de olvidar su condición de indígena, querían escapar de su lengua,...La institucionalización de la Educación Bilingüe detiene a esa escapatoria. Indígenas que querían desindigenizarse ven en la Educación Bilingüe un espacio, su espacio de reflexión y de concientización... (Carlos Moreno, 9 de enero de 2014).

Este testimonio evidencia la negación de su propia existencia: la colonialidad del ser. La colonialidad del ser se refiere a la no-existencia y la deshumanización, una negación del status del

10 En el III Congreso de la Ecuarunari (movimiento indígena de alcance regional) fue electo unánimemente, representante de la Confederación del Movimiento Indígena de Chimborazo (CO-MICH), Delfín Tenesaca ser humano que se inició dentro de los sistemas de complicidad del colonialismo y esclavitud (Walsh, 2007).

El matrimonio "ansiado" de un indígena con una mestiza -luego de su movilidad social a través de la educación- ve, al parecer, la necesidad de blanquearse, transformándose y modificándose, dejando de ser para ser un no ser. Pero también, la subjetividad sería siempre una manera de ser y, al mismo tiempo, de no ser. Similar a este testimonio parece muy frecuente, no descubrir qué somos, sino rechazar lo que somos. Imaginado y creando lo que podríamos ser, borrando su ser o nuestro ser. En definitiva, traza la línea de fuga para escapar de los mecanismos y estructuras modernas de saber-poder, por medio de la desindigenización.

A fin de bloquear la línea de fuga, la EIB crea programas de alfabetización, instituciones educativas de todos los niveles, (centros educativos comunitarios, colegios, institutos, universidades) y, además, estas entidades educativas se articulan como un andamiaje en la formación de conciencia crítica, constituyéndose parte del proceso del despertar indígena. A pesar de estos objetivos, la EIB, desde sus inicios, operaba con una serie de dificultades como la escasez de maestros entrenados en las áreas de kichwa y cultura; paradójicamente algunas de las posiciones creadas por el Ministerio de Educación para profesores bilingües han sido ocupadas por no-bilingües debido a la falta de profesionales con formación en las materias que debían enseñarse en el sistema intercultural (Montaluisa, 1990 citado en Martínez Novo, 2009).

No estábamos preparados para el nacimiento de la EIB. La EIB surge en el momento menos esperado y menos preparado. La reacción de los padres de familia fue adversa, también fue así de las comunidades indígenas. De las reuniones cerradas dentro del Ministerio y de la CONAIE surge la EIB, sin previa planificación. No estábamos preparados para administrar muchos centros educativos, sino pocos (Emilio Ajitimbay, 29 de enero del 2014). 
Este testimonio concuerda con la siguiente hipótesis:

[...] la preservación de las lenguas y culturas indígenas ha sido más un objetivo de ciertos agentes externos como los etno-lingüistas, la Iglesia progresista y la izquierda, y de algunos líderes indígenas, que un deseo de los indígenas de base (Martínez, 2009, p. 192).

La pregunta que surge es: ¿Algunas experiencias educativas, como Escuelas Radiofónicas Populares del Ecuador-ERPE, no sirvieron para la concientización? Más allá de la respuesta afirmativa o negativa, el intento de reaparición de esos saberes de abajo, de esos saberes no calificados y hasta descalificados, de esos saberes locales, de esos saberes particulares -Foucault (2006 [1976]) diría, saber de la gente-, yo diría saberes de los pueblos indígenas, encuentran limitaciones, tensiones y ambigüedades en los protagonistas de casa adentro y casa afuera $11^{13}$, que no permiten enfrentar la colonialidad del saber y la geopolítica dominante del conocimiento1214. Además, las cuestiones del apartado anterior -del ser dejando de ser, ¿qué somos? Y en términos Foucaultianos diríamos: ¿Qué es el sujeto?- no es solamente un problema ontológico; también contienen dos dimensiones: una dimensión ética y política, y otra epistemológica. La primera se referiría no sólo a cuál es el tipo de relación establecida entre quién es considerado ser y quién no, sino también cuáles son los propósitos de su negación y afirmación de su condición de ser. Por otra parte, la dimensión epistémica indica las condiciones de posibilidad de conocimiento en sí. Esto se evidencia, por ejemplo, en la presentación de iconografías de los pueblos, nacionalidades indígenas y afroecuatorianos en los textos escolares llamados

11 La casa adentro indica los procesos internos de las organizaciones, pero más que todo de las comunidades, para construir y fortalecer un pensamiento y un conocimiento propios.

12 Para Catherine Walsh, la manera de enfrentar la colonialidad del saber es reconstruyendo y fortaleciendo pensamientos y conocimientos propios, no como un saber folclórico local, sino como epistemología, sistemas de conocimiento (2007). kukayos pedagógicos. Este conocimiento (saber) de sí (ser) pone en duda a la legitimidad y hegemonía de las representaciones y conocimientos y, en términos de estos últimos, los contenidos indígenas son puestos en las aulas escolares de todos los niveles interculturales bilingües como la historia de los líderes indígenas $13^{15}$, de las organizaciones indígenas, las tradiciones y costumbres de los pueblos o nacionalidades y sus cosmovisiones. Estos textos, nunca entraron por lo menos a los archivos de los centros escolares monolingües de cantón Riobamba. En este sentido, la EIB socava al conocimiento "universal" y colonial, constituyéndose en un aporte a la insurgencia de los saberes sometidos.

Por otro lado, la EIB no está distante de algunas dificultades como los kukayos pedagógicos abandonados en varios centros educativos con poco interés hacia los contenidos indígenas; esto se debe a que algunos maestros hispanos e indígenas no estaban preparados para recibir y utilizar textos autoimaginados por los propios actores $\mathrm{y}$, paralelamente a la producción de los kukayos pedagógicos, no se elaboraron materiales didácticos para profesores y estudiantes en las diversas lenguas indígenas a nivel institucional, con excepción de algunos esfuerzos desde los niveles regionales o provinciales. Las imágenes fabricadas y su circulación en los textos escolares, están íntimamente ligadas a la cosmovisión de cada particularidad indígena. Dichos discursos representacionales, tanto los narrados como los visuales, informarían sobre los "indios imaginados", los que en distintos periodos históricos se han convertido en un capital cultural que ha servido a los intereses de los distintos imagineros (Muratorio, 1994, p. 10).

Estas ambigüedades y contradicciones en el campo epistémico y político no solo existen entre la EIB y el Estado, sino también dentro de los propios agentes interculturales bilingües. Por un lado, se le da

13 En los textos Kukayos pedagógicos elaborados por la Dirección Regional Sierra, aparecen la vida, lucha y pensamiento de indígenas como Alejo Sáes, Fernando Daquilema y Dolores Cacuango, también las historias de la CONAIE, ECUARUARI y demás organizaciones indígenas. 
poca importancia al conocimiento de los mayores y a las formas no occidentales de inscribir y transmitir conocimiento, como menciona Carmen Martínez Novo (2009); en el campo lingüístico acontece un hecho similar: los maestros pasan la mayoría de su tiempo enseñando alfabetización en español, los padres demandan que se les eduque a sus hijos en español y que se les enseñe a leer y a escribir en este idioma (2009). Por otro lado, el discurso oficial -sometido dentro de un campo de lucha contra la estructura y contra sus propios agentes- continúa exigiendo la aplicación de los principio lingüísticos: "la lengua nativa constituye la lengua principal de educación y el español tiene el rol de segunda lengua y lengua de relación intercultural" (MOSEIB, 1992, p. 13); y, en término epistemológicos, el Modelo de la EIB menciona: "desarrollar un programa que rescate y actualice la etnociencia de acuerdo con la teoría integrada de la ciencia y la cosmovisión que caracteriza a los pueblos indígenas" (1992, p. 12). Parece no solo haber distancia entre los discursos y las prácticas educativas sino, también, en un campo de lucha permanente, en una doble vía: contra el Estado y entre y desde sus propios agentes.

\section{Conclusiones}

En el campo educativo, al decir de Julia Varela (1993), Michel Foucault, como es bien sabido, nunca dedicó a la educación un trabajo sistemático y acabado. Sin embargo, muestra las relaciones y juegos de poder en las relaciones pedagógicas, por ejemplo en la transmisión de saberes, cuando se acepta que alguien sabe más que otro (Lechuga, 2007). Por eso, el pensamiento de Foucault cobra vigencia en el campo educativo en tanto que en Vigilar y castigar no analiza únicamente las cárceles sino también el hospital, la escuela, el orfelinato y la fábrica.

Así como la educación es un ámbito privilegiado para el ejercicio del poder, pues también es uno de los escenarios de resistencias e insurrecciones políticas, epistémicas, aunque John Gledhill (2000) afirme que "el poder provoca inevitablemente "resistencias" tiene poca base real. Sin embargo, la palabra clave para entender los juegos de poder y evitar caer en la dominación es la resistencia; pues, donde hay poder hay resistencia. Hay resistencia cuando alguien dice "no", cuando se opone a una situación determinada con la intención de modificarla o bien evitarla. Su modelo "capilar" del poder privilegia la micropolítica de la resistencia o la infraeducativa.

El castigo físico a los y las estudiantes se expresaba de múltiples maneras: con empujones contra el pizarrón; los reglazos en cualquier parte del cuerpo, preferentemente, en las manos o en la cabeza; los pellizcos; los golpes, las sacudidas; las tiradas de las orejas. Estos castigos cumplían el rol de corregir, guiar, mejorar las fallas cometidas. Los cuerpos se sometían a la docilidad, la obediencia, disciplina y corrección con el fin de hacerlos trabajar y convertirlos en productivos, en fuerza de trabajo físico e intelectual. La violencia al cuerpo escolar no se avergonzaba, se expresaba exhibiéndose públicamente. Mientras más se presentaba en público más efectivo era el castigo.

Frente a una educación punitiva, centralizada en el castigo ritualizado al cuerpo, bancaria; frente al sistema educativo que recrea y reproduce las jerarquías raciales de la sociedad ecuatoriana; frente a cierto educadores que reproducen las jerarquías raciales en sus salones de clase; frente a la producción experiencias traumáticas llenas de vejámenes y obstáculos en el paso por la escuela, el colegio y la universidad (De la Torre, 1996), emerge la educación intercultural bilingüe como una alternativa y un proyecto político, epistémico de los pueblos indígenas, que atenúa a la forma de educación prohibitiva/ productiva; aunque en ocasiones reproduce los mismos "vicios" que el sistema educativo tradicional. De cierta manera, expresa el tránsito de una educación disciplinaria a una educación de control.

\section{Referencias bibliográficas}

Castro-Gómez, S. (2005). La poscolonialidad explicada a los niños. Bogotá: Universidad del Cauca y Universidad Javeriana. 
De la Torre, C. (1996). El racismo en el Ecuador. Quito: Abya-Yala.

Deleuze, G. (2014) [1986]. El poder. Curso sobre Foucault. Tomo II. Buenos Aires: Cactus.

De Sousa Santos, B. (2010). Enriquecer la democracia construyendo la plurinacionalidad. Quito: Fundación Rosa Luxemburgo.

Dirección de Educación Intercultural Bilingüe (1992). Sistema de Educación Intercultural Bilingüe. Quito: EIB.

Durkheim, E. (1976). Educación y sociología. Bogotá: Editorial Linotipo.

García, F. (2007). Los pueblos indígenas del Ecuador: derechos y bienestar. Informa alternativo sobre el cumplimiento del Convenio 169 de la OIT. Quito: FLACSO.

Federici, S. (2016). Calibán y la bruja. Mujeres, cuerpo y acumulación originaria. Quito: Abya-Yala.

Foucault, M. (2006) [1976]. Defender la sociedad. México: Fondo de Cultura Económica. (2009) [1976]. Vigilar y castigar. México: Siglo Veintiuno.

Hernández, A. (2014). Diálogos Sur-Sur: Una lectura latinoamericana de los feminismos poscoloniales. En: K. Bidaseca y J. Obarrio (Comps.), Legados, genealogías y memorias poscoloniales en América Latina: Escrituras fronterizas desde el Sur (pp. 162-195). Buenos Aires: Godot.

Herrera, C. (2013). Castigos corporales y escuela en la Colombia de los siglos XIX y XX. Revista Iberoamericana de Educación, 62, 69-87.

Gledhill, J. (2000). El poder y sus disfraces. Barcelona: Ediciones Ballaterra.

Macas, L. (2005). La necesidad política de una reconstrucción epistémica de los saberes ancestrales. Buenos Aires: Clacso.

Lechuga, G. (2007). Foucault. México: Universidad Autónoma Metropolitana.
Lesteime, D. (2011). Ciencia y biopoder: del discurso científico a la instrumentalización biopolítica del saber. Revistas Colombiana de Filosofía de la Ciencia, 22, 47-53.

Martínez, C. (2009). La crisis del proyecto cultural del movimiento indígena. En: C. Martínez (Comp.), Repensando los movimientos indígenas (pp. 173-196). Quito: FLACSO-Ecuador.

Mignolo, W. (2000). Historias locales/diseños globales. Madrid: Akal.

Morey, M. (2008). Michel Foucault, un diálogo sobre el poder y otras conversaciones. Barcelona: Alianza Editorial.

Muratorio, B. (1994). Introducción: discursos y silencios sobre el indio en la conciencia nacional. En: B. Muratorio (Comp.), Imágenes e imagineros (pp. 9-24). Quito: FLACSO-Ecuador.

Negri, A. (2004). Multitud. Guerra y democracia en la era del imperio. Barcelona: Limppergraf.

Negri, A. y Hardt, M. (2002). Imperio. Barcelona: Limppergraf.

Palerm, Á. (2008). Antropología y marxismo. México: CIESAS.

Parrini, R. (2007). Panópticos y laberintos. Subjetivación, deseo y corporalidad en una cárcel de hombres. México: El Colegio de México.

Tejeda, J. (2012). Biopoder en los cuerpos. Revista Memoria Académica, 1, 13-25.

Walsh, C. (2007). Interculturalidad colonialidad y educación. Revista Educción y Pedagogía, 48, 25-35.

Varela, J. (1993). Prólogo a la edición española. En: Foucault y educación. Disciplinas y saber, 5-10.

Veiga-Neto, A. (2013). Biopolítica, normalización y educación. Cuadernos de Pensamiento Biopolítico Latinoamericano, 1, 10-20. 


\title{
La concepción simple de la lectura en alumnos de $4^{\circ}$ de primaria de una escuela fiscal de Quito \\ The simple view of reading in $4^{\star}$ grade grade students from a public school in Quito
}

Investigación

\author{
Diana Sofía Zevallos Polo \\ Universidad de Las Américas - Ecuador \\ sofia.zevallos@udla.edu.ec \\ Nelly Patricia Arcos Araujo \\ Universidad de Las Américas - Ecuador \\ patricia.arcos@udla.edu.ec \\ Juan Cruz Ripoll Salceda \\ Universidad de Navarra - España \\ juancruzripoll@maristaspamplona.es
}

Recibido: 12 de abril de 2016 / Aceptado: 5 de enero de 2017

\section{Resumen}

La concepción simple de la lectura es un modelo que trata de explicar la comprensión lectora a partir de dos variables, que son la habilidad para la descodificación y la comprensión del lenguaje oral. En los últimos años se ha desarrollado un extenso conjunto de investigaciones sobre este modelo en lectores de inglés. Aunque se han realizado estudios en otros idiomas con sistemas ortográficos transparentes, apenas ha habido investigaciones en lectores de español. El propósito de esta investigación ha sido recoger datos sobre la aplicabilidad de la concepción simple de la lectura a la lectura del español. Para ello se evaluó con la batería PROLEC-R y con el test CLP a 87 alumnos de una escuela pública de la ciudad de Quito. Los resultados indican que incorporar la fluidez o velocidad de lectura al modelo puede ser más adecuado para explicar la comprensión lectora del español. La variable más relacionada con la comprensión lectora de textos fue la comprensión oral, aunque la descodificación y la velocidad de lectura hicieron una pequeña contribución adicional. En cambio, la comprensión lectora de oraciones sólo se relacionó de forma significativa con la descodificación. Esto indica que en la enseñanza y en la evaluación de la lectura es necesario considerar especialmente la comprensión oral, la precisión en la descodificación y la velocidad en la descodificación.

Descriptores: Adquisición de la lectura, competencia lingüística, comprensión de lectura, español, Ecuador, investigación educativa.

\footnotetext{
Abstract

The simple view of reading is a model that tries to explain the reading comprehension from two variables which are decoding accuracy and oral language comprehension. There is an extensive research on
}

Forma sugerida de citar: Zevallos Polo, Diana, Arcos Araujo, Nelly \& Ripoll Salceda, Juan (2017). La concepción simple de la lectura en alumnos de $4^{\circ}$ de primaria de una escuela fiscal de Quito. Alteridad, 12(1), pp. 115-122. 
this model in English readers. Although, some studies have been done in other languages with transparent orthographic systems, there are few investigations with Spanish readers. The purpose of this study has been to collect data on the applicability of the simple view of reading to Spanish reading comprehension, so 87 students of a public school from Quito were assessed with the PROLEC-R and CLP tests. The results show that join fluency or reading speed to the model may be more appropriate to explain the Spanish reading comprehension. Oral comprehension was the most

\section{Introducción'1}

La concepción simple de la lectura (CSL) es un modelo de comprensión lectora que propone que la comprensión lectora es el resultado de la interacción entre dos grandes grupos de procesos: los procesos de descodificación y los procesos de comprensión general del lenguaje.

La formulación original de esta idea (Gough y Tunmer, 1986; Hoover y Gough, 1990) propone que la comprensión lectora es el resultado de la interacción entre la descodificación, que puede ser evaluada mediante pruebas de lectura de palabras o de pseudopalabras, y la comprensión general del lenguaje, que puede ser evaluada mediante pruebas de comprensión oral con un contenido similar al empleado para evaluar la comprensión lectora.

Este modelo ha sido extensamente investigado hasta el punto de que se han publicado tres meta-análisis acerca de él. El primero de estos meta-análisis (Gough, Hoover y Peterson, 1996) revisó 17 estudios realizados con alumnos de primaria o universitarios hablantes de inglés, encontrando relaciones entre descodificación y comprensión lectora y entre comprensión del len-

1 Este trabajo ha sido realizado como parte del proyecto PR2015196 (Eficacia del método "Teatro de Lectores" para mejorar la lectura de alumnos de $4^{\circ}$ de primaria con bajo nivel socio-económicol de la Facultad de Educación y Carrera de Psicopedagogía de la Universidad de las Américas - Quito. related variable to the text reading comprehension; even thought decoding and reading speed made a small additional contribution. On the other hand, reading comprehension of sentences was only related in a significant way to decoding accuracy. These results show that the oral comprehension, the decoding accuracy and the decoding speed are essential in teaching and assessing reading.

Keywords: Reading acquisition, linguistic competence, reading comprehension, Spanish, Ecuador, educational research.

guaje y comprensión lectora, del mismo sentido que las propuestas por la CSL.

El segundo meta-análisis (Florit y Cain, 2011) comparó 20 estudios realizados con alumnos hablantes de inglés que se iniciaban a la lectura con 13 estudios realizados con alumnos que se iniciaban a la lectura en otras lenguas europeas con ortografías más transparentes, como el griego, holandés, francés o finés. En este trabajo se muestra cómo durante los primeros años de aprendizaje de la lectura se puede encontrar una diferencia entre el inglés y otras lenguas más transparentes. En inglés la habilidad de descodificación influye más en la comprensión lectora que la comprensión del lenguaje, mientras que, en otros idiomas, la comprensión del lenguaje se relaciona más con la comprensión lectora que la descodificación. Además, en esos lenguajes con ortografía transparente, la fluidez lectora parece relacionarse con la comprensión lectora en mayor medida que la precisión en la lectura de palabras.

El tercer meta-análisis es el de Ripoll, Aguado y Castilla-Earls (2014), que localizaron 62 estudios realizados con alumnos de primaria hablantes de inglés. Aunque confirma existencia de las relaciones entre descodificación y comprensión lectora y entre comprensión del lenguaje y comprensión lectora identificadas en los meta-análisis anteriores, Ripoll et al. encuentran que también existe una relación moderada entre descodificación y comprensión del lenguaje. 
Tal como ha podido verse, la mayor parte de los estudios sobre la CSL se han realizado con hablantes de inglés. La lengua inglesa tiene un sistema ortográfico muy opaco por la complejidad de las correspondencias entre letras y sonidos. Por eso resulta muy aventurado trasladar un modelo de lectura basado en datos obtenidos de hablantes de inglés a otros idiomas (Share, 2008).

Respecto a la posible aplicación de la CSL a la comprensión lectora en español, el trabajo de Florit y Cain (2011) debe tomarse con cautela, ya que sólo uno de los estudios seleccionados (Proctor, Carlo, August y Snow, 2006) aportaba datos sobre el español. Además, los participantes en ese estudio eran alumnos de $4^{\circ}$ de primaria bilingües en español e inglés.

Florit y Cain sugieren que la carencia de estudios en idiomas como el español se podría deber al hecho de que uno de sus criterios de selección era que los estudios hubieran sido publicados en inglés, de modo que podría haber otros estudios publicados en español no considerados en ese meta-análisis.

Ripoll (2011) sólo encontró tres estudios en los que se examinaban las relaciones entre descodificación, comprensión del lenguaje y comprensión lectora en alumnos con español como lengua materna (Cuetos, Rodríguez y Ruano, 2007; Morales, Verhoeven y van Leeuwe, 2008; Infante, 2011). La primera referencia en español a la CSL es de Alegría (2006), que la denomina "modelo simple de lectura", pero hasta 2012 no se encuentran los primeros estudios que intentan analizar la utilidad de este modelo para explicar la comprensión lectora en hablantes nativos de español (Infante, Coloma y Himmel. 2012; Kim y Pallante, 2012).

La utilidad de la CSL para explicar la comprensión lectora de hablantes monolingües de español ha sido investigada con alumnos chilenos (Infante et al., 2012; Kim y Pallante, 2012), españoles (Mesa, Melgarejo y Saldaño, 2013) y peruanos (Morales, Verhoeven y van Leeuwe, 2008, 2011; Tapia, Aguado y Ripoll, 2016).

Una de las principales utilidades de este modelo es servir como guía para la enseñanza de la competencia lectora, para la detección temprana de problemas en esa competencia y para orientar la actuación ante esos problemas. En este sentido, frente a una orientación que considera que la comprensión de textos es un dominio de aprendizaje con entidad propia, como se puede ver en la educación ecuatoriana (Ministerio de Educación, 2012), la CSL establece que no tiene sentido separar el dominio de comprensión de textos escritos del dominio oral, puesto que la comprensión oral es un componente necesario para la comprensión lectora.

El propósito principal de este estudio es aportar nuevos datos, en este caso con alumnos ecuatorianos, acerca de la validez de la CSL para explicar la comprensión lectora en alumnos hablantes de español. Pero también se pretende analizar cómo varían las relaciones entre los componentes del modelo cuando la descodificación es evaluada mediante medidas de precisión o medidas de velocidad y cuando la comprensión lectora es evaluada mediante pruebas de comprensión de textos y mediante pruebas de comprensión de oraciones.

\section{Fundamentación teórica y metodológica}

Para conseguir los objetivos del estudio se ha empleado un método correlacional. Este método se ha elegido por un motivo teórico: que la CSL es un modelo que expone las relaciones entre sus componentes. Sin embargo, también hay una razón práctica: como consecuencia de lo anterior, la mayor parte de los estudios sobre la CSL tienen un enfoque correlacional, de modo que la adopción de este método permite establecer comparaciones.

A partir del modelo de la CSL se estableció la necesidad de evaluar el rendimiento de los alumnos en descodificación, comprensión oral y comprensión lectora, con el fin de cuantificar las relaciones existentes entre las tres variables. Para profundizar más en esas relaciones, la descodificación fue evaluada con medidas de precisión y velocidad y la 
comprensión lectora con medidas de comprensión de oraciones y comprensión de textos.

Los participantes evaluados fueron 87 alumnos de $4^{\circ}$ grado de educación primaria de la Escuela Fiscal Mixta Costa Rica, ubicada en la Parroquia Nayón de la ciudad de Quito. Esta escuela colabora con el programa "Teatro de Lectores" en la Biblioteca Infantil UDLA Educa y las evaluaciones fueron realizadas como parte de ese programa.

Los alumnos fueron evaluados con el test de lectura PROLEC-R y el test de comprensión lectora CLP 4, forma A. El test PROLEC-R consta de varias subescalas que valoran procesos perceptivos, léxicos, sintácticos y semánticos de la lectura, concretamente, son pruebas de lectura de letras (Nombrar letras), discriminar pares de palabras iguales o diferentes (Igual-diferente), lectura de palabras, lectura de pseudopalabras, comprensión de estructuras gramaticales, interpretación de los signos de puntuación, comprensión de oraciones, comprensión lectora de textos y comprensión oral. En todas las pruebas, excepto las de comprensión, se consideran tanto la precisión (número de aciertos) como el tiempo que se emplea para realizarlas. En las pruebas de comprensión (Estructuras gramaticales, Comprensión de oraciones, Comprensión de textos y Comprensión oral) sólo se considera la precisión. El test PROLEC-R tiene una fiabilidad media, medida con el alfa de Cronbach, de 0,79.

El test CLP 4 valora la comprensión lectora mediante preguntas de elección múltiple y una tarea de clasificación, realizadas a partir de tres textos narrativos. La forma A del test CLP 4 tiene una fiabilidad, medida con la correlación producto-momento de Pearson. de 0,971.

Los alumnos fueron evaluados individualmente durante el mes de octubre de 2015 en las instalaciones de su centro escolar. Se evaluó a 89 alumnos, pero se descartaron los datos de dos de ellos que no pudieron completar las pruebas de evaluación.

Los alumnos fueron evaluados por 19 estudiantes de la carrera de Psicopedagogía de la Universidad de las Américas. Estos estudiantes recibieron una formación sobre la aplicación de los dos tests de evaluación que incluía prácticas previas de su uso. El proceso de evaluación de los alumnos fue supervisado por la coordinadora de la carrera de Psicopedagogía.

\section{Análisis y resultados}

Analizamos la estructura factorial de las pruebas de Nombrar letras, Igual-diferente, Lectura de palabras, Lectura de pseudopalabras, Signos de puntuación y Comprensión oral, tanto las medidas de precisión como las de tiempo. En el análisis factorial no se incluyeron los resultados de pruebas de comprensión lectora (CLP, Comprensión de textos, Comprensión de oraciones y Estructuras gramaticales) porque la CSL predice un solapamiento considerable entre estos resultados y los de pruebas de descodificación o comprensión oral.

En el análisis factorial comparamos tres modelos:

En primer lugar, un modelo con dos factores: descodificación y comprensión oral, que serían los dos predictores de la comprensión lectora propuestos originalmente por la CSL.

El segundo modelo era de tres factores: precisión de la descodificación, velocidad de descodificación y comprensión oral. Este modelo parte de la constatación que realizaron Florit y Cain (2011) de que, en las lenguas transparentes, la fluidez lectora puede ser un predictor mejor que la precisión lectora. También trata de desarrollar esa constatación, ya que el meta-análisis no deja claro si la fluidez incorpora el efecto de la descodificación o pueden hacer contribuciones independientes a la predicción de la comprensión.

El tercer modelo contaba con cuatro factores: procesos perceptivos, procesos léxicos, procesos sintácticos y procesos semánticos. En este caso se trata de un modelo basado en la propia estructura del test PROLEC-R, al que pertenecían las pruebas.

El análisis se realizó mediante el método de la máxima verosimilitud, con rotación varimax. 
Los datos no se ajustaban al modelo de dos factores $(\mathrm{p}=0,03)$, además los factores obtenidos en este modelo estaban relacionados con la precisión de la descodificación y la velocidad de la descodificación, no con la descodificación y la comprensión oral.

Los datos sí que se ajustaban al modelo de tres factores $(\mathrm{p}=0,63) \mathrm{y}$, además, se distribuían según lo previsto: precisión en la descodificación, velocidad en la descodificación y comprensión, con la peculiaridad de que el tiempo de la prueba de Igual-diferente y el número de aciertos de la prueba de Signos de puntuación tenían más peso en el factor en el que se situaba la comprensión oral que en los otros dos factores.

Los datos también se ajustaban al modelo de cuatro factores $(\mathrm{p}=0,68)$, que además explicaba una parte de la varianza $(55,9 \%)$ mayor que la explicada por el modelo de tres factores $(47,8 \%)$. Sin embargo, los factores no se ajustaron a la estructura prevista, sino que aparecieron los tres mismos factores que en el modelo anterior (precisión y velocidad de descodificación y comprensión) y un cuarto factor formado por el número de aciertos en la prueba de Nombrar letras que quizá podría identificarse con la velocidad de denominación, una variable que ha sido propuesta como predictor de la comprensión tras tener en cuenta el efecto de la descodificación y de la comprensión oral (Ripoll et al., 2014).

Para no producir una tabla de correlaciones demasiado extensa agrupamos los resultados estableciendo: a) una variable de Comprensión lectora, formada por la suma de aciertos obtenidos en las pruebas CLP y Comprensión de textos del PROLEC-R, b) una variable de Comprensión de frases, formada por la suma de aciertos de las pruebas Estructuras gramaticales y Comprensión de oraciones, c) una variable de Precisión de descodificación, formada por el número de aciertos en las pruebas de Lectura de palabras y Lectura de pseudopalabras, d) una variable de Velocidad de descodificación, formada por el tiempo invertido en las pruebas de Lectura de palabras y Lectura de pseudopalabras y e) una variable de Comprensión oral. En la tabla 1 se puede ver la matriz de correlaciones.

Tabla 1. Matriz de correlaciones

\begin{tabular}{|l|l|l|l|l|l|}
\hline \multicolumn{2}{|c|}{ CL CF } & \multicolumn{2}{c|}{ PD } & \multicolumn{1}{c|}{ CO } \\
\hline CL & 1 & $0,46^{* *}$ & $0,32^{*}$ & $-0,31^{*}$ & $0,51^{* *}$ \\
\hline CF & $0,46^{* *}$ & 1 & $0,46^{* *}$ & $-0,19$ & 0,18 \\
\hline PD & $0,32^{*}$ & $0,46^{* *}$ & 1 & $-0,38^{* *}$ & 0,20 \\
\hline VD & $-0,31^{*}$ & $-0,19$ & $-0,38^{* *}$ & 1 & $-0,17$ \\
\hline CO & $0,51^{* *}$ & 0,18 & 0,20 & $-0,17$ & 1 \\
\hline
\end{tabular}

Nota: la significación está ajustada según el método de Holm y se representa de la siguiente forma: * $p<0,05 ; * * p<0,01$. CL $=$ comprensión lectora, $C F=$ comprensión de frases, $\mathrm{PD}=$ precisión de descodificación, VD = velocidad de descodificación, $\mathrm{CO}=$ comprensión oral.

Por su interés, al haber sido una cuestión debatida en trabajos anteriores, señalaremos que la correlación entre la precisión en la lectura de palabras y la comprensión lectora fue 0,19 ( $\mathrm{p}=$ $0,08)$ y la correlación entre la precisión en la lec- tura de pseudopalabras y la comprensión lectora fue $0,36(p<0,01)$.

Calculamos una regresión múltiple para predecir la comprensión lectora a partir de la precisión en la descodificación, la velocidad de descodificación y la comprensión oral. La ecuación 
de regresión fue significativa $(\mathrm{F}(3,81)=13,74$, $\mathrm{p}<0,01)$ con una $\mathrm{R}^{2}$ de 0,337 . La comprensión lectora de los participantes era igual a 4,756 + $1,426^{\star}($ Comprensión oral $)+0,119^{*}($ Precisión $)$ $-0.01^{\star}$ (Velocidad).

Mediante otra regresión múltiple tratamos de predecir la comprensión de oraciones a partir de la precisión y velocidad de descodificación y de la comprensión oral. La ecuación de regresión también fue significativa $(\mathrm{F}(3,83)=7,656, \mathrm{p}<$ $0,01)$ con una $\mathrm{R}^{2}$ de 0,217 . La comprensión de oraciones de los participantes era igual a 9,607 $+0,28^{\star}($ Comprensión oral $)+0.209^{\star}($ Precisión $)$ $-0.003^{*}$ (Velocidad).

Para determinar la contribución única de las variables predictoras en la explicación de la varianza de los resultados de comprensión lectora y de comprensión de oraciones, realizamos una serie de regresiones paso a paso. La comprensión oral explicaba un 19,3\% único de la varianza de los resultados de comprensión lectora, la precisión de descodificación un 2,6\% y la velocidad en la descodificación un 2,1\%.

La contribución de la precisión y de la velocidad de descodificación era significativa si la regresión sólo incluía la comprensión oral y una de las dos medidas de descodificación. En cambio, cuando la regresión incluía la comprensión oral, la precisión de descodificación y la velocidad de descodificación, la contribución de las dos últimas medidas no era significativa.

La precisión en la descodificación explicaba un $14,9 \%$ único de la varianza de los resultados de comprensión de oraciones, mientras que la velocidad de descodificación y la comprensión oral explicaban menos de un $1 \%$ único de la varianza.

Los resultados de Nombrar letras (precisión o velocidad) no hicieron una aportación significativa a la comprensión de textos o de oraciones tras tener en cuenta los efectos de la comprensión oral, la precisión y la velocidad en la descodificación.

\section{Discusión y conclusiones}

El análisis de los datos indica que, en la muestra evaluada, el principal predictor de la comprensión lectora de oraciones es la descodificación, mientras que el mejor predictor de la comprensión lectora de textos es la comprensión oral. La precisión de la descodificación y la velocidad de descodificación formaron factores separados y ambas variables explicaron una pequeña parte única de los resultados de comprensión de textos, tras tener en cuenta el efecto de la comprensión oral. Estos resultados indican que, para los alumnos evaluados, un modelo con tres predictores (comprensión oral, precisión en la descodificación y velocidad en la descodificación) puede explicar la comprensión lectora mejor que el modelo clásico de la CSL, que cuenta con dos predictores (precisión de la descodificación y comprensión oral).

Resulta interesante poner estos resultados en relación con otras investigaciones sobre las relaciones entre los componentes de la CSL en hablantes de lenguas con ortografía transparente $y$, especialmente, de español.

$\mathrm{Al}$ igual que en Florit y Cain (2011) y en varios estudios realizados en español (Infante, 2001, Morales et al. 2008, 2011; Mesa et al., 2013) la relación de la comprensión oral con la comprensión de textos fue mayor que la de la descodificación con la comprensión de textos. En cambio, Infante et al., (2012) encontraron que la relación entre descodificación y comprensión lectora fue mayor que la relación entre comprensión oral y comprensión lectora, que no llegó a ser significativa. En este estudio se ha encontrado un resultado parecido cuando la comprensión lectora se evalúa mediante pruebas de comprensión de oraciones. En ese caso, la descodificación se convierte en el mejor y prácticamente el único predictor. Es necesario destacar que Infante et al. no evaluaron la comprensión lectora con una prueba de comprensión de oraciones, sino de textos, narrativos y expositivos.

En contra de lo indicado en Florit y Cain (2011) o en Tapia et al. (2016), la velocidad de 
lectura no tuvo una relación con la comprensión de textos mayor que la de la precisión en la descodificación. Mesa et al. (2013) no tenían una medida de precisión de la descodificación para comparar con la de velocidad. Aun así, la relación entre velocidad lectora y comprensión lectora no llegó a ser significativa.

Por último, la parte de la varianza de los resultados de comprensión lectora explicada por la descodificación y la comprensión oral (un $34 \%$ ) ha sido idéntica a la obtenida en Morales et al. (2011), pero menor que la que se ha obtenido en otros estudios: un 60\% en Joshi, Tao, Aaron y Quiroz (2012) o un 50\% en Tapia et al. (2016). Esto indica que existe una parte notable de la comprensión lectora que no se puede explicar o predecir a partir de la descodificación y la comprensión del lenguaje. Ripoll et al. (2014) señalan cómo se han propuesto algunas variables que podrían explicar una parte adicional de la comprensión lectora tras tener en cuenta los efectos de la descodificación y la comprensión del lenguaje. La mejor estudiada de estas variables es la velocidad de denominación, que podría explicar en torno a un $4 \%$ adicional de la varianza de los resultados de comprensión lectora. Aunque no era un objetivo de este estudio, se ha encontrado relación entre la comprensión lectora y los resultados en una prueba de velocidad de denominación de letras. Sin embargo, la velocidad de denominación no hizo ninguna contribución adicional a la explicación de la comprensión tras tener en cuenta los resultados de la descodificación y la comprensión del lenguaje.

Una conclusión muy importante de estos datos es que para una adecuada enseñanza de la competencia lectora habría que tener en cuenta tanto la precisión en la descodificación como la fluidez y la comprensión del lenguaje oral y, consecuentemente, ante dificultades de rendimiento en comprensión lectora convendría evaluar esos aspectos. Desde una perspectiva práctica, Ripoll y Aguado (2016) indican distintos recursos para evaluar y desarrollar esos tres componentes que han mostrado tener una relación significativa con la comprensión lectora.

No obstante, la dispersión en los resultados que se ha puesto de manifiesto en esta sección, indica que, además de otras investigaciones sobre las relaciones entre los predictores de la comprensión lectora, son necesarios estudios de síntesis en los que se establezca cómo la edad y otras características de los alumnos o el tipo de pruebas utilizadas para medir las distintas variables, afectan a las relaciones entre los componentes del modelo.

\section{Referencias bibliográficas}

Alegría, J. (2006). Por un enfoque psicolingüístico del aprendizaje de la lectura y sus dificultades -20 años después-. Infancia y Aprendizaje, 29(1), 93-111.

Cuetos, F., Rodríguez, B., Ruano E. y Arribas, D. (2007). Prolec-R. Evaluación de los procesos lectores - revisado. Madrid: TEA.

Florit, E., y Cain, K. (2011). The simple view of reading: Is it valid for different types of alphabetic orthographies? Educational Psychology Review 23, 553-576. doi: 10.1007/s10648011-9175-6

Gough, P. B., Hoover, W. A., y Peterson, C. L. (1996). Some observations on a simple view of reading. En: C. Cornoldi, y J. Oakhill (Eds.), Reading comprehension difficulties: Processes and intervention. (pp. 1-13). Mahwah, NJ: Lawrence Erlbaum Associates.

Gough, P.B. y Tunmer, W.E. (1986). Decoding, reading, and reading disability. Remedial and Special Education, 7, 6-10. doi: 10.1177/074193258600700104

Hoover, W. A., y Gough, P. B. (1990). The simple view of reading. Reading and Writing: An Interdisciplinary Journal, 2(2), 127-160. doi: 10.1007/BF00401799

Infante, M. D. R. (2001). Social background and reading disabilities: Variability in decoding, reading comprehension, and listening comprehension skills. Columbia: Universidad de Missouri.

Infante, M., Coloma, C. J. y Himmel, E. (2012). Comprensión lectora, comprensión oral y decodificación en escolares de $2^{\circ}$ y $4^{\circ}$ 
básico de escuelas municipales. Estudios Pedagógicos, 38(1), 149-160. doi: 10.4067/ S0718-07052012000100009

Joshi, R. M., Tao, S., Aaron, P. G. y Quiroz, B. (2012). Cognitive component of componential model of reading applied to different orthographies. Journal of Learning Disabilities, 45(5), 480486. doi: $10.1177 / 0022219411432690$

Kim, Y. S. y Pallante, D. (2012). Predictors of reading skills for kindergartners and first grade students in Spanish: a longitudinal study. Reading and Writing, 25(1), 1-22. doi: 10.1007/s11145-010-9244-0

Mesa, G., Tirado, M. J. y Saldaña, D. (2013). El retraso en el desarrollo del lenguaje y los prolemas de comprensión lectora: una exploración del modelo simple de lectura. Revista de Logopedia, Foniatría y Audiología, 33(3), 136-145.

Ministerio de Educación (2012). Estándares de calidad educativa. Aprendizaje, gestión escolar, desempeño profesional e infraestructura. Quito: Ministerio de Educación.

Morales, S., Verhoeven, L., y van Leeuwe, J. (2008). Socio-cultural predictors of reading literacy in fourth graders in Lima, Peru. Written Language \& Literacy, 11(1), 15-34. doi: 10.1075/wll.11.1.03mor

Morales, S., Verhoeven, L., y van Leeuwe, J. (2011). Socio-cultural variation in reading comprehension development among fifth graders in
Peru. Reading and Writing, 24, 951-969. doi: 10.1007/s11145-010-9242-2

Proctor, C. P., Carlo, M., August, D., y Snow, C. (2006). The intriguing role of Spanish language vocabulary knowledge in predicting English reading comprehension. Journal of Educational Psychology, 98, 159-169.

Ripoll, J. C. (2011). La concepción simple de la lectura en educación primaria: una revisión sistemática. Pamplona: Universidad de Navarra.

Ripoll, J. C. y Aguado, G. (2016). Cuatro patas para mejorar la comprensión lectora. Educar y Orientar, 4, 38-40.

Ripoll, J. C., Aguado, G. y Castilla-Earls, A. P. (2014). The simple view of reading in elementary school: A systematic review. Revista de Logopedia, Foniatría y Audiología, 34, 17-31. doi: 10.1016/j.rlfa.2013.04.006

Share, D. L. (2008). On the Anglocentricities of current reading research and practice: the perils of overreliance on an "outlier" orthography. Psychological Bulletin, 134(4), 584615. doi: 10.1037/0033-2909.134.4.584.

Tapia, M, Aguado, G. y Ripoll, J. C. (2016, Julio). Validation of simple view of reading in Spanish. En L. Verhoeven (Presidencia). 23 annual meeting, dirigido por Society for the Scientific Study of Reading. Oporto. Disponible en https://www.triplesr.org/validation-simple-view-reading-spanish 


\section{Normas Editoriales}

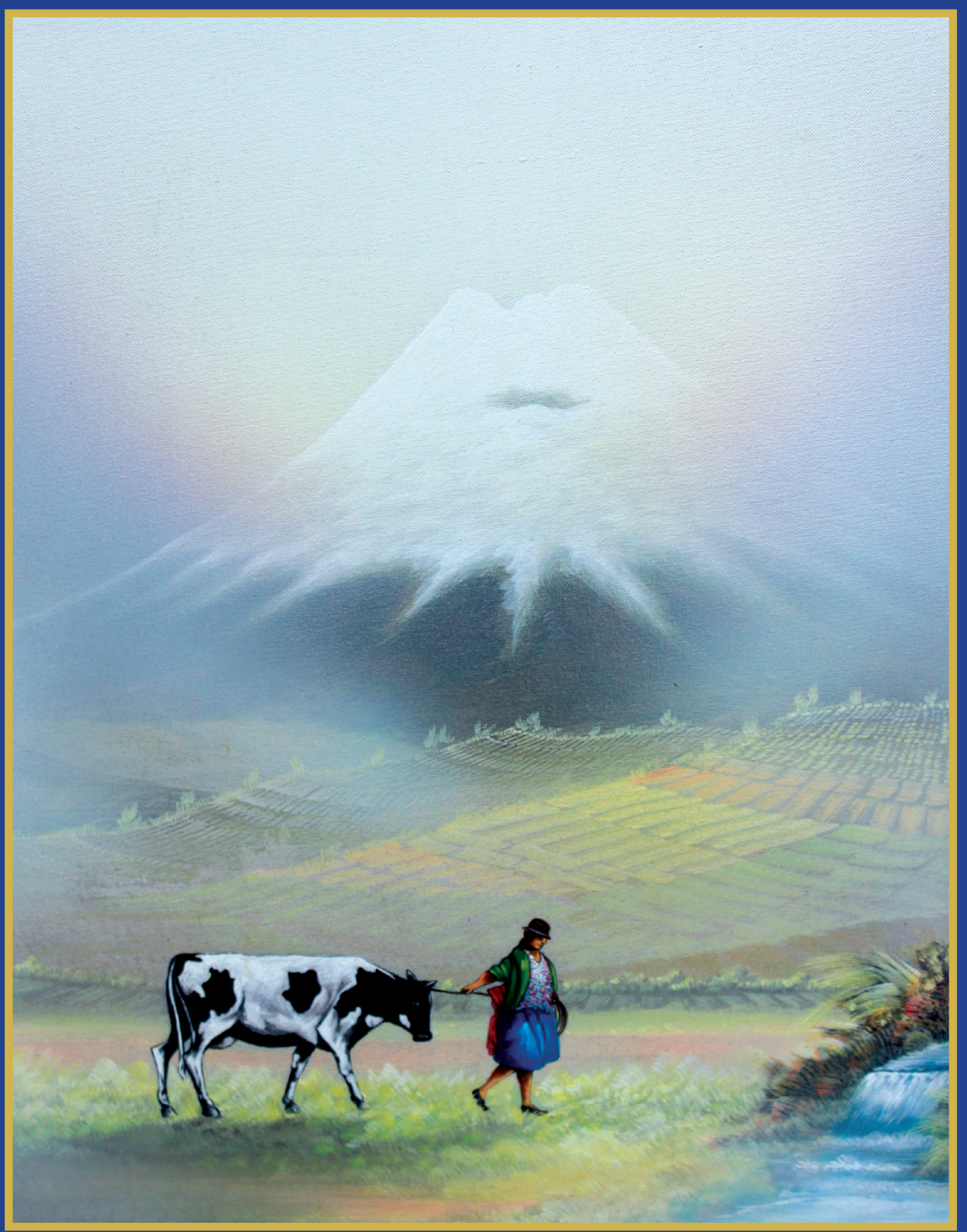

Mujer de los Andes Acrílico sobre lienzo 


\section{Alteridad. Revista de Educación http://alteridad.ups.edu.ec/ p-ISSN:1390-325X / e-ISSN:1390-8642 Normas de Publicación en «Alteridad»}

\section{Información general}

«Alteridad» es una publicación científica bilingüe de la Universidad Politécnica Salesiana de Ecuador, editada desde enero de 2006 de forma ininterrumpida, con periodicidad fija semestral, especializada en Educación y sus líneas transdisciplinares como Didáctica, Políticas Públicas, Gerencia de Centros Escolares, Educomunicación, TIC, entre otras.

Es una revista científica arbitrada, que utiliza el sistema de evaluación externa por expertos (peer-review), bajo metodología de pares ciegos (doble-blind review), conforme a las normas de publicación de la American Psychological Association (APA). El cumplimiento de este sistema permite garantizar a los autores un proceso de revisión objetivo, imparcial y transparente, lo que facilita a la publicación su inclusión en bases de datos, repositorios e indexaciones internacionales de referencia.

«Alteridad» se encuentra indexada en el directorio y catálogo selectivo del Sistema Regional de Información en Línea para Revistas Científicas de América Latina, el Caribe, España y Portugal (Latindex), en el Sistema de Información Científica REDALYC, en el Directorio de Revistas de Acceso Abierto DOAJ y en repositorios, bibliotecas y catálogos especializados de Iberoamérica.

La revista se edita en doble versión: impresa (ISSN: 1390-325X) y electrónica (e-ISSN: 13908642), en español e inglés, siendo identificado además cada trabajo con un DOI (Digital Object Identifier System).

\section{Alcance y política}

\subsection{Temática}

Contribuciones originales en materia de Educación, así como áreas afines: Didáctica, Políticas Públicas, Gerencia de Centros Escolares, Educomunicación, TIC... y todas aquellas disciplinas conexas interdisciplinarmente con la línea temática central.

\subsection{Aportaciones}

«Alteridad» edita preferentemente resultados de investigación empírica sobre Educación, redactados en español y/o inglés, siendo también admisibles informes, estudios y propuestas, así como selectas revisiones de la literatura (state-of-the-art).

Todos los trabajos deben ser originales, no haber sido publicados en ningún medio ni estar en proceso de arbitraje o publicación. De esta manera, las aportaciones en la revista pueden ser:

- Investigaciones: 5.000 a 6.500 palabras de texto, incluyendo título,a resúmenes, descriptores, tablas y referencias.

- Informes, estudios y propuestas: $5.000 \mathrm{a}$ 6.500 palabras de texto, incluyendo título, resúmenes, tablas y referencias.

- Revisiones: 6.000 a 7.000 palabras de texto, incluidas tablas y referencias. Se valorará especialmente las referencias justificadas, actuales y selectivas de alrededor de unas 70 obras. 
«Alteridad» tiene periodicidad semestral (20 artículos por año), publicada en los meses de enero y julio y cuenta por número con dos secciones de cinco artículos cada una, la primera referida a un tema Monográfico preparado con antelación y con editores temáticos y la segunda, una sección de Misceláneas, compuesta por aportaciones variadas dentro de la temática de la publicación.

\section{Presentación, estructura y envío de los manuscritos}

Los trabajos se presentarán en tipo de letra Arial 10 , interlineado simple, justificado completo y $\sin$ tabuladores ni espacios en blanco entre párrafos. Solo se separarán con un espacio en blanco los grandes bloques (título, autores, resúmenes, descriptores, créditos y epígrafes). La página debe tener 2 centímetros en todos sus márgenes.

Los trabajos deben presentarse en documento de Microsoft Word (.doc o .docx), siendo necesario que el archivo esté anonimizado en Propiedades de Archivo, de forma que no aparezca la identificación de autor/es.

Los manuscritos deben ser enviados única y exclusivamente a través del OJS (Open Journal System), en el cual todos los autores deben darse de alta previamente. No se aceptan originales enviados a través de correo electrónico u otra interfaz.

\subsection{Estructura del manuscrito}

Para aquellos trabajos que se traten de investigaciones de carácter empírico, los manuscritos seguirán la estructura IMRDC, siendo opcionales los epígrafes de Notas y Apoyos. Aquellos trabajos que por el contrario se traten de informes, estudios, propuestas y revisiones podrán ser más flexibles en sus epígrafes, especialmente en Material y métodos, Análisis y resultados y Discusión y conclusiones. En todas las tipologías de trabajos son obligatorias las Referencias.

1. Título (español) / Title (inglés): Conciso pero informativo, en castellano en primera línea y en inglés en segunda. Se aceptan como máximo 80 caracteres con espacio. El título no solo es responsabilidad de los autores, pudiéndose proponer cambios por parte del Consejo Editorial.

2. Nombre y apellidos completos: De cada uno de los autores, organizados por orden de prelación. Se aceptarán como máximo 3 autores por original, aunque pudieren existir excepciones justificadas por el tema, su complejidad y extensión. Junto a los nombres ha de seguir la categoría profesional, centro de trabajo, correo electrónico de cada autor y número de ORCID. Es obligatorio indicar si se posee el grado académico de doctor (incluir Dr./Dra. antes del nombre).

3. Resumen (español) / Abstract (inglés): Tendrá como extensión máxima 230 palabras, primero en español y después en inglés. En el resumen se describirá de forma concisa y en este orden: 1) Justificación del tema; 2) Objetivos; 3) Metodología y muestra; 4) Principales resultados; 5) Principales conclusiones. Ha de estar escrito de manera impersonal "El presente trabajo analiza...". En el caso del abstract no se admitirá el empleo de traductores automáticos por su pésima calidad.

4. Descriptores (español) / Keywords (inglés): Se deben exponer 6 descriptores por cada versión idiomática relacionados directamente con el tema del trabajo. Será valorado positivamente el uso de las palabras claves expuestas en el Thesaurus de la UNESCO.

5. Introducción y estado de la cuestión: Debe incluir el planteamiento del problema, el contexto de la problemática, la justificación, fundamentos y propósito del estudio, utilizando citas bibliográficas, así como la literatura más significativa y actual del tema a escala nacional e internacional.

6. Material y métodos: Debe ser redactado de forma que el lector pueda comprender con facilidad el desarrollo de la investigación. En su caso, describirá la metodología, la 
muestra y la forma de muestreo, así como se hará referencia al tipo de análisis estadístico empleado. Si se trata de una metodología original, es necesario exponer las razones que han conducido a su empleo y describir sus posibles limitaciones.

7. Análisis y resultados: Se procurará resaltar las observaciones más importantes, describiéndose, sin hacer juicios de valor, el material y métodos empleados. Aparecerán en una secuencia lógica en el texto y las tablas y figuras imprescindibles evitando la duplicidad de datos.

8. Discusión y conclusiones: Resumirá los hallazgos más importantes, relacionando las propias observaciones con estudios de interés, señalando aportaciones y limitaciones, sin redundar datos ya comentados en otros apartados. Asimismo, el apartado de discusión y conclusiones debe incluir las deducciones y líneas para futuras investigaciones.

9. Apoyos y agradecimientos (opcionales): El Council Science Editors recomienda a los autor/es especificar la fuente de financiación de la investigación. Se considerarán prioritarios los trabajos con aval de proyectos competitivos nacionales e internacionales. En todo caso, para la valoración científica del manuscrito, este debe ir anonimizado con XXXX solo para su evaluación inicial, a fin de no identificar autores y equipos de investigación, que deben ser explicitados en la Carta de Presentación y posteriormente en el manuscrito final.

10. Las notas (opcionales) irán, solo en caso necesario, al final del artículo (antes de las referencias). Deben anotarse manualmente, ya que el sistema de notas al pie o al final de Word no es reconocido por los sistemas de maquetación. Los números de notas se colocan en superíndice, tanto en el texto como en la nota final. No se permiten notas que recojan citas bibliográficas simples (sin comentarios), pues éstas deben ir en las referencias.
11. Referencias: Las citas bibliográficas deben reseñarse en forma de referencias al texto. Bajo ningún caso deben incluirse referencias no citadas en el texto. Su número debe ser suficiente para contextualizar el marco teórico con criterios de actualidad e importancia. Se presentarán alfabéticamente por el primer apellido del autor.

\subsection{Normas para las referencias}

\section{Publicaciones periódicas}

Artículo de revista (un autor): Valdés-Pérez, D. (2016). Incidencia de las técnicas de gestión en la mejora de decisiones administrativas [Impact of Management Techniques on the Improvement of Administrative Decisions]. Retos, 12(6), 199-213. https://doi. org/10.17163/ret.n12.2016.05

Artículo de revista (hasta seis autores): Ospina, M.C., Alvarado, S.V., Fefferman, M., \& Llanos, D. (2016). Introducción del dossier temático "Infancias y juventudes: violencias, conflictos, memorias y procesos de construcción de paz" [Introduction of the thematic dossier "Infancy and Youth: Violence, Conflicts, Memories and Peace Construction Processes"]. Universitas, 25(14), 91-95. https:// doi.org/10.17163/uni.n25.\%25x

Artículo de revista (más de seis autores): Smith, S.W., Smith, S.L. Pieper, K.M., Yoo, J.H., Ferrys, A.L., Downs, E.,... Bowden, B. (2006). Altruism on American Television: Examining the Amount of, and Context Surronding. Acts of Helping and Sharing. Journal of Communication, 56(4), 707-727. https://doi. org/10.1111/j.1460-2466.2006.00316.x

Artículo de revista (sin DOI): Rodríguez, A. (2007). Desde la promoción de salud mental hacia la promoción de salud: La concepción de lo comunitario en la implementación de proyectos sociales. Alteridad, 2(1), 28-40. (https:// goo.gl/zDb3Me) (2017-01-29). 


\section{Libros y capítulos de libro}

Libros completos: Cuéllar, J.C., \& MoncadaParedes, M.C. (2014). El peso de la deuda externa ecuatoriana. Quito: Abya-Yala.

Capítulos de libro: Zambrano-Quiñones, D. (2015). El ecoturismo comunitario en Manglaralto y Colonche. En V.H. Torres (Ed.), Alternativas de Vida: Trece experiencias de desarrollo endógeno en Ecuador (pp. 175198). Quito: Abya-Yala.

\section{Medios electrónicos}

Pérez-Rodríguez, M.A., Ramírez, A., \& GarcíaRuíz, R. (2015). La competencia mediática en educación infantil. Análisis del nivel de desarrollo en España. Universitas Psychologica, 14(2), 619-630. https://doi.org.10.11144/ Javeriana.upsy14-2.cmei

Es prescriptivo que todas las citas que cuenten con DOI (Digital Object Identifier System) estén reflejadas en las Referencias (pueden obtenerse en http://goo.gl/gfruh1). Todas las revistas y libros que no tengan DOI deben aparecer con su link (en su versión on-line, en caso de que la tengan, acortada, mediante Google Shortener: http:// goo.gl) y fecha de consulta en el formato indicado.

Los artículos de revistas deben ser expuestos en idioma inglés, a excepción de aquellos que se encuentren en español e inglés, caso en el que se expondrá en ambos idiomas utilizando corchetes. Todas las direcciones web que se presenten tienen que ser acortadas en el manuscrito, a excepción de los DOI que deben ir en el formato indicado (https://doi.org/XXX).

\subsection{Epígrafes, tablas y gráficos}

Los epígrafes del cuerpo del artículo se numerarán en arábigo. Irán sin caja completa de mayús- culas, ni subrayados, ni negritas. La numeración ha de ser como máximo de tres niveles: 1. / 1.1. / 1.1.1. Al final de cada epígrafe numerado se establecerá un retorno de carro.

Las tablas deben presentarse incluidas en el texto en formato Word según orden de aparición, numeradas en arábigo y subtituladas con la descripción del contenido.

Los gráficos o figuras se ajustarán al número mínimo necesario y se presentarán incorporadas al texto, según su orden de aparición, numeradas en arábigo y subtituladas con la descripción abreviada. Su calidad no debe ser inferior a 300 ppp, pudiendo ser necesario contar con el gráfico en formato TIFF, PNG o JPEG.

\section{Proceso de envío}

Deben remitirse a través del sistema OJS de la revista dos archivos:

1. Presentación y portada, en la que aparecerá el título en español e inglés, nombres y apellidos de los autores de forma estandarizada con número de ORCID, resumen, abstract, descriptores y keywords y una declaración de que el manuscrito se trata de una aportación original, no enviada ni en proceso de evaluación en otra revista, confirmación de las autorías firmantes, aceptación (si procede) de cambios formales en el manuscrito conforme a las normas y cesión parcial de derechos a la editorial (usar modelo oficial de portada).

2. Manuscrito totalmente anonimizado, conforme a las normas referidas en precedencia.

Todos los autores han de darse de alta, con sus créditos, en la plataforma OJS, si bien uno solo de ellos será el responsable de correspondencia. Ningún autor podrá enviar o tener en revisión dos manuscritos de forma simultánea, estimándose una carencia de cuatro números consecutivos (2 años). 


\section{Alteridad. Revista de Educación http://alteridad.ups.edu.ec/ p-ISSN:1390-325X / e-ISSN:1390-8642 \\ Publication guidelines in «Alteridad»}

\section{General information}

«Alteridad» is a bilingual scientific publication of the Universidad Politécnica Salesiana of Ecuador, published since January 2006 in an uninterrupted manner, with a fixed biannual periodicity, specialized in Education and its transdisciplinary lines such as Didactics, Public Policies, Management of Schools, Educomunication, ICT, among others.

It is scientific journal, which uses the peerreview system, under double-blind review methodology, according to the publication standards of the American Psychological Association (APA). Compliance with this system allows authors to guarantee an objective, impartial and transparent review process, which facilitates the publication of their inclusion in reference databases, repositories and international indexing.

"Alteridad» is indexed in the directory and selective catalog of the Regional Online Information System for Scientific Journals of Latin America, the Caribbean, Spain and Portugal (Latindex), in the Scientific Information System REDALYC, in the Directory of Journals of Open Access DOAJ and in repositories, libraries and specialized catalogs of Latin America.

The journal is published in a double version: printed (ISSN: 1390-325X) and digital (e-ISSN: 1390-8642), in English and Spanish, each work being identified with a DOI (Digital Object Identifier System).

\section{Scope and policy}

\subsection{Theme}

Original contributions in Education, as well as related areas: Didactics, Public Policies, Management of Schools, Edu-communication, ICT ... and all interdisciplinary disciplines related to the central theme.

\subsection{Contributions}

«Alteridad» preferably publishes results of empirical research on Education, written in Spanish and / or English, as well as reports, studies and proposals, as well as selected state-of-theart literature reviews.

All works must be original, have not been published in any medium or be in the process of arbitration or publication.

- Research: 5,000 to 6,500 words of text, including title, abstracts, descriptors, charts and references.

- Reports, studies and proposals: 5,000 to 6,500 words of text, including title, abstracts, charts and references.

- Reviews: 6,000 to 7,000 words of text, including charts and references. Justified references, would be specially valued. (current and selected from among 70 works) 
«Alteridad» has a biannual periodicity ( 20 articles per year), published in January and July and counts by number with two sections of five articles each, the first referring to a Monographic topic prepared in advance and with thematic editors and the second, a section of Miscellaneous, composed of varied contributions within the theme of the publication.

\section{Presentation, structure and submission of the manuscripts}

Texts will be presented in Arial 10 font, single line spacing, complete justification and no tabs or white spaces between paragraphs. Only large blocks (title, authors, summaries, descriptors, credits and headings) will be separated with a blank space. The page should be 2 centimeters in all its margins.

Papers must be submitted in a Microsoft Word document (.doc or .docx), requiring that the file be anonymized in File Properties, so that the author/s identification does not appear.

Manuscripts must be submitted only and exclusively through the OJS (Open Journal System), in which all authors must previously register. Originals sent via email or other interfaces are not accepted.

\subsection{Structure of the manuscript}

For those works that are empirical investigations, the manuscripts will follow the IMRDC structure, being optional the Notes and Supports. Those papers that, on the contrary, deal with reports, studies, proposals and reviews may be more flexible in their epigraphs, particularly in material and methods, analysis, results, discussion and conclusions. In all typologies of works, references are mandatory.

1. Title (Spanish) /Title (English): Concise but informative, in Spanish on the first line and in English on the second. A maximum of 80 characters with spaces are accepted.
The title is not only the responsibility of the authors, changes being able to be proposed by the Editorial Board.

2. Full name and surnames: Of each of the authors, organized by priority. A maximum of 3 authors will be accepted per original, although there may be exceptions justified by the topic, its complexity and extent. Next to the names must follow the professional category, work center, email of each author and ORCID number. It is mandatory to indicate if you have the academic degree of doctor (include Dr./Dra before the name).

3. Abstract (Spanish) / Abstract (English): It will have a maximum extension of 230 words, first in Spanish and then in English. : 1) Justification of the topic; 2) Objectives; 3) Methodology and sample; 4) Main results; 5) Main conclusions. It must be impersonally written "This paper analyzes .... In the case of the abstract, the use of automatic translators will not be accepted due to their poor quality.

4. Descriptors (Spanish) / Keywords (English): 6 descriptors must be presented for each language version directly related to the subject of the work. The use of the key words set out in UNESCO's Thesaurus will be positively valued.

5. Introduction and state of the issue: It should include the problem statement, context of the problem, justification, rationale and purpose of the study, using bibliographical citations, as well as the most significant and current literature on the topic at national and international level .

6. Material and methods: It must be written so that the reader can easily understand the development of the research. If applicable, it will describe the methodology, the sample and the form of sampling, as well as the type of statistical analysis used. If it is an original methodology, it is necessary to 
explain the reasons that led to its use and to describe its possible limitations.

7. Analysis and results: It will try to highlight the most important observations, describing them, without making value judgments, the material and methods used. They will appear in a logical sequence in the text and the essential charts and figures avoiding the duplication of data.

8. Discussion and conclusions: Summarize the most important findings, relating the observations themselves with relevant studies, indicating contributions and limitations, without adding data already mentioned in other sections. Also, the discussion and conclusions section should include the deductions and lines for future research.

9. Supports and acknowledgments (optional): The Council Science Editors recommends the author (s) to specify the source of funding for the research. Priority will be given to projects supported by national and international competitive projects. In any case, for the scientific evaluation of the manuscript, it should be only anonymized with XXXX for its initial evaluation, in order not to identify authors and research teams, which should be explained in the Cover Letter and later in the final manuscript.

10.The notes (optional) will go, only if necessary, at the end of the article (before the references). They must be manually annotated, since the system of footnotes or the end of Word is not recognized by the layout systems. The numbers of notes are placed in superscript, both in the text and in the final note. The numbers of notes are placed in superscript, both in the text and in the final note. No notes are allowed that collect simple bibliographic citations (without comments), as these should go in the references.

11.References: Bibliographical citations should be reviewed in the form of references to the text. Under no circumstances should references not mentioned in the text be included. Their number should be sufficient to contextualize the theoretical framework with current and important criteria. They will be presented alphabetically by the first last name of the author.

\subsection{Guidelines for references}

\section{Periodic publications}

Journal article (author): Valdés-Pérez, D. (2016). Incidencia de las técnicas de gestión en la mejora de decisiones administrativas [Impact of Management Techniques on the Improvement of Administrative Decisions]. Retos, 12(6), 199-2013. https://doi. org/10.17163/ret.n12.2016.05

Journal Article (Up to six authors): Ospina, M.C., Alvarado, S.V., Fefferman, M., \& Llanos, D. (2016). Introducción del dossier temático "Infancias y juventudes: violencias, conflictos, memorias y procesos de construcción de paz" [Introduction of the thematic dossier "Infancy and Youth:Violence, Conflicts, Memories and Peace Construction Processes"]. Universitas, 25(14), 91-95. https:// doi.org/10.17163/uni.n25.\%25x

Journal article (more tan six authors): Smith, S.W., Smith, S.L. Pieper, K.M., Yoo, J.H., Ferrys, A.L., Downs, E.,... Bowden, B. (2006). Altruism on American Television: Examining the Amount of, and Context Surronding. Acts of Helping and Sharing. Journal of Communication, 56(4), 707-727. https://doi. org/10.1111/j.1460-2466.2006.00316.x

Journal article (without DOI): Rodríguez, A. (2007). Desde la promoción de salud mental hacia la promoción de salud: La concepción de lo comunitario en la implementación de proyectos sociales. Alteridad, 2(1), 28-40. (https://goo.gl/zDb3Me) (2017-01-29).

\section{Books and book chapters}

Full books: Cuéllar, J.C., \& Moncada-Paredes, M.C. (2014). El peso de la deuda externa ecuatoriana. Quito: Abya-Yala. 
Chaprter of book: Zambrano-Quiñones, D. (2015). El ecoturismo comunitario en Manglaralto y Colonche. En V.H. Torres (Ed.), Alternativas de Vida: Trece experiencias de desarrollo endógeno en Ecuador (pp. 175198). Quito: Abya-Yala.

\section{Digital media}

Pérez-Rodríguez, M.A., Ramírez, A., \& GarcíaRuíz, R. (2015). La competencia mediática en educación infantil. Análisis del nivel de desarrollo en España. Universitas Psychologica, 14(2), 619-630. https://doi.org.10.11144/ Javeriana.upsy14-2.cmei

It is prescriptive that all quotations that have DOI (Digital Object Identifier System) are reflected in the References (can be obtained at http://goo.gl/gfruh1). All journals and books that do not have DOI should appear with their link (in their online version, if they have it, shortened by Google Shortened: http://goo.gl) and date of consultation in the indicated format.

Journal articles should be presented in English, except for those in Spanish and English, in which case it will be displayed in both languages using brackets. All web addresses submitted must be shortened in the manuscript, except for the DOI that must be in the indicated format (https://doi.org/XXX).

\subsection{Epigraphs, Figures and Charts}

The epigraphs of the body of the article will be numbered in Arabic. They should go without a full box of capital letters, neither underlined nor bold. The numbering must be a maximum of three levels: 1. / 1.1. / 1.1.1. A carriage return will be established at the end of each numbered epigraph.
The charts must be included in the text in Word format according to order of appearance, numbered in Arabic and subtitled with the description of the content.

The graphics or figures will be adjusted to the minimum number required and will be presented incorporated in the text, according to their order of appearance, numbered in Arabic and subtitled with the abbreviated description. Their quality should not be less than $300 \mathrm{dpi}$, and it may be necessary to have the graph in TIFF, PNG or JPEG format.

\section{Submission process}

Two files must be sent through the OJS system of the journal:

1. Presentation and cover, in which the title in Spanish and English will appear, names and surnames of the authors in a standardized form with ORCID number, abstract in both Spanish and English, descriptors and keywords and a statement that the manuscript is an Original contribution, not sent or in the process of being evaluated in another journal, confirmation of the signatory authors, acceptance (if applicable) of formal changes in the manuscript according to the rules and partial transfer of rights to the publisher (use official cover model).

2. Manuscript totally anonymized, according to the guidelines referred in precedence.

All authors must register with their credits on the OJS platform, although only one of them will be responsible for correspondence.No author can submit or have in review two manuscripts simultaneously, estimating an absence of four consecutive numbers (2 years). 